\title{
The 10 day bach: A net zero energy home
}

A story of the design and operation of the First Light house in the 2011 Solar Decathlon

By Ben Jagersma

This thesis was submitted to the Victoria University of Wellington

In fulfilment of the requirements for the degree of Master of Architecture

School of Architecture and Design

Victoria University of Wellington, 2011 


\section{Author:}

Benjamin Jagersma

School of Architecture

Victoria University of Wellington

jagersbenj@myvuw.ac.nz

\section{Primary Supervisor:}

Professor Brenda Vale

School of Architecture

Victoria University of Wellington

brenda.vale@vuw.ac.nz 


\section{Abstract}

Held every two years in Washington DC and run by the US Department of Energy the Solar Decathlon is a competition that challenges architecture and engineering students from all over the world to come up with new and innovative ways to design and construct low energy homes. For the first time in the competition's history a team from New Zealand was selected to compete in the 2011 competition. This thesis documents the design process of the First Light house from concept to construction focusing on the relationship between energy and architecture in a New Zealand home designed for the Solar Decathlon.

The challenge for the young architects and engineers competing in the competition is to develop ways of reducing energy consumption and to raise awareness of the energy saving benefits of highly efficient home design to the public. Despite this being the underlying philosophy, this thesis suggests that the competition is structured in a way that rewards technology over passive design innovation in architecture. A typical Solar Decathlon house is epitomized by a large solar array generating the power needing to run an oversized mechanical system. The New Zealand entry challenges this trend with the design of a home that is focused on ways to improve passive strategies for reducing energy use first before relying on technology. The question is whether a home designed with this philosophy in mind can still meet the strict requirements set out in the ten contests embedded in the Solar Decathlon?

Designing a home to meet these requirements was also, in many ways, contradictory to the house's philosophy. The conceptual driver of the First Light house was the iconic 'kiwi bach.' Commonly defined as "something you built yourself, on land you don't own, out of materials you borrowed or stole," the bach gives a unique model of comfort and how people might live in a space. Its values are associated with a relationship with the outdoors, a focus on the social aspects of the home and a simple use of technology. As the project developed it was also apparent 'the bach', if it were used all year round, could become a symbol for the current state of many New Zealand homes; cold, damp, unhealthy and wasteful of energy. Finding ways to improve this while maintaining the essence of the bach became one of the major motivations throughout the design process. The 
challenge with this was that the goals associated with designing a 'kiwi bach' for a New Zealand climate were, in many ways, conflicting with the requirements of the Solar Decathlon competition.

Using comprehensive thermal modelling the First Light house was designed as a net zero energy home that could meet the requirements of two quite unique briefs for two distinctly different climates. Throughout this thesis the often contradictory relationship between the First Light house as a Solar Decathlon entry and the First Light house as an energy efficient 'kiwi bach' is explained. Broken into three parts the thesis looks at the passive design of the home and the optimization of the building envelope through thermal modelling, the active side of the design and the generation of solar energy and finally documents the actual performance of the house both in Wellington and in Washington DC during the competition. 


\section{Contents}

Abstract $\quad 5$

$1 \quad$ Introduction 21

2 The starting point: The Schematic design proposal 25

2.1 The State of housing in New Zealand 25

2.2 The team 26

2.3 The Concept 28

2.4 The site $\quad 29$

2.5 The competition $\quad 32$

2.5.1 Judged contests $\quad 32$

- Architecture

- Engineering

- Affordability

2.5.2 Measured contests

- Comfort zone

- Hot water, Appliances and Home Entertainment

- Energy balance

2.6 The house - The initial design 36

2.6.1 Technologies and energy use $\quad 39$

2.7 The objective $\quad 40$

2.8 The method 40

3 Comfort zone and Climate

3.1 An introduction to thermal comfort 43

3.2 Climate 46

3.3 Thermal modeling - Assumptions 49

3.3.1 Construction $\quad 49$

3.3.2 Heating and Internal Gains 50

3.3.3 Air exchange - Ventilation and infiltration $\quad 50$

3.3.4 Modeling Variations 50

$4 \quad$ Insulation 
6.1 Skylight Glazing

7 Passive cooling: Shading and Ventilation

7.2 Ventilation

8.1 The final model

8.1.1 HVAC performance specification

9.1 Hot water

9.2 Appliances

108

9.3 Home entertainment 
17 Appendix E: Drying cupboard tests

18 Appendix F: Dinner party energy use 


\section{List of figures}

Many of the images used throughout this thesis are photographs taken by the First Light team as a part of the project. All images below where a source has not been given have been credited to First Light

Figure 1: Image of completed house in Washington DC

Figure 2: The team celebrating second place in Architecture outside the Capitol building in Washington DC 19

Figure 3: The First Light brand 20

Figure 4: Artistic impression of conceptual design 22

Figure 5: Conceptual design models of 2011 Solar Decathlon teams

Figure 6: The solar canopy

Figure 7: Energy use of a typical New Zealand home. Source: (Isaacs, Camilleri, et al. 2010)

Figure 8: A Traditional kiwi bach

Figure 9: Site plan (Source: US Department of Energy)

Figure 10: Site location plan (Source: US Department of energy)

Figure 14: Diagram of how people loose heat from their bodies (Source: Lechner 2009)

Figure 15: Comparison of temperature and humidity in Wellington and Washington DC (Source: Autodesk, Ecotect analysis 2011)

Figure 16: Graph of temperatures in New Zealand throughout the entire year compared with Washington DC

Figure 17: Figure in here

Figure 18: Ecowool insulation arrives at the construction site in Lyal Bay

Figure 19: Comparison of variation in annual maximum, mean and minimum internal temperatures $\left({ }^{\circ} \mathrm{C}\right)$ due to increase in insulation R-value $\left(\mathrm{m}^{2 \circ} \mathrm{C} / \mathrm{W}\right)$

Figure 20: HVAC energy use during competition with an increase in insulation $\mathrm{R}$ value $\left(\mathrm{m}^{2 \circ} \mathrm{C} / \mathrm{W}\right)$ 55

Figure 21: Installation of wool insulation

Figure 22: Installed wool insulation in roof and wall

Figure 25: Variation in minimum, mean and maximum annual internal 
Figure 26: Variations in HVAC energy use with $100 \mathrm{~mm}$ concrete slab compared with baseline for the period from September 15 - October 15

Figure 27: Variations in hourly internal temperature with $100 \mathrm{~mm}$ and $800 \mathrm{~mm}$ (9.3" \& 31.5") concrete slab compared with baseline for the period from September 15 - October 15

Figure 28: Craning the modules into place on Frank Kitts Park

Figure 29: Detailing of the concrete floor and timber decking

Figure 30: The skylight

Figure 31: Annual maximum, mean and minimum internal temperature $\left({ }^{\circ} \mathrm{C}\right)$ with glazing area between $0 \%$ and $100 \%$ of baseline area

Figure 32: Variations in hourly internal temperature with glazing area between $0 \%$ and $100 \%$ of baseline area concrete slab compared with exterior for the period from September 15 - October 15.

Figure 33: Variations in hourly internal temperature with glazing area between $100 \%$ and $400 \%$ of baseline area concrete slab compared with exterior for the period from September 15 - October 15.

Figure 34: Artist's impression of the architectural impact of central space showing the skylight

Figure 35: Composite skylight glazing construction details (a) Triple Layer Danpalon with translucent glass wool insulation, (b) Profilit glass channel with nano-gel insulation, (c) ETFE 4 layer pillow

Figure 38: Daylight anaylsis of the skylight preformed in Autodesk Ecotect Analysis software

Figure 39: Comparison of annual maximum, mean and minimum internal temperatures $\left({ }^{\circ} \mathrm{C}\right)$ with various shading devices

Figure 40: Energy consumption in New Zealand with interior, exterior and twin shading options

Figure 41: Energy consumption during competition with interior, exterior and twin shading options

Figure 43: Maximum heat gain and loss through the window glazing over entire year

Figure 45: Thermal image of bifold doors, North facing glazing and skylight of the First Light house (Source: Image courtesy of BRANZ)

Figure 47: At 1200mm the Canopy provides full shading on December 21st in New Zealand and on June 21st the canopy is sized to allow full solar gain throughout the day

Figure 52: Angle of installed canopy slats 
Figure 56: Incremental construction of the final 'super model'

Figure 57: Simulated heating and cooling loads (kW) of HVAC system from August to October in Washington DC

Figure 60: Daily energy consumption (kWh) of HVAC system during competition under the simulated weather scenario; hot, calm and raining

Figure 61: Monthly energy use of the HVAC system (kWh) in Wellington, New Zealand

99

Figure 62: Part of the house's energy monitering system (TRING) that represents energy use by the size of 'tree rings'

Figure 63: Evacuated tube solar hot water collectors

Figure 64: Parabolic solar collector (Source: Image courtesy of Anrew Wallace)

Figure 65: Hourly output (W) of Evacuated tube and Flat plate solar hot water systems on an average and 10\% low day of solar radiation in New Zealand

Figure 66: Diagram of hydronic drying cupboard

Figure 67: Images of dryer mock up used for the intial tests

Figure 68: Diagram of Hot Water system

Figure 69: Completed drying cupboard

Figure 70: Fisher and Paykel applainces

Figure 71: Guests enjoying the first dinner party in the First Light house

Figure 72: Energy use per day during the competition period

Figure 73: Pie graph of energy use during competition

Figure 74: Graph of the monthly energy consumption (kWh) of the First Light house throughout year in New Zealand

Figure 75: 225W Polycrystalline solar panels

Figure 76: Schematic diagram of First Light electrical system

Figure 77: Probability density function

Figure 78: Diagram of intial panel layout and spacing on canopy

Figure 79: Energy generation of solar array at different angles throughout the year in Wellington

Figure 80: Simulated energy consumption vs generation using weather data from September 2005

Figure 81: Energy consumption vs generation throughout year in New

Figure 82: First Light house on Frank Kitts park from above 
Figure 84: Panoramic image of First Light house on Frank Kitts Park 127

Figure 85: Student construction on Frank Kitts park 128

Figure 86: Students giving public tours through the house 128

Figure 87: Lines of people waiting to view the house 129

Figure 88: Faulty seal at the base of the bifold doors (Source: Image courtesy of BRANZ)

Figure 89: Blower door test on the First Light house

Figure 90: Final team photo before the house was shipped to DC for the competition

Figure 91: Completed house in Washington DC

Figure 92: Temperature and Humidity sensor

Figure 93: Observer preforming spot check of sensors

Figure 94: Decathlete reading flow meter while preforming a hot water draw off

Figure 95: Observer monitering hot water draw off

Figure 96: September 22 peformance anaylsis

Figure 97: Team scores at the end of Day 1 of the competition

Figure 98: Signage ready the first public tours

Figure 99: Energy use of all 20 teams throughout on the 22 September, the first day of the competition

Figure 100: September 23 peformance anaylsis

Figure 101: Team scores at the end of Day 2 of the competition

Figure 102: Temperature of New Zealand house compared with the three leading teams in the comfort zone contest

Figure 103: Relative humidity of the top 7 teams during the scoring period of the 23 September

Figure 104: Energy balance of New Zealand compared with the top three teams by the end of the $23^{\text {rd }}$ of September

Figure 105: September 24 peformance anaylsis

Figure 106: Team scores at the end of Day 3 of the competition

Figure 107: Graph of top three teams humidity during score period compared with New Zealand

Figure 108: Public lining up to view the house despiet the rain

Figure 109: September 25 peformance anaylsis

Figure 110: Team scores at the end of Day 4 of the competition

Figure 111: The team ready for another day of tours and grey skies

Figure 112: Energy balance of all teams on day 4

Figure 113: New Zealand's energy balance compared with top three teams on September 24th 
Figure 114: September 26 peformance anaylsis

Figure 115: Team scores at the end of Day 5 of the competition

Figure 116: September 27 peformance anaylsis

Figure 117: Team scores at the end of Day 6 of the competition

Figure 118: The team awaiting announcement of the affordability contest results

Figure 119: September 28 peformance anaylsis

Figure 120: Team scores at the end of Day 7 of the competition

Figure 121: Architecture competition results

Figure 122: Energy balance on 28th September of top six teams

Figure 123: September 29 peformance anaylsis

Figure 124: Team scores at the end of Day 8 of the competition

Figure 125: Architecture competition results

Figure 126: Energy balance on 28th September of top six teams

Figure 127: September 30 peformance anaylsis

Figure 128: Celebration after winning engineering contest

Figure 129: Team scores at the end of Day 9 of the competition

Figure 130: Graph of the accumulation of points throughout

competition

Figure 131: Final energy balance of top 6 teams

Figure 132: Final placings in the 2011 Solae Decathlon

Figure 133: Team scores at the end of Day 9 of the competition

Figure 134: Team Celebrations after finishing in third place

Figure 135: Summary of Final results

Figure 136: New Zealand's cumulative energy use throughout the competition period

Figure 137: Actual points earned versus potential points for each individual contest

Figure 138: NZ Flag outside the First Light house

Figure 139: Measured contest scores versus judged contests

Figure 140: Brendan, Eli and Nick with Joe outside the teams HQ during the competition 


\section{List of tables}

Table 1: Construction R-Values used for baseline simulation

Table 2: NZ Building code requirement of R-value for ceiling, wall, floor

\& glazing (Source: Isaacs, Thermal Insulation 2007, 110

Table 3: Thickness of polystyrene and the corresponding R-Value $\left(\mathrm{m}^{2 \circ} \mathrm{C} / \mathrm{W}\right)$

Table 4: Construction R-value of individual building elements

Table 5: Total heating and cooling energy of the house with skylight compared with no skylight during the competition period

68

Table 6: Thermal and optical specifications for various glazing types (source: Window 5)

Table 7: Thermal and optical properties of composite skylight glazing options

Table 8: Thermal and optical specifications for Metro Glasstech intial suggested IGU (source: Metro Glasstech and Window 5)

Table 9: Thermal and optical specifications for various glazing types (source: Window 5)

Table 10: Construction R-value of glazing and skylight

Table 11: Percentage shading of south facing windows of canopy louvers at various angles

Table 12: Construction R-Values used for final simulation

Table 13: Conditions of worst case weather file

Table 14: Estimated energy use of comfort zone contest

Table 15: Estimated energy use for hot water contest

Table 16: Estimated energy use for hot water contest

Table 17: Estimated energy use for Home entertainment contest

Table 18: Total Estimated energy use of the First Light house during the competition

Table 19: Estimated energy generation versus consumption during the 2005 competition

Table 20: Total monthly energy generation versus consumption in Wellington

Table 21: Thermal resistance of individual building elements

Table 22: Breakdown of the layers within the roof construction and their 
Table 23: Breakdown of the layers within the wall construction and their $\mathrm{R}$ values

Table 24: Breakdown of the layers within the floor construction and their $\mathrm{R}$ values

Table 25: Breakdown of the layers within the timber floor construction and their $\mathrm{R}$ values

203

Table 26: Construction of weather files

204

Table 27: Test results of prototype dryer

216

Table 28: Energy use of first dinner party

Table 29: Energy use of second dinner party

220

Table 30: Total competition energy use per day 


\section{Acknowledgements}

This project would not have been possible if it wasn't for the tremendous help and support from many wonderful people from around New Zealand. For me, this journey began late in 2009 and throughout I have been honoured to have met and worked with some amazing individuals both in the industry and within the university

Firstly, to all of our sponsors thank you for your support and guidance throughout the project. To successfully design, build and transport a small solar powered home to Washington DC, not to mention finishing in the top three teams, is a huge accomplishment and would not have been possible without you. One of the elements that have made this project successful is the collaboration between the university and industry in New Zealand. Many people have been involved throughout the design and construction, often giving their time, expertise and materials in kind to help the project. For me, personally I have made some great friends and contacts that I look forward to working with in the future.

Thank you to Victoria University of Wellington for your continued support throughout the entire project both individually and to the whole team. Individually the financial support provided by the university was extremely helpful and meant our full focus could be put into the research, design, and construction of a successful entry into the competition. This project is unique and was a huge learning process for all. Many people from within the university have been involved in the project in a wide range of capacities and I am grateful for all of your help, guidance and support along the way.

I would also like to acknowledge my supervisor Brenda Vale. Your positive encouragement and detailed focus, especially during the last six weeks of the written phase of the thesis has been greatly appreciated. Brenda and Robert, thank you also for all of the help you have given us throughout the last two years. We have all learnt so much from your tremendous knowledge.

Thank you to Anna, Eli and Nick. It is difficult to describe the enormous respect and appreciation I have for you all as architects. Over the last two years we have been through it all, and come out the other end great 
friends. I look am excited about working with you in the future and can't wait for First Light 2012!

Throughout the project a team of students also worked on the project. To the entire team thank you for your hard work and tireless commitment. You made this project a success! Specific regard goes to Liam, Andrew, Rob and Josh who I worked closely with throughout the simulation phase of the project and whose results have made a large contribution to this research. Thank you for your help and your guidance. For an architect, venturing into the world of simulation and building science was initially daunting but greatly rewarding, and having your support throughout is greatly appreciated.

Finally, thank you to my family and friends for your personal support, in particular my partner Amanda for your smiles and laughter. You got me through!

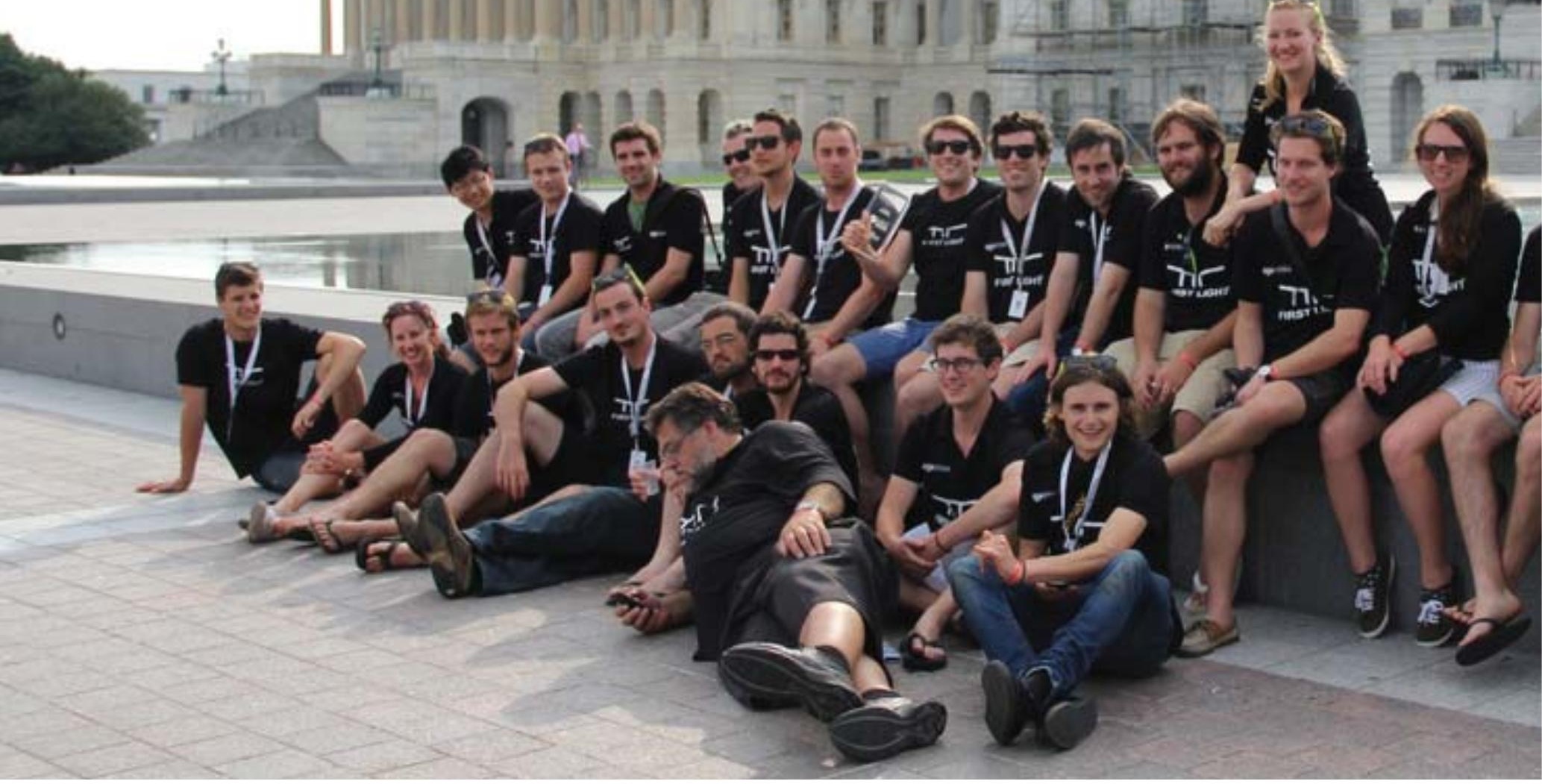

Figure 2: The team celebrating second place in Architecture outside the Capitol building in Washington DC 


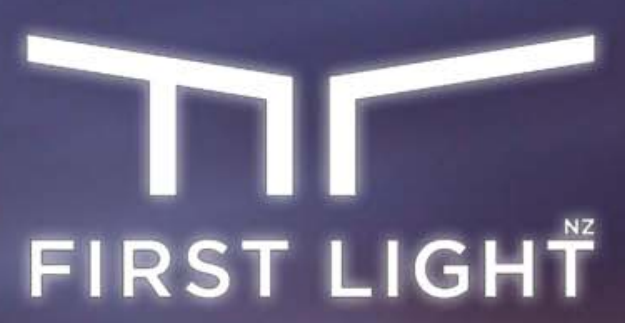

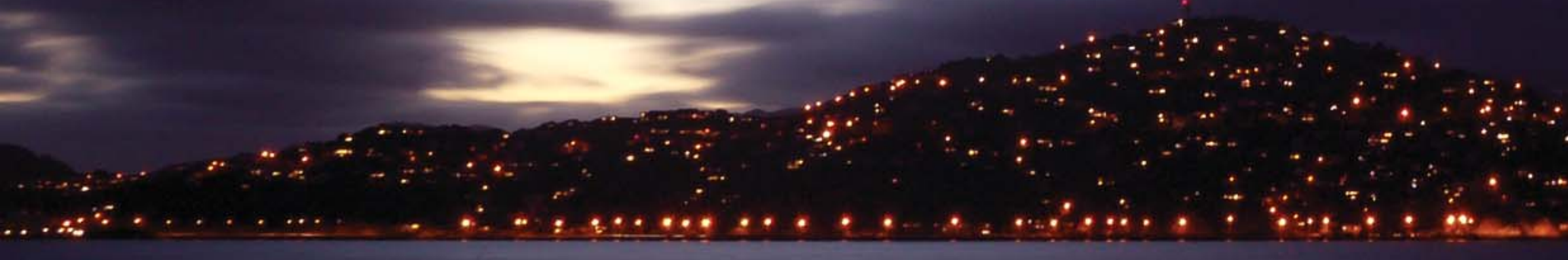
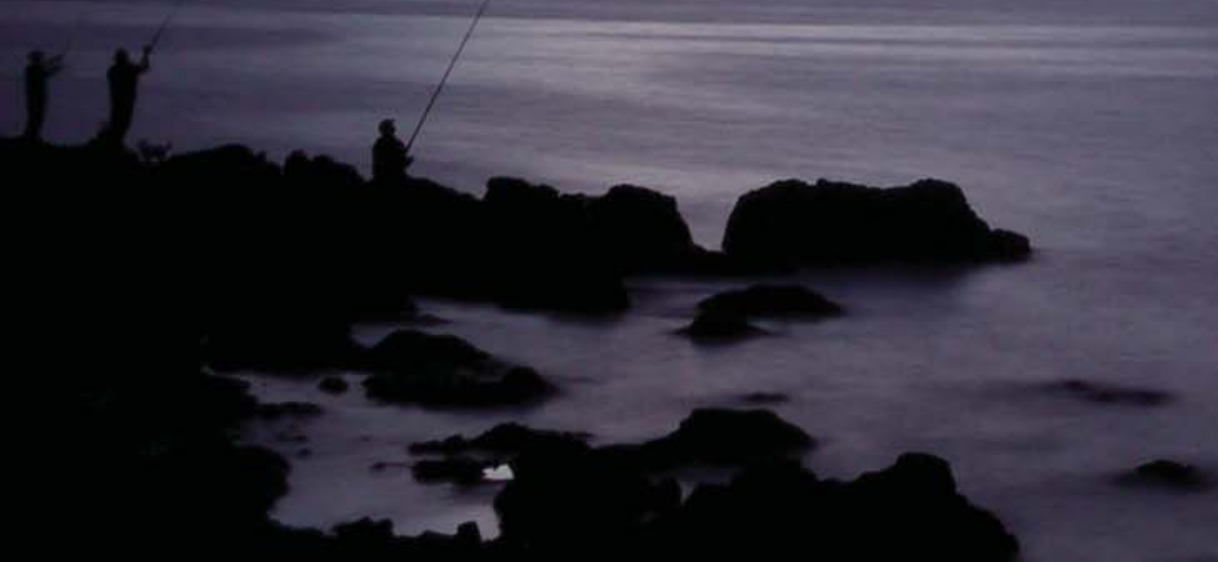

Figure 3: The First Light brand 


\section{Introduction}

In September 2011, twenty university led teams from all over the world descended on West Potomic Park in Washington DC to compete in the US Department of Energy's (DOE) Solar Decathlon. The competition challenges teams to design, build and operate a small, net zero energy home that is built off site, transported to Washington DC and constructed there in less than seven days. Once complete, the houses form a solar village where they are monitored, measured and judged in ten unique contests over the course of ten days. During this period the houses are open to the public when thousands of people make the journey to the banks of the Potomac River to experience these unique and innovative solar powered homes.

First held in 2002, there have since been 91 decathlon homes constructed and set up in Washington DC as a part of the competition. Since its inception it has grown to become one of the most anticipated design competitions ever held. For the 2011 Solar Decathlon teams were selected from a rigorous two stage application process that involved the submission of an initial proposal by the university followed by a conceptual design presentation and 1:50 scale model of the proposed design (Figure 5). This process took over three months but by early 2010 the teams that had been selected for the 2011 competition had been announced. One of the finalists was a small 'kiwi bach' from Victoria University in Wellington, New Zealand. Being the first ever country from the southern hemisphere in the competition and the first country in the world to see the light every day it was appropriate that the team was named First Light. Once they were selected the team had less than two years to develop the house from the conceptual design into a fully functioning, net zero energy home that could be constructed in Washington DC.

This thesis focuses on the energy use of the house and documents the design process from the initial selection into the competition through to final construction and the overall performance of the house during its time in Washington DC. Through comprehensive thermal modelling the thesis looks at how both the passive and active design of the house has 
been optimized to reduce its energy use in New Zealand as well as meet the requirements of the five measured contests in the Solar Decathlon. Designed with the same rigour as a yacht the First Light house was constructed in September 2011, in Washington DC, where it was sailed for ten days under a strict set of rules, in a specific climate against nineteen other teams but, instead of using the wind, it was powered by the sun.
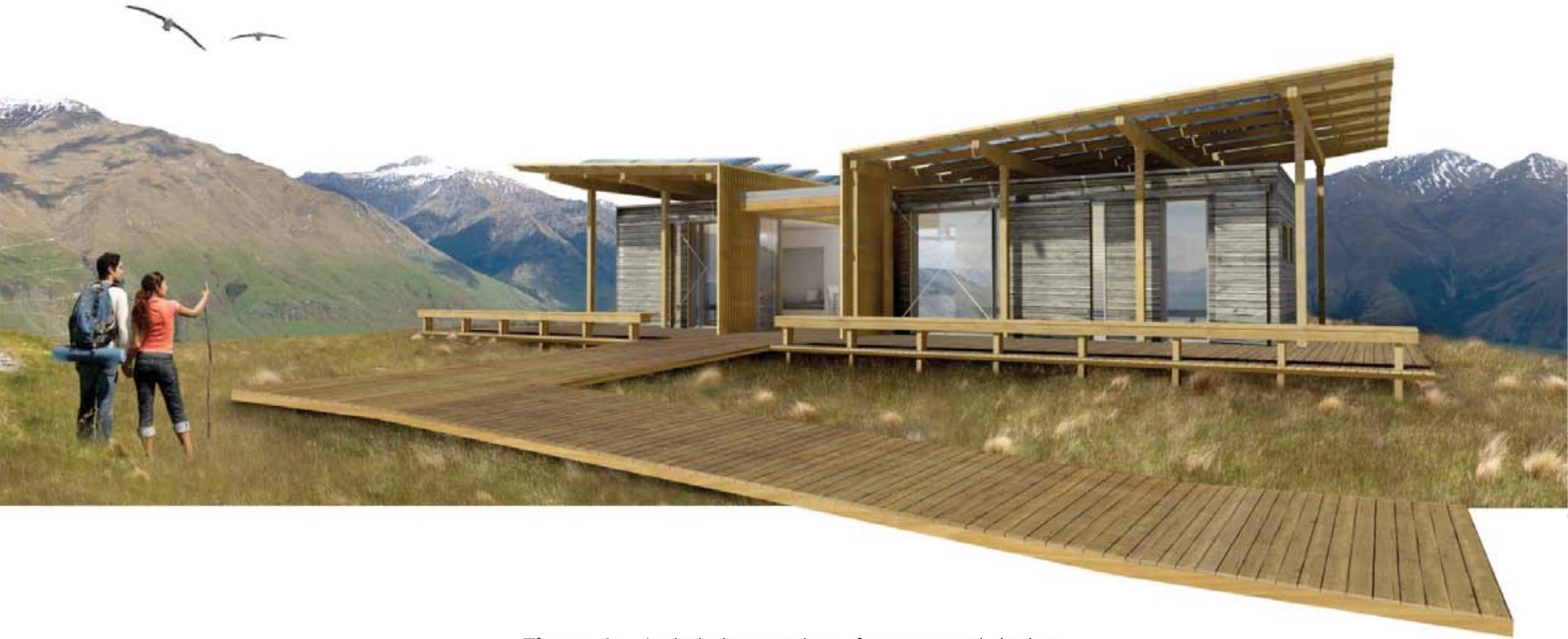

Figure 4: Artistic impression of conceptual design 

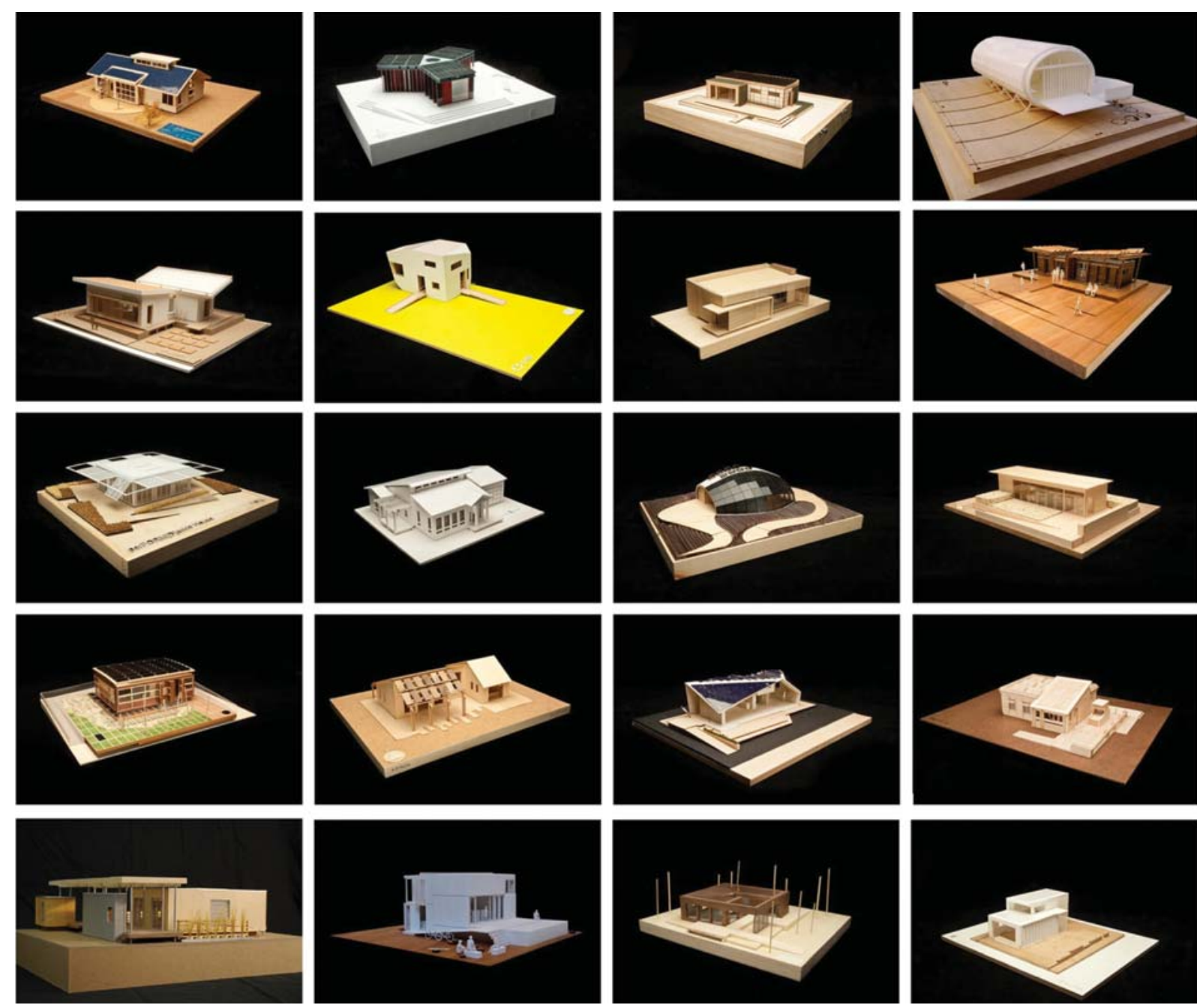

Figure 5: Conceptual design models of 2011 Solar Decathlon teams 


\section{The starting point: The Schematic design proposal}

\subsection{The State of housing in New Zealand}

The starting point for the ideas associated with the First Light house arose out of the current state of housing in New Zealand. Although much of the focus over the last two years was on designing a home that best met the requirements of the competition a major focus was on the performance of the house back home in New Zealand. It was essential that the house that was presented in the 2011 Solar Decathlon was based on kiwi ideals designed for a New Zealand climate. At present New Zealand homes are cold, damp, and unhealthy and consume large amounts of energy. A recent study performed by the Building Research Authority in New Zealand, the Household Energy End-use study, (HEEP) quantified how, where and why energy was being used in New Zealand homes, based on monitoring of energy and end uses in a national sample of 400 homes. The study found that the average total energy use per household was 11,410 kWh/yr (Isaacs, Camilleri, et al. 2010, 13). Of this energy used in homes over a third was being used to keep them warm, on average using 3,820kWh/yr (Isaacs, Camilleri, et al. 2010, 15).

The study went into detail about how this energy was being use. It found that despite using this average energy for space heating New Zealand homes were extremely cold. Based on the data from the study it was found the mean indoor ambient winter temperature of the houses studied was well below the World Health Organisation (WHO) healthy indoor temperature range of between $18-24^{\circ} \mathrm{C}$ (WHO 1987, 14). These low indoor temperatures are associated with poor health, a variety of social and economic problems and contribute to mould and dampness in houses. The study concluded that there are three critical factors that contribute to low indoor temperatures; thermal performance of the building envelope, the type and source of heating, and how heating is used. By looking into how, why and when people use energy the study has been able to 


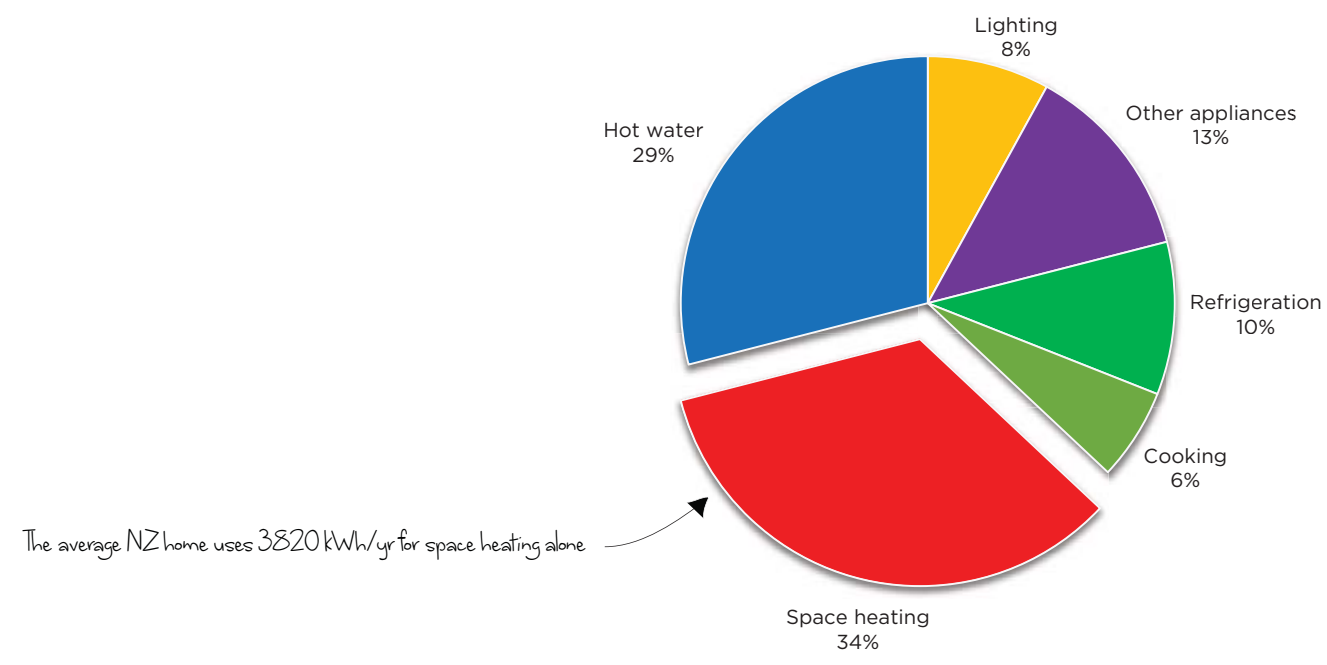

Figure 7: Energy use of a typical New Zealand home. Source: (Isaacs, Camilleri, et al. 2010)

highlight that reducing heat lost through the building envelope and the implementation of more efficient means of heating could reduce the energy wasted in unsuccessfully 'heating' New Zealand homes.

In order to design a net zero energy home that would meet the competition requirements it was essential to reduce the energy consumption of every aspect of the building design. As space heating is the biggest energy consumer in an average NZ home, focusing on ways to reduce this through passive design strategies would not only improve the New Zealand situation but would also help to meet the comfort requirements of the Solar Decathlon. The aim was to use the constraints of the competition to design a healthy, comfortable and zero energy home that was ideal for New Zealand conditions.

\subsection{The team}

After being selected to compete the First Light house began its transformation from an initial concept dreamed up by four architectural students into a real, energy self-sufficient home. The first step was to put together a schematic design proposal that was submitted to the US Department of Energy that described the design in its current form, the objectives of the project and a methodology for developing the design. This document was compiled by the four graduate students who had 
developed the concept design as a part of a studio paper in the final year of their architecture degree.

Before developing the proposal and the subsequent design the project was split into four clearly defined areas of research. These comprised architecture and logistics, interior design and landscape, marketing and communications, and finally engineering and technologies. By separating the project into four areas of research the team could focus more rigorously on the development of the design to meet the performance criteria of the contests embedded in each area of research. This would push the boundaries of the initial design concept and create a more evolved design that would perform optimally in all 10 contests within the competition. 


\subsection{The Concept}

Before investigating the concept design of the First Light house it is worth introducing the ideas that have been essential to its design over the past two years. Below is a quote from the schematic design proposal (Appendix K) that was submitted to the organizers in March 2010, at the beginning of the project. This proposal was the first document to explain the concept design in its entirety.

"...The iconic "Kiwi bach" provided a perfect precedent for identifying the core values behind a uniquely New Zealand lifestyle. Traditionally situated in remote locations, the bach was a refuge away from city life. Here, recreation and socialization were a priority. As primarily a summer destination, life at the bach took place as much outside, on large decks and patios, as it did inside. This resulted in a seemingly modest house with open plan living, simple amenities, and shared accommodation. Our house brings these ideals of bach life into a contemporary setting, providing a permanent residence where recreation and social activities are united with a simple use of technologies."

From this initial design statement there are three core values that were extracted to form the foundation of the design;

- Relationship with the outdoors

- Focus on socialisation

- Use of simple technologies.

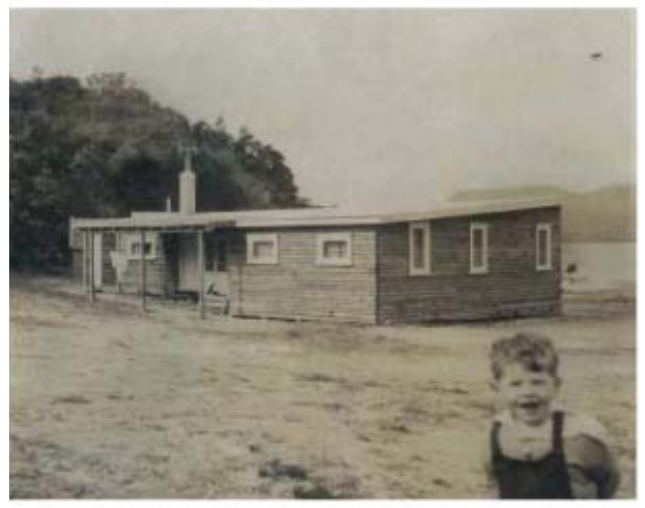

Figure 8: A Traditional kiwi bach

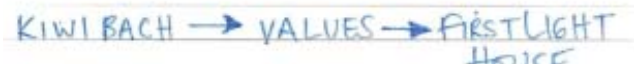
HOUSE. 
Throughout the process these core values have been used as a way of focusing the design. By separating the project into four separate areas there was the potential to drift away from the original concept. Whenever the research pushed the design in a particular direction, these values were used as guidelines to evaluate design decisions. But within these original values there is very little about a concept for energy use within the house. It is discussed throughout the document but is never stated as being an explicit driver of the design. It is understood in the proposal that in order to compete in the competition the house must be net zero energy (ie. it must generate at least as energy much as it uses). The proposal did discuss the fact that reducing the energy the house consumes would have a direct influence on its cost.

"If we can achieve our desired energy consumption, we will be able to reduce the number of solar panels on the roof. This will have a dramatic impact on the affordability of the home and will make it more accessible to a wider range of individuals in both New Zealand and the US."

The development of the design from this initial proposal very quickly became about balancing design decisions with their direct effect on the overall energy use of the house and therefore its cost. Although it is not explicitly stated within the schematic design proposal, energy use was as much of an influence on the design as the three original core values.

\subsection{The site}

There are two quite distinctly different sites for the First Light house. The first is a flat site, $23.8 \times 18.3 \mathrm{~m}$ (78'x 60') square, located in West Potomac Park, in Washington DC. Originally the competition site was to be the National Mall between the Capitol building and the Washington Monument but this was changed mid-way through the project to West Potomac Park. (Figure 10) The site, on the banks of the Potomac River, is situated along the path between the Lincoln and Jefferson Memorials. It gets full access to all day sun and has beautiful views across the river. The layout of the competition village was split into five streets running east-west with four houses on each. Each site faced due south (Figure 9) and was governed by a solar envelope that restricted the size and the height of the house within the site boundary. 
The other site was a hypothetical section of the same dimensions in Wellington, New Zealand. For the purposes of this project a specific site within Wellington was not chosen but it was assumed it would have the same site parameters as for the competition.

The location of the site was extremely important for the start of the investigation into the performance of the house within a particular climate. For the purposes of this project the design of the house was optimized for both climates at different times of the year. This will be explained in more detail later on.

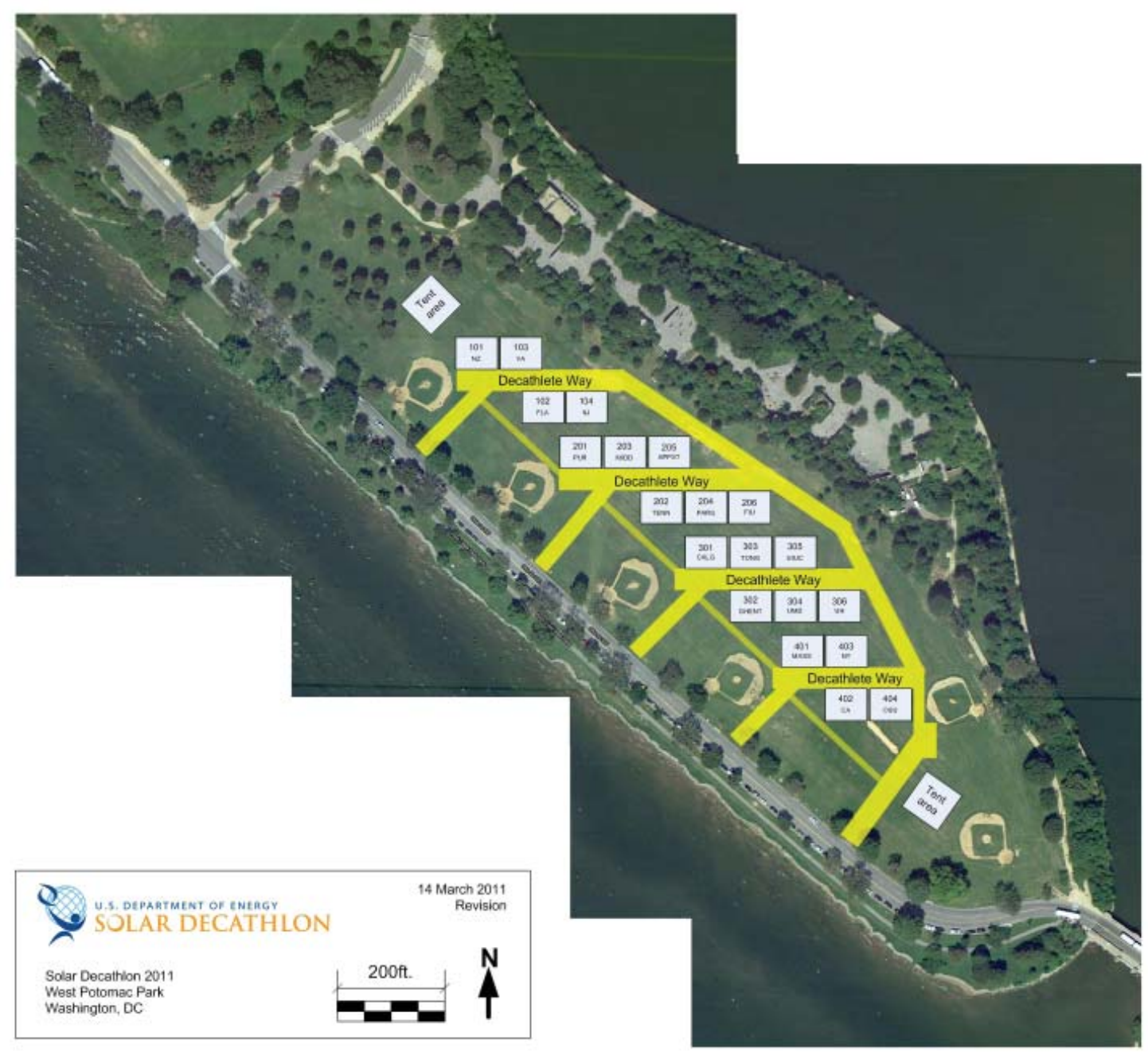

Figure 9: Site plan (Source: US Department of Energy) 


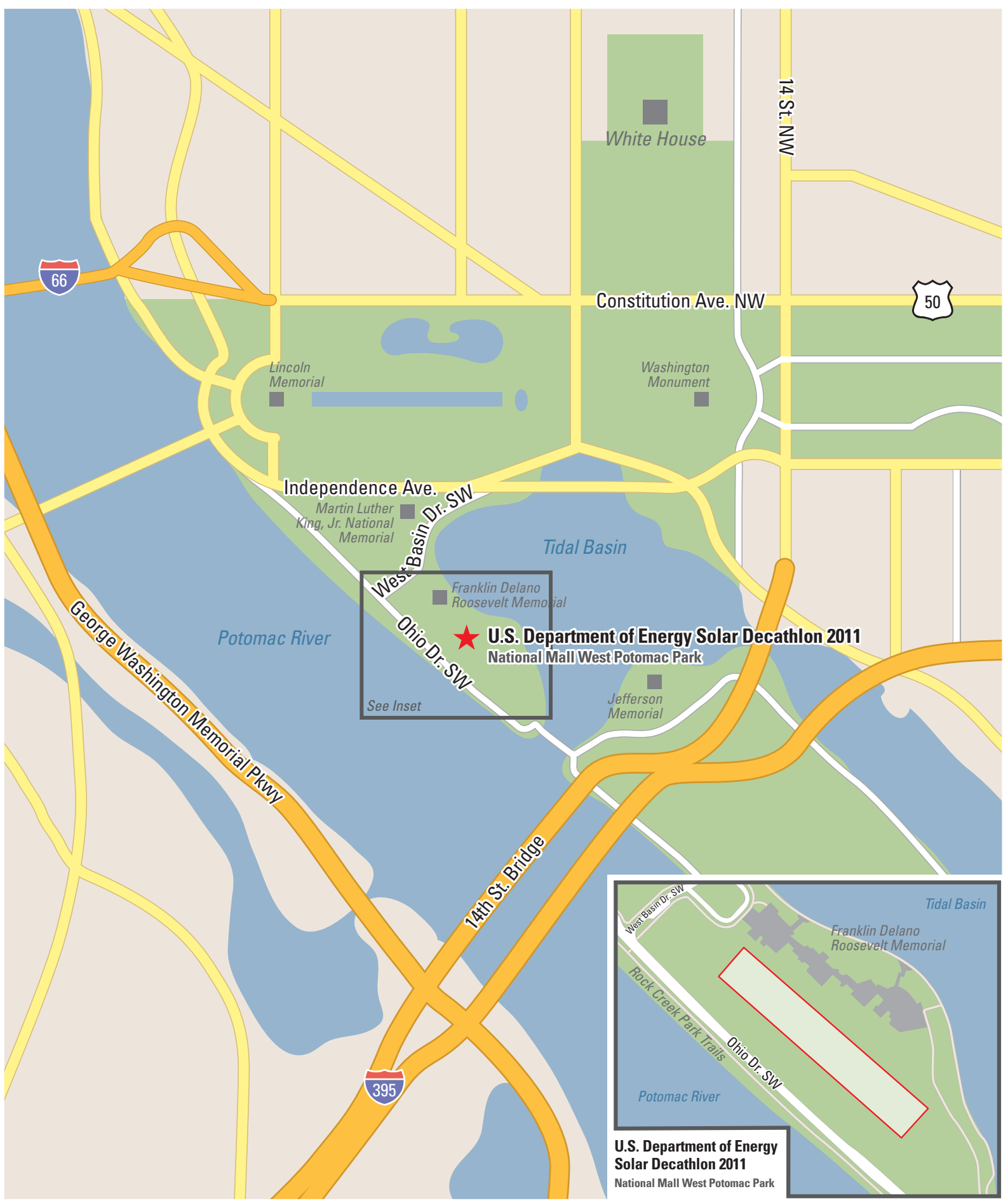

Figure 10: Site location plan (Source: US Department of energy) 


\subsection{The competition}

Often considered the Olympics of house design and being a Decathlon the competition is split into 10 , equally rated contests, made up of architecture, engineering, affordability, communications, market appeal, comfort zone, hot water, appliances, home entertainment and energy balance. Worth 100 points each, the contests are split into five judged and five measured contests each with a very specific set of requirements. The creator and director of the Solar Decathlon, Richard King stated "the aim of the competition is to raise awareness's of the energy saving benefits of highly efficient home design and renewable energy technologies." When developing the concept for the competition King came up with a concept of 10 different contests that together challenged teams to design a home that would best achieve this aim. Appendix A gives further details about the specific requirements of each contest.

\subsubsection{Judged contests}

The judged competitions were adjudicated by a panel of 'experts' in each particular field who critique the homes based on the drawings, images and marketing material and on the quality of the houses in the first two days of the competition. The results are announced incrementally over the course of the competition.

\section{- Architecture}

The architecture contest was judged by a team of 'esteemed architects' who focused on five specific areas of the design. These included the architectural elements such as scale and proportion of the space, its holistic design, lighting, inspiration, and finally the documentation of the drawings and the specification. Worth only 100 points, it was rated with the same importance as home entertainment and hot water. In 2007 architecture was worth 200 points but was reduced back to 100 for the 2009 and 2011 competitions. Unfortunately, there is no mention in the marking schedule or reward for the use of passive design strategies. 


\section{- Engineering}

Like architecture, the judging of the engineering contest is based on five categories. In the Solar Decathlon the engineering is specifically focused on the HVAC system. A team of judges look 'under the hood' of the home and establish the functionality, efficiency and reliability of the mechanical systems. Unique, innovative solutions are encouraged and clear documentation was imperative. But, being specifically focused on the mechanical systems there is no mention of the engineering involved with transporting the house and, like the architecture competition, there is no specific mention of the passive design elements. Although the functionality and efficiency of the HVAC system would improve with a well-designed thermal envelope there was no direct mention of passive systems within the rules but instead a very distinct focus on technologies.

\section{- Affordability}

New to the 2011 competition the affordability contest was introduced to encourage teams to design and build affordable homes that combine energy efficient construction and appliances with renewable energy technologies. In the past, with no limits to affordability, the teams that were competitive in the Decathlon were those that had large budgets and could afford the latest in cutting edge technology. The aim of the affordability contest was to put the focus back on the design of the home rather than the technologies within it. By doing this the US Department of Energy hoped to encourage consumers to adapt and introduce the energy saving techniques displayed by the teams into their own homes and building projects. Unfortunately the cost limits set by the competition were still relatively high, especially considering the size of the houses.

\subsubsection{Measured contests}

The measured competitions monitor how each house performs against a very specific set of criteria in Washington DC during the 10 days of the competition. This thesis focuses on the measure contests in the Solar Decathlon and documents how the First Light house has been designed to meet each of the requirements of all five of the measured contests as outlined below. 


\section{- Comfort zone}

The comfort zone is one of the toughest of all 10 contests within the Solar Decathlon and a major part of this thesis is concerned with this one issue. The Solar Decathlon challenges teams to design a home that remains within an extremely limited temperature and humidity range throughout the competition. Sensors placed throughout the home monitor the temperature and humidity every fifteen minutes over the contest week. To be eligible for full points teams must maintain a comfort zone between $21.7^{\circ} \mathrm{C}$ and $24.4^{\circ} \mathrm{C}$ and below $60 \%$ relative humidity over the monitored period. These narrow comfort parameters are significantly lower than what is typical in the majority of energy efficient buildings around the world. The question is what effect do these narrow comfort requirements have on the design of a Solar Decathlon house and its subsequent energy use?

\section{- Hot water, Appliances and Home Entertainment}

The sporting metaphor often used to describe the contests within the Solar Decathlon is extremely relevant in the Hot water, Appliances and Home Entertainment contests. These contests turn activities like the production of hot water, washing and drying clothes and the running of the refrigerator into standalone events worth points in the competition. Like the comfort zone contests each has a very specific set of rules that teams must meet to be eligible for full points. In reality these contests in combination with the comfort zone form a method for simulating the typical energy use of a house as a way to distinguish the subsequent energy efficiency of each of the houses in the Solar Decathlon. But the heavy weighting of points in these three contests, $30 \%$ of the overall score, make them more important than the architecture and engineering contests combined.

\section{- Energy balance}

The final measured competition is the energy balance contest. Throughout the competition a bi-directional energy meter monitors the energy production and consumption of each house. To receive full points each house must generate at least as much energy as it consumes over the course of the 10 days of the competition, whatever the weather. 
With the innovative homes that are produced and the public awareness the competition attracts the Solar Decathlon has grown to become one of the most anticipated design competitions ever held. 


\subsection{The house - The initial design}

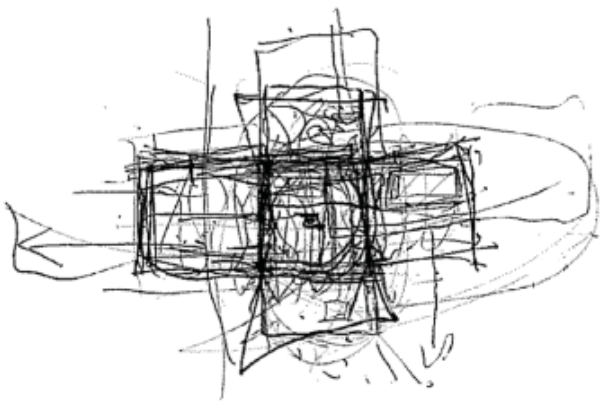

Once the space the house could occupy within the site boundary, the rules were understood and the competition requirements were ascertained the plan of the house could be developed. Due the size restraints for the floor plan governed by the competition rules, and the need to pack the house into containers for shipping, there had to be an economy in planning that made use of all the space available. The plan is based on a simple, compact form with two closed-in pavilions that house the sleeping and study space surrounding a central eating area. (Figure 11)

"A long box, cut in half creates the living end and the sleeping end. In the cut, the bi-section, lie the dining room and the kitchen (the eating bit)"

The three major functions of the home-living, eating and sleeping-fitted within a single space that ran along the 'sunny-side' of the house. The living end of the home was designed around a built-in couch that transformed into a sleeping space for extra guests. The sleeping end was separated by a study unit which divided the room, adding privacy to the bedroom. The eating space in the centre was the entry, central meeting area, kitchen and dining space. It was the 'social' heart of the home as well as the vehicle for connecting with the outdoors. In the original design this central space was fully glazed, with a transparent roof, no shading and large bi-folding doors on either side. (Figure 12) This space captured the essence of the three core values of the project and was a major conceptual driver of the design. Along the 'cold' side of the house ran the services core that housed the bathroom, laundry, and kitchen. Moving the more discrete functions to this side of the house was a deliberate passive design feature which added another layer of insulation against the cold on the outside and allowed the living, dining and eating spaces to make the most of the sun throughout the day.

The schematic design proposal briefly discussed the passive design features of the house, and concluded that they were a major driver of the design. Although not specifically stated the general idea presented within the proposal was that reducing space heating and cooling energy use through passive solar design features would reduce the overall energy demand of the house. The original concept was designed with triple 


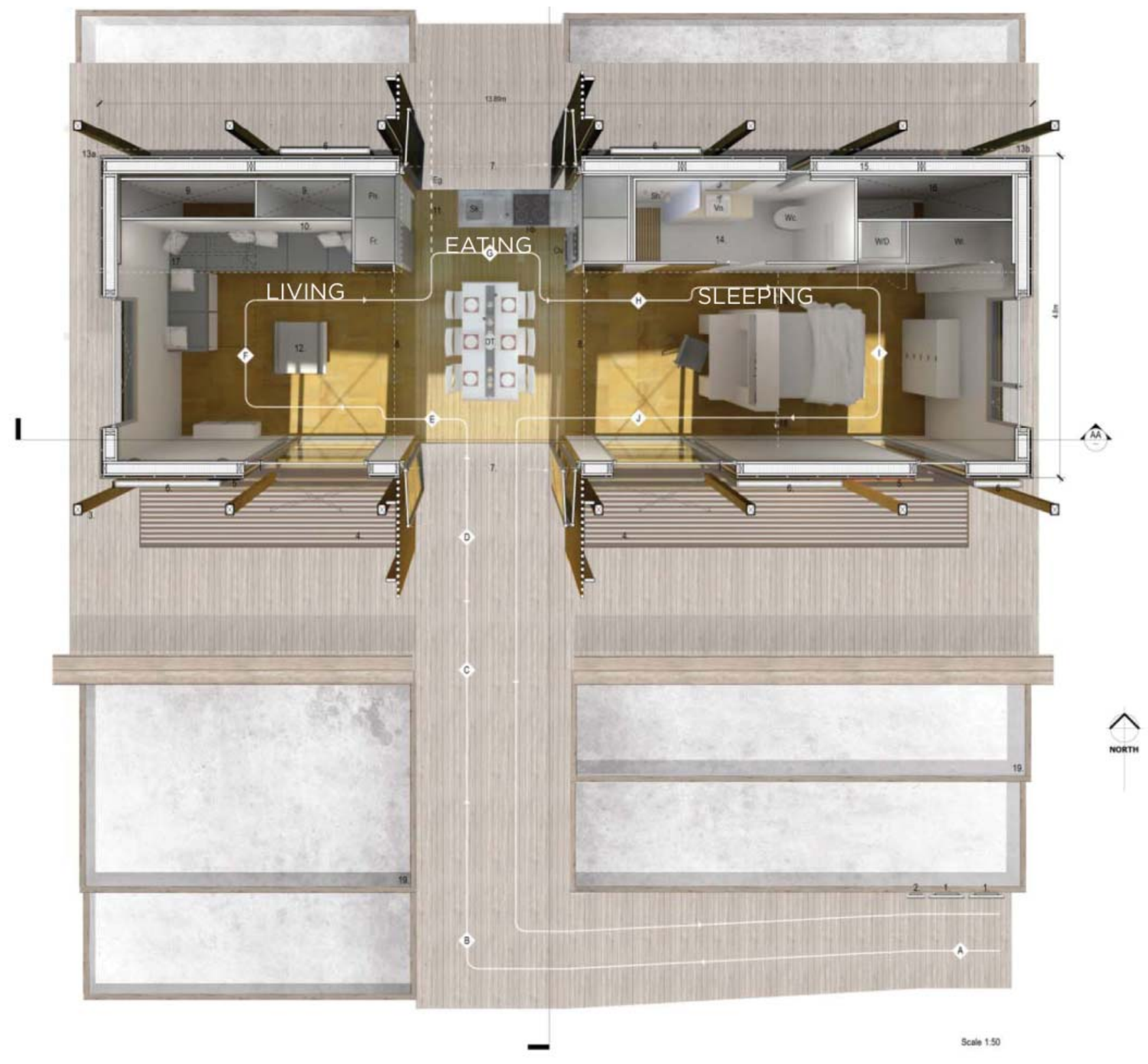

Figure 11: Conceptual floor plan of the First Light house

"Along box, cut in half creates the living end and the sleeping end. In the cut, the bi-section, lie the dining room and the kitchen (the eating bit)" 
glazed windows and high levels of insulation within the building envelope to reduce heat loss. A 'solar' canopy, designed to provide shading of the large windows during the summer months and maximise solar gain during the winter, became the main passive solar design feature. This timber canopy gave the house its unique form as well as providing the structure for the solar panels, lifting them up off the building envelope. At this stage of the design process there had been very little use of computer models for thermal simulation. The proposal concluded that the next step in the design would be to create a model that could be used to optimize the building envelope and improve the performance of the passive design of the house.
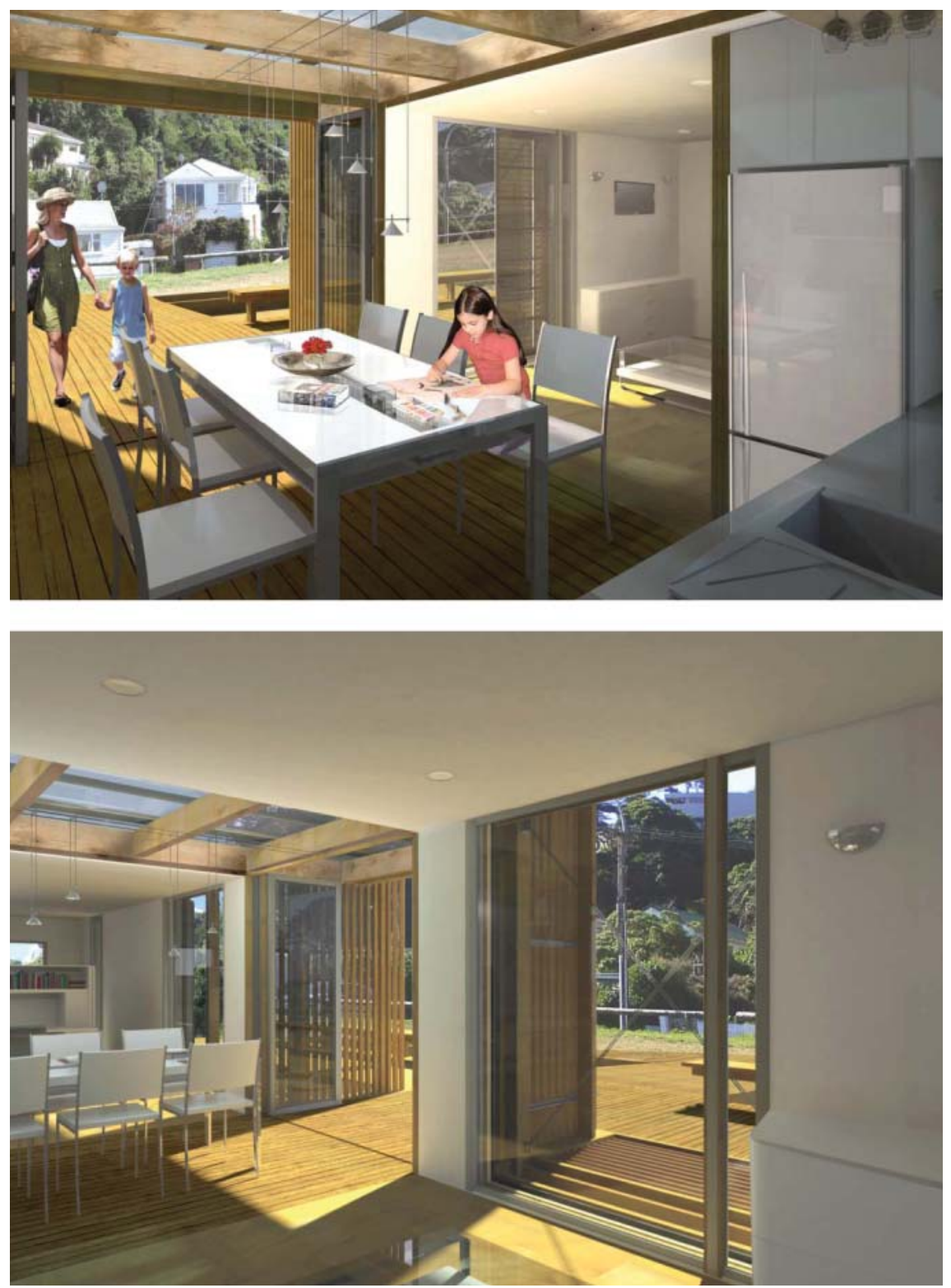

Figure 12: Intial interior renders of First Light house 


\subsubsection{Technologies and energy use}

Despite not having completed any thermal simulations there had been some basic calculations on energy use which had been used to size the solar array. It was estimated that 33 monocrystalline solar panels were needed to generate all of the energy the house would consume during the competition. As a back up to this the design proposed the use of dye-sensitized solar cells detailed into a sliding façade. Through a simple calculation of the daily energy consumption based on the competition schedule it was estimated at this early stage that the house would consume $12-14 \mathrm{kWh}$ per day. Interestingly from this early phase of the design there was a discussion about the need to improve the performance of the heating and cooling system in order to reduce this energy consumption.

"Considering the huge role heating and cooling have on the energy consumption of the house, designing a simple system that uses small amounts of power to achieve the thermal comfort outlined in the competition will go a long way to reducing our total energy consumption"

The heating and cooling system described in the initial design was a simple solution of two wall mounted heat pumps on either side of the central space. There was a strong emphasis on automation and control in this initial concept through a centralised building management system. This would control the house and provide information to the user about energy and water consumption. Along with LED lighting and energy efficient appliances, an evacuated tube solar hot water system was used to generate all of the hot water for the home. Although there is little science behind any of the decisions made up until this point the ideas relating to both the building and the technologies within it formed a solid foundation for refinement. The next step discussed in the proposal was to use this information to form a comprehensive model that could be used for thermal and energy simulation to determine accurately how the house would perform and how it could be improved. 


\subsection{The objective}

With this starting point in the schematic design proposal it was essential that the goals of the project were outlined. With the split into four distinct areas of research there were four different ways of working towards the two goals of winning the 2011 Solar Decathlon and improving house design in New Zealand. In order to achieve these, the design would have to meet the requirements of all ten competitions within the Solar Decathlon. This thesis looks at the engineering of the overall design of the First Light house, an element that is integral to success in the Solar Decathlon. From the engineering side of the project the goals were simple-design a house that both during the competition and over an entire year in NZ would use less energy than it generates. To do this, four other measured competitions, comfort zone, hot water, appliances and home entertainment became critical to the overall design because they were linked to energy use. Using the schematic design as the starting point and focusing on the requirements of each of the measured contests the design was developed to meet these goals.

\subsection{The method}

The method for developing the concept design into a net zero energy home began with a systematic approach to improving the efficiency of every element of the design. All four of the relevant measured contests were analysed in depth starting with the thermal comfort competition. This thesis is in part the story of this development. Chapter $\mathbf{3}$ looks at how the schematic design was translated into a computer model that was run through thermal simulation software in order to find areas where the building envelope could be improved. Once this baseline model was constructed simulations concentrated on reducing heating and cooling loads while maintaining thermal comfort using passive design strategies. The thermal comfort goal used during the first phase of simulations was the temperature and humidity requirements set for the contest $\left(21.7^{\circ} \mathrm{C}\right.$ $24.4^{\circ} \mathrm{C}$ and below $60 \% \mathrm{RH}$ ). Using the baseline model, several variations were made to the building fabric in order to reduce heating and cooling loads. These variations were: 
- Envelope insulation levels - Chapter 4

- High or low mass flooring - Chapter $\mathbf{5}$

- Glazing and skylight - Chapter 6

- Shading and ventilation - Chapter $\mathbf{Z}$

The model was run through two different energy simulation programs and results were analyzed separately to ensure the accuracy of the observed trends. Once an optimal envelope was established a 'super model' (final computer model) was created that represented the final design that would be constructed. With the super model created Chapter $\mathbf{8}$ discusses how this was used to simulate the performance of the heating and cooling system in the house during a number of different climatic conditions for both the competition in Washington DC and in Wellington. This information was used to size the mechanical system for the house appropriately and to calculate its energy use.

After establishing the best method for reducing energy use in the thermal comfort competition the same process was completed for hot water, appliances, and home entertainment as discussed in Chapter 9. Each element of all three contests was analysed to find areas where energy could be saved. Once performance was optimized the information was put into a final simulation that included everything in the house that would consume power. This gave an accurate estimate of energy use, from which the size of the solar array could be calculated, as shown in Chapter 10.

The process described above was focused entirely on reducing the overall energy use of the house. As this is only one aspect of the overall design, compromises in performance were made to ensure the overall goals of the project were met. In the chapters this process will be explained in more detail. Information on the simulated performance of the house and how this affected the design process will be explained. The thesis concludes with Chapter 11 and $\mathbf{1 2}$ which analyses the actual performance of the house both during the competition and when it was set up in New Zealand in Frank Kitts Park. 


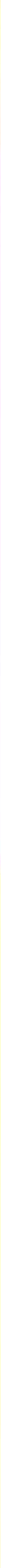




\section{Comfort zone and Climate}

\subsection{An introduction to thermal comfort}

"Thermal comfort - that condition of mind which expresses satisfaction with the thermal environment" (ASHRAE Standard 2003, 7)

The traditional kiwi bach or holiday home, from which the concept for the First Light house developed, was a place not designed for thermal comfort all year round since it was normally occupied in the summer. For a competition with strict comfort criteria it is perhaps ironic that the 'kiwi bach' was used as the conceptual driver. In fact the non-conventional nature of the bach is enshrined in the common definition as "something you built yourself, on land you don't own, out of materials you borrowed or stole." (In turn, this definition seemed quite fitting for the project; a student built house, on a Washington DC park, from materials that were borrowed or donated.) In the bach there was no need for strict comfort controls. On sunny days when it was too hot to be inside, all the doors and windows would be open and the occupants would be dressed in shorts and t-shirts, sitting outside on the deck. If it was too cold the users would be dressed in long pants and Swanndris (a New Zealand woollen shirt), snuggled up under a blanket with a hot water bottle on the couch. In terms of the Solar Decathlon definition of comfort, therefore, the bach is not a great model on which to base the design of an energy efficient solar powered house. The nostalgic memory of getting home from the beach and having to open up all the doors and windows and wait $15 \mathrm{mins}$ before going inside the house because it was unbearably hot, is not associated with good building design. However, although the bach envelope did not provide a model for reducing energy use, how people lived in the space did. Within the bach occupants had full control over their space. If it was too hot people opened the doors and windows. If it was too cold they closed the blinds and put on another jersey. People acclimatized 


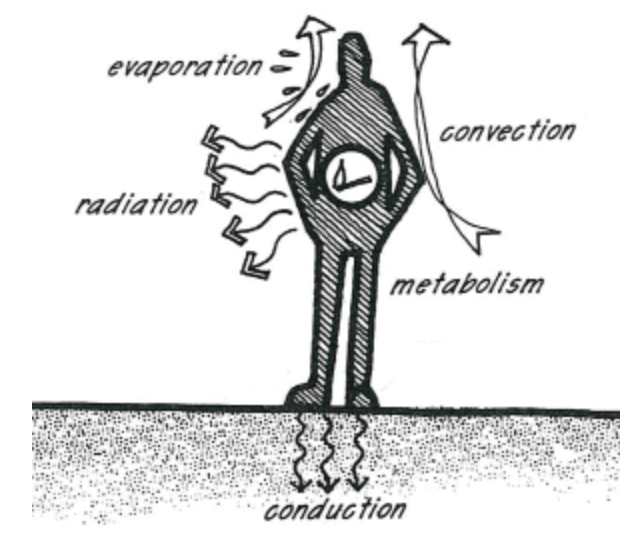

Figure 14: Diagram of how people loose heat from their bodies (Source: Lechner 2009) to a wider comfort band without the reliance on energy for heating and cooling. This posed an interesting challenge for the design of the First Light house. Could there be a way to translate the values associated with comfort in the traditional 'kiwi bach' to a house designed to meet a strict set of comfort requirements for a competition in Washington DC?

The thermal comfort zone is the range of temperatures and humidity within which people feel comfortable. It is easy to measure the temperature and humidity in a room but it is more difficult to say at what temperature a person feels comfortable. Imagine a family in autumn who made the journey to the bach for the Easter weekend eager to make the most of the last weekend before winter. Late one evening, sitting around the kitchen table playing New Zealand monopoly they do not notice the drop in room temperature that has occurred since the sun has set. The game is nearing its end and it is has become competitive; the parents both have a glass of NZ wine and the children are looking a little red after spending the day playing cricket under the autumn sun. Despite it being cold the family feel comfortable in the space. This is a long way from the scientific view of comfort. Szokolay (Szokolay 2004, 17) splits the variables which affect comfort into three distinct groups.

- Environmental factors, including temperature and humidity;

- $\quad$ personal factors including activity, clothing and acclimatisation;

- $\quad$ and contributing factors including age and gender.

The environmental factors are the physical conditions in a room that can be measured. Szokolay separates these into four environmental factors that are closely interdependent; air temperature, humidity, air movement and thermal radiation (Szokolay 2004, 17). The air temperature and humidity, the presence of draughts in a room and the surface temperature of the walls, floor and ceilings can all be measured. It is more difficult to measure the personal factors that affect the comfort of a person in a space.

The environmental parameters Szokolay discusses relate to how people lose heat from their bodies. The human body core is normally around $37^{\circ} \mathrm{C}$ and is continually losing heat to the surroundings (Lechner 2009, 56). In order to maintain thermal equilibrium bodies must loose heat at the same rate that the metabolism produces it. (John, Owen and Steemers 1986, 
60)The more work done by a person the more heat is generated. For the family sitting around the table playing a board game there are a range of personal factors that increase their bodies' heat output. The game is competitive, the wine is kicking in and they are all a little burnt from a day in the sun. In order to remain comfortable this extra heat must be lost to the environment. Luckily the colder conditions inside the bach are sufficient for them to remain comfortable.

When thinking about comfort it is essential to have an understanding of the ways in which the human body loses heat through radiation, convection and evaporation. (Figure 14) For example, in the cold bach in the early morning, the family sitting round the table for breakfast with the sun streaming through the windows would be gaining more radiant heat from the glass than they were losing to the cold air. By understanding the ways in which human bodies lose heat architects can design for a larger comfort zone in order to reduce heating and cooling loads throughout the year. This though, was not the approach taken by the US Department of Energy in the 2011 Solar Decathlon. Ironically a competition challenging the highest levels of energy efficiency sets a strict comfort zone based on an air temperature range that is impossible to stay within without the use of mechanical heating and cooling.

For the comfort zone competition the criteria were defined as follows.

\section{Temperature}

All available points are earned for keeping the time average interior dry bulb temperature between $21.7^{\circ} \mathrm{C}\left(71.0^{\circ} \mathrm{F}\right)$ and $24.4^{\circ} \mathrm{C}\left(76.0^{\circ} \mathrm{F}\right)$ during the score period.

\section{Humidity}

All available points are earned by keeping the time averaged interior relative humidity below $60 \%$ during the score period.

Throughout this project there was an on-going dichotomy between the goals of the project as an energy efficient kiwi bach and the goal to win the 2011 Solar Decathlon. Often there were times where the two goals were contradictory. Keeping the house within a $2.7^{\circ} \mathrm{C}$ temperature range 
is a difficult goal under any conditions, and impossible to achieve without the use of mechanical heating and cooling, especially considering the variability of weather in Washington DC at the end of September. The two goals that were set of designing a winning entry for the competition and an energy efficient home in NZ were also in opposition. To achieve such a strict comfort band meant closing the house up and relying on a HVAC system. This contradicted the design of a kiwi bach that could maintain a wider comfort range by being opened or closed to the environment based on the personal 'comfort' situation of the user. The following chapters explain the development of the schematic design in order to achieve both. The aim was to design a house that could meet the competition requirements in Washington DC but that could also return to NZ and operate as a NZ home.

\subsection{Climate}

"We must begin by taking note of the countries and the climates in which homes are to be built if our designs for them are correct. One type of house seems appropriate for Egypt, another for Spain...one still for Rome... it is obvious that design for our homes ought to conform to a diversity of climates" The ten books of architecture - Vitruvius

As Vitruvius indicates, designing a building in harmony with climate is an age old idea and essential for an energy efficient home. For the First Light house the design had to be optimized for two, quite different climates. The house had to be presented to the judges of the architecture competition as a home designed for a Wellington climate. But in order to win the Solar Decathlon the house had to perform in the measured contests which were tested during a 10 day period in September in Washington DC. One of the challenges of the competition is preparing a house for the unpredictable weather of Washington DC in September. Temperatures and humidity can vary greatly, from an average high of $23^{\circ} \mathrm{C}\left(73^{\circ} \mathrm{F}\right)$ to an average low temperature of only $5^{\circ} \mathrm{C}\left(41^{\circ} \mathrm{F}\right)$ during the period. (Guzowski 2010, 147) Figure 16 shows the temperature throughout the year in New Zealand and compares these with Washington DC, highlighting the September period of the competition. Despite it being autumn in the US the maximum temperatures are still higher than those experienced in the peak of summer in Wellington. Accurate and appropriate climate data was essential for the 
energy simulations of the house.

Weather files for the initial thermal simulations were sourced from the US DOE Energy Plus Weather File Database. For the simulations based in Wellington, the weather files were based on data gathered at the Wellington International airport and compiled by the New Zealand National Institute of Water and Atmospheric Research (NIWA). For Washington DC the information was collected at Ronald Reagan Airport, Arlington, VA and compiled by the US National Renewable Energy Laboratory (NREL)

These weather files are ideal for simulating and comparing heating and cooling loads over an entire year because they deal with long term averages and typical weather conditions. This makes them perfect for the design of the First Light house for its lifetime within NZ. However, when designing for only a 10 period in Washington DC they become inaccurate. Because the weather files represent typical rather than extreme conditions, it becomes more difficult to design for a possible worst-case scenario that could occur during the 10 days of the competition. Because of this, simulations were run for August, September and October rather than focusing on the 10 day period alone. Design day data was also used where possible to ensure that the house was designed to meet the potential worst case scenario climatic conditions during the competition. This was especially important later on in the design process, when it came to sizing the HVAC system.

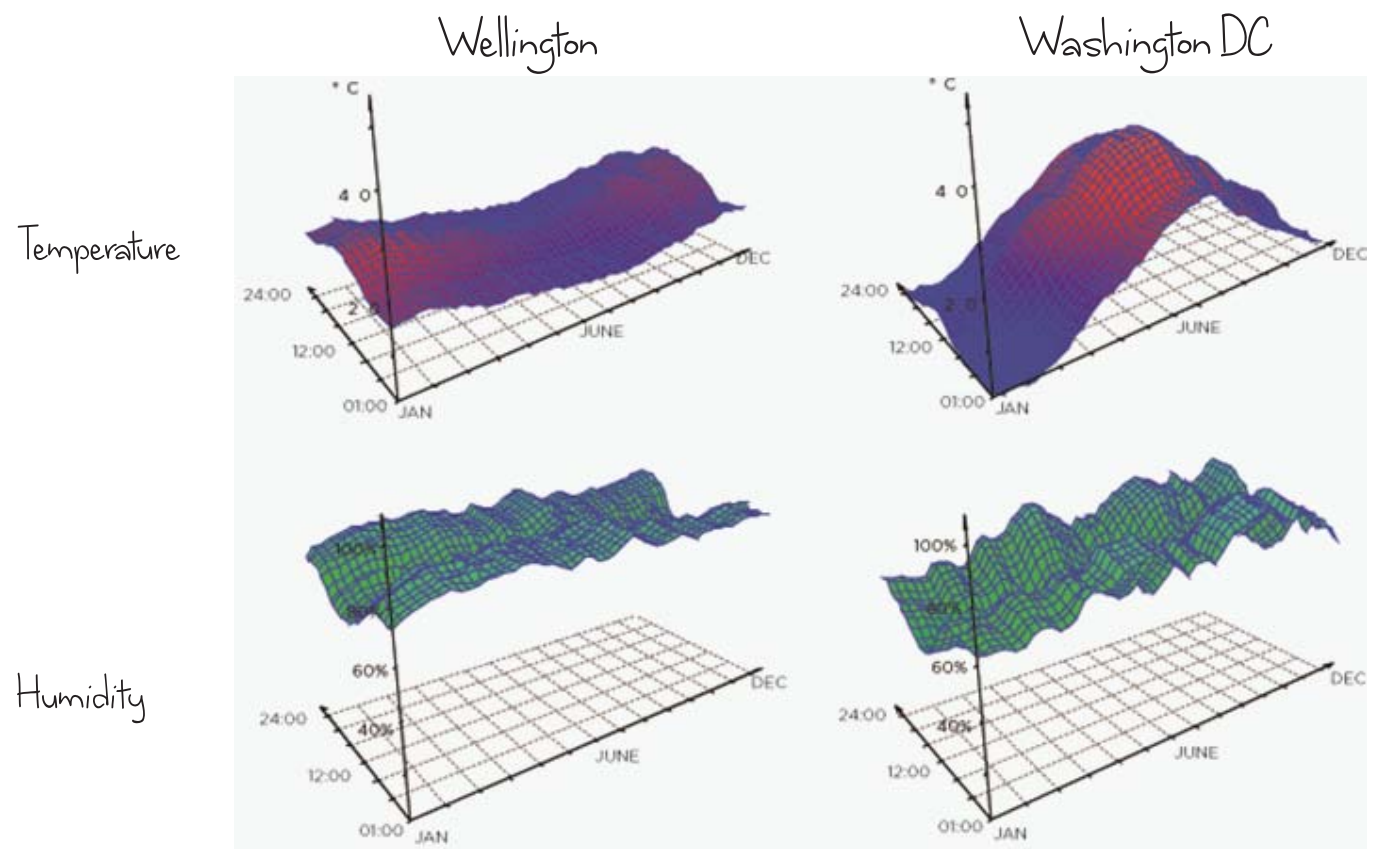

Figure 15: Comparison of temperature and humidity in Wellington and Washington DC (Source: Autodesk, Ecotect analysis 2011) 


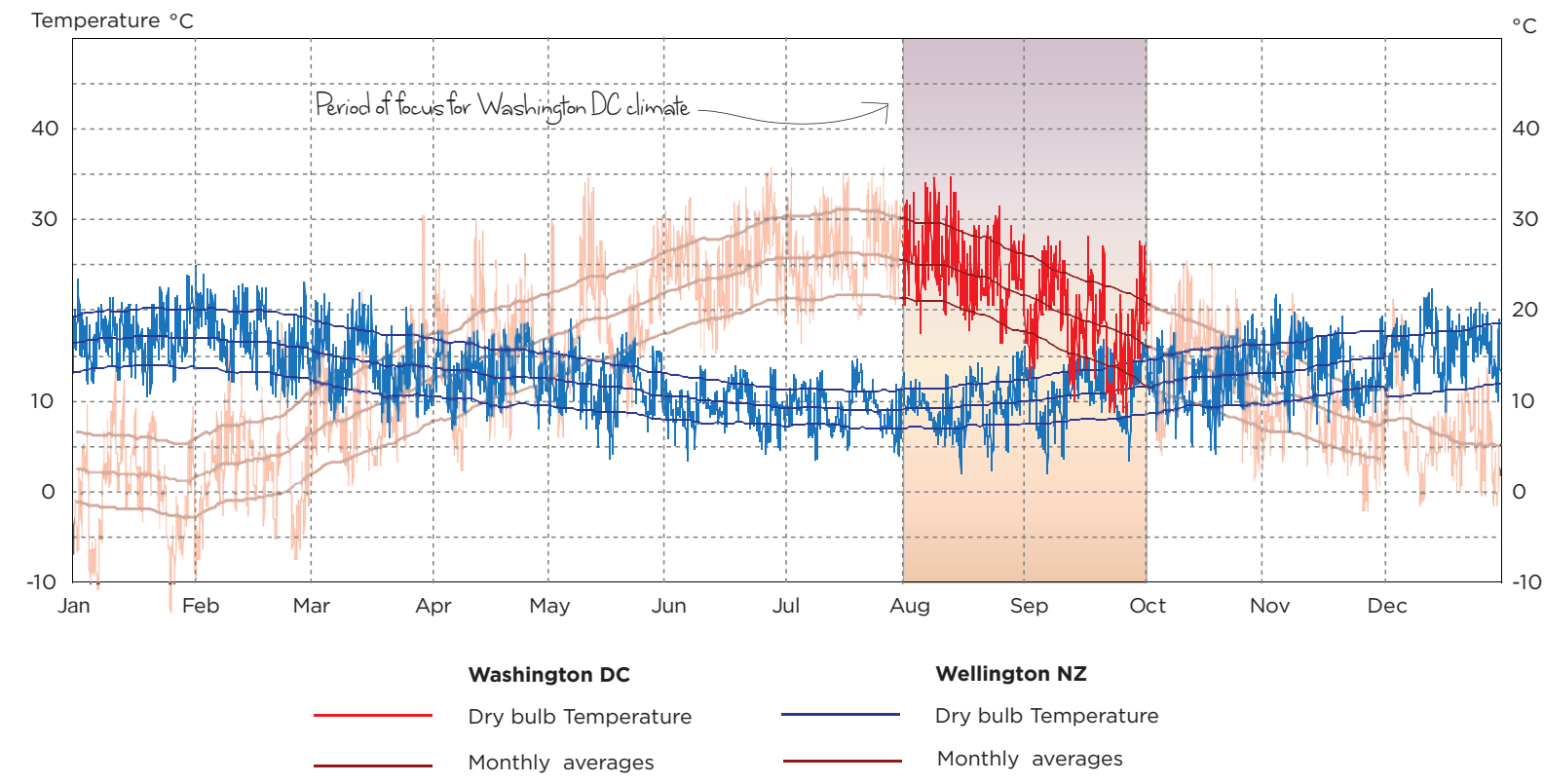

Figure 16: Graph of temperatures in New Zealand throughout the entire year compared with Washington DC

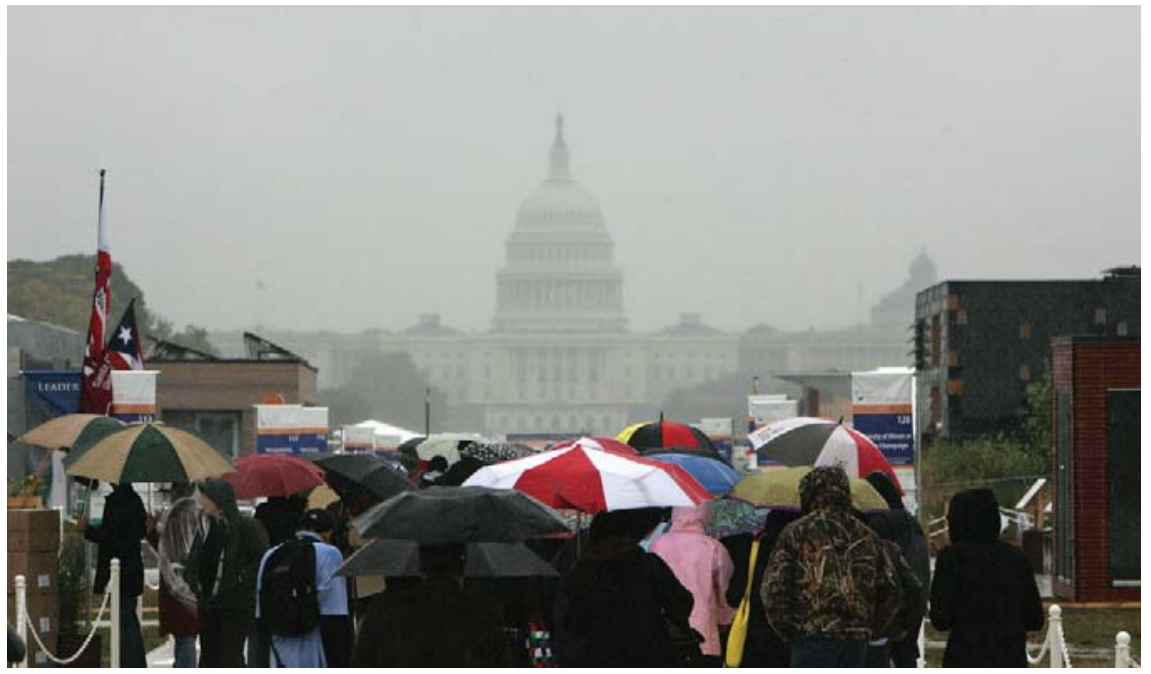

Figure 17: Rain during the 2009 Solar Decathlon (Source: NREL Solar Decathlon, http://www.flickr.com/photos/44085838@N03/4225695283/) 


\subsection{Thermal modeling - Assumptions}

\subsubsection{Construction}

Before beginning the simulation process it was necessary to make certain assumptions about the construction of the building and how, when and where it was likely to be used once it was built.

The initial wall construction used in the baseline model was put together from information provided in the schematic design proposal. The initial wall construction used was structurally insulated panels consisting of $200 \mathrm{~mm}$ of rigid foam insulation sandwiched between two layers of oriented strand board. Table 1 presents the building elements used in the initial thermal model.

\begin{tabular}{lll}
\hline ELEMENT & DESCRIPTION & R-VALUE \\
\hline Walls & SIPS Panels & $\mathrm{R}-6.4$ \\
\hline Floor & SIPS Panels, Timber Lining & $\mathrm{R}-6.4$ \\
\hline Roof & SIPS Panels & $\mathrm{R}-6.4$ \\
\hline Windows & $\begin{array}{l}\text { 6mm Standard Glass, Air Filled, Double Glazing, } \\
\text { Aluminum Frames }\end{array}$ & $\mathrm{R}-0.26$ \\
\hline Skylight & $\begin{array}{l}\text { 6mm Standard Glass, Air Filled, Double Glazing, } \\
\text { Aluminum Frames }\end{array}$ & $\mathrm{R}-0.26$ \\
\hline Canopy & Timber & - \\
\hline
\end{tabular}

Table 1: Construction R-Values $\left(\mathrm{K} \cdot \mathrm{m}^{2} / \mathrm{W}\right)$ used for baseline simulation 


\subsubsection{Heating and Internal Gains}

The only heat gains to the building simulated in the initial baseline model were those from solar gains through the windows. Internal gains due to occupants, appliances and lighting loads were added later on in the design process.

\subsubsection{Air exchange - Ventilation and infiltration}

The initial natural ventilation rate of $4 \mathrm{ACH}$ used in the model defines the air exchange through opening windows and doors to provide fresh air to the space. In the simulation this fresh air is added to the space at the external air temperature at that particular time, taken from the climate data.

Infiltration is caused by air leakage in the building envelope. In order to increase thermal comfort and reduce energy consumption it was important to reduce uncontrolled air movement through infiltration. The rate of infiltration was modeled at $0.1 \mathrm{ACH}$. At this early stage in the design process a very high standard for air tightness in the house was set. Considerable time was spent developing the details of the construction in order to achieve this.

\subsubsection{Modeling Variations}

Using the baseline model, several variations were made to the building fabric in order to reduce heating and cooling loads. Each variation in the model was simulated independently. This made the effect of the changing element visible against the original baseline model. The best performing variations were then compiled incrementally and a simulation was performed at each step to ensure that the variations that were made were not opposing each other. For example thermal mass was added to 
the design to reduce the effect of the internal gains and help with passive heating of the house during the winter. At the same time the shading canopy was altered to reduce solar gains. Both changes were modeled independently and compared to the baseline model. When these elements were brought together a simulation was performed to ensure that the increase in shading did not eliminate the effect of adding the thermal mass. 


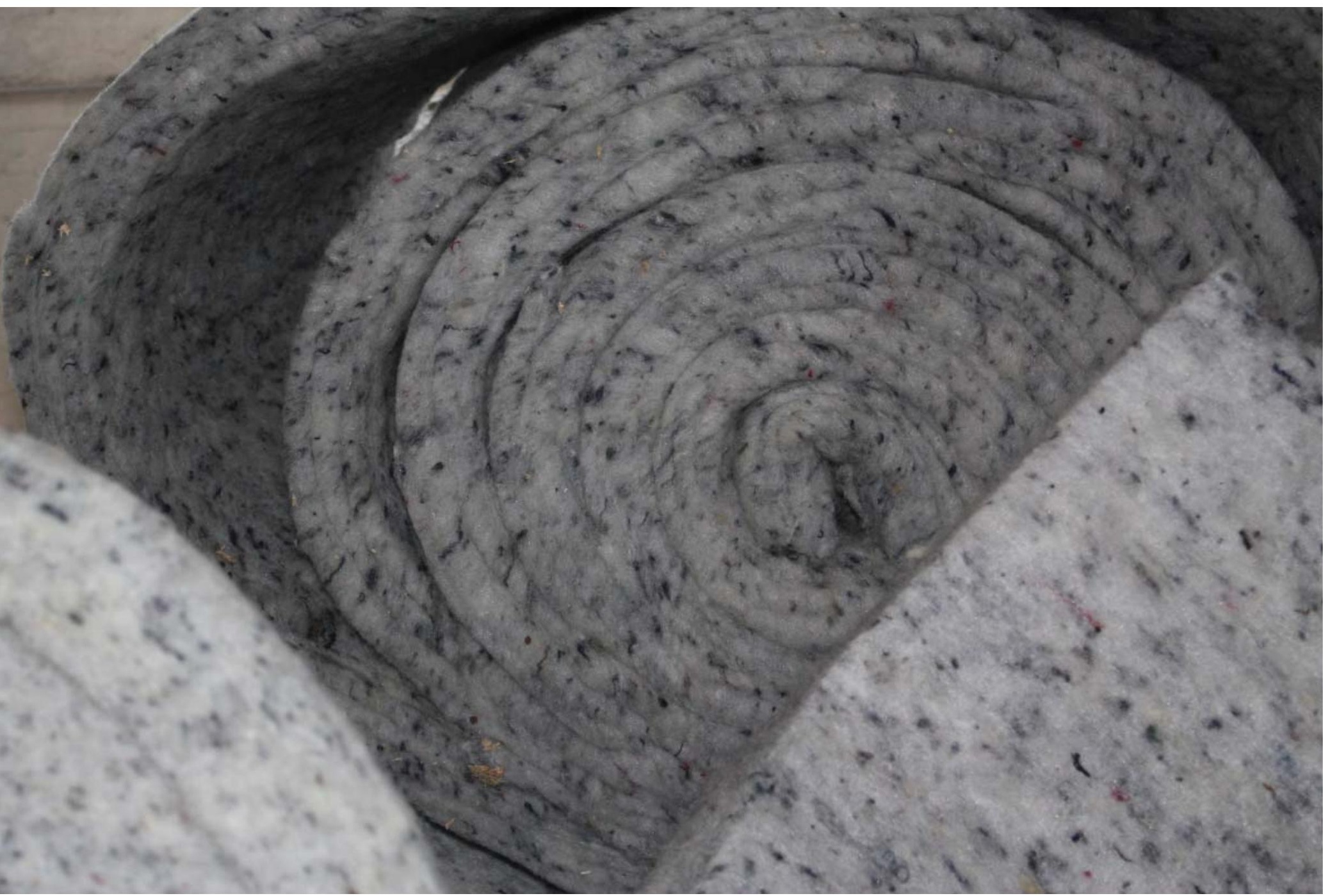

Figure 18: Ecowool insulation arrives at the construction site in Lyal Bay 


\section{CHAPTER 4 Insulation}

Heat loss in a building occurs mainly by transmission through external surfaces and by infiltration and ventilation through cracks and openings in the building envelope (Lechner 2009, 463). Significant reductions in these heat losses will make a significant contribution to energy saving (Szokolay 2004). Insulation is used in buildings in order to reduce heat losses through the building envelope via conduction, convection and radiation. Insulation materials have a greater thermal resistance which reduces the rate that heat energy is transferred through a part of the building to the outside. The figure which represents the thermal resistance of a building element is called its $\mathrm{R}$ value $\left(\mathrm{m}^{2} . \mathrm{K} / \mathrm{W}\right)$. For a square metre of the building envelope the $\mathrm{R}$ value measures the temperature difference required to transfer one watt of energy (Vale and Vale 1980, 19), so an R value of 1 means for a square metre of material a single degree temperature difference between the outside and the inside will transfer one watt of energy. The greater the $R$ value the better it is at resisting the transfer of heat. The level of thermal resistance and the amount of insulation required in a building is dependent on the climate. In New Zealand insulation has been mandatory in homes since 1978. Table 2 shows the current building code requirement for the $\mathrm{R}$ value of a building element in Wellington, New Zealand. Older houses are not required to upgrade to meet current building code standard and so many New Zealand homes are under insulated. The New Zealand building code specifies a minimum level of insulation. For the design of a highly energy efficient building the level of insulation needed to be much greater. Using climate data for both New Zealand and Washington DC the model of the house was run through the thermal simulation software and the $R$ value was increased to find the level of thermal resistance needed for the optimum performance.

\begin{tabular}{|l|l|l|l|l|l|}
\hline Year & Standard & Ceiling & Wall & Floor & Glazing \\
\hline 1978 & NZS 4218P:1977 & 1.9 & 1.5 & 0.9 & - \\
\hline 2000 & NZBC H1/AS1 & 1.9 & 1.5 & 1.3 & - \\
\hline 2007 & NZBC H1/AS1 & 2.9 & 1.5 & 1.3 & 0.26 \\
\hline
\end{tabular}

Table 2: NZ Building code requirement of R-value for ceiling, wall, floor \& glazing (Source: Isaacs, Thermal Insulation 2007, 110 
In order to determine the optimization point at which adding more insulation would have little or no effect, the expanded polystyrene insulation thickness in all walls, floors and ceilings was increased from $12.5 \mathrm{~mm}$ to $1600 \mathrm{~mm}\left(0.5^{\prime \prime}-63^{\prime \prime}\right)$ doubling the thickness each time. The corresponding R-values are shown in Table 3.

\section{Polystyrene Thickness ( $\mathrm{mm})$}

$12.5 \mathrm{~mm}$

$25 \mathrm{~mm}$

$50 \mathrm{~mm}$

$100 \mathrm{~mm}$

$200 \mathrm{~mm}$

$400 \mathrm{~mm}$

$800 \mathrm{~mm}$

$1600 \mathrm{~mm}$
R-Value $\left(\mathrm{m}^{2 \circ} \mathrm{C} / \mathrm{W}\right)$

0.4
0.9
1.7
3.4
6.9
13.8
27.6
55.2

0.4

0.9

1.7

3.4

6.9

13.8

27.6

55.2

Table 3: Thickness of polystyrene and the corresponding $\mathrm{R}$-Value $\left(\mathrm{m}^{2 \circ} \mathrm{C} / \mathrm{W}\right)$

The results from the simulation run in a Wellington climate use air temperature in the space to show the effect of changing levels of insulation. As can be seen in Figure 19, the increase in insulation by a magnitude of up to 64 times results in relatively small changes in the maximum, mean, and minimum temperature over the course of an entire year in New Zealand. As the amount of insulation increases there is less of an effect on the internal temperature. Figure 19 shows the optimization
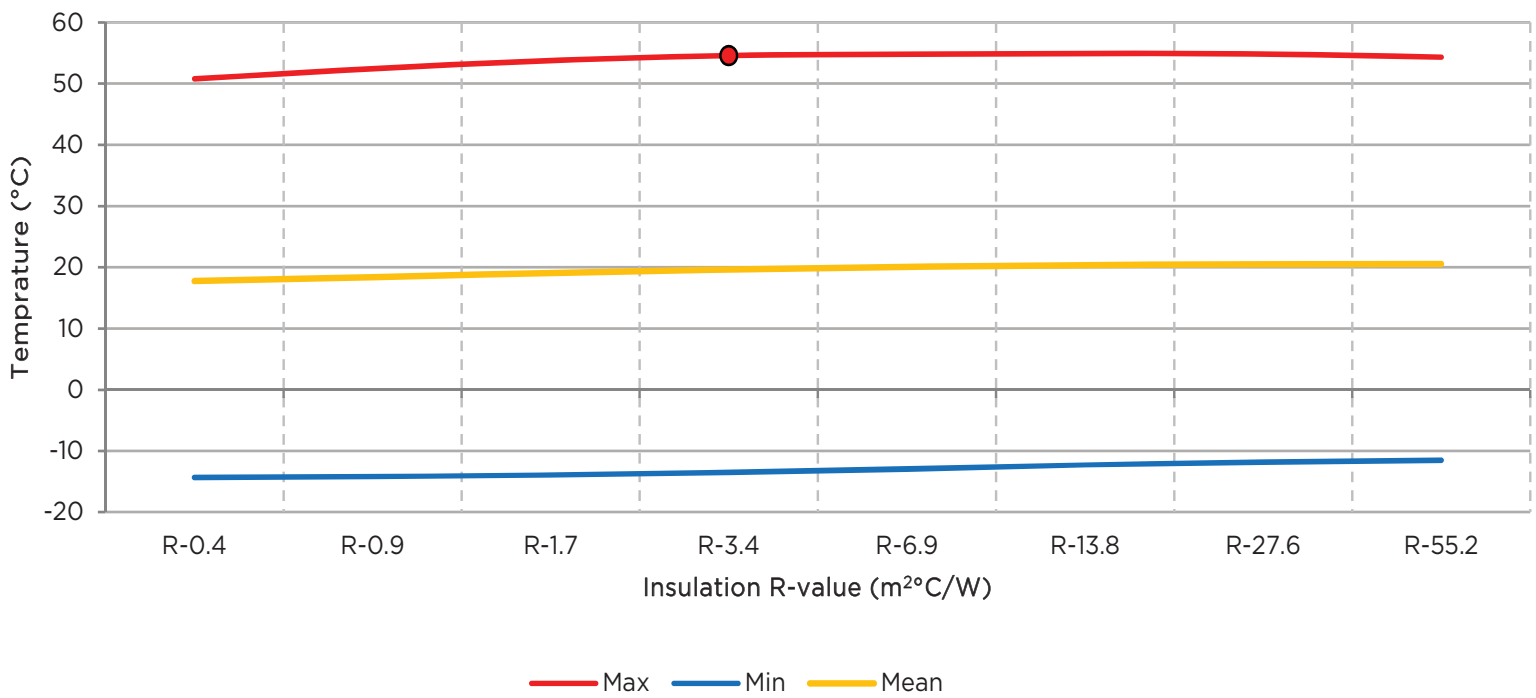

Figure 19: Comparison of variation in annual maximum, mean and minimum internal temperatures $\left({ }^{\circ} \mathrm{C}\right)$ due to increase in insulation $\mathrm{R}$-value $\left(\mathrm{m}^{2 \circ} \mathrm{C} / \mathrm{W}\right)$ 
point between R-3.4 and R-6.9 for the maximum temperature. For the mean and minimum temperatures it is more difficult to extrapolate an optimization point from this graph as both continue to rise slightly up to an insulation level of R-55, a wall thickness of over one and half metres.

These results gave a good indication of the level of insulation required for a New Zealand climate, although when the simulation was run through a Washington DC climate using climate data for the competition period the results were more conclusive. For the results optimized for the competition, R values were limited to R2 - R9. Instead of looking at air temperature the simulation focused on the HVAC load sums for the period and the peak loads of the HVAC system. The temperature requirements for the comfort zone contest were used as the set points for the heating and cooling system.

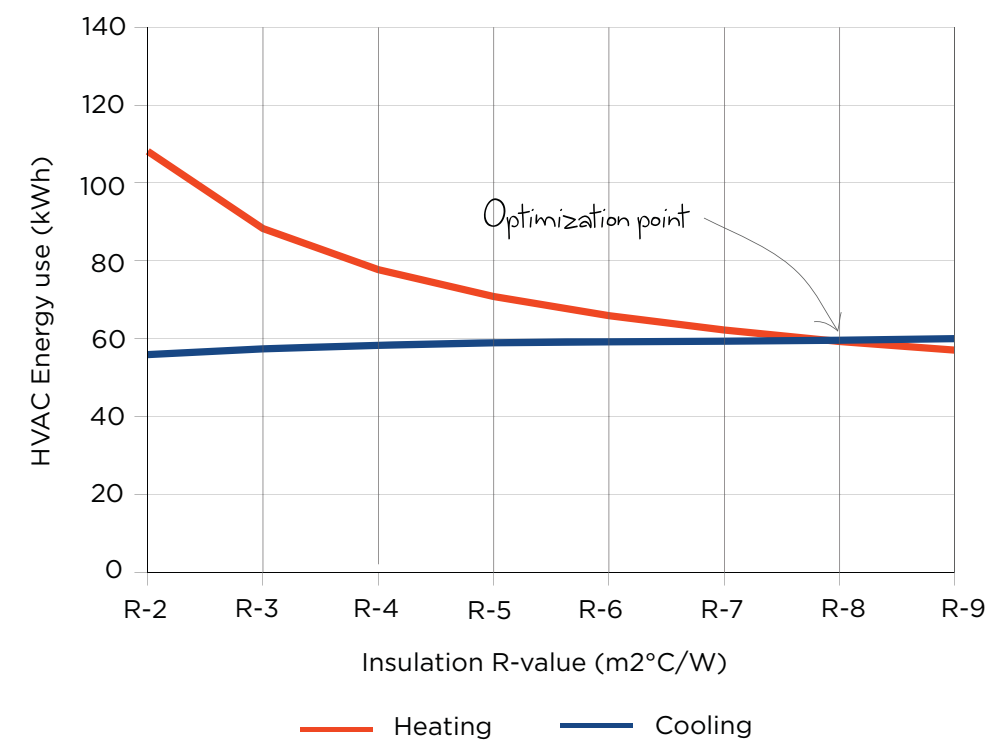

Figure 20: HVAC energy use during competition with an increase in insulation $\mathrm{R}$ value $\left(\mathrm{m}^{2 \circ} \mathrm{C} / \mathrm{W}\right)$

Figure 9 shows the energy use of HVAC system during the competition and indicates that when the $\mathrm{R}$ value is low adding insulation has a significant impact on the loads of the building. As the levels of insulation increase the magnitude of its impact on total energy use is reduced. The graph clearly shows that the optimization point for the insulation during the competition is between R8-9. This was a significant amount of insulation, especially for a New Zealand climate. Looking at energy use over the 
10 days the difference between R6 and R9 is less than 10kWh. Through discussions with the architecture team it was decided that the extra cost and complexity in the detailing associated with adding this extra insulation did not justify the extra energy saving during the competition. As well as this, the size of mechanical system need to achieve the peak loads would be the same whether insulation levels of R6 or R9 were used. It was decided the R6 level of thermal resistance would give a significant energy saving towards achieving the comfort levels of the competition.

Of all materials, dry air has the lowest thermal conductivity (Szokolay 2004, 43). Within a cavity convection currents will allow the transfer of heat from a warmer place to a cooler place. The purpose of insulation is to keep the air still, dividing it into small cells with a minimum amount of actual insulation material in the matrix. As used in the initial simulation, polystyrene is an effective means of achieving this but there are also other materials that can be used to achieve similar performance. Sheep's wool has been used in New Zealand for generations for its insulating properties. When wool fibres are packed together, they form millions of tiny air pockets which trap air, and in turn serve to keep the warmth in during winter and out in the summer making it an ideal for insulation (Lechner 2009, 464). There are also thirteen times more sheep than people in New Zealand making it an abundant and sustainable natural resource that tells a unique story of a very kiwi product, making it perfect for use in the First Light house. A local NZ company, Ecowool, helped to develop 3 layers

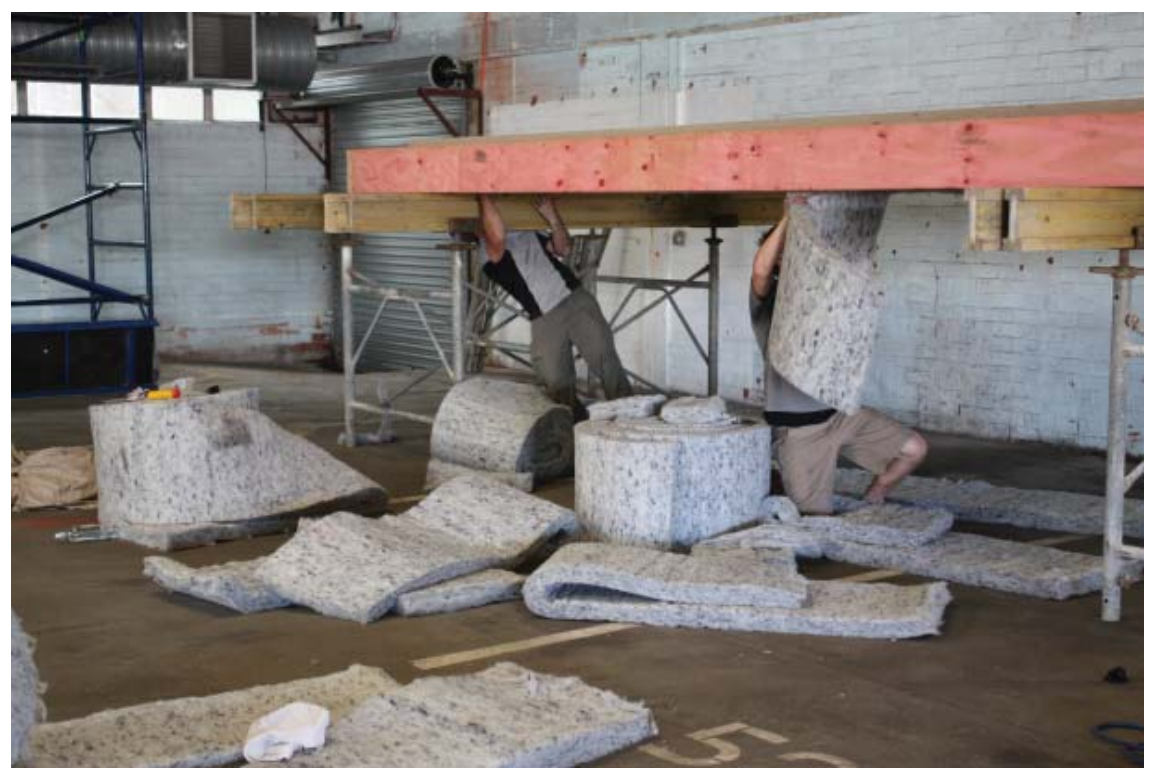

Figure 21: Installation of wool insulation 


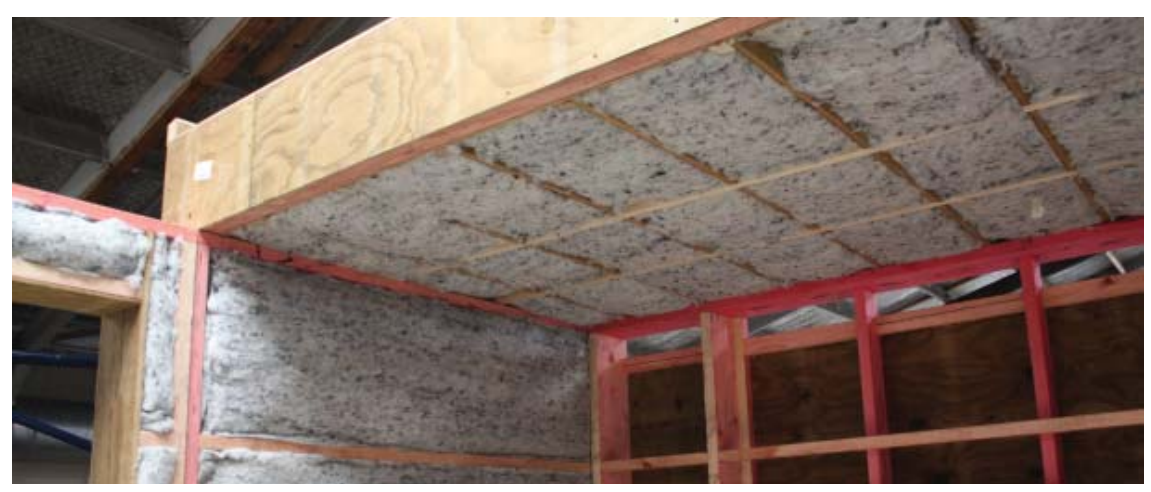

Figure 22: Installed wool insulation in roof and wall

of wool insulation for the house that would achieve the desired level of thermal performance required from the simulations (Figure 21 and 22).

To achieve a well-insulated thermal envelope it is not just the type of insulation that is critical to heat loss. In a timber framed building, thermal bridging can occur where framing has a lower R-value than the insulating material within the cavities. Heat loss through these weak points in a building envelope can have a significant impact on the energy use of a house (Szokolay 2004, 44). Within the initial schematic design SIPs panels were used as the construction method. Because of this form of construction there is no heat loss due to thermal bridging. By using wool insulation within a timber framed wall the detailing of the structure to avoid thermal bridging became critical to the performance of the walls, floors and roof. Within the walls a staggered, double stud system limited thermal bridging to the LVL studs between the modules. Once the details were developed to avoid thermal bridging the R-value of each of the building elements was calculated based on the method described in the New Zealand building code, NZS 4214 (2002) and outlined in Table 4 (Appendix B). Due to the careful consideration of the details and the high performance of the wool insulation the thermal resistance of the walls, floors and roof came extremely close to meeting the goals set by the initial simulations.

\begin{tabular}{|lc|}
\hline Building Element & Construction R-value $\left(\mathrm{m}^{2} .{ }^{\circ} \mathrm{C} / \mathrm{W}\right)$ \\
\hline Roof & 6.48 \\
\hline Wall & 5.77 \\
\hline Concrete Floor & 5.46 \\
\hline Timber Floor & 5.88 \\
\hline
\end{tabular}

Table 4: Construction R-value of individual building elements 


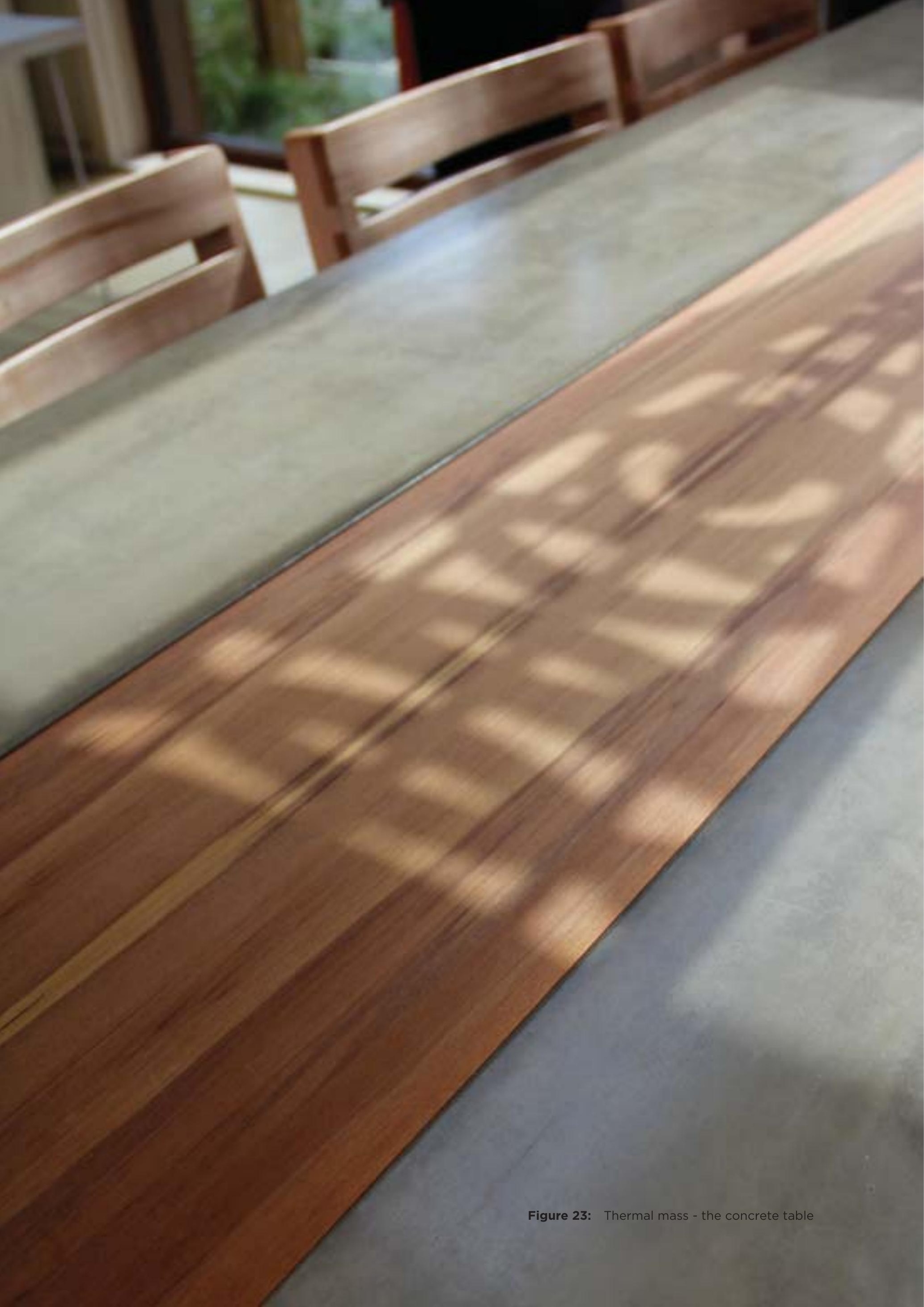




\section{CHAPTER 5 Thermal mass}

The initial simulations completed on the baseline model in New Zealand demonstrated a swing between large extremes in temperatures inside the space. Ironically the initial design was performing in a very similar way to a typical New Zealand home, going from very hot in the summer to very cold in winter. There were a number of reasons for these extremes, including the type and size of the glazing, placement of shading devices and amount of natural ventilation. These will be discussed separately in

Chapter 6 and Chapter 7. Another reason for these high temperature swings is the type of construction in the schematic design. The initial design consisted of lightweight building materials, high levels of insulation and a large amount of glazing. In the summer, the lightweight building construction would overheat due to solar gain through the windows. As there was no way of storing this excess heat when the heat input stopped the space cooled down very quickly. In order to reduce these peak temperatures a simulation was performed that investigated the use of thermal mass. As the house had to be shipped to the other side of the world and assembled in only seven days the extent to which mass could be used in the construction was limited. The initial investigation looked at the effect on the internal temperature of adding a layer of concrete to the floor. The idea was that the mass could capture some of the excess heat during the day, and utilize it during the night when the ambient temperature was lower. It would also have the effect of smoothing out peaks in the internal temperature experienced due to the lightweight structure's rapid response to variations in temperature and solar radiation.
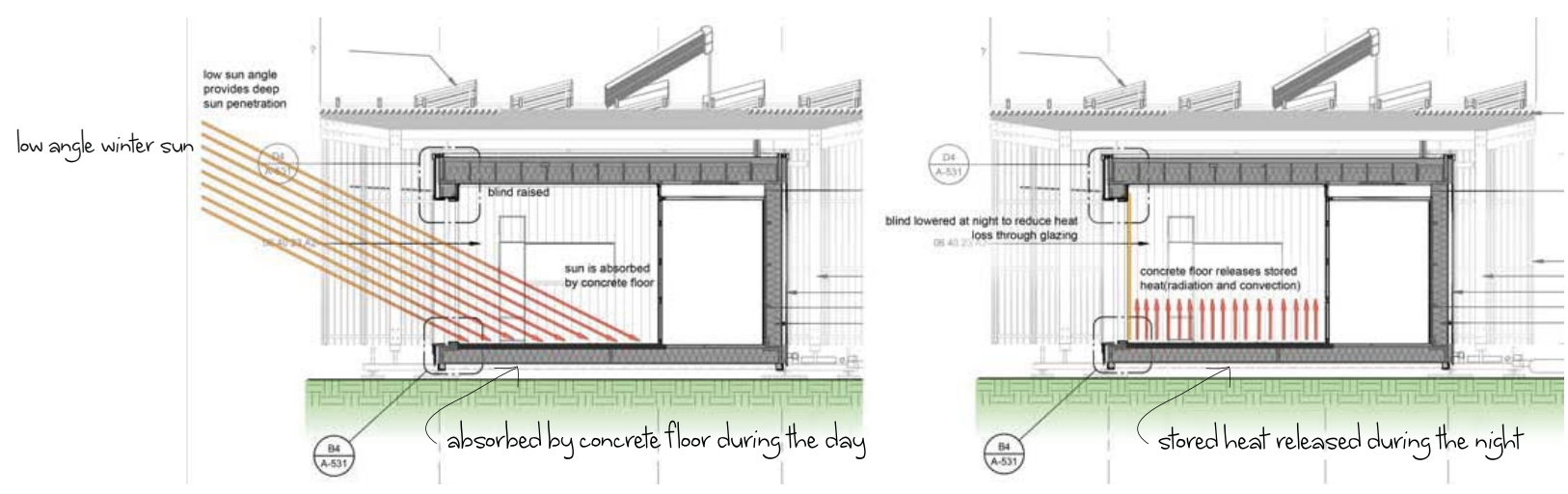


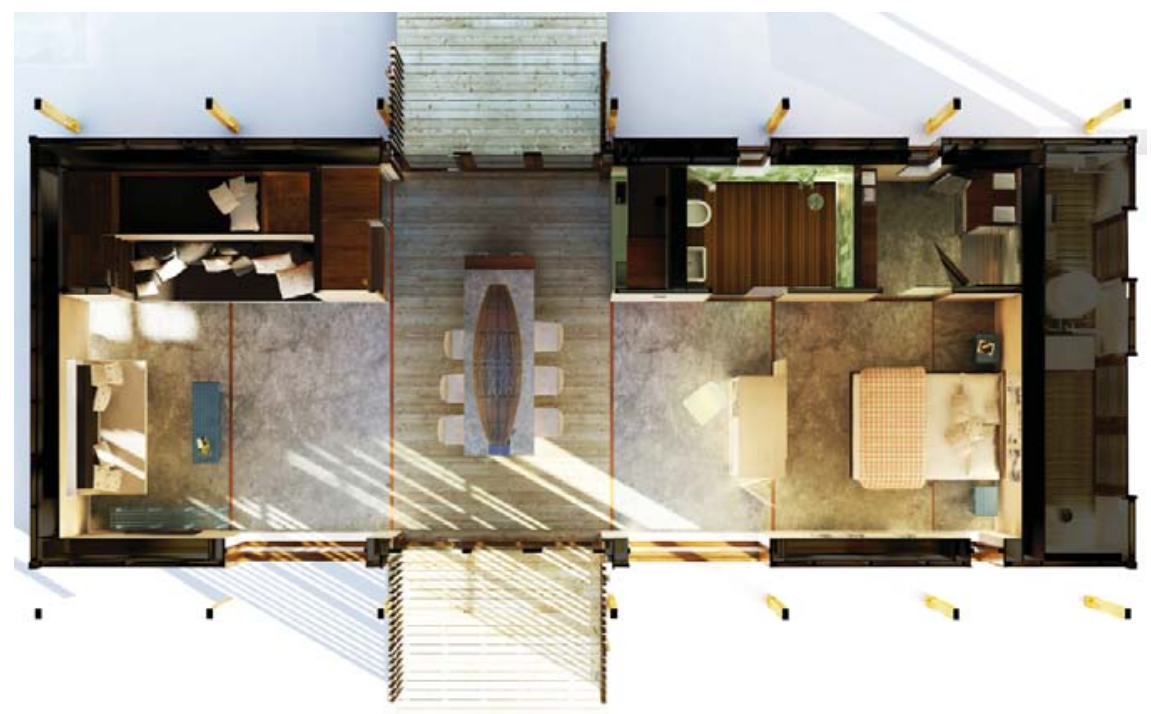

Figure 24: Artists impression of timber decking running through centre of home

Mass was introduced as a concrete layer in the floor on either side of the central space. This central space remained a timber floor as initially modeled. It was decided that keeping the integrity of the timber decking running through the central space was critical to the architectural concept (Figure 24). The floor was modeled as solid poured concrete of varying thicknesses, without any floor coverings, and $240 \mathrm{~mm}$ of expanded polystyrene insulation underneath. As with the investigation of insulation, mass was added at varying thickness to find the optimum level of performance.

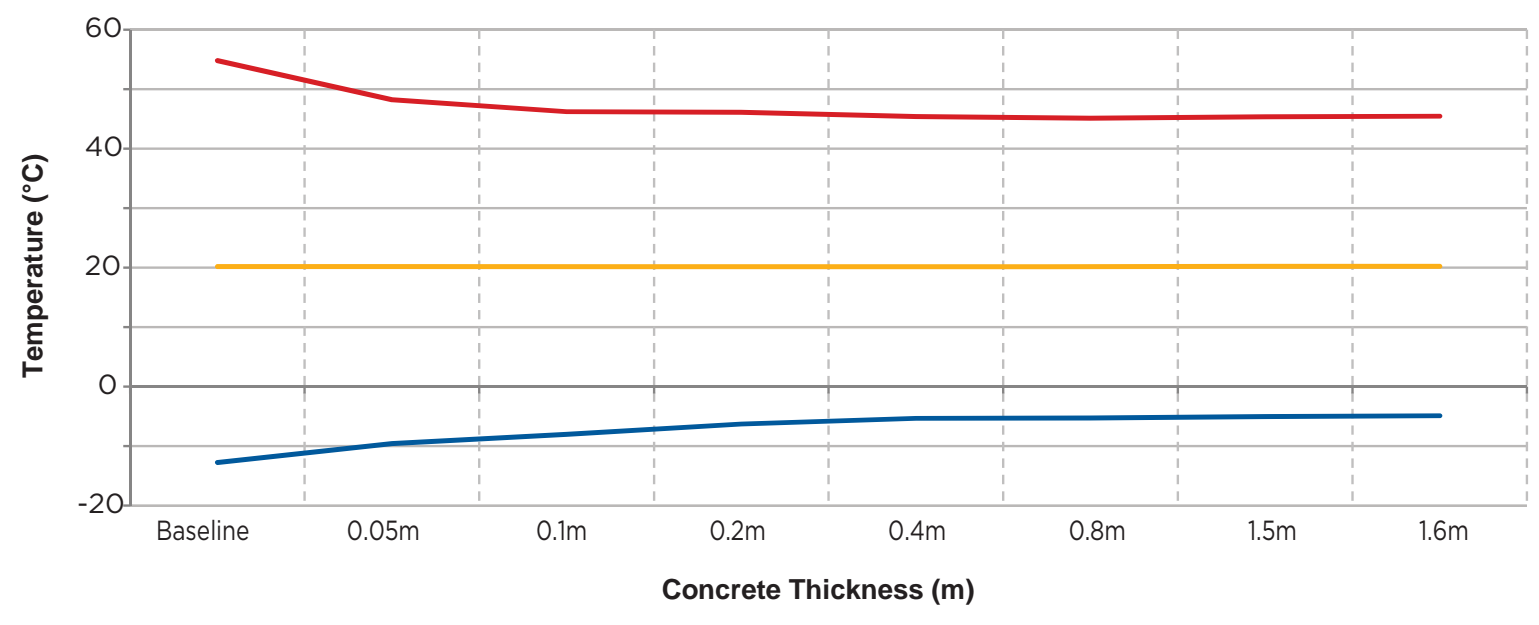

$\longrightarrow$ Min $\longrightarrow$ Average $\longrightarrow$ Max

Figure 25: Variation in minimum, mean and maximum annual internal temperature with the addition of a concrete topping to the floor 
Figure 25 shows the effect that the addition of varying thicknesses of concrete had on the internal temperature in New Zealand throughout the year. The graph shows that even a small addition of mass reduced the extremes of temperature within the space.

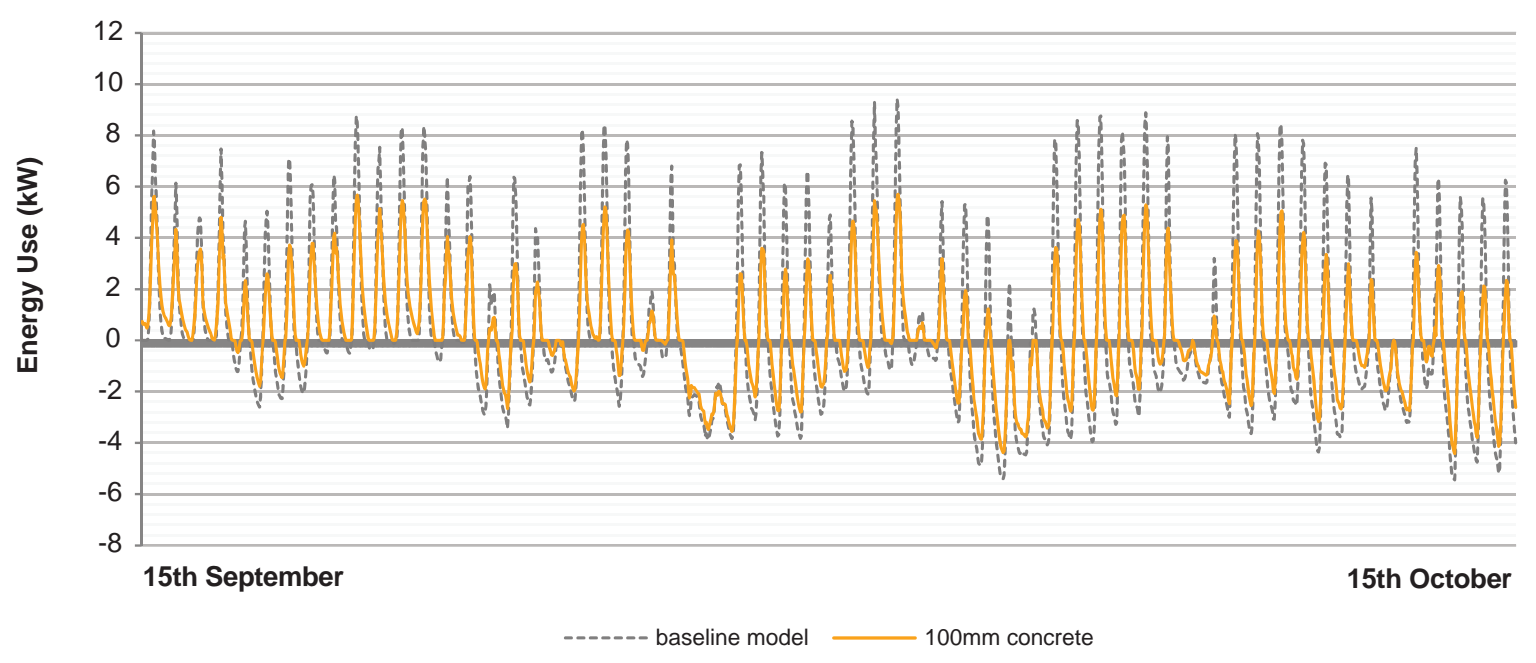

Figure 26: Variations in HVAC energy use with $100 \mathrm{~mm}$ concrete slab compared with baseline for the period from September 15 - October 15

$100 \mathrm{~mm}$ of concrete reduced the minimum and maximum temperature in the space by close to $10^{\circ} \mathrm{C}$, a significant change in peak temperature. The next simulation focused on the effect $100 \mathrm{~mm}$ of concrete would have the peak heating and cooling loads to maintain the comfort zone during the competition compared with the baseline model. Figure 26 shows a comparison of the heating and cooling loads required for the house during this period. Using only $100 \mathrm{~mm}$ of concrete there would be a $2 \mathrm{~kW}$ reduction in the size of the heating system and close to $1 \mathrm{~kW}$ for cooling. This is a significant reduction in the size of the systems needed to maintain the comfort zone during the competition.

In order to reduce energy use during the competition the ideal situation would be to maintain the comfort zone passively, without having to use the heating and cooling system. Figure 27 shows the internal temperatures with $100 \mathrm{~mm}$ of concrete, throughout the competition, compared with the base line model. 


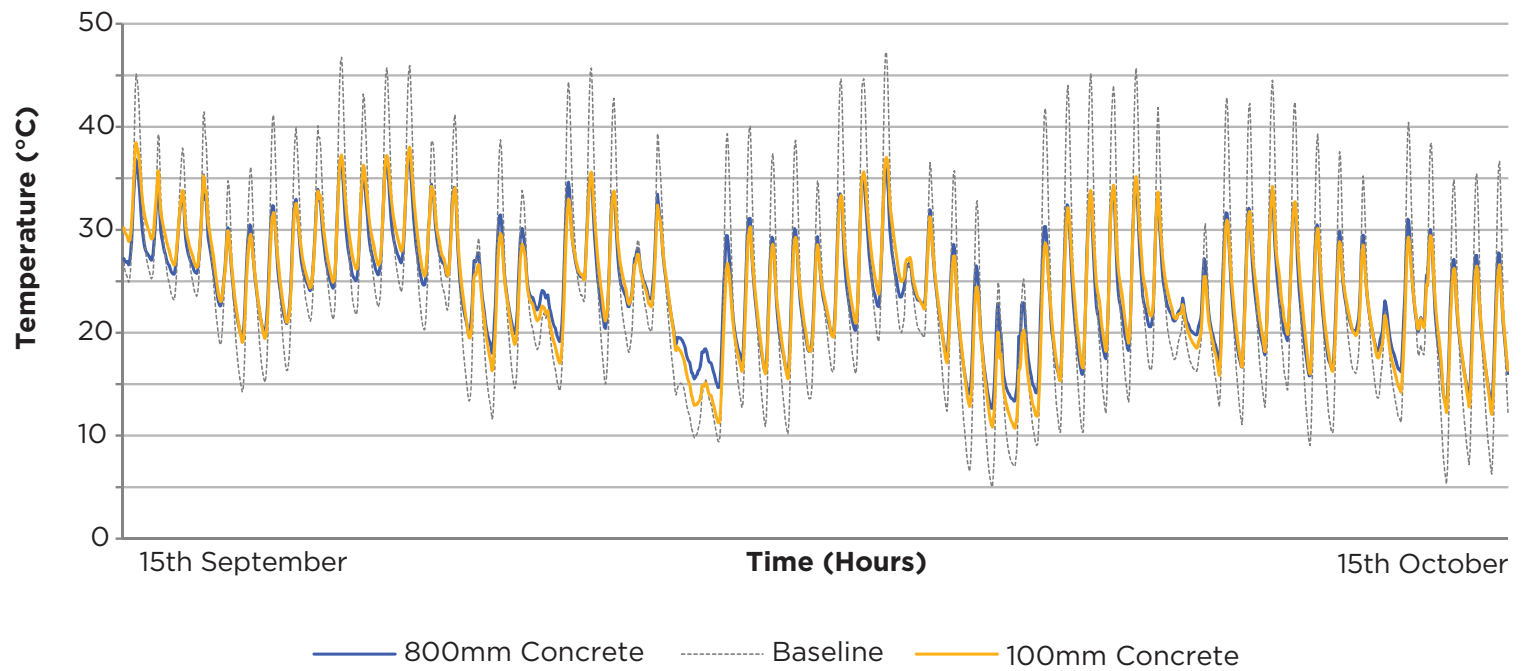

Figure 27: Variations in hourly internal temperature with $100 \mathrm{~mm}$ and $800 \mathrm{~mm}$ (9.3" \& 31.5") concrete slab compared with baseline for the period from September 15 - October 15

The graph shows a smoothing out of the peaks in internal temperature through the addition of a small amount of mass. The mass passively regulates the temperature and aids in meeting the strict requirements for the thermal comfort competition.

The transportation of the home was one of the complexities that came with the concrete floor

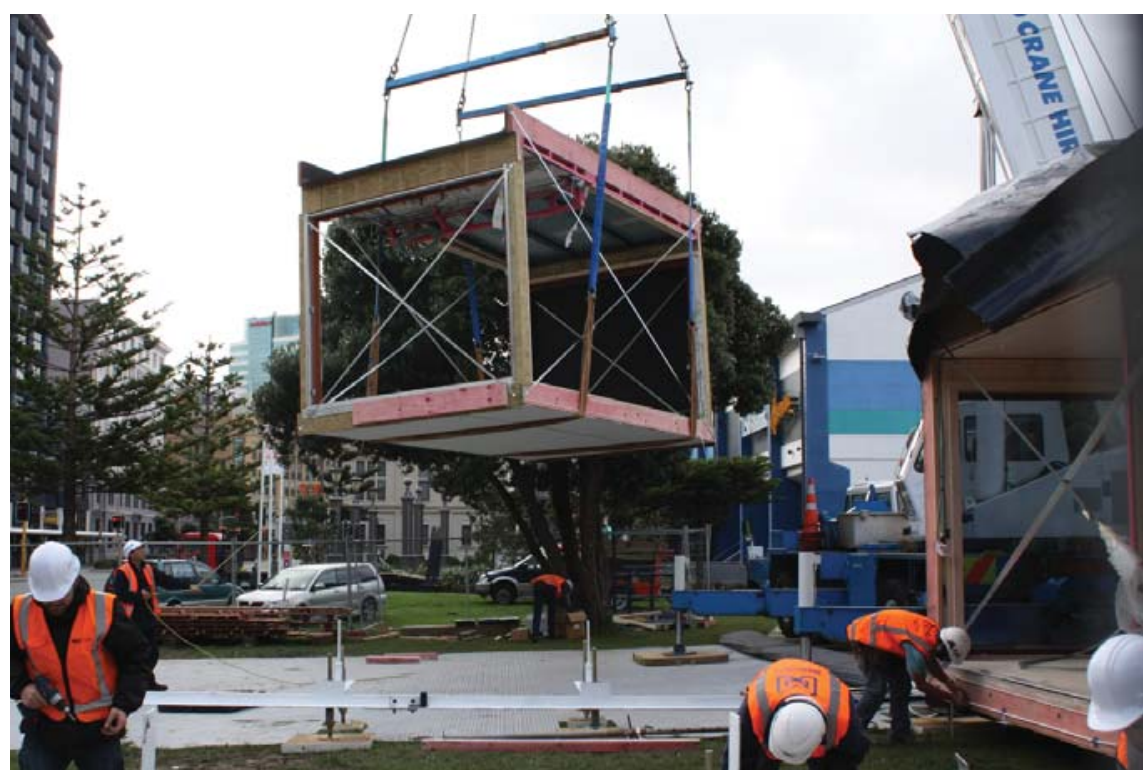

Figure 28: Craning the modules into place on Frank Kitts Park 
Adding concrete to the design of a modular, transportable home was always going to be a challenge. $100 \mathrm{~mm}$ of concrete was presented as the optimum amount of mass for the space. From the results, though, even $50 \mathrm{~mm}$ achieved an improvement in the building's performance. Adding thermal mass was important both for the performance during the measured contests in the competition but also for the development story presented to the engineering judges. Although having an effect during the competition the thermal mass would have the greatest impact when the house was constructed in New Zealand and used over an entire year. Thermal mass was presented to the judges as a passive solar design feature that was essential to the engineering of the home. It was decided that $50 \mathrm{~mm}$ of concrete was achievable from a detailing and transportation point of view but that this reduced level would provide the performance and engineering potential for the competition. In order for the concrete to perform optimally as thermal mass the next step was to analyze the glazing in the First Light house to ensure there was enough solar gain for the mass to perform as intended.

\footnotetext{
The concrete floor was not only an essential part of the passive design but a beautiful element in the First Light house
}

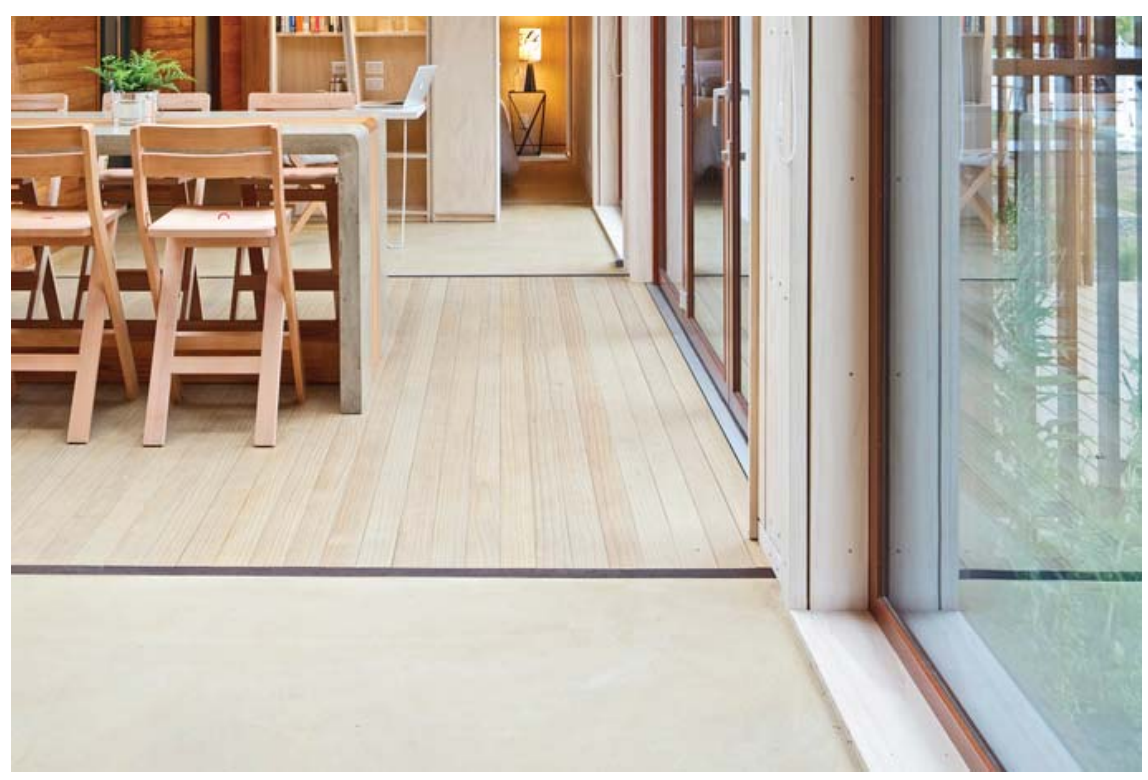

Figure 29: Detailing of the concrete floor and timber decking 


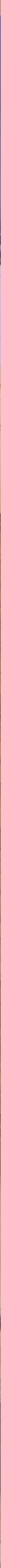




\section{Glazing and skylight}

The schematic design model that was presented to the organizers of the competition had large amounts of glazing and a central skylight over the dining space. Glazing was an essential part of the architectural concept but it was also integral to reducing the house's reliance on energy for heating and cooling. In traditional New Zealand homes glazing is the weak point in the building envelope. With the requirement for window insulation (double glazing) only being introduced into the New Zealand building code in 2007, for many New Zealand homes the $\mathrm{R}$ value for glazing is very low. In most cases with only single glazing, heat loss through the windows is significant in increasing the energy consumed for space heating. Even for homes that meet the building code requirement for double glazing heat loss through windows is significant, often because these are so large. Double glazing, R-0.26, is almost twice as good at stopping heat loss as single glazing of R-0.13, but is seven times less effective as an ordinary insulated stud wall of R-1.9 (Lechner 2009, 484-486). Even the highest performing windows available on the market are not as effective as a wall at reducing heat loss. However, during the winter months when the sun is shining and it is cold outside, north facing windows can be used to heat the home passively, because, when the sun shines the windows gain more heat than they lose (Szokolay 2004, 55). Some means of storing this heat is needed if use is to be made of it when the sun is not shining. Because windows can collect heat from the sun, the correct sizing, placement and type of glazing can dramatically reduce energy use during the winter. During the summer however, without correctly sized shading, windows can have the opposite effect. In the First Light house the size and type of glazing was investigated more than any other building element. With large north facing windows and a glazed skylight, thermal mass and a highly insulated thermal envelope, glazing became not only key to the architectural concept but integral to the energy requirements of the home.

Window to wall ratio (WWR) is the measure of the percentage area of a building's exterior envelope that is made up of glazing. Using thermal simulation it is possible to test the performance of the house with different window to wall ratios. The windows on each façade, including the roof 
were modeled together as a percentage of the total wall area. This made it easier to reduce incrementally the size of the windows on each façade for the purpose of simulation. The WWR are based on the existing area of glazing in the model i.e. $100 \%$ represents the existing area and $0 \%$ represents no glazing.

The WWR was compared with the maximum, average and minimum temperatures across a full year. There is a clear correlation between the glazing area and the internal temperature as shown in Figure 31. Over a year the average internal air temperature of the original WWR sits at a comfortable $19.9^{\circ} \mathrm{C}$. At $50 \%$ of the original WWR the average temperature is below $18^{\circ} \mathrm{C}$ and drops considerably as the area of glazing is reduced. The results suggest that the original WWR proposed in the schematic design proposal was close to the optimal for the First Light house in New Zealand.

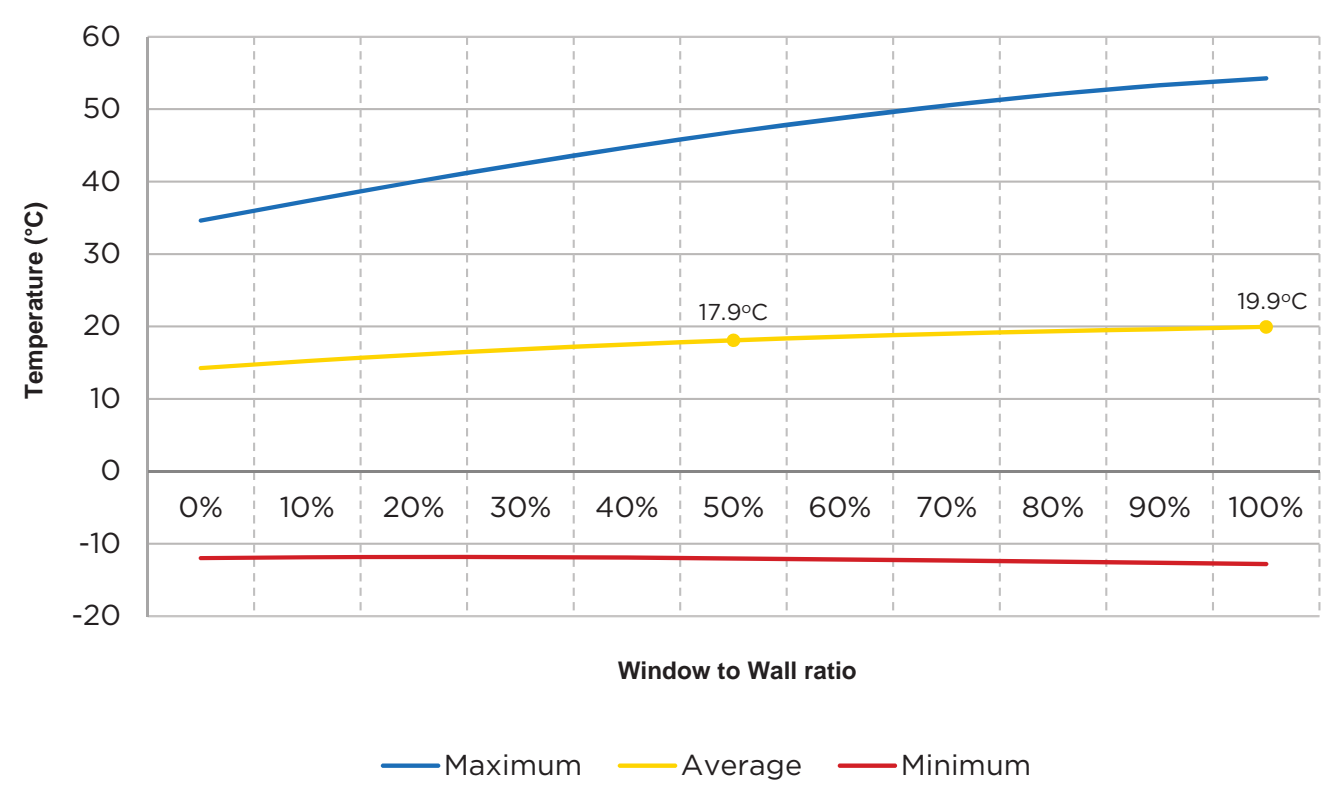

Figure 31: Annual maximum, mean and minimum internal temperature $\left({ }^{\circ} \mathrm{C}\right)$ with glazing area between $0 \%$ and $100 \%$ of baseline area

As with previous simulations, the maximum air temperature inside the space is extremely high. As the window to wall ratio is reduced the maximum temperature inside the space decreases. The original design was modeled with the solar canopy which shaded the large north facing windows during the summer. When the highest temperature was reached in the simulation these windows were shaded from direct solar gain. Therefore reducing the WWR on the north façade should have no effect on the maximum temperature. As the skylight is the only building element 
not shaded the postulation is that reducing the size of the skylight alone is what was causing the decrease in maximum temperature seen in Figure 31. Consequently, further investigation was required to understand the direct effect of the skylight on energy use.

The skylight is critical to the architectural concept of the house but thermally it is also the weak point in the building envelope. Therefore it was modeled independently from the rest of the house, this time concentrating on the period of the competition. For these simulations the shading canopy was removed in order to gain a clear indication of the correlation between the area of skylight glazing and the internal temperatures.

From Figure 32 and Figure 33 there is a clear relationship between the area of the skylight and performance of the First Light house. Reducing the area of the skylight for the period in Washington DC has a considerable effect on the peak indoor temperature. If the skylight were removed completely the maximum indoor temperature would be reduced by $10^{\circ} \mathrm{C}$. This would have a major impact on the house's overall energy use for the competition. The average temperature of the space with the skylight was $25.2^{\circ} \mathrm{C}$, outside the comfort band for the competition. Without the skylight the average temperature was reduced to $23.1^{\circ} \mathrm{C}$. Removing the skylight meant the existing glazing area would be sufficient to achieve the necessary heat gains for the competition to maintain the house within the comfort zone. Removing the skylight would significantly improve the

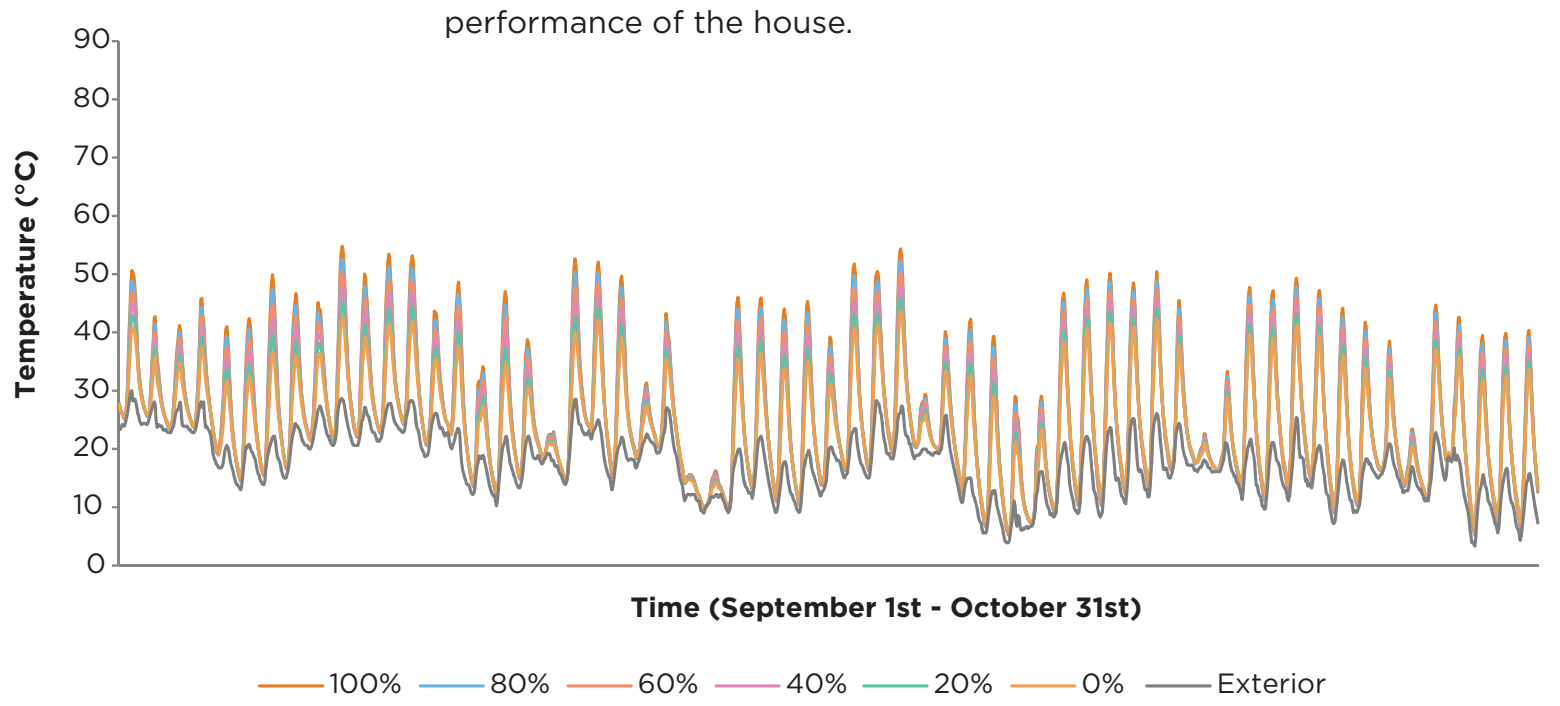

Figure 32: Variations in hourly internal temperature with glazing area between $0 \%$ and $100 \%$ of baseline area concrete slab compared with exterior for the period from September 15 - October 15. 


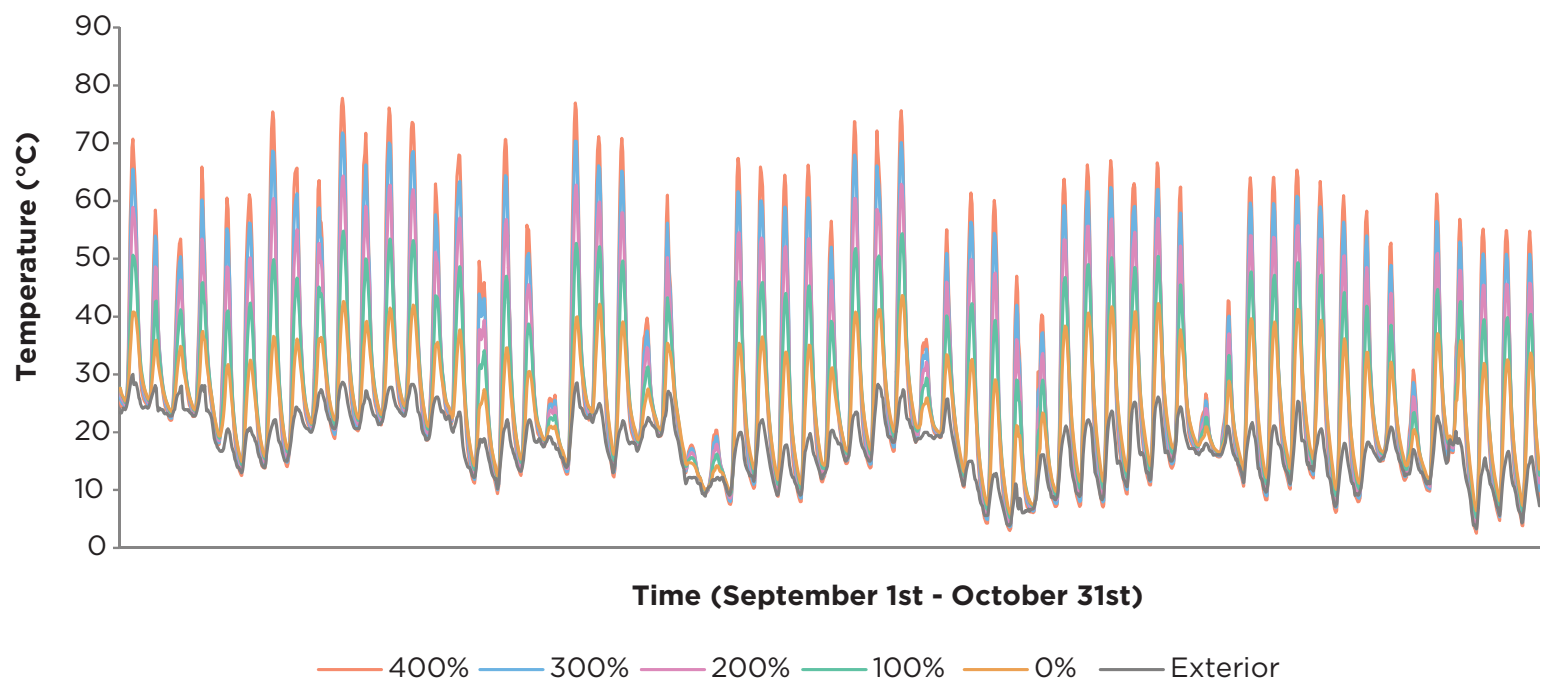

Figure 33: Variations in hourly internal temperature with glazing area between $100 \%$ and $400 \%$ of baseline area concrete slab compared with exterior for the period from September 15 - October 15.

From a passive performance it is important to understand the effect the skylight has on comfort but from a competition point of view the real question is the effect the skylight has on the total energy use of the house. From the simulation presented in Table 5, it was possible to compare the total heating and cooling loads during the competition. With the skylight, the total energy needed to maintain the competition comfort zone is $214 \mathrm{kWh}$. This was compared to a model where the skylight was replaced with a roof of the same thermal resistance as the rest of the house. In this model the energy needed to maintain comfort was $184 \mathrm{kWh}$, nearly $30 \mathrm{kWh}$ less than with the skylight, a significant reduction in the total energy use during the competition period. These results posed an interesting question to the design team. Was the extra energy needed to maintain comfort with a skylight the price to pay for a building element that was critical to the architectural concept?

\begin{tabular}{llll}
\hline & Cooling energy & Heating energy & Total \\
\hline With skylight & 76.94 & 137.50 & $\mathbf{2 1 4 . 4 4}$ \\
Without Skylight & 44.53 & 129.79 & $\mathbf{1 8 4 . 3 2}$ \\
\hline
\end{tabular}

Table 5: Total heating and cooling energy of the house with skylight compared with no skylight during the competition period 
As the Solar Decathlon was a competition based on 10 different criteria, the decision to keep the skylight came down to points. The skylight had a direct effect on 5 of the 10 contests; architecture, engineering, comfort zone, energy use and affordability. It was assumed that the skylight, if well detailed, would be an advantage in both architecture and engineering. If the mechanical system was sized appropriately and further measures were taken to shade and insulate the skylight no points would be lost in comfort. Of course the initial simulations showed that this would increase overall energy use. But, as there was no limit to the size of the solar array, this could be easily overcome by adding extra photovoltaic panels to generate the extra energy. There was an extra cost both for these solar panels and in detailing the skylight but this was seen as a small price to pay for the architectural impact of the skylight. It was decided that the extra points that would be gained in architecture would far outweigh the points that would be lost from having the extra cost in the affordability contest. Having committed to the idea of the skylight the next stage of development focused on how to improve its performance without losing its architectural impact.

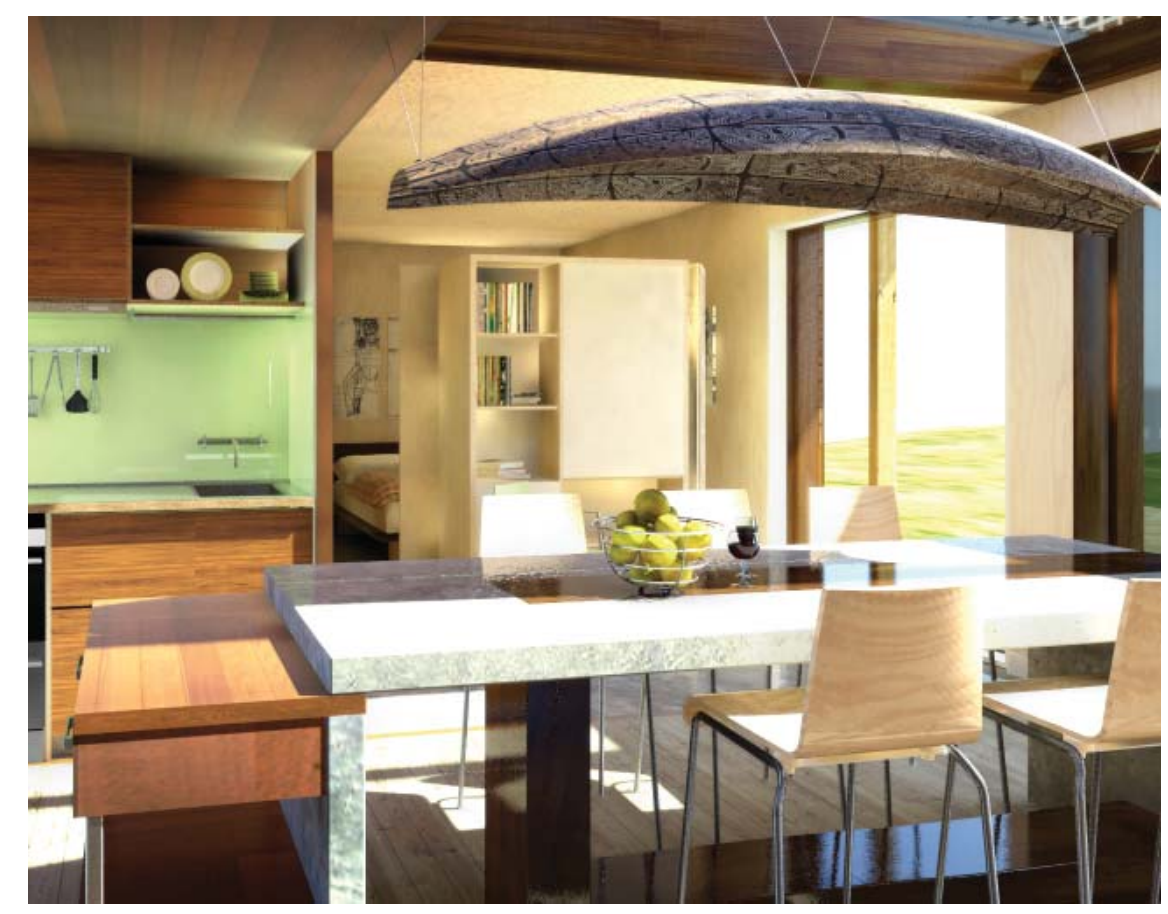

Figure 34: Artist's impression of the architectural impact of central space showing the skylight 


\subsection{Skylight Glazing}

At this point in the design process the skylight was $19 \mathrm{~m}^{2}$, and spanned the entire width of the First Light house. To improve its performance and to allow a services bulkhead to run the length of the house, its size was reduced to $13.6 \mathrm{~m}^{2}, 70 \%$ of its original size. Initially it was modeled as a double insulated glazing unit (IGU) with an $R$ value of 0.26 . As it was identified as a major source of heat gain and loss it was modeled separately to the rest of the windows and a range of different types of glazing were tested. The glazing itself in the skylight, whether it is plastic or glass, has almost no thermal resistance. It is the air spaces, the surface films and the low e coatings which resist the flow of heat. Three different types of glass were used in the simulations (Low-e + Tint, Low-e, Reflective + Tint) in double, triple and quad units, each with argon and air fill giving a total of 18 variations. In addition to traditional glazing three alternative high performance overhead glazing materials were tested; Danpalon Polycarbonate, Pilkington Profilit glass channel with nano-gel, and ETFE (Ethyltetrafluroethylene) pillows. For comparison the simulations have also been performed by replacing the skylight with R-6 SIPs, the same roof detail modeled for the rest of the house. Figure 35 gives construction details and Table 6 the thermal and optical specifications.

Table 6: Thermal and optical specifications for various glazing types (source: Window 5)

\begin{tabular}{|c|c|c|c|c|c|c|c|c|c|c|c|}
\hline \multirow{2}{*}{ Glazing Type } & \multirow{2}{*}{$\begin{array}{l}\text { W5 } \\
\text { ID \# }\end{array}$} & \multirow{2}{*}{$\begin{array}{l}\text { Thick } \\
(\mathrm{mm})\end{array}$} & \multirow{2}{*}{ Tsol } & \multicolumn{2}{|c|}{ Rsol } & \multirow{2}{*}{ Tvis } & \multicolumn{2}{|c|}{ Rvis } & \multicolumn{2}{|c|}{ Emis } & \multirow{2}{*}{$\begin{array}{l}\mathrm{K},(\mathrm{W} / \\
\mathrm{m} \cdot \mathrm{K})\end{array}$} \\
\hline & & & & Front & Back & & Front & Back & Front & Back & \\
\hline Standard Clear & 9804 & 6.0 & 0.77 & 0.07 & 0.07 & 0.88 & 0.08 & 0.08 & 0.84 & 0.84 & 1.0 \\
\hline Low-e + Tint & 5374 & 7.9 & 0.10 & 0.09 & 0.56 & 0.27 & 0.05 & 0.04 & 0.84 & 0.02 & 1.0 \\
\hline Low-e & 5440 & 7.9 & 0.28 & 0.49 & 0.56 & 0.77 & 0.07 & 0.06 & 0.84 & 0.02 & 1.0 \\
\hline Reflective + Tint & 2751 & 5.6 & 0.12 & 0.63 & 0.44 & 0.17 & 0.6 & 0.56 & 0.84 & 0.84 & 1.0 \\
\hline
\end{tabular}

\section{Legend:}

W5 ID \# Window 5 ID number

Thick Thickness

Tsol Solar Transmittance at Normal Incidence

Tvis Visible Transmittance at Normal Incidence

Rsol Solar Reflectance at Normal Incidence

Rvis Visible Reflectance at Normal Incidence

Emis Infrared Hemispherical Emissivity

K Conductivity at Normal Incidence (W/m.K) 


\begin{tabular}{|cccc}
\hline & Tvis & SHGC & U-value \\
\hline Danpalon Single & 0.31 & 0.44 & 1.53 \\
\hline Profilit Nano-gel & 0.38 & 0.31 & 0.19 \\
\hline ETFE 4 Layer & 0.8 & 0.7 & 1.47 \\
\hline Danpalon Triple & 0.36 & 0.21 & 0.56 \\
\hline
\end{tabular}

Table 7: Thermal and optical properties of composite skylight glazing options

To compare the different glazing types, design days were used to simulate the energy used to maintain the comfort zone on a worst case scenario day in New Zealand. The energy consumed by the HVAC system in kWh for each of the different options is shown in Figure 36. From the results more energy is consumed in heating on the coldest day than cooling on the hottest. This means that heat loss through the skylight is more significant than the heat gain. In heating, triple glazing performs better than double due to the extra layer of air. Normally this air space is filled with dry air but the thermal resistance is increased by replacing the air with argon. From the four composite glazing options, Nano gel and Danpalon improve the performance of the skylight by $5-10 \mathrm{kWh}$ in heating demand due to their higher $\mathrm{R}$ values. In cooling, though, they all use more energy than the standard glazing units. The most pronounced example of this is the ETFE pillow which approximately doubles the cooling load compared with the glass options. In cooling, the energy use varies more, depending on the glass type, than the number of layers in the IGU and the type of gas. Adding a Low-e coating that allows light into the space but not the heat of the sun is desirable. The type of Low-e coating used in the simulations has a low solar heat gain co-efficient (SHGC) and is transparent to visible radiation but reflective to both short wave and long wave infrared radiation. Adding a Low-e coating improves the performance of the house in cooling load by over $5 \mathrm{kWh}$.

Danpalon
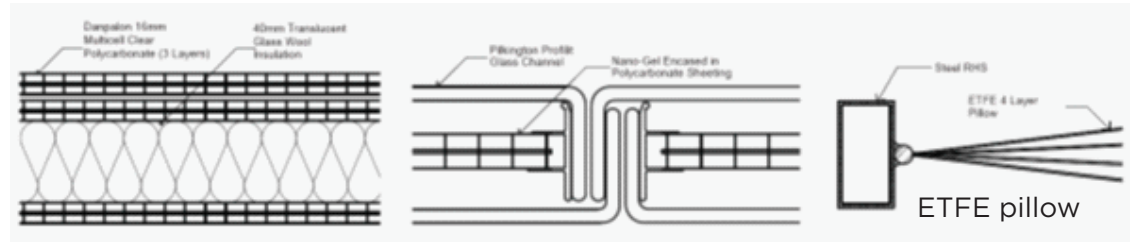

Glass channel with nano-gel

Figure 35: Composite skylight glazing construction details (a) Triple Layer Danpalon with translucent glass wool insulation, (b) Profilit glass channel with nano-gel insulation, (c) ETFE 4 layer pillow 


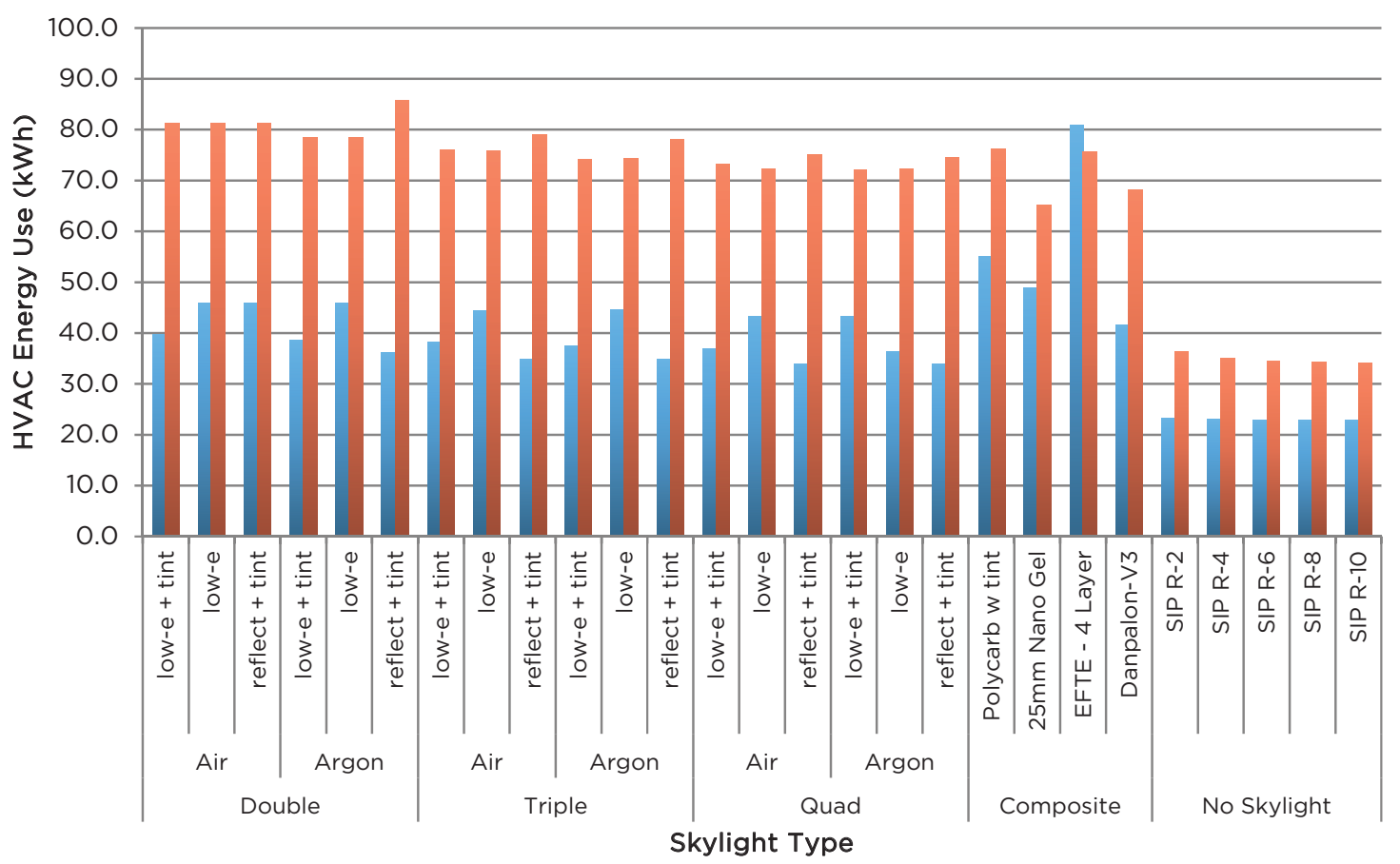

Cooling energy Heating energy

Figure 36: Skylight Constructions - Design Day HVAC Energy Use (kWh)

The previous simulation concluded that the best performing glazing option was quad glazing, with an argon fill and a Low-e coating. This is based on the extremes of temperature over an entire year in New Zealand. Looking at heat gain and heat loss, Figure 37 explores the effect of different types of glazing during the competition period. Compared to the previous simulation, heat loss is insignificant. Differences between the various types of glazing are minimal, with the exception of the Nano-gel which offers a significant reduction. Heat gain on the other hand is substantially higher during the competition period and so the effect of adding a Low-e coating and tint to the glass is more pronounced. The single layer polycarbonate, Nano-gel and ETFE all perform very poorly and result in higher heat gain, almost double in the case of the ETFE (9.7kW peak), while the triple layer Danpalon is in the same range as the glass options. From these results the composite glazing options were discarded and it was decided a standard glazed skylight would be designed. Of the best performing options the difference between the quad and triple glazing was insignificant, especially during the competition. Argon gas offered the greatest thermal resistance against heat loss and a Low-e coating with a tint had the greatest impact on heat gain. 


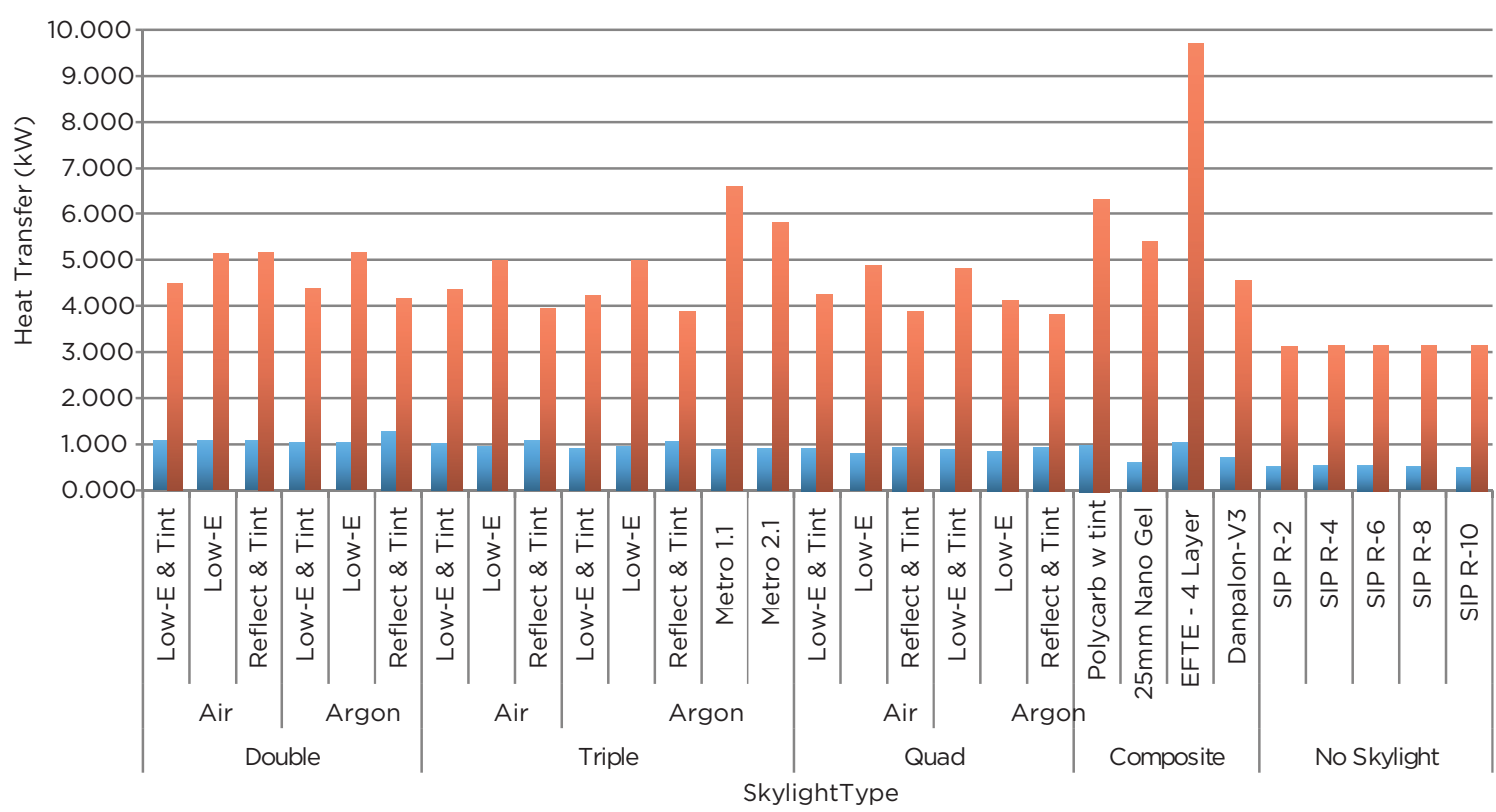

Heat Gain (kW)

Heat Loss $(\mathrm{kW})$

Figure 37: SEffect of different types of glazing on heat loss and gain through the skylight during the competition

Up to this point the simulations were based on theoretical glazing types.

Triple IGU, Low-e coating and an argon fill was the optimum glazing specification for the skylight. These specifications were taken to Metro Glass, a local glass manufacturer and a glazing unit was selected based on this criteria. Their specifications are outlined in Table 8 and were input into the simulation. The initial glazing options Metro Glass supplied performed extremely well at reducing heat loss (better than any of the glazing options previously tested), although there were significantly higher heat gains than expected. This was resolved in further iterations by replacing the outer layer of clear glass with a tinted glass that excluded more solar radiation while still allowing an acceptable visible light transmission into the space. In addition to thermal simulation, day lighting analysis was performed on the skylight in order to ensure there were sufficient indoor light levels (Figure 38). 


\begin{tabular}{|c|c|c|c|c|c|c|c|c|c|c|}
\hline Glazing Type & $\begin{array}{l}\text { Thick } \\
(\mathrm{mm})\end{array}$ & Tsol & $\begin{array}{l}\text { Rsol } \\
\text { Front }\end{array}$ & Back & Tvis & $\begin{array}{l}\text { Rvis } \\
\text { Front }\end{array}$ & Back & $\begin{array}{l}\text { Emis } \\
\text { Front }\end{array}$ & Back & $\begin{array}{l}\mathrm{K}(\mathrm{W} / \\
\mathrm{mK})\end{array}$ \\
\hline Standard Clear & 5.7 & 0.77 & 0.07 & 0.07 & 0.88 & 0.08 & 0.08 & 0.84 & 0.84 & 1.0 \\
\hline Argon Gas & 12 & & & & & & & & & 0.026 \\
\hline 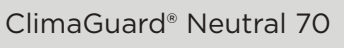 & 5.7 & 0.558 & 0.18 & 0.13 & 0.75 & 0.05 & 0.07 & 0.17 & 0.84 & 1 \\
\hline Argon Gas & 12 & & & & & & & & & 0.027 \\
\hline ClimaGuard ${ }^{\circledast}$ Neutral 70 & 5.7 & 0.558 & 0.18 & 0.13 & 0.75 & 0.05 & 0.07 & 0.17 & 0.84 & 1 \\
\hline
\end{tabular}

\section{Legend:}

\begin{tabular}{|c|c|c|c|}
\hline & & Tvis & $\begin{array}{l}\text { Visible Transmittance at Normal } \\
\text { Incidence }\end{array}$ \\
\hline Thick & Thickness & Rvis & $\begin{array}{l}\text { Visible Reflectance at Normal } \\
\text { Incidence }\end{array}$ \\
\hline Tsol & $\begin{array}{l}\text { Solar Transmittance at Normal } \\
\text { Incidence }\end{array}$ & Emis & Infrared Hemispherical Emissivity \\
\hline Rsol & Solar Reflectance at Normal Incidence & K & Conductivity at Normal Incidence \\
\hline
\end{tabular}

Table 8: Thermal and optical specifications for Metro Glasstech intial suggested IGU (source: Metro Glasstech and Window 5)

Figure 38: Daylight anaylsis of the skylight preformed in Autodesk Ecotect Analysis software 


\subsection{Skylight Shading}

One of the ideas that developed from the concept of the bach was that users had control over their own space. Even with the extensive investigation into the best performing glazing system the user had no control of the effect the skylight had on their comfort. The results from both simulations above show that even with the best performing glazing system, the skylight created large cooling loads during the summer and even bigger heating loads during the winter. During the competition, heat gain through the skylight had the greatest impact on energy use therefore shading was a key strategy that was investigated for achieving thermal comfort. The greatest challenge in adding shading to the design was detailing the shading device so it did not detract from the effect of the skylight. For the initial simulations the visual impact was ignored and the shading was modeled as $300 \mathrm{~mm}$ external and internal louvers at three different settings, $60^{\circ}$ open, $30^{\circ}$ open, and fully closed. At this stage there was no need to worry about aesthetics in the world of simulations. Figure 39 shows the maximum, mean and minimum temperatures with the different louver variations. As can be seen in this graph the minimum internal temperature stays the same throughout the simulations, at $-12{ }^{\circ} \mathrm{C}$ $\left(10.4^{\circ} \mathrm{F}\right)$ on the coldest winter day. As expected the shading has no effect during cold winter days. The most prominent change is the drop in maximum temperature when the skylight was fully shaded with the external louvers closed. This results in the internal temperature dropping from $54.8^{\circ} \mathrm{C}\left(129^{\circ} \mathrm{F}\right)$ in the baseline model to $39.6^{\circ} \mathrm{C}\left(103^{\circ} \mathrm{F}\right)$. This clearly demonstrates the significant impact the skylight has on the internal temperature and the importance of reducing the solar gain during the summer.

Detailing for the shading system so that it fitted with the architectural concept was easy to control and construct, and was as affordable, was 


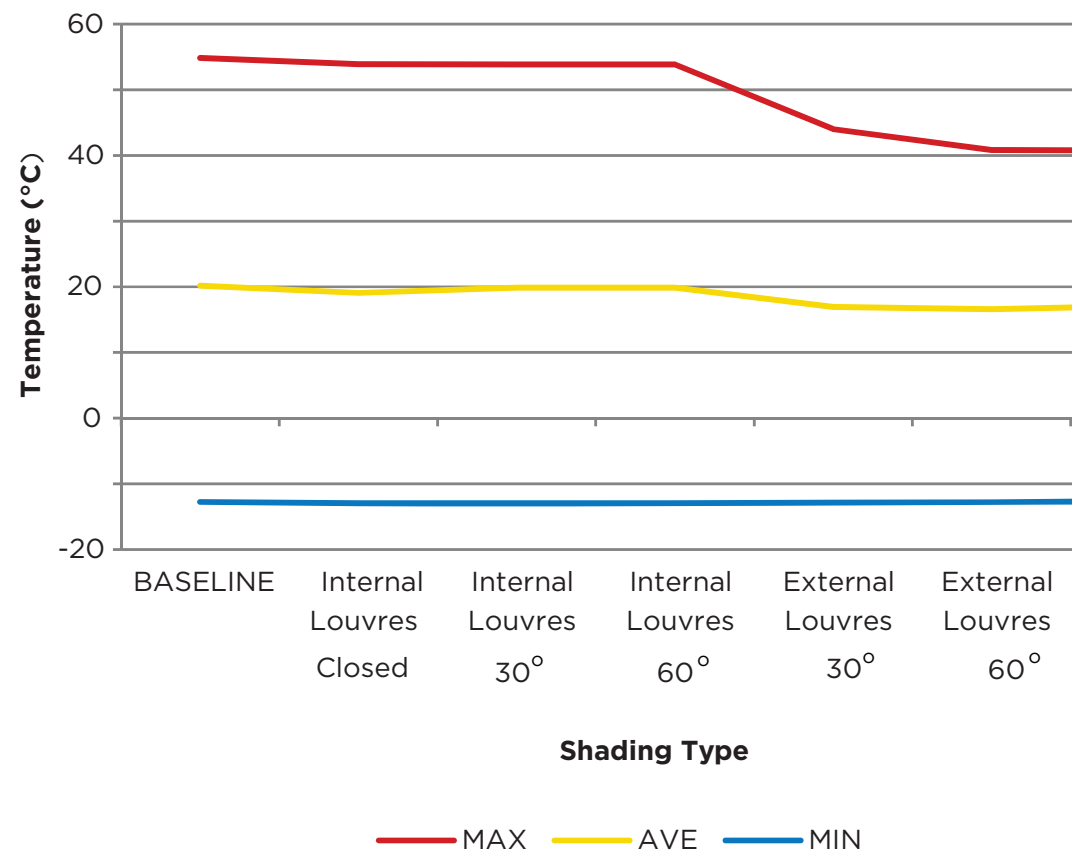

Figure 39: Comparison of annual maximum, mean and minimum internal temperatures $\left({ }^{\circ} \mathrm{C}\right)$ with various shading devices

extremely difficult. The large, bulky louvers that were modeled for the simulations detracted from the purity of the skylight itself. In the simulation they were modeled as fixed louvers providing shading all year round. Despite the improvement in energy use this did not allow the user control over the environment and detracted from the experience of the space. This led to suggestions of operable louvers and roll-away exterior blinds, all of which added complexity and cost to an already expensive building element. The most practical form of shading, from a construction point of view, was the use of an interior shading device. However, from energy rejection point of view, this was far less effective. Figure 40 and Figure 41 compare the HVAC energy use with an interior and exterior shade. An exterior shade consumed 13kWh less energy during the competition and $160 \mathrm{kWh}$ less energy throughout an entire year. This is because an exterior shade would reflect solar energy outside the house, before it reached the skylight and was admitted into the space. Thus, heat gain was significantly reduced. An interior shade, on the other hand, absorbed solar radiation once it was already through the skylight. This created a heat gain in the space that during the competition would result in a cooling load leading to an increase in the house energy demand. For a bach, though, with a more general definition of comfort, interior blinds could be effective. Because they can be adjusted, the user has greater control over their own comfort in the space. They shade the space from radiant heat during the 
summer, reduce glare, and most importantly act as insulation. Throughout the skylight simulations a large focus was on the competition and finding ways to reduce heat gain, despite the largest loads coming from heat loss during a year in New Zealand. An interior blind, despite resulting in larger energy use during the competition, would provide shading during the summer as well as help reduce heat loss during the winter. At night it would also reduce the "black hole" effect experienced through radiant heat loss created by the exposed glazing. For the skylight and story of a kiwi bach the added benefits in terms of comfort in New Zealand outweighed the energy savings for the competition. For this reason an interior shading system was detailed for the First Light house.

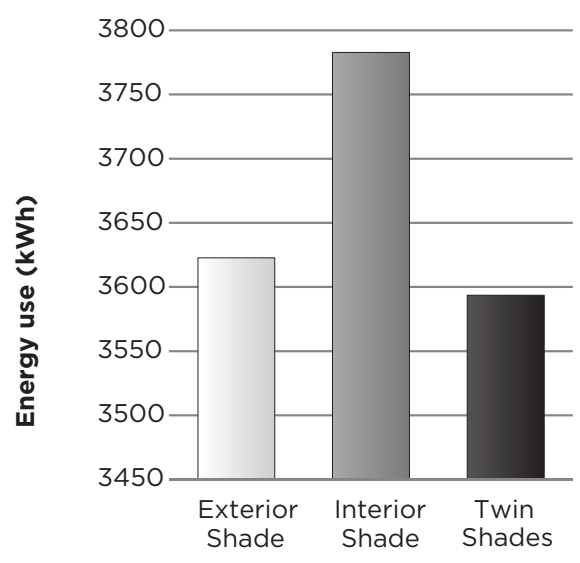

Figure 40: Energy consumption in New Zealand with interior, exterior and twin shading options

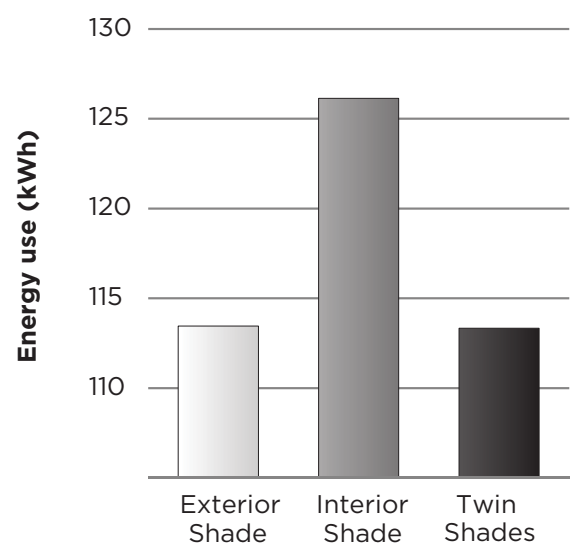

Figure 41: Energy consumption during competition with interior, exterior and twin shading options 


\subsection{Window Glazing}

Orientation is critical to a design that seeks to maximize solar gain throughout the year. Figure 42 shows the daily solar radiation received throughout the year based on different window orientations. This paticular diagram is set up for the Northern hemisphere but remains apropriate for the southern hemisphere. All orientations except for south receive maximum solar radiation in summer (Lechner 2009, 214). The majority of glazing in the First Light house is on the north façade to make use of the sun through the winter months but also designed to minimize solar gain during the summer. The purpose of the diagram is to highlight how much solar radiation north windows collect compared to any other orientation in winter. Thus, north facing windows are desirable from both shading and a passive solar heating point of view. It is interesting that horizontal glazing, like the skylight, receives large amounts of sunshine during the summer, and very little during the winter. Similarly, east and west windows are not desirable from a heating and cooling point of view. With an improved skylight design that is shaded during the summer, a similar process was used to increase the performance of the rest of the glazing. Improvements were modeled by altering the construction of the glazing units, and by changing the glass type, the number of layers, and the gas fill, just as for the skylight. The baseline was a standard $6 \mathrm{~mm}$ clear double IGU with air fill. For comparison, five high performance glasses were chosen from the LBNL Window 5 database as detailed below in Table 9. Each glass was tested in a double and quad IGU, with both air and argon fill for each, giving 20 variations in total.

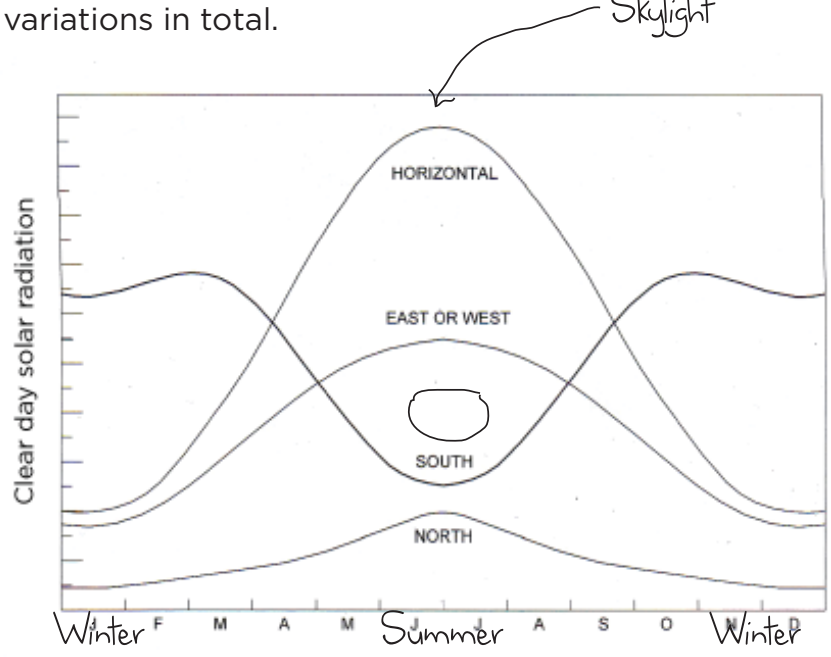

Figure 42: All orientations except for north receive maximum solar radiation in summer (Note: Diagram for northan hemisphere). A skylight receives four times the solar heat that north windows receive at the peak of summer. (Source: Lechner 2009, 214) 


\begin{tabular}{|c|c|c|c|c|c|c|c|c|c|c|}
\hline \multirow{2}{*}{ Glazing Type } & \multirow{2}{*}{$\begin{array}{l}\text { Thick } \\
(\mathrm{mm})\end{array}$} & \multirow{2}{*}{ Tsol } & \multicolumn{2}{|c|}{ Rsol } & \multirow{2}{*}{ Tvis } & \multicolumn{2}{|c|}{ Rvis } & \multicolumn{2}{|c|}{ Emis } & \multirow{2}{*}{$\mathrm{K}$} \\
\hline & & & Front & Back & & Front & Back & Front & Back & \\
\hline Standard Clear & 6.0 & 0.77 & 0.07 & 0.07 & 0.88 & 0.08 & 0.08 & 0.84 & 0.84 & 1.0 \\
\hline Low-e + Tint & 7.9 & 0.10 & 0.09 & 0.56 & 0.27 & 0.05 & 0.04 & 0.84 & 0.02 & 1.0 \\
\hline Low-e & 7.9 & 0.28 & 0.49 & 0.56 & 0.77 & 0.07 & 0.06 & 0.84 & 0.02 & 1.0 \\
\hline Low Trans. & 5.8 & 0.10 & 0.08 & 0.33 & 0.11 & 0.07 & 0.30 & 0.84 & 0.63 & 1.0 \\
\hline Reflective + Tint & 5.6 & 0.12 & 0.63 & 0.44 & 0.17 & 0.6 & 0.56 & 0.84 & 0.84 & 1.0 \\
\hline Reflective & 6 & 0.27 & 0.60 & 0.46 & 0.47 & 0.40 & 0.42 & 0.84 & 0.84 & 1.0 \\
\hline
\end{tabular}

\section{Legend:}

W5 ID \# Window 5 ID number

Tvis Visible Transmittance at Normal Incidence

Thick Thickness

Tsol Solar Transmittance at Normal Incidence

Rvis Visible Reflectance at Normal Incidence

Rsol Solar Reflectance at Normal Incidence

Emis Infrared Hemispherical Emissivity

K Conductivity at Normal Incidence (W/m.K)

Table 9: Thermal and optical specifications for various glazing types (source: Window 5)

The main performance factors that were considered were the heat loss and gain through the glazing throughout the entire year in NZ. As heat gain was the major factor affecting the house during the competition and as the canopy would shade the south facing glazing, simulations focused on the performance in New Zealand. All of the selected high performance glasses were a significant improvement over the standard clear glass used in the base model. Adding a reflective tint to the glass reduced the maximum heat gain in the space from $12.5 \mathrm{~kW}$ to $3.1 \mathrm{~kW}$. Figure 43 shows that the choice of glass has a much more significant impact on reducing the solar gain than the gas type or number of layers of glass. As was found with the skylight, heat loss through the glazing is much more dependent on the layers of glass and the gas fill than for the heat gain. The tinted reflective glass which performed the best in preventing heat gain through the windows has the worst performance with reducing heat loss. The best glass for reducing heat loss through the windows is the tinted Low-e 
glass, with the argon filled IGU. It reduced the heat loss from $2.5 \mathrm{~kW}$ in the baseline to $0.7 \mathrm{~kW}$.

The thermal resistance of a window consists of two parts: the glazing and the frame. In large windows most of the heat is lost through the glazing, but in smaller windows the frames become critical. Most of the window

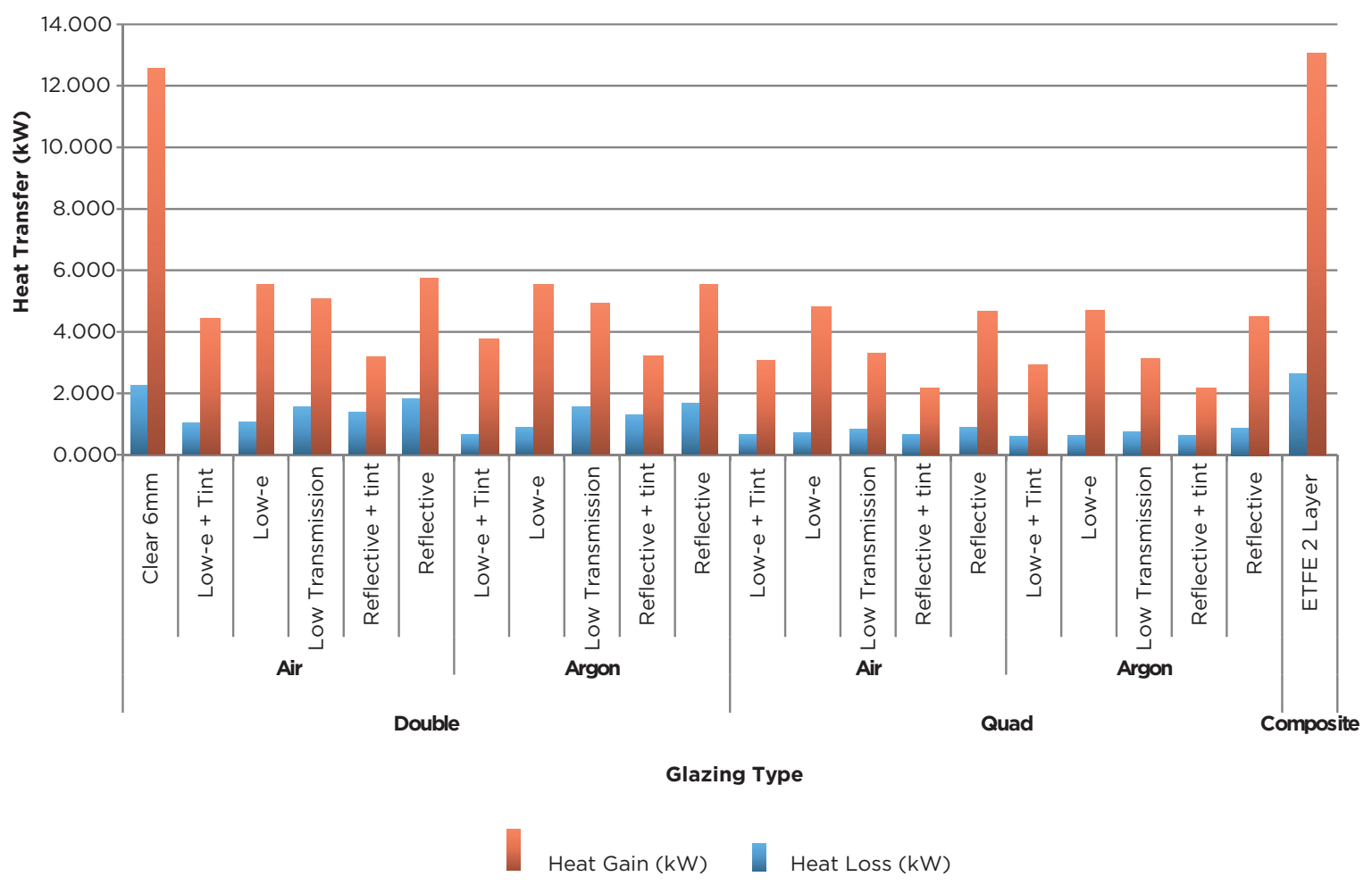

Figure 43: Maximum heat gain and loss through the window glazing over entire simulation in the First Light house concentrated on the type of glazing but a comparison was completed on the frame of the bi fold door in the central space. In order to determine the heat flow paths of both a solid timber framed door and a thermally broken aluminum frame the details were simulated through LBNL's THERM, a two-dimensional building heat transfer modeling software package. Figure 44 represents the flow of heat through both types of frame detail. Because of the high performing, triple glazed windows both frame options are not as good at resisting the flow of heat as the insulated glazing unit itself. But the comparison shows that the timber frame has a far greater thermal resistance than the thermally broken aluminum frame. This analysis helped with the specification of the windows that would be used in the First Light house. As with the thermal resistance of the walls, once the details were established for the skylight and the windows themselves, the total thermal resistance (Table 10) was calculated using NZBC Clause H1. (Appendix B shows final H1 report). 


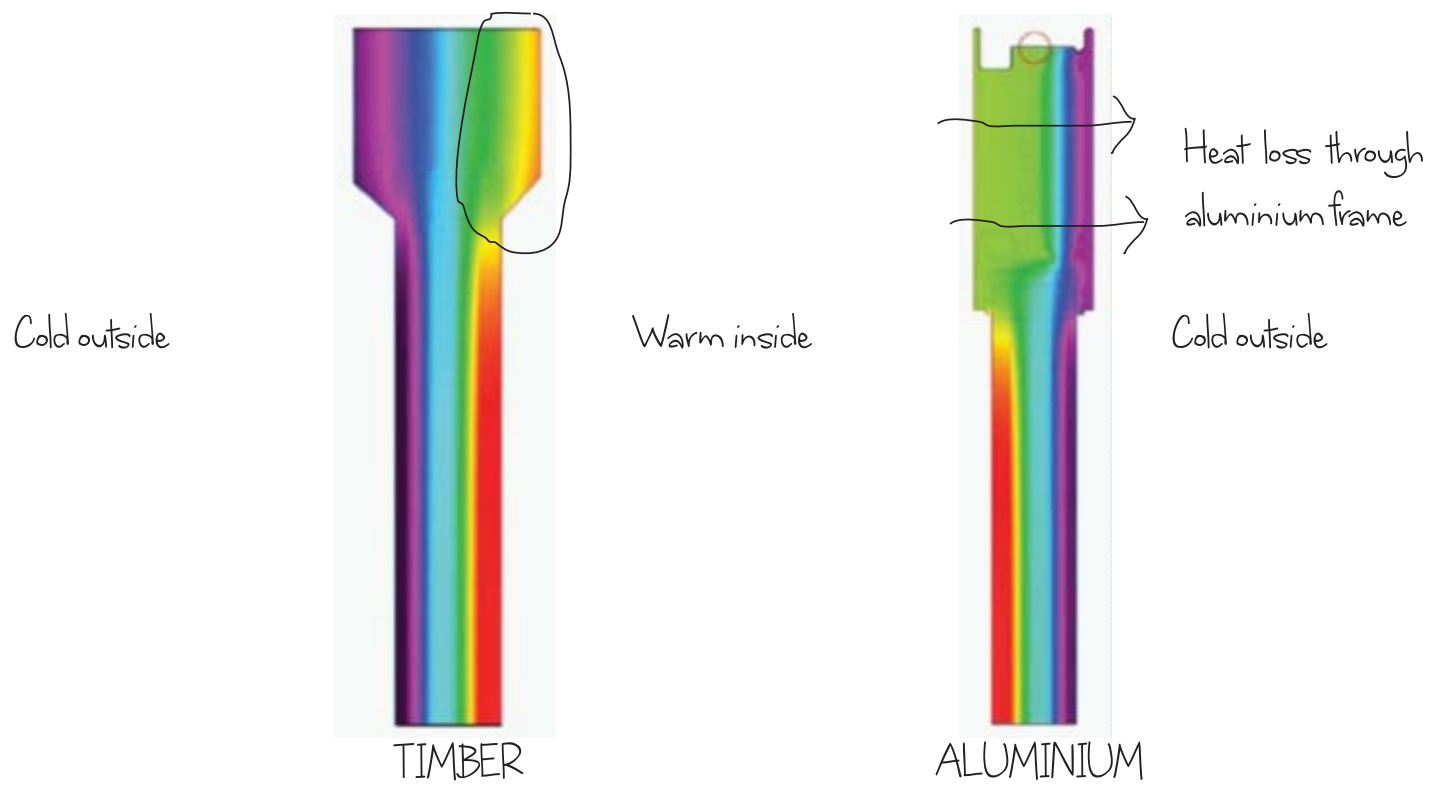

Figure 44: Heat transfer of timber frame versus a thermally broken aluminium frame

\begin{tabular}{|c|c|}
\hline Building Element & Construction R-value $\left(\mathrm{m}^{2}{ }^{\circ}{ }^{\circ} \mathrm{C} / \mathrm{W}\right)$ \\
\hline Glazing & 1.11 \\
\hline Skylight & 1.11 \\
\hline
\end{tabular}

Table 10: Construction R-value of glazing and skylight

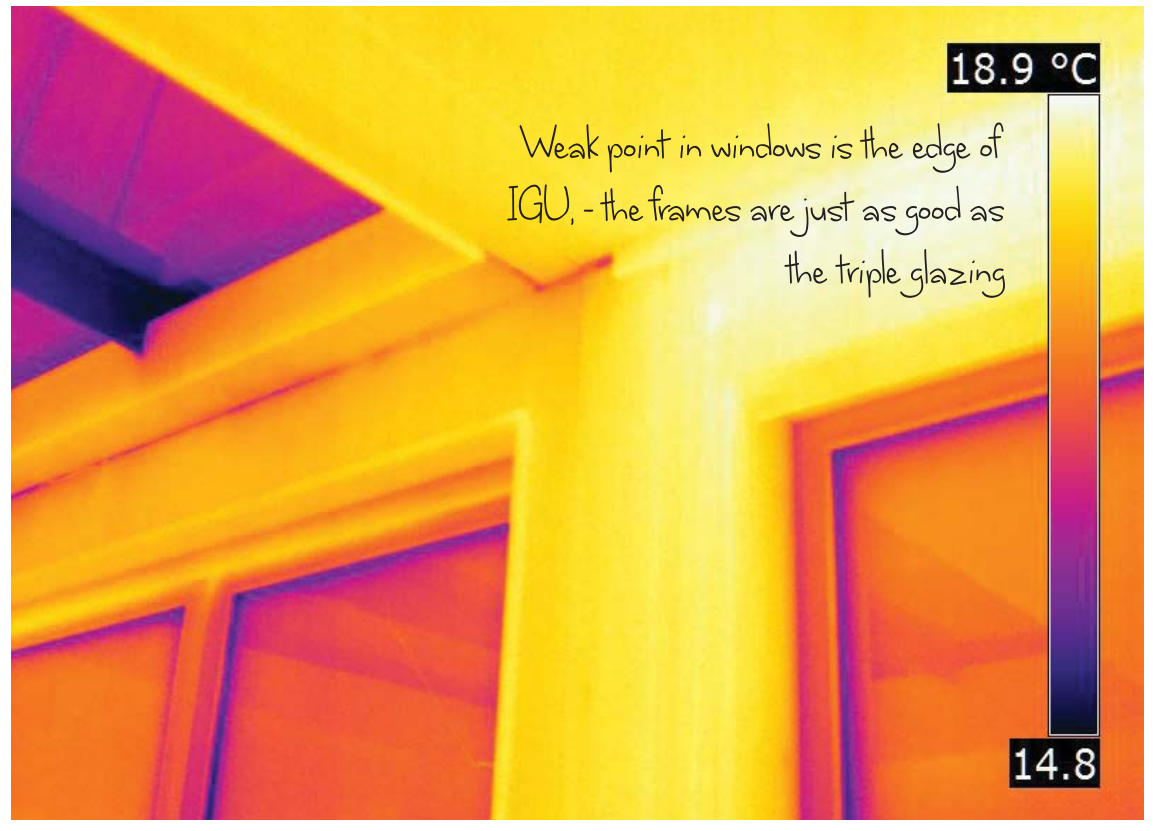

Figure 45: Thermal image of bifold doors, North facing glazing and skylight of the First Light house (Source: Image courtesy of BRANZ) 
Figure 46: Shading of the solar canopy 


\section{Passive cooling: Shading and Ventilation}

\subsection{Shading}

As with passive solar systems, orientation is critical with shading. Large areas of north facing glazing in the schematic design made a fixed shading device desirable to reduce heat gain. Blocking the sun before it reaches the building, particularly the glazed but also the opaque surfaces, (including the roof) and reflecting the solar radiation is fundamental to the prevention of heat gain (Lechner 2009, 213). To prevent passive solar heating when it is not wanted, shading must be used to minimize the direct solar radiation that reaches the house and penetrates the windows. The concept of the solar canopy was to provide shading to the First Light house underneath it as well as the large north facing windows, reducing the amount of direct solar radiation hitting the house in a New Zealand summer. The canopy was also the mounting platform for the photovoltaic array, intended to allow air flow around the photovoltaic modules, passively cooling them and allowing them to operate at their maximum efficiency. The canopy's horizontal overhang over the north facing windows is very effective during the summer because the sun is high in the sky. When the sun is low, during the winter it allows full solar gain, passively heating the space. The accurate sizing of the canopy overhang is critical to reducing overheating in the house.

In the original model the overhang was modeled at $1200 \mathrm{~mm}$, which was calculated during the schematic design phase from a shading study of the winter and summer sun angles in New Zealand. With this overhang the canopy fully shaded the north windows during the summer months but allowed full solar gain during the winter as shown in Figure 47. 


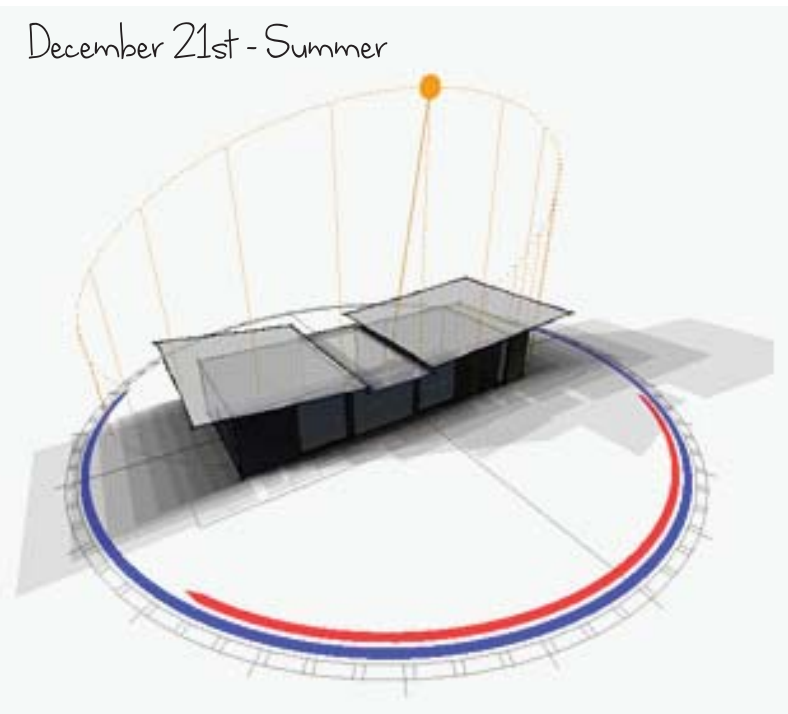

June 21st- Winter

Figure 47: At $1200 \mathrm{~mm}$ the Canopy provides full shading on December 21 st in New Zealand and on June 21st the canopy is sized to allow full solar gain throughout the day

During the competition, when these large windows were faced south though, it only shaded half of their full height throughout the day. Figure 48 and 49 show the average daily solar radiation that penetrates through the glazing during the competition. The question is what effect did this solar gain during the competition have on the comfort of the space and therefore the energy use of the First Light house?

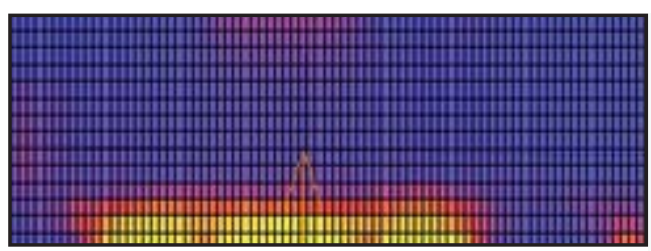

At $1200 \mathrm{~mm}$ the canopy did not fully shade the south facing windows during the competition

Figure 48: Amount of average daily solar radiation penetrates glazing during competition
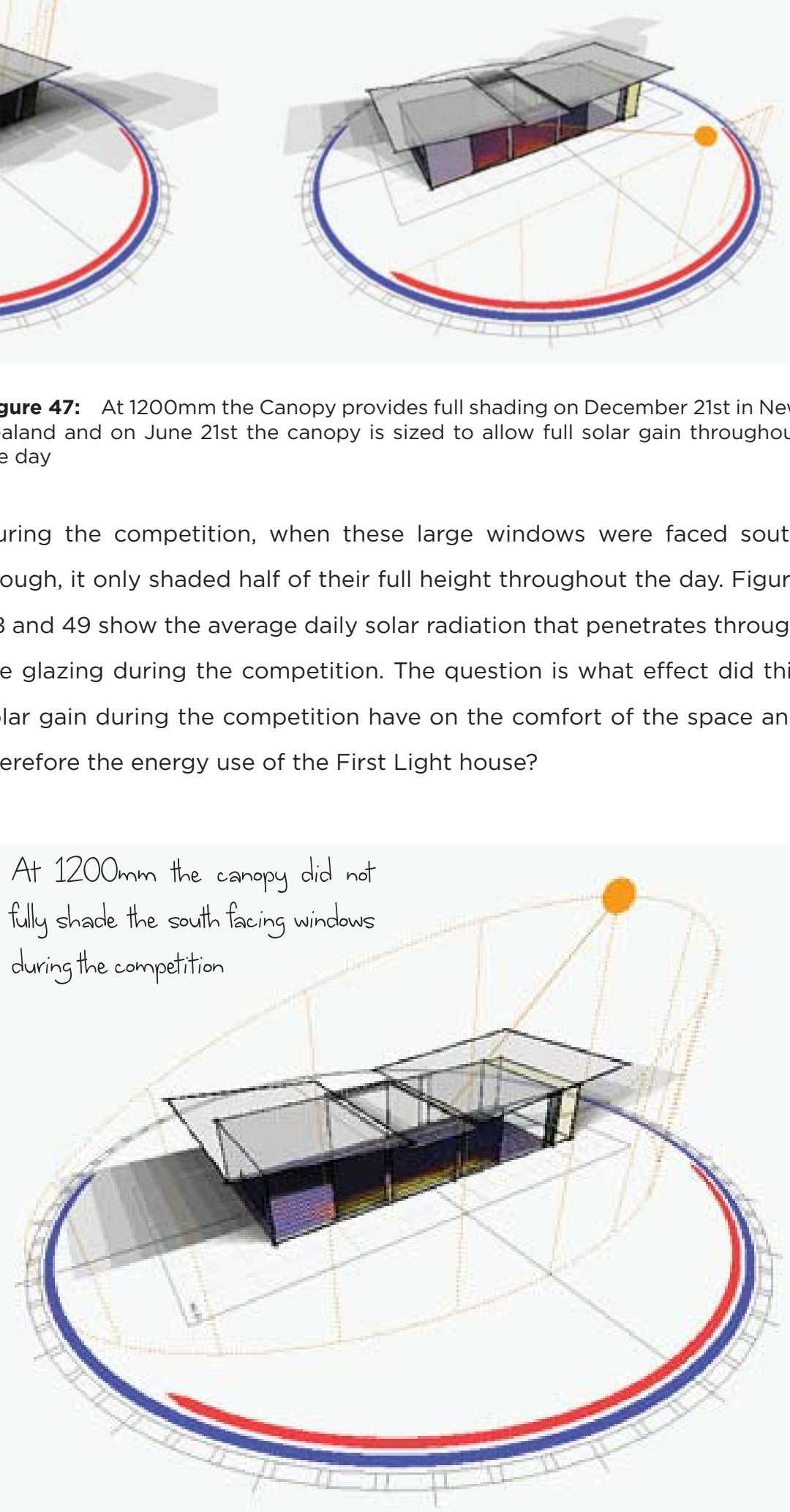

Figure 49: Solar position at 12:00 noon during the competition 
Firstly, in order to determine the optimum shading during the competition five different canopoy overhangs were modelled. In these simulations the baseline model was updated with all of the variations, including insulation, thermal mass and glazing that had been tested previously. The use of the sun to passively heat the house was an essential aspect of the energy reducing strategy in the home, especially for building elements like the thermal mass. It was, therefore, essential for the shading anylsis that these elements were represented in the model as they would appear in the final house. This would ensure that the necessary solar gain was achieved during the competition. The canopy overhangs that were modeled range from no shading through to fully shaded throughout the day for a $2.7 \mathrm{~m}$ overhang. With the south windows fully shaded the average temperature during the competition sat perfectly within the temperature band at $22.7^{\circ} \mathrm{C}$. However, $2.7 \mathrm{~m}$ is a considerable overhang. In fact, with this overhang the south winodws would be fully shaded from September through to April in New Zealand. The limit of the shading from a construction and aesthetic point of view was $1800 \mathrm{~mm}$, which at 12 noon during September in Washington DC shades two thirds of the south facing windows. (Figure 48 and 49) With this level of shading the average temperature in the space without any mechanical heating or cooling was $23.4^{\circ} \mathrm{C}$ (Figure 50). This was within the comfort bracket for the competition. Movable shading blinds that came up from the bottom of the south facing windows to shade the lower third were investigated as another option. The extra complexity and cost that this added to the design outwieghed the energy saving that it would create. Low level planting along both large south facing windows added a small amount of aditional shading during the competition.

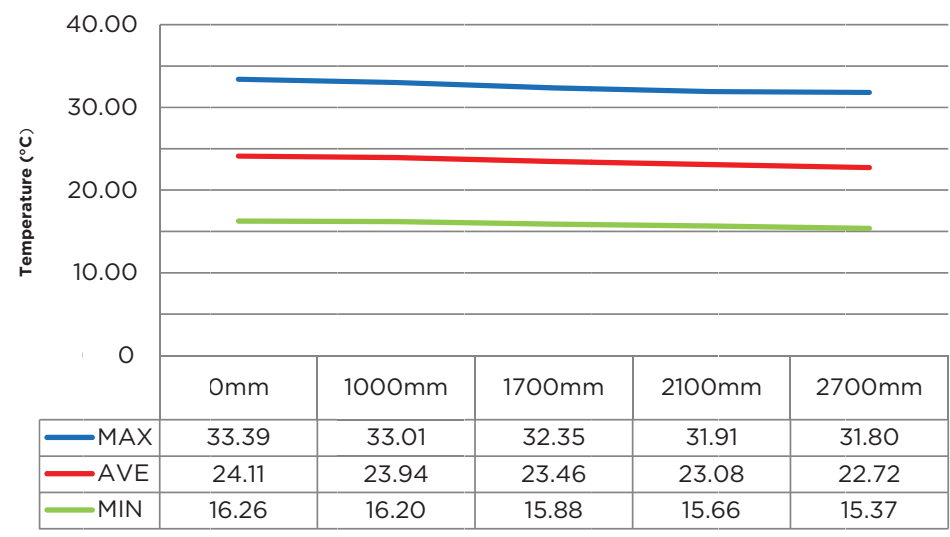

Figure 50: Maximum, average and minimum temperature inside the space during the competition with increased canopy overhang. 
Once the extent of the overhang was decided, the angle of the louvres in the canopy had to be designed in order to provide shading of the windows. In the thermal simulation the shading device had been modeled as a flat panel. From a aesthetic and construction point of view this was not ideal. The canopy was initially designed as a beautifully light structure that hovered above the pavillions underneath. If it was now to be constructed as a bulky, solid shading device, although practical, this would detract from its architectural quality. Angled louvres were designed as a means of providing shading to the south facing windows underneath while maintaining a graceful form. The challenge was choosing an angle that would fully shade the windows in summer in New Zealand, would look pleasing to the eye, and would not require a large amount of material for the construction. The trouble was that when the sun was lower, as for the competition, the ideal spacing of the louvres did not fully shade the then south facing windows. Table 11 show the precentage of the south façade (north façade in New Zealand) that the louvres shaded at different angles in September in Washington DC.

\begin{tabular}{|cccc|}
\hline ANGLE & SHADED & UNSHADED & $\%$ SHADED \\
\hline $\mathbf{0}^{\circ}$ & 123.4 & 179.9 & 40.7 \\
$\mathbf{3 0}^{\circ}$ & 196 & 107.5 & 64.6 \\
$\mathbf{3 5}^{\circ}$ & 202.2 & 101.1 & 66.7 \\
$\mathbf{4 0}^{\circ}$ & 208.3 & 94.7 & 68.7 \\
$\mathbf{4 5}^{\circ}$ & 212.9 & 90.9 & 70.1 \\
$\mathbf{9 0}^{\circ}$ & 215.4 & 88 & 71.0 \\
\hline
\end{tabular}

Table 11: Percentage shading of south facing windows of canopy louvers at various angles

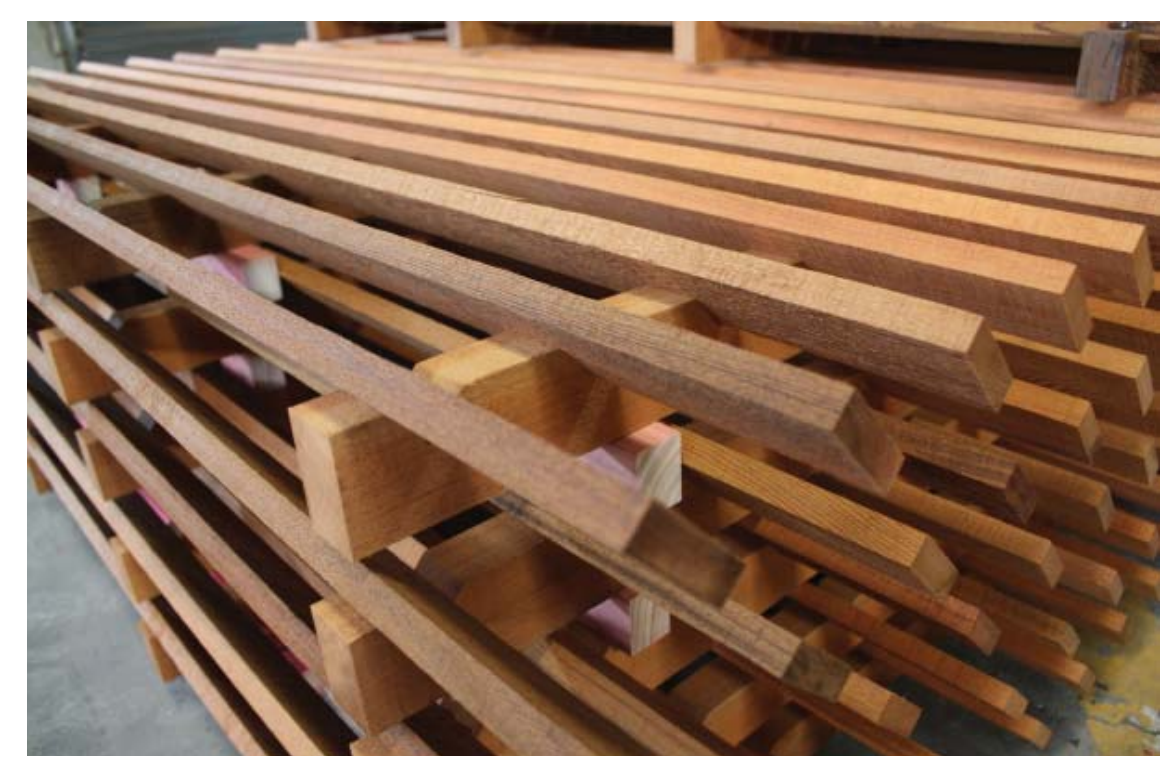

Figure 51: Canopy slats stacked during construction 


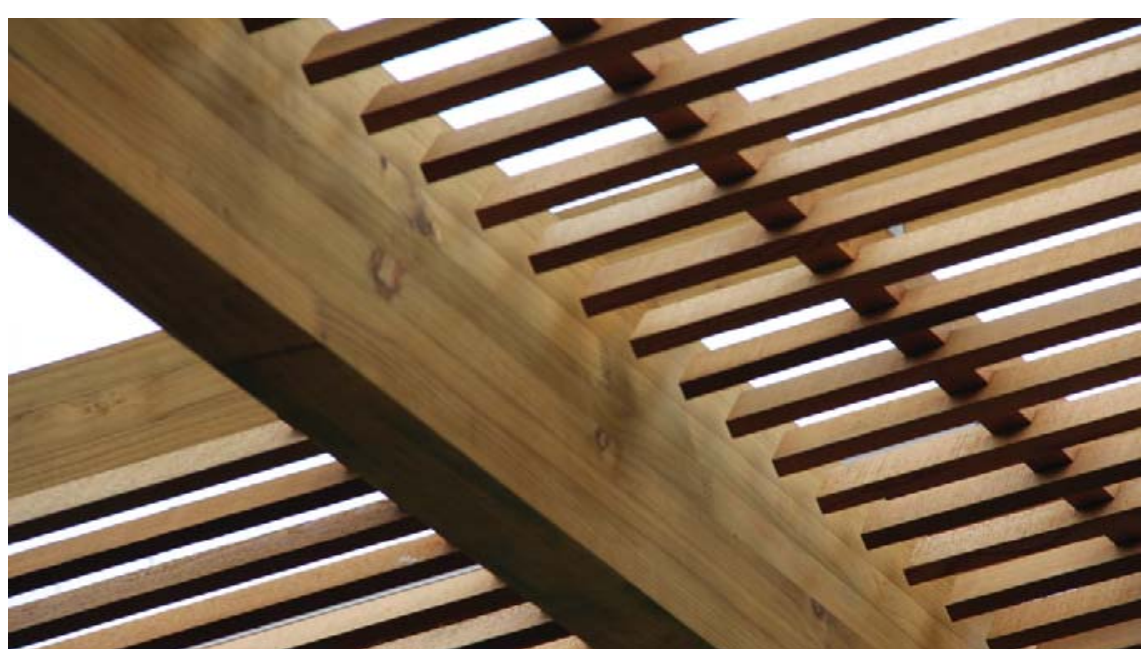

Figure 52: Angle of installed canopy slats

At an angle of $45^{\circ}$ the louvers provide $70 \%$ shading. This would have a small effect on solar gain through the south facing windows during the competition. This would also have the most effect on the internal temperature during the middle of the day when the sun was at its highest. At this time of the day during the competition the comfort zone contest would be suspended because public tours would be running through the house. Because of this, the HVAC system would be turned off and therefore the effect of only $70 \%$ shading on the house's total energy use would be minimal. This analysis was adequate justification for the larger spacing of the louvers. These simulations helped to formulate an idea of the effect of different design decisions and find a synthesis between architecture and energy efficiency.

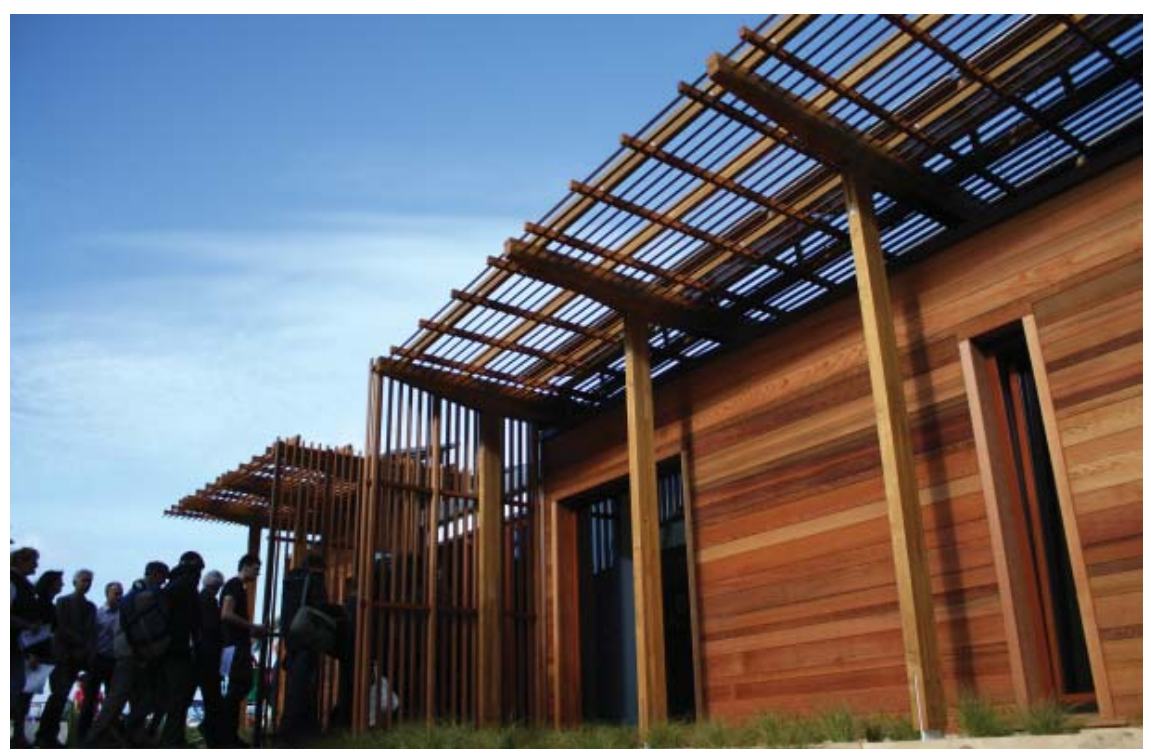

Figure 53: Solar canopy during public exhibition on Frank Kitts Park 


\subsection{Ventilation}

Ventilation provides cooling by using air to carry heat away from a building and the human body (Szokolay 2004, 40). This air movement can be induced by natural or mechanical power. Szokolay separates the term ventilation into three different processes that serve different purposes in a building;

1. Supply of fresh air

2. Remove internal heat

3. Promotion of heat dissipation from the skin

Each can be applied to help describe how ventilation has been used in the First Light house. Every effort has been made to reduce heat loss through infiltration of air by designing an air tight building envelope. Because of this high level of air tightness sufficient fresh air must be introduced into the space to maintain a healthy indoor air quality. Both controlled ventilation and infiltration causes a flow of heat. For example if the First Light house was warmer than the outside, introducing fresh air would mean replacing warm inside air with cold air from the outside, which would introduce a heating load, consuming more energy. But in order to maintain a healthy indoor environment ventilation cannot be completely eliminated to save energy. Because of the strict performance required for the competition and the designed air tightness, a combination of mechanically controlled ventilation and natural ventilation has been used in the First Light house. The use of mechanical ventilation to introduce fresh air is described in the following chapter.

Natural ventilation, depending on the outside temperature, can be used through the opening and closing of windows to remove a buildup of internal heat. Depending on the outside temperature, during the competition outside air could be introduced to the space to help maintain the comfort zone. Looking at the maximum, minimum and average temperatures during the competition using natural ventilation could have a significant effect on the maximum air temperature in the space. The effect of internal gains from the heat of occupants, appliances and lighting can also be reduced through natural ventilation. Openable windows at either end and on either side of the building, as well as bi folding doors 
on either side of the central space could be used during the competition for natural cooling.

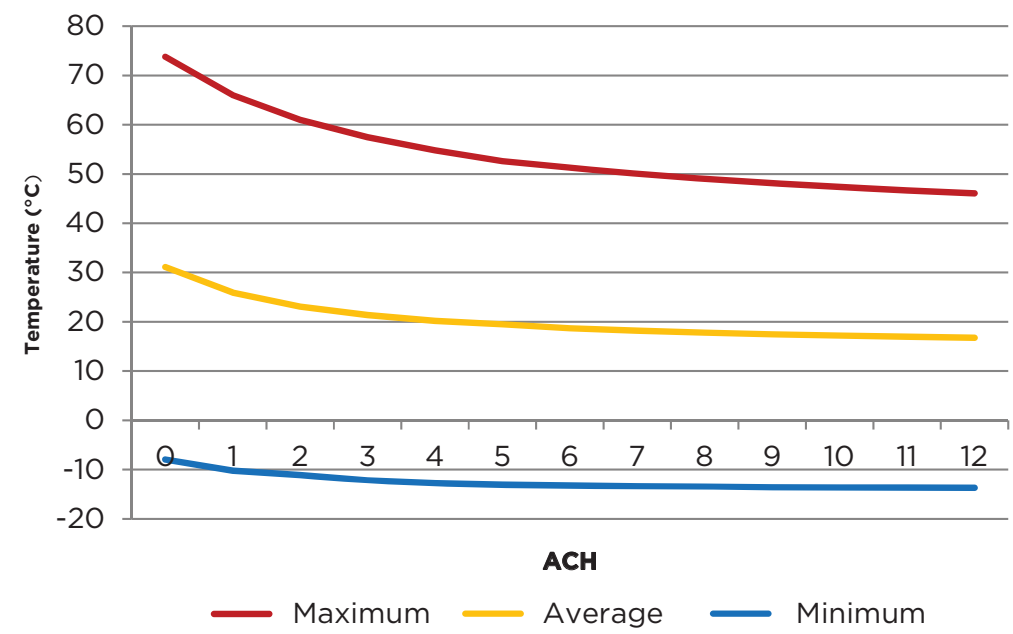

Figure 54: Effect of natural ventilation on the maximum, mean and minimum temperatures in Washington DC

Looking at weather data for Washington DC during the competition period there are times where passive cooling through natural ventilation could be used as an effective design strategy. But, because of the variability of weather conditions in Washington DC relying on natural ventilation alone was risky. From the simulations different levels of natural ventilation had a significant effect on the heating and cooling loads of the HVAC system. As it is more difficult to control the rate of air exchange through opening the windows it was decided that mechanical ventilation would be the dominant form of fresh air supply to the house during the competition.

In contrast to the way the house has been designed to run during the competition, natural ventilation is an essential part of how the house performs in New Zealand. Szokolay's third purpose of ventilation, to promote heat dissipation from the skin to aid in the passive cooling of the human body (Szokolay 2004, 41), is integral to the concept of the First Light house. Large bi folding doors on either side of the central space open up and become an essential ingredient for maintaining thermal comfort during the summer. In combination with shading, ventilation has been used in the First Light house to reduce energy use both during the competition and throughout the year in New Zealand. 


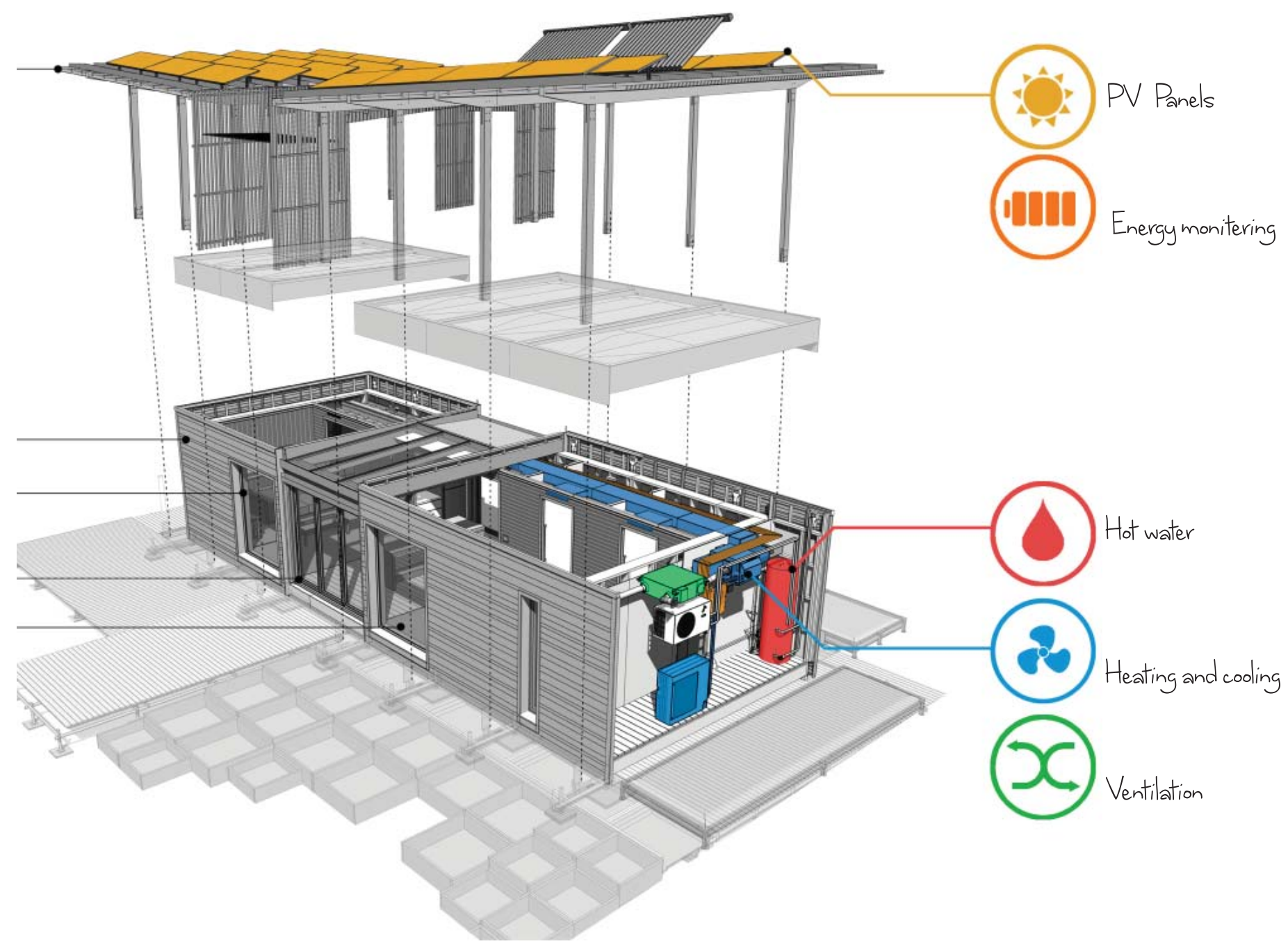

Figure 55: Diagram of the active technologies in the final design og the First Light home 


\section{ACTIVE DESIGN}

\section{Mechanical system}

\subsection{The final model}

Where the passive controls discussed in the previous chapters could not fully ensure thermal comfort an energy-based mechanical system was used to supplement their performance. In the First Light house the passive controls were designed to reduce the energy load of the heating, ventilation and air conditioning (HVAC) system. A final 'super model' was created from the results of the initial simulations and included all of the design changes that had occurred. This model represented the final design that would be constructed and was used to size the HVAC system and to simulate the final energy use of the house. Table 12 below presents the final construction details of the building elements that were used in the new model.

\begin{tabular}{llr}
\multicolumn{1}{c|}{ ELEMENT } & \multicolumn{1}{c}{ DESCRIPTION } & R-VALUE \\
\hline Walls & $\begin{array}{l}\text { LVL Framing, Ecofleece Insulation, Plywood External and } \\
\text { Internal Linings. Cedar External Weatherboards }\end{array}$ & R-5.77 \\
\hline Floor - Timber & $\begin{array}{l}\text { LVL Joists, Ecofleece Insulation, Plywood Linings, Timber } \\
\text { Interior Finish }\end{array}$ & R-5.88 \\
\hline Floor - Concrete & $\begin{array}{l}\text { LVL Joists, Ecofleece Insulation, Plywood External Lining, } \\
\text { Concrete Internal Finish }\end{array}$ & R-6.48 \\
\hline Roof & $\begin{array}{l}\text { Plywood Framing, Ecofleece Insulation, Plywood External } \\
\text { Lining, OSB Internal Lining }\end{array}$ & R-1.11 \\
\hline Glazing - Windows & $\begin{array}{l}\text { 6mm Metro Low-E Glass, Argon Filled, Triple Glazing, Timber } \\
\text { Frames }\end{array}$ & \begin{tabular}{l} 
R-1.11 \\
\hline Glazing - Skylight
\end{tabular} \\
\hline Shading Canopy & Frames & Timber \\
\hline
\end{tabular}

Table 12: Construction R-Values used for final simulation 
The changes to each of the building elements were assembled incrementally and a new simulation preformed as each change was added to the original base model. Because each design change was tested independently of the others it was essential that as they were combined they still preformed as intended during the competition. Figure 56 shows the construction of the super model that was used to size the HVAC system.

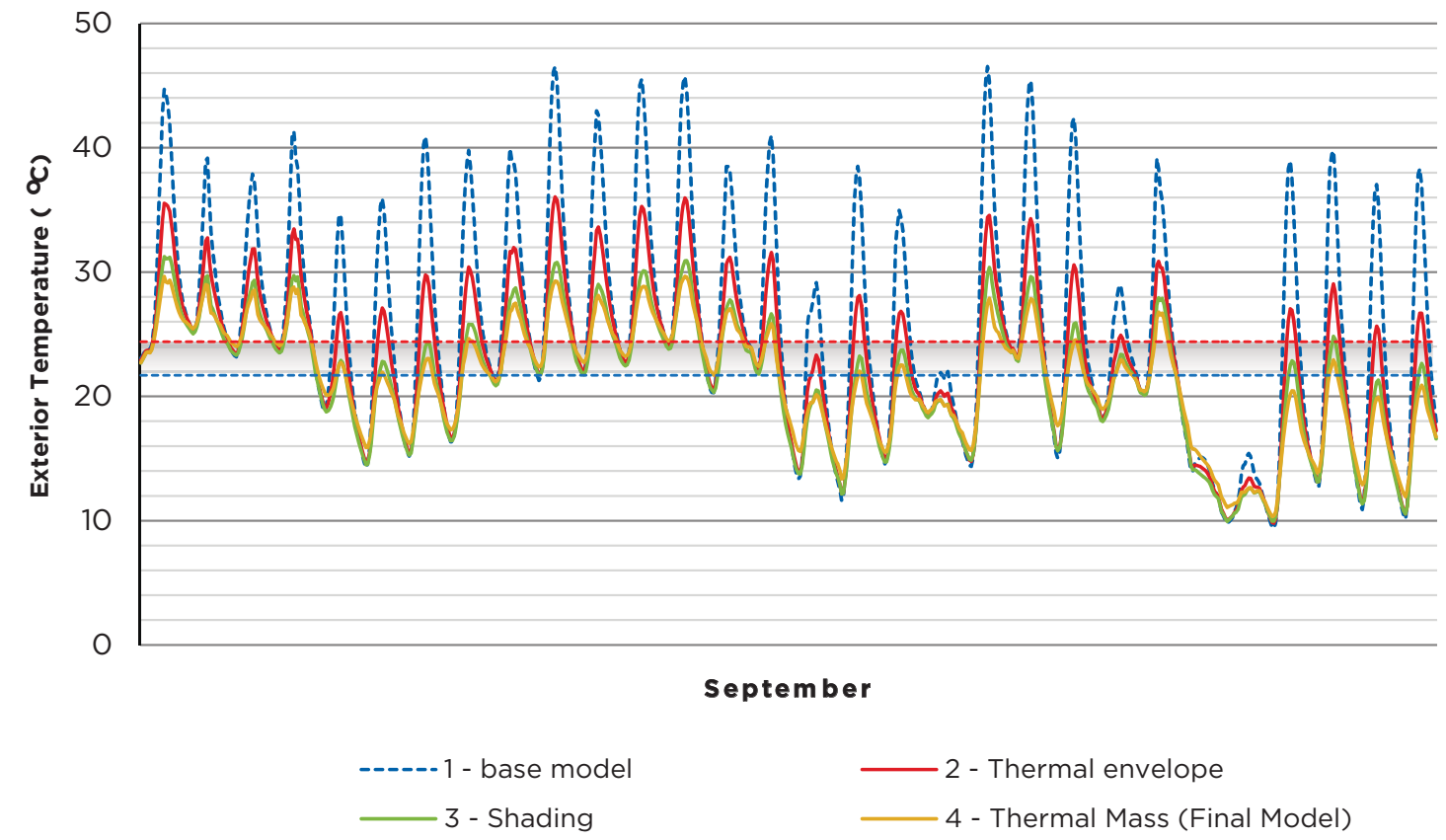

Figure 56: Incremental peformance of the final 'super model'

The aim of this series of simulations was to develop a performance specification for the HVAC system that established both the size and the annual energy consumption. The size of the system was based on the peak heating and cooling loads during the competition. The size of the system needed to meet the strict comfort zone requirements during the competition was larger than the system needed to meet the requirements for a year in New Zealand. For this reason the focus was on sizing the system to meet the requirements of the competition. Typically the heating or cooling capacity of a system would be sized to match the heat loss/heat gain on the worst conditions throughout the year, therefore design day data is used. But sizing a system based on a 10 day period in September is more difficult. The weather files that were using for the simulations were based on average weather conditions and so did not account for the possible worst case scenario during September. Because of the potential for a wide range of weather conditions in Washington DC at that time of 
the year, accurately sizing the system was a challenge. In order to reduce the risk of under sizing the system the simulations were run from August through to October. By studying the months before and after September there was a greater possibility of sizing the system to meet the potential worst case scenario conditions for both heating and cooling during the competition. Figure 57 shows the results of these simulations. In August there is very little need for heating with a peak cooling load of $4.5 \mathrm{~kW}$. Towards the end of September leading into October when the outside temperature was starting to drop the peak heating load was $2 \mathrm{~kW}$. When the simulations were run using design day data for a year in New Zealand the opposite requirements were desired with $4.5 \mathrm{~kW}$ for heating, and $1.5 \mathrm{~kW}$ for cooling. From these simulations the performance specification was developed from which the system was designed

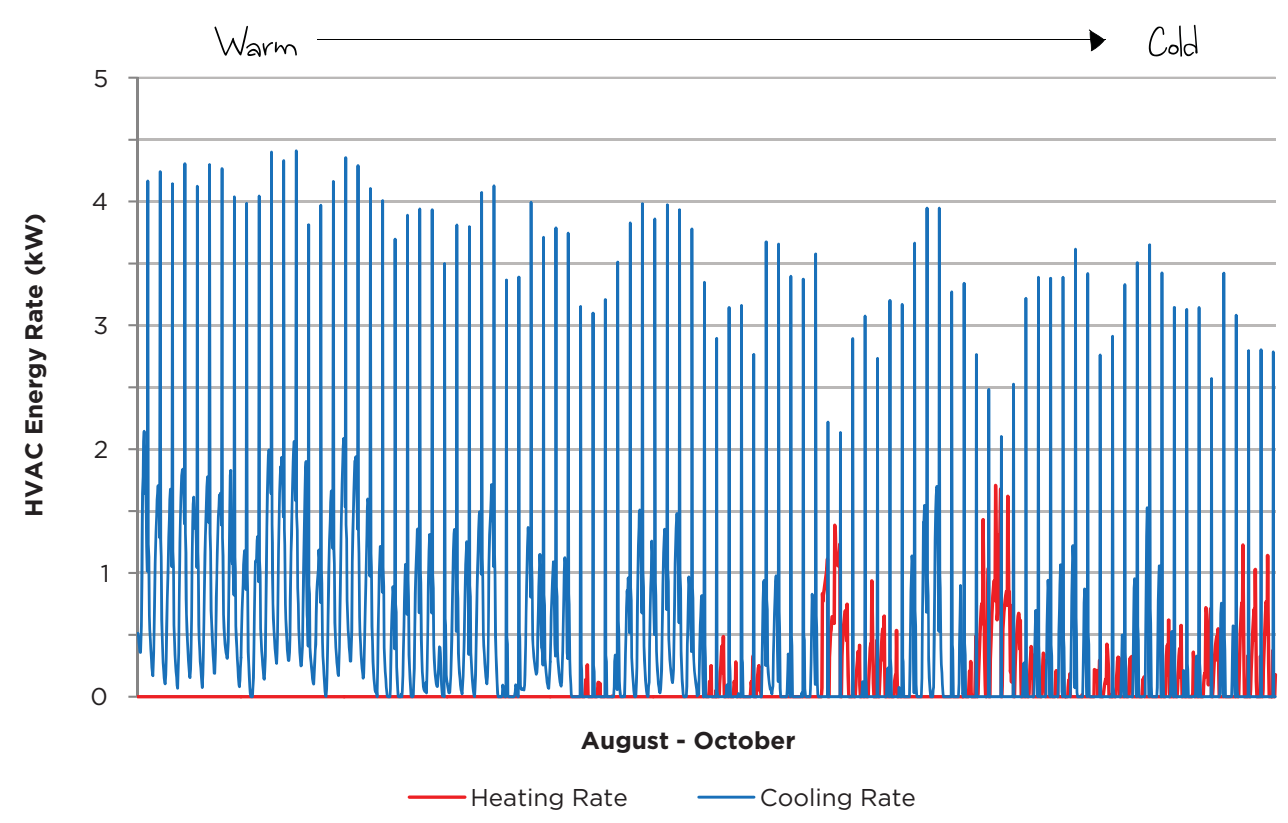

Figure 57: Simulated heating and cooling loads ( $\mathrm{kW}$ ) of HVAC system from August to October in Washington DC

\subsubsection{HVAC performance specification}

- Cooling Capacity $4.5 \mathrm{~kW}$ in cooling design conditions

- Heating Capacity $2.5 \mathrm{~kW}$ in heating design conditions

- $\quad$ COP 3.0 minimum

- $\quad$ Power Input $~ 1.50 \mathrm{~kW}$

- Power Supply 1 Phase, 230 V, $50 \mathrm{~Hz}$

- Guaranteed Operating Range outdoor -20 to $+35^{\circ} \mathrm{C}$ 


\subsection{Mechanical system design}

The original schematic design proposed a simple split-unit air conditioning system consisting of two high wall units at either end of the indoor space and a separate ventilation system. The development of a bulkhead that ran the entire length of the house opened up the opportunity to develop a ducted HVAC system where the heating, ventilation and air conditioning system could be combined and concealed in a mechanical shed. The ducted system allowed greater flexibility and control of the comfort zone compared to the standard indoor unit originally proposed. This flexibility allowed multiple outlets to achieve a more consistent internal temperature throughout the entire space. Aesthetically this was also an advantage as there was only a small supply air grille for each outlet, as opposed to the large indoor unit typically found in New Zealand domestic installations. Utilizing a ducted system also allowed easy integration with the energy recovery ventilation system (ERV). This was crucial for reducing the energy consumption of the heat pump side of the system while at the same time ensuring adequate fresh air. From the simulations $4.5 \mathrm{~kW}$ was the required output of the system. To ensure adequate air distribution throughout the entire space and that the system would meet the worst case scenario load the system needed to be oversized. The heat pump that was selected had a rated output of $7.1 \mathrm{~kW}$ for cooling and $8.0 \mathrm{~kW}$ for heating, with a rated input of $2.48 \mathrm{~kW}$ and $2.47 \mathrm{~kW}$ respectively. This resulted in a co-efficient of performance (COP) of 2.86 for cooling and 3.24 for heating, which was well within the desired performance requirements.

In order to maintain a healthy and comfortable indoor air quality, especially given how air tight the building had been designed, it was necessary to introduce a certain amount of fresh outdoor air. Because of the tight temperature band, natural ventilation could only be relied on when the outdoor temperature was within the comfort zone. From the simulations this air was often significantly cooler or warmer than the internal conditioned temperature and thus required energy to bring it within the comfort band even with mechanical ventilation. The purpose of the ERV was to precondition the fresh incoming air using energy from the exhaust air from the space. This minimized the energy use of the heat pump by reducing the difference between the input air temperature and the required output temperature, while at the same time ensuring there 
was ample fresh air. A centralized building management system, designed specifically for the house, controlled the flow of air to each of the four outlet grills to maintain the comfort zone within the space.

The system was designed to function as follows:

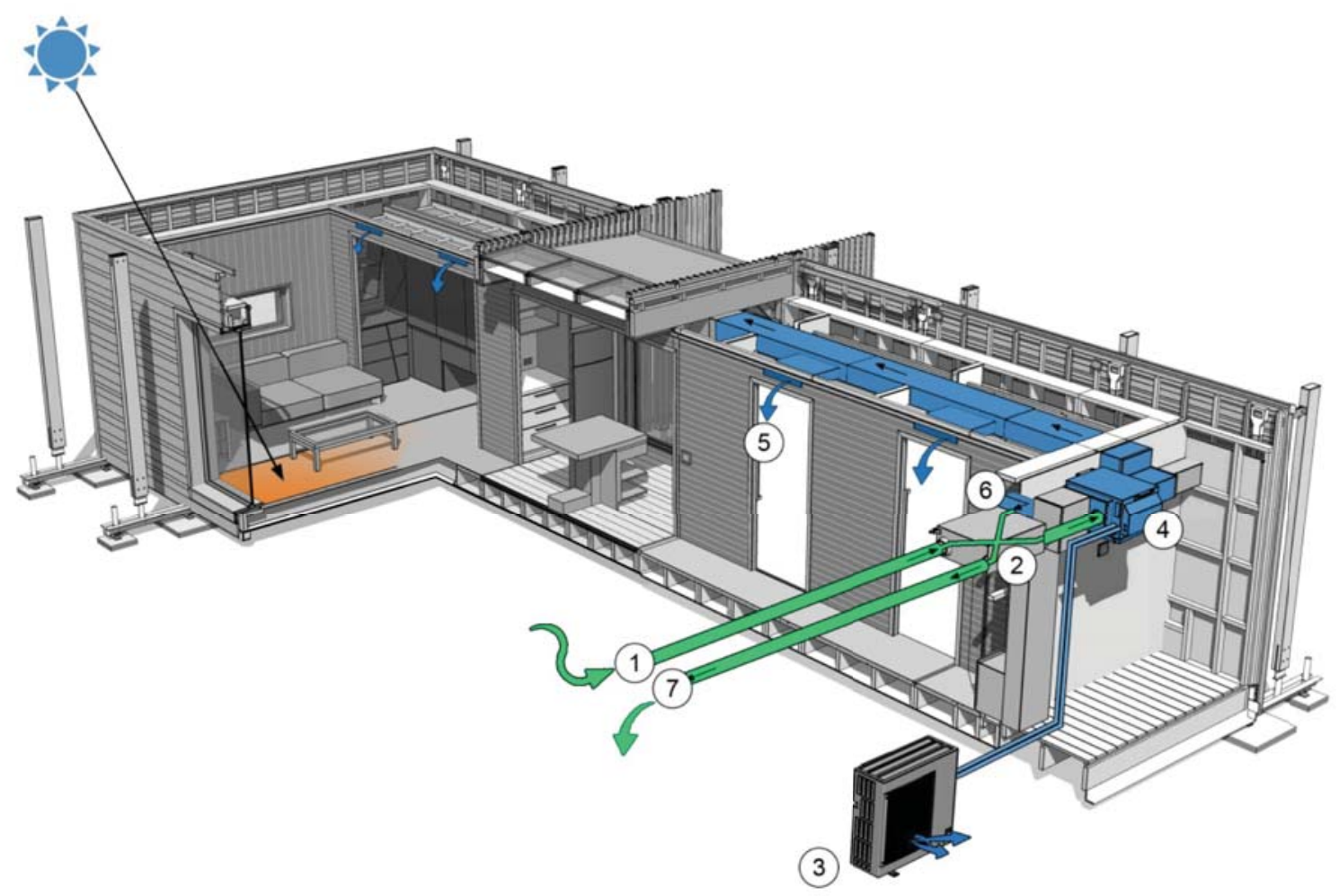

Figure 58: Diagram of HVAC system

1. Fresh outside air is drawn in from the outside

2. It is passed through an energy recovery ventilation unit system (ERV) which recovers useful energy from outgoing stale air and before it is expelled to the outside

3. A highly efficient outdoor condenser draws warmth from or dumps into, the outside air and transfers it to the fresh in coming air once it has passed through the ERV

4. A heat pump blows this conditioned, fresh air through insulated duct work that runs the length of the building

5. Specially designed air diffusers throw air into the interior space creating a comfortable living environment throughout the entire house

6. A portion of the air from inside the house is drawn back out through a return air duct. It is re conditioned and circulated back through the house while a smaller portion of air is extracted and replaced with fresh incoming air. The system thus maintains a comfortable and healthy indoor environment no matter what the season. 


\subsection{Comfort Zone energy use}

Once the HVAC system was designed, a simulation was performed to determine the worst case scenario energy load of the HVAC system during the competition period, in order to size the photovoltaic array. To do this a series of weather files were created for the competition based on real life weather data from the last 15 years for the 10 day period. Once the data was collected, every hour of the day was then averaged and a standard deviation model used to create the worst $5 \%$ and best $5 \%$ for several weather variables. These weather variables included dry bulb temperature, direct and diffuse solar radiation, precipitation, wind speed, cloud cover and relative humidity. The weather values were then collated into eight different weather files, each expressing different weather phenomena that could be experienced during the competition. These eight weather files were expressed as shown below (Appendix $C$ gives details of each weather file )

- CCS (Cold, Calm and Sunny)

- CWS (Cold, Windy and Sunny)

- $\quad$ CCR (Cold, Calm and Raining)

- CWR (Cold, Windy and Raining)

- HCS (Hot, Calm and Sunny)

- HWS (Hot, Windy and Sunny)

- HCR (Hot, Calm and Raining)

- HWR (Hot, Windy and Raining)

- WASH (Washington weather file)

These weather files were then used in Energy Plus to determine the energy use of the mechanical system as designed under different weather scenarios during the competition.

The challenge with designing a system for just a 10 day period, especially in Washington DC in September, is predicting the weather. In the past Solar Decathlons the weather has played a major role in determining which teams are successful during the competition. Creating eight different weather scenarios helped to identify and improve areas of weakness in the First Light house under particular atmospheric conditions. The results of these weather file simulations on the final design can be seen in Figure 59. The First Light house performed best in the colder temperatures of 
Washington's September climate resulting in less than 20kWh (CCR, CWR) consumed for heating and cooling across the competition, even when these conditions were combined with a high level of solar radiation the HVAC system consumed less than 50kWh (CCS, CWS). On the other hand, when conditions were hot (HCS, HWS, HCR, HWR) the energy consumption of the HVAC system was far greater. The worst case scenario for the First Light house was a day that was hot, calm and sunny. When these conditions occurred during the competition period the energy consumption of the HVAC system reached close to $100 \mathrm{kWh}$.

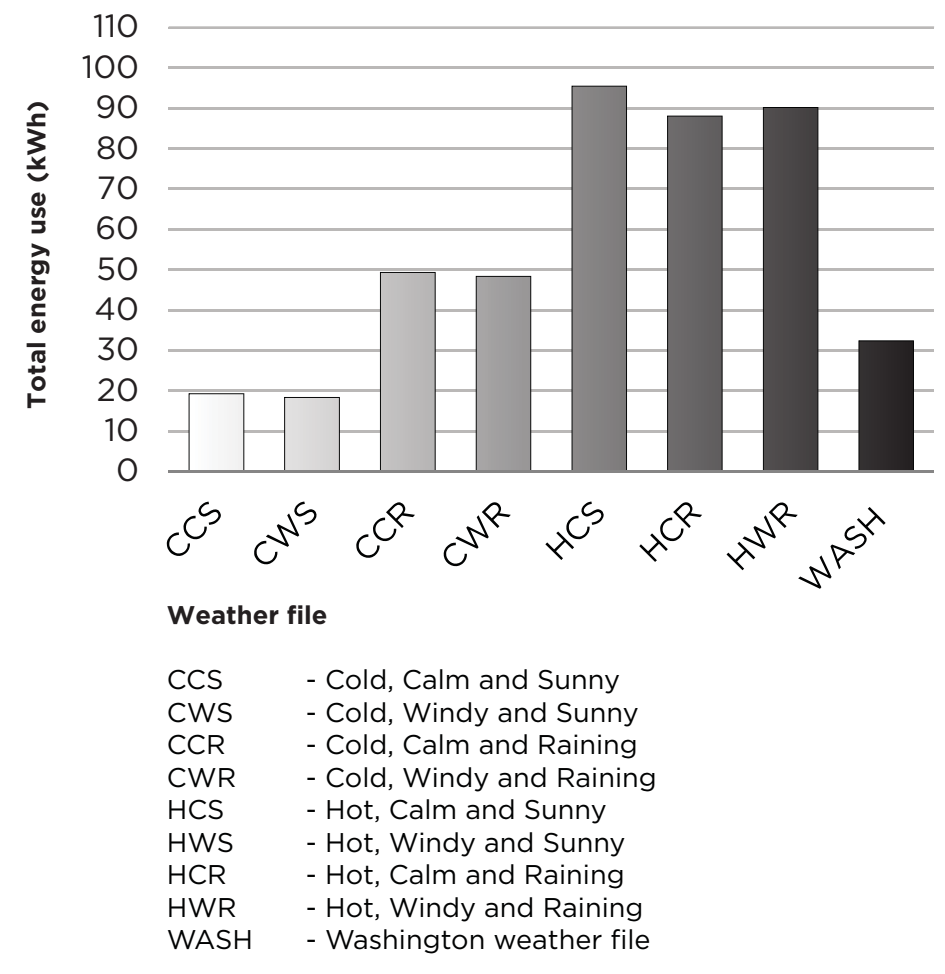

Figure 59: Comparison of Total energy use of HVAC system during competition under 8 different weather scenarios

For a house that had been designed to a very high level of energy efficiency this was a significant amount of energy for just heating and cooling. Table 13 shows the conditions the worst case weather file was based on. This series of simulations would prove to be extremely beneficial during the competition period for understanding the strengths and weaknesses of the house. From a tactical perspective these simulations helped in making decisions on how the house should be run during the competition. 


\begin{tabular}{ccc}
\hline \multicolumn{1}{c}{ Weather File 2 (Hot Calm Sun) } \\
\hline Direct Solar \\
Diffuse Solar \\
Wind Direction \\
Wind Speed & Best conditions for $\left.\begin{array}{l}\text { High 5\% } \\
\text { High 5\% }\end{array}\right)$ \\
Temperature & energy generation & $\begin{array}{c}\text { Southerly } \\
\text { Low 5\% } \\
\text { High 5\% point } \\
\text { Precipitation } \\
\text { Cloud Cover }\end{array}$ \\
Relative Humidity & Low 5\% \\
Low 5\% \\
High 5\%
\end{tabular}

Table 13: Conditions of worst case weather file

As with many of the previous simulations it is the hot, sunny days during the competition that would consume the largest amount of energy. These conditions were experienced when there were also high levels of direct and diffuse solar radiation, ideal for energy generation. Therefore, these conditions were not taken as the worst case scenario for the competition. Instead the energy consumed when conditions were hot, calm and raining were used in the following simulations to measure the total energy use of the house. The conditions were the same as above with low 5\% direct and diffuse solar radiation. During these conditions a total of $90 \mathrm{kWh}$ of energy were consumed over the course of the ten days. With the addition of the energy use of the controls and building management system the total energy that would be consumed to achieve full points in the comfort zone contest was $98.78 \mathrm{kWh}$. (Table 14)

\begin{tabular}{ll}
\hline Comfort Zone & \\
\hline Heating, Cooling and Ventilation & $90.00 \mathbf{k W h}$ \\
Touch Screen Display (BMS) & $6.27 \mathbf{k W h}$ \\
BMS Controls & $\mathbf{2 . 5 1 k W h}$ \\
\hline
\end{tabular}

Table 14: Estimated energy use of comfort zone contest

The energy use under these climatic conditions despite being high, was not surprising due to simulations performed throughout the design process. But the performance of the HVAC system, when simulated over an entire year in Wellington, New Zealand was extremely energy efficient, consuming only $1750 \mathrm{kWh}$, or $22 \mathrm{kWh} / \mathrm{m}^{2}$ per year. Even though there were parts of the design not totally suited to the high temperatures of Washington DC, the house performed exceptionally well under Wellington conditions. As predicted the greatest amount of energy needed to 


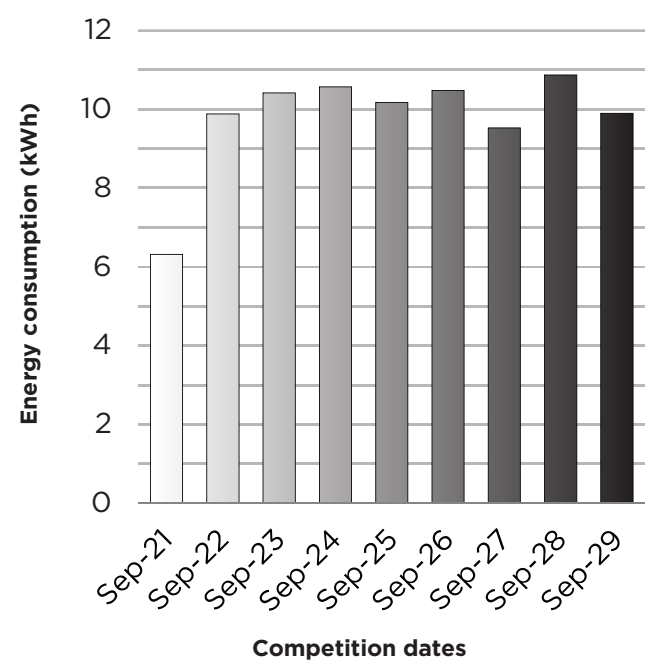

Figure 60: Daily energy consumption ( $\mathrm{kWh}$ ) of HVAC system during competition under the simulated weather scenario; hot, calm and raining

maintain comfort occurs during the winter months, with $200 \mathrm{kWh}$ alone being consumed during July (Figure 61). As these were the conditions the First Light house was designed to meet, these results were presented to the engineering judges of the competition. But, even if the judges scored the design highly in the engineering contest, to win the Solar Decathlon the house had to perform on the day, in real life conditions in Washington DC. How the house did in its home climate was inconsequential if it could not perform during the competition. Fully understanding these worst case scenarios was fundamental to the success of the First Light house.

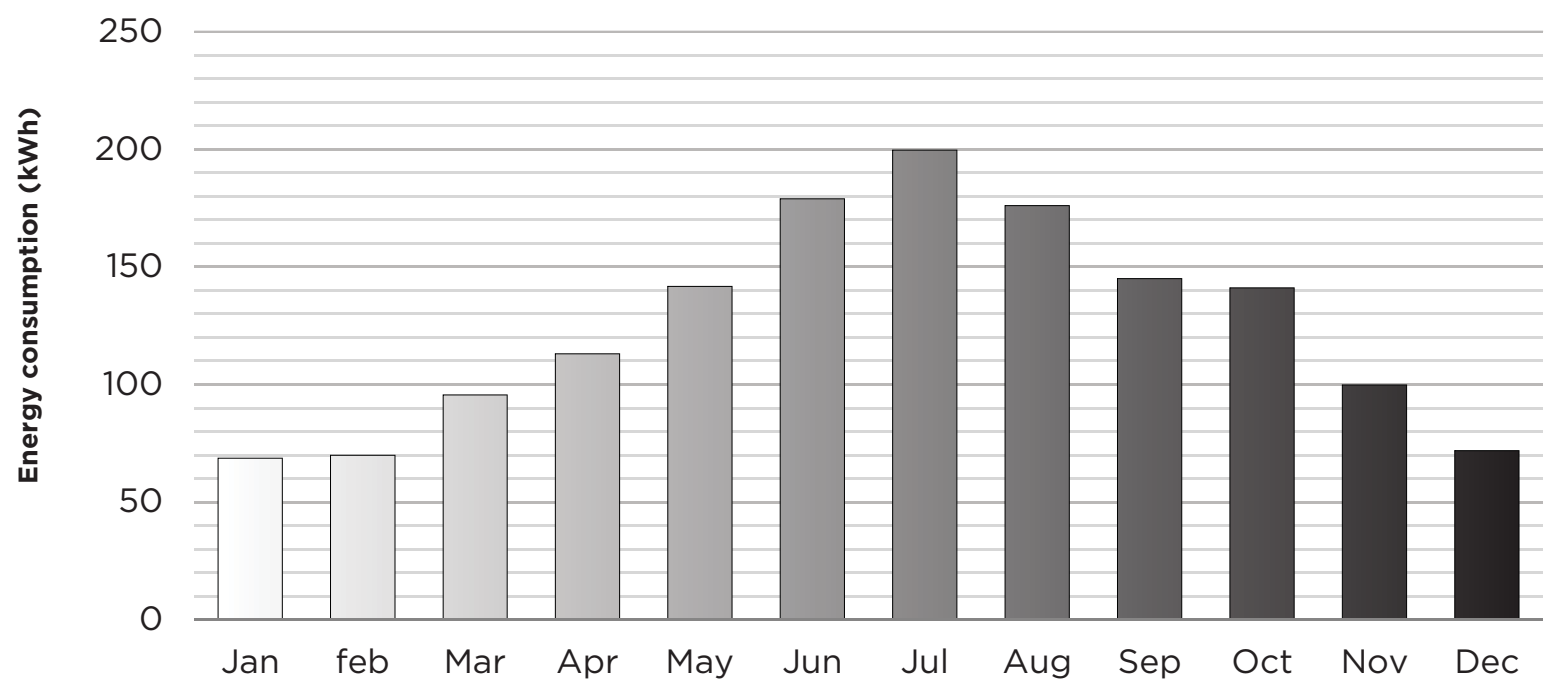

Figure 61: Monthly energy use of the HVAC system (kWh) in Wellington, New Zealand 


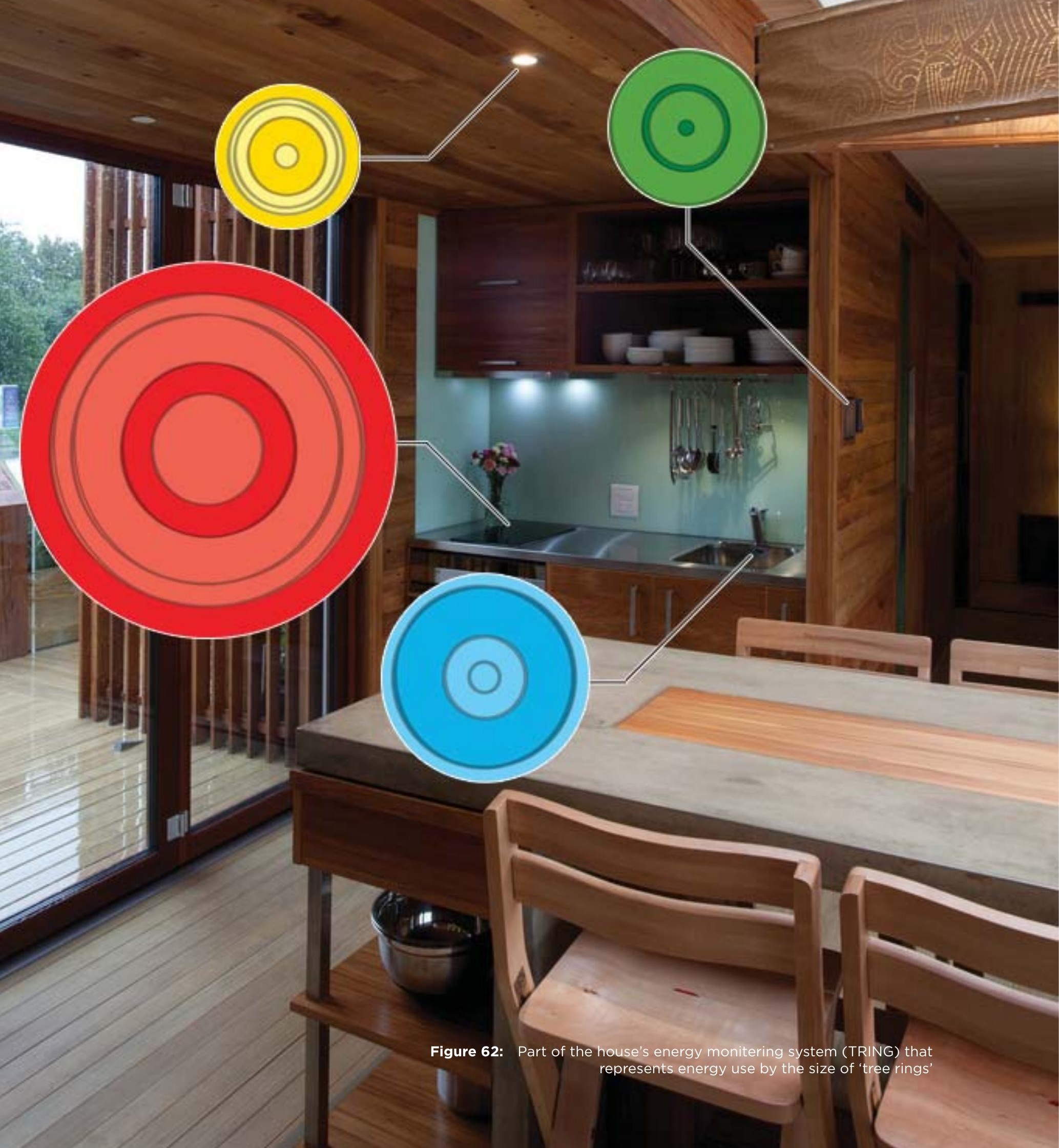




\section{CHAPTER 9 Energy use}

Having sized the mechanical system and established its energy use, the next step before sizing the photovoltaic array was to establish the energy use of the rest of the house. Before the competition a schedule of the other three, measured contests was distributed to all of the teams which outlined what would be tested and how often during the 10 days (Appendix D). This allowed teams to predict accurately how much energy would be needed for hot water, appliances and home entertainment. In the First Light house, each of the three areas was developed with the same rigour as was used in the comfort zone contest. This thesis will briefly introduce each of the three areas and some of the decisions that were made to reduce energy use. As a large part of these three areas are not directly related to the architectural decisions related to performance that were made throughout the design process they will not be discussed in as much detail as for the comfort zone contest in previous chapters.

The organizers of the competition provided teams with a detailed timeline of the competition which outlined when energy would be consumed for heating and cooling, appliances, home entertainment and lighting (see Appendix D). In the First Light home the electrical loads came from;

- Heat pump heating and Cooling

- Energy recovery ventilation

- $\quad$ BMS and touch screen display

- Hot water system and water pumps

- Appliances (refrigerator, freezer, washing machine, hydronic dryer, dishwasher, oven, hob, range hood, kettle)

- $\quad \mathrm{TV} /$ Home entertainment system and computer

- $\quad$ LED lighting

The schedule that was produced mapped out every element in the home that would consume energy throughout the competition. With this information it was easy to see the effect of each of the three areas on the total energy use and where further reductions use could be made. 
$+\frac{1}{x-1}=$

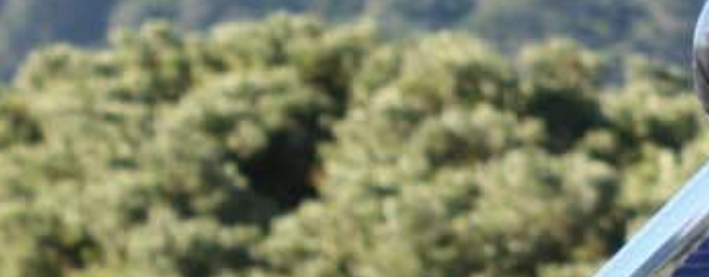

a. $x$ र

a $1,+2$

iftingaty

thy

$15 \times x+2$

$2 x+1$

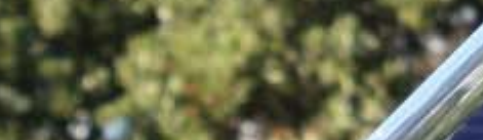

1.

(1)

27 $\lim _{-1}$ 


\subsection{Hot water}

\begin{tabular}{|ll}
\hline Hot Water & $\mathbf{3 k W h}$ \\
\hline Hot Water & $\mathbf{0}$ \\
Water pumps & $\mathbf{3 k W h}$ \\
\hline
\end{tabular}

Table 15: Estimated energy use for hot water contest

The first of these is the hot water contest. During the competition 15 gallons ( 57 litres) of water was drawn off 16 times during the contest week. At each water draw off the water temperature had to be at least $43.3^{\circ} \mathrm{C}$ $\left(110^{\circ} \mathrm{F}\right)$ to be eligible for full points. To meet these requirements, it was essential that the hot water system was designed to use as little energy as possible. In New Zealand, hot water accounts for approximately $30 \%$ of the average energy use of a New Zealand home (Isaacs, Camilleri, et al. 2010). With dramatically improving solar hot water technology and high levels of sunshine, solar hot water is becoming an accessible, convenient and affordable way of reducing energy use in NZ. The current uptake of solar heating in New Zealand is very low, with only $2 \%$ of houses use solar energy for heating water (Pollard 2008, 53). Using the latest in solar hot water technology the aim was to gain full points for the hot water contest using no energy generated from the photovoltaic array. This would mean designing and sizing a solar hot water system that would use only the sun's energy to heat water. A wide variety of different products and systems were tested with the major focus on flat plate versus evacuated tubes. Figure 65 shows one of the initial investigations, which compared thirty evacuated tubes against a flat plate of the same size with varying levels of solar radiation based on actual data for Washington DC. Along with more traditional systems two new innovative technologies, both developed in New Zealand, were also investigated including an evacuated flat plate solar panel and a parabolic solar collector (Figure 64).

From these investigations, the decision on which collector to use came down to the drying cupboard, a building element that was proposed early on in the design process and was being developed in parallel with the design of the home. One of the contests within the appliances competition challenged teams to wash and dry six bath towels in only three hours. Ironically, in a competition that challenged the highest levels of energy efficiency the organizers had created a situation where teams 


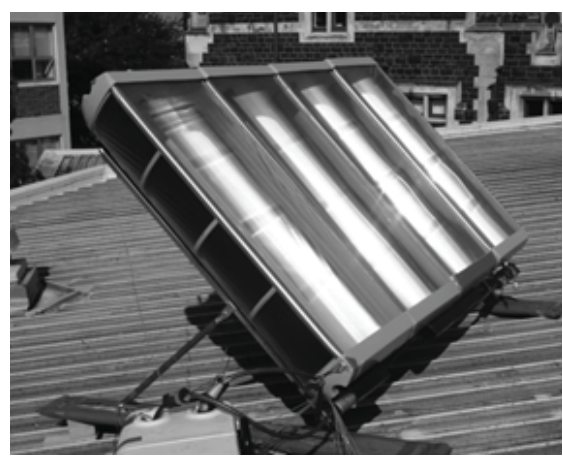

Figure 64: Parabolic solar collector (Source: Image courtesy of Anrew Wallace)

had no choice but to use a mechanical dryer, an appliance which typically uses large amounts of energy. In the traditional kiwi bach clothes would be dried in the sun outside on the deck, meaning there was no need for a dryer. Therefore, from an early stage in the design process the team investigated how to meet the requirements of the competition without a traditional dryer. The solution was a hydronic drying cupboard which used hot water from the sun and the movement of air to dry towels. The concept, based on ideas that have been around for generations, utilized the sun's energy to heat water. The water was pumped through a heat exchanger at the base of the insulated cupboard which warmed the air as it was blown through the towels hung inside the dryer.

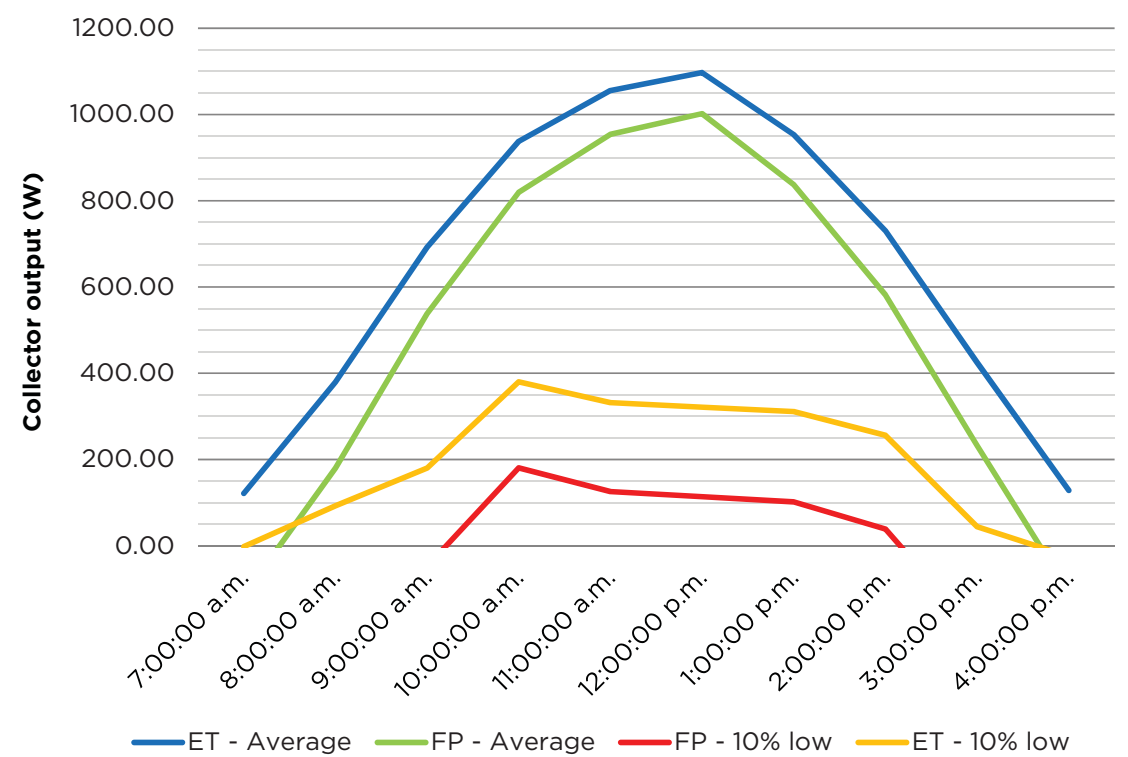

Figure 65: Hourly output (W) of Evacuated tube and Flat plate solar hot water systems on an average and $10 \%$ low day of solar radiation in New Zealand 


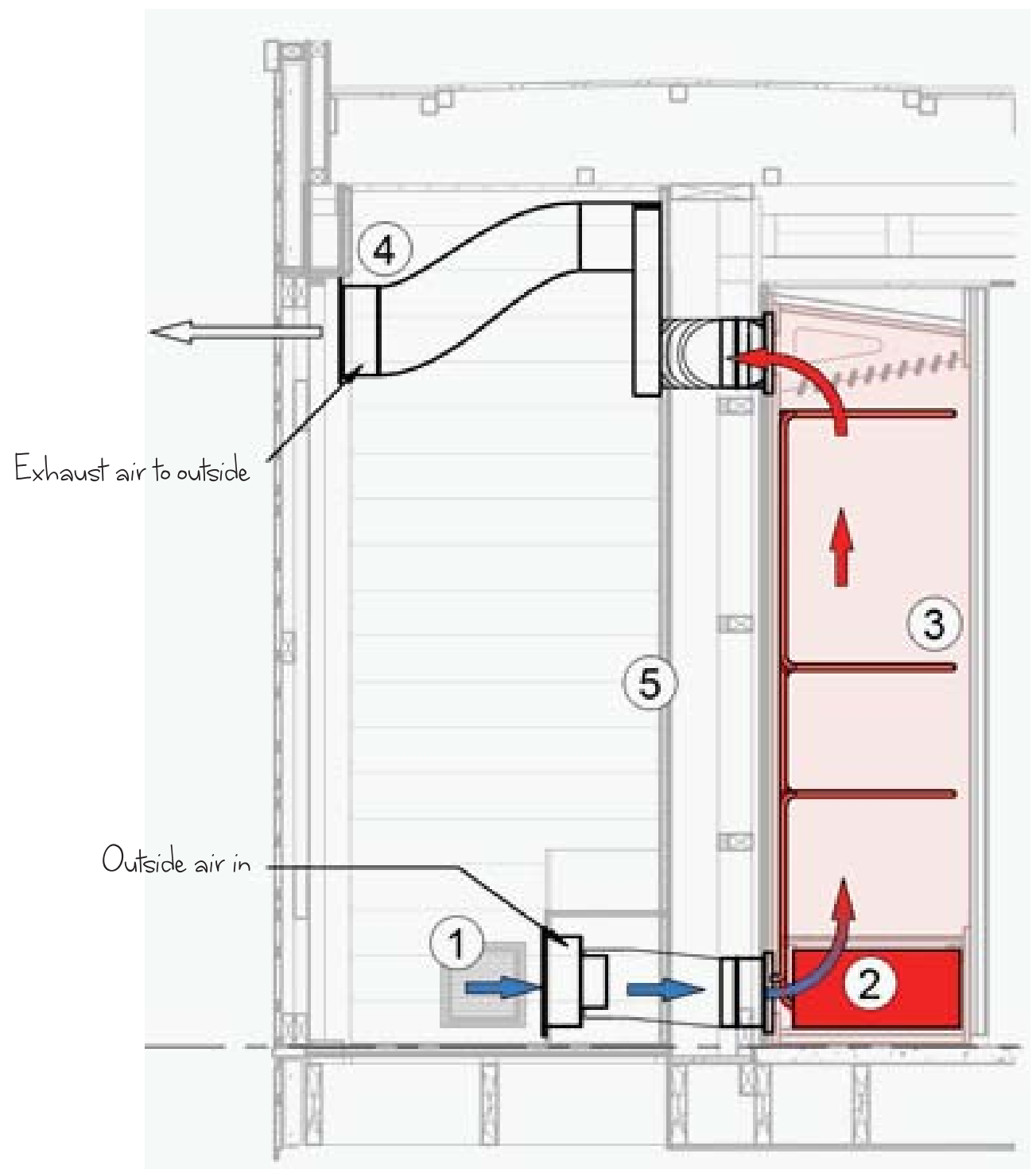

Figure 66: Diagram of hydronic drying cupboard

The following is a brief explanation of how it was designed function

1. A small $60 \mathrm{~W}$ fan draws in air from the outside

2. The air is passed through a heat exchanger at the base of the dryer. Hot water, heated by the sun is passed through the heat exchanger heating the air as it passes through.

3. Towels, hung on heated copper towel rails, dry as warm air rises within the drying cupboard

4. A small exhaust air fan made from a recycled computer fan helps to draw out the warm air from inside the dryer to the outside

5. A programmable logic controller (PLC) controls the flow of air and water inside the drying room. A sensor inside the drying room provides information to the controller about temperature and humidity. Using 
this information it controls air flow and temperature within the cupboard to maximize the drying potential and minimize drying time. The drying room also acts as a heat dump during periods of high solar insolation or in case the temperature in the tank reaches $90^{\circ} \mathrm{C}$. It is a way of releasing some of the energy to safe and manageable levels without losing all of the heat.

An initial mockup of the drying cupboard proved that the concept was very efficient, with the only energy consumed being by the water pump and two small fans (Figure 67). From the initial tests the hotter the water was, the more efficient the system and the faster the towels dried (Appendix E). From the simulations evacuated tube collectors were most effective for achieving high temperatures and were therefore selected for the First Light house. The system was sized to meet the hot water needs of the house during the competition for the water draw offs, the dishwasher and the hydronic drying cupboard. It was calculated that $10.4 \mathrm{kWh}$ of energy would need to be generated per day by the evacuated tubes in order to meet these requirements. From this information a forty tube system was designed with a highly insulated $360 \mathrm{~L}$ hot water tank to store any excess energy that was generated on sunny days. For periods of low solar insolation, especially in winter in New Zealand, an air to water heat pump was included in the design as an energy efficient back up to the solar collectors.
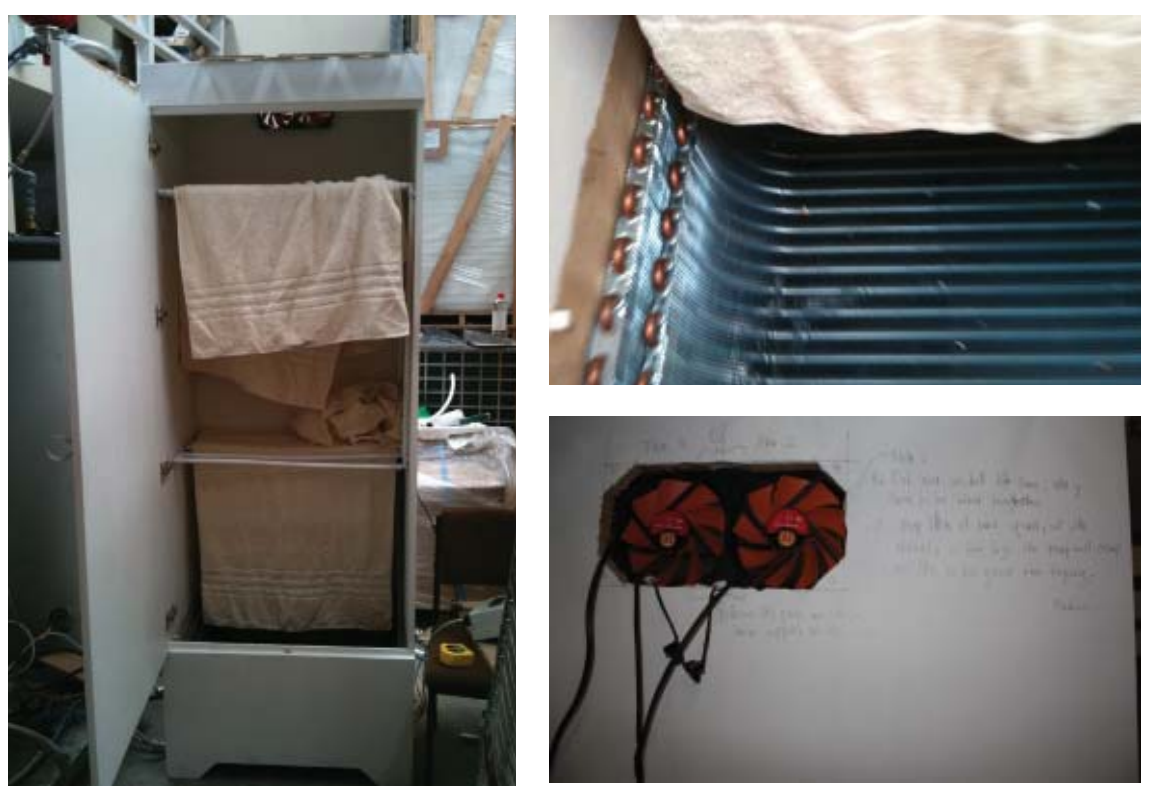

Figure 67: Images of dryer mock up used for the intial tests 


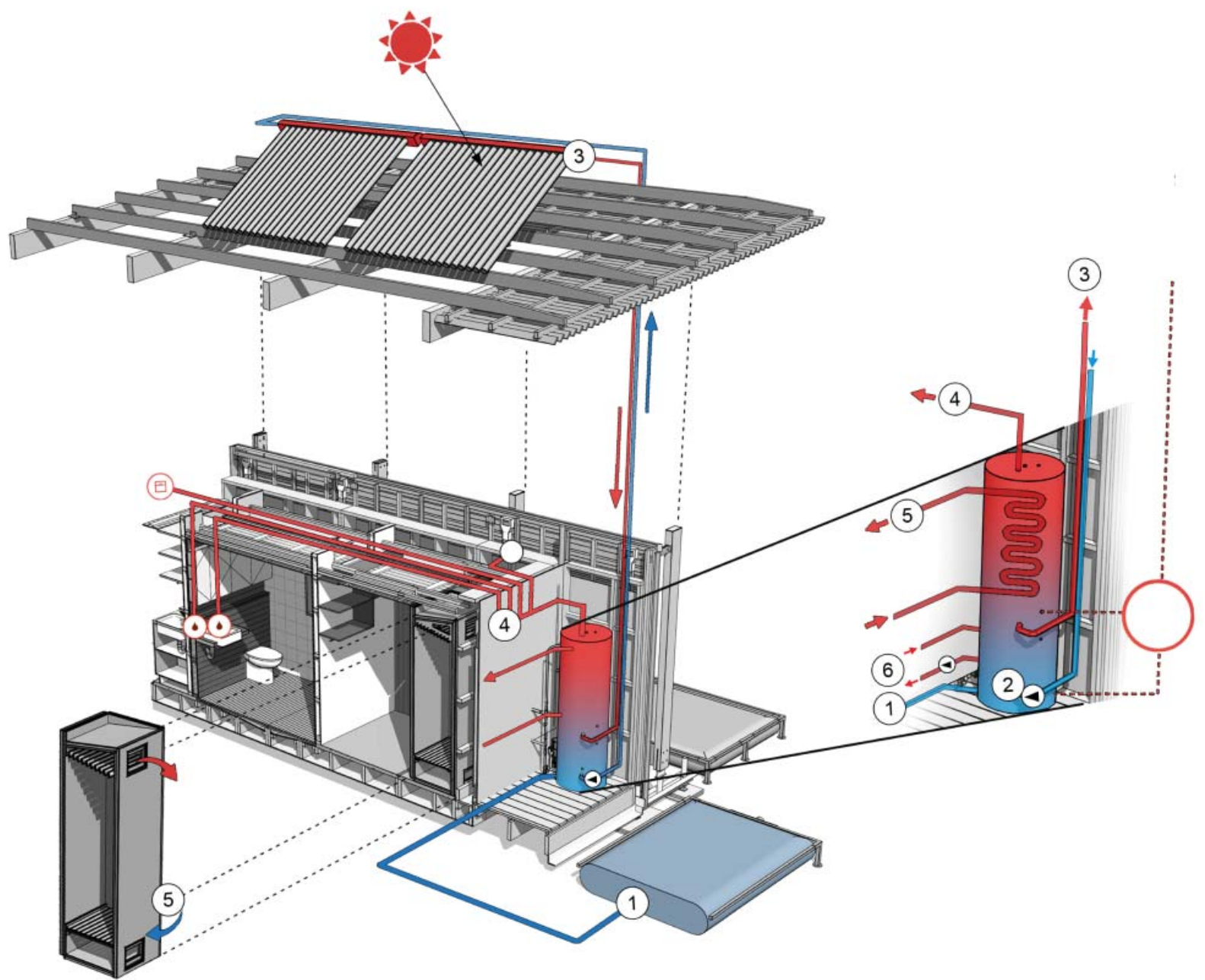

Figure 68: Diagram of Hot Water system

The hot water system in the First Light house was designed to function as follows:

1. Fresh water from the supply water tank is pumped into the bottom of the hot water tank

2. A 360 litre, super insulated hot water tank stores the hot water generated by the solar panels

3. 40 Evacuated tubes harness free solar energy to heat up water: as the heat pipes within the tubes heat up a solar controller senses the rise in temperature and pumps water up to the canopy to be heated

4. A hot water manifold supplies hot water to the house, via separate hot water lines running to each outlet

5. A closed loop hot water circuit pumps water to the hydronic drying room where fresh air is heated in order to dry clothing and towels quickly and efficiently

6. An air to water heat pump provides back up heating for the system for periods of low sunshine

The hot water system was sized so that no extra energy would be needed 
to be generated by the PV array to meet the requirements during the competition. It was found in the simulations that even during periods of low solar radiation in September the evacuated tubes would produce enough energy to meet the hot water draw offs and run the dryer.

\subsection{Appliances}

\begin{tabular}{|ll|}
\hline Appliances & $10.35 \mathrm{kWh}$ \\
\hline Refrigerator/freezer & $\mathbf{4 . 7 5 k W h}$ \\
Clothes Washer & $0.82 \mathrm{kWh}$ \\
Clothes Dryer & $\mathbf{2 . 8 8 k W h}$ \\
Dishwasher & $\mathbf{1 . 8 9 k W h}$ \\
\hline
\end{tabular}

Table 16: Estimated energy use for hot water contest

In the appliances contest the fridge/freezer, washing machine, clothes dryer and dishwasher each had to meet a set of performance criteria that was monitored during the competition. These criteria were used to ensure that the appliances in the home functioned as intended but were also a way of simulating energy use in the house during the contest week. Compared with the 'hot water' and 'comfort zone' contests above, for most teams, both the appliance and home entertainment competitions were not weather dependent. Full points were gained by simply running the appliances at the required time as long as they meet the performance criteria. In the case of the dishwasher, washing machine and refrigerator/ freezer ${ }^{1}$ this was extremely simple. But, in the First Light house, with no mechanical dryer, this was slightly more complicated. As described above a method for reducing the house's energy consumption was to dry the six bath towels required in the competition without using a traditional dryer, something that had not been tried before in any of the previous solar decathlon competitions. Using a traditional dryer it was estimated that with 8 drying cycles throughout competition week the dryer would

For this project, Fisher and Paykel used an existing fridge the E331T and significantly

improved its performance to reduce its energy use to meet the design requirements of the competition. The labelled energy consumption of the E331T was $405 \mathrm{kWh} / \mathrm{yr}$ as per AU/NZ standards. With improvements to the condenser, the type of refrigerant used and the installation of the new 'Britten compressor', which was also smaller and had enhanced temperature control, the total energy consumption of the fridge was reduced to $200 \mathrm{kWh} / \mathrm{yr}$ or $23 \mathrm{~W}$. 
consume close to $20 \mathrm{kWh}$ of energy. Using the hydronic dryer, to dry the same amount of washing would only use $2.88 \mathrm{kWh}, 85 \%$ less than a traditional dryer. The clothes dryer competition was worth 40 out of 100 available points for the appliances contest. Traditionally, teams target this contest for full points. Because the innovative drying cupboard was fully reliant on the collection of solar hot water there was a risk that despite the significant energy saving, if there was period of no sunshine at the beginning of the competition it might be difficult to get the water temperature hot enough to completely dry the towels within the period of time allowed. If this was the case though, all teams would only be generating small amounts of energy from their photovoltaic array, but their energy hungry dryers would still be consuming energy. If there were low periods of sunshine, the dryer might lose points in the appliances contest but would make up these points and be an advantage compared to other houses in the energy balance at the end of the competition. Because it was also an innovative and unique design solution there was also the potential to gain points in the subjective engineering contest.

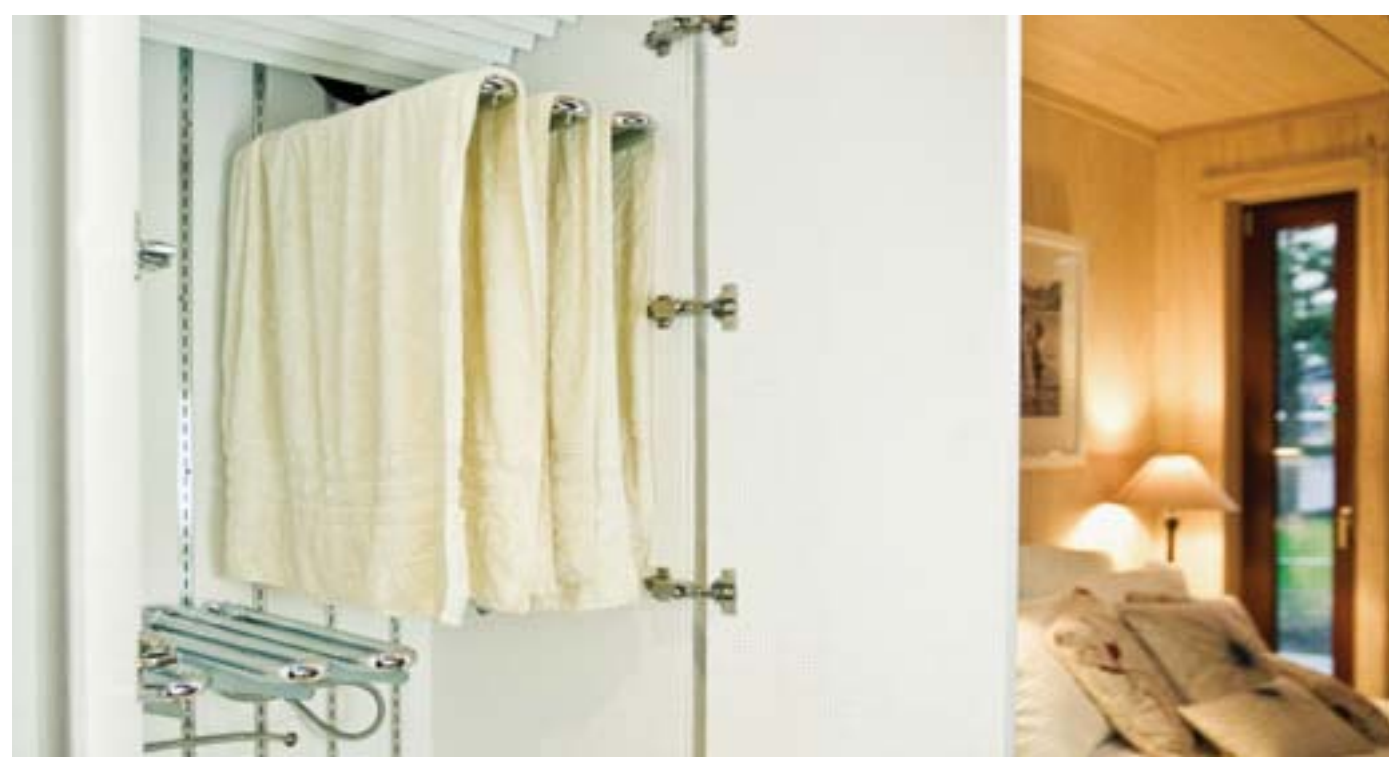

Figure 69: Completed drying cupboard 


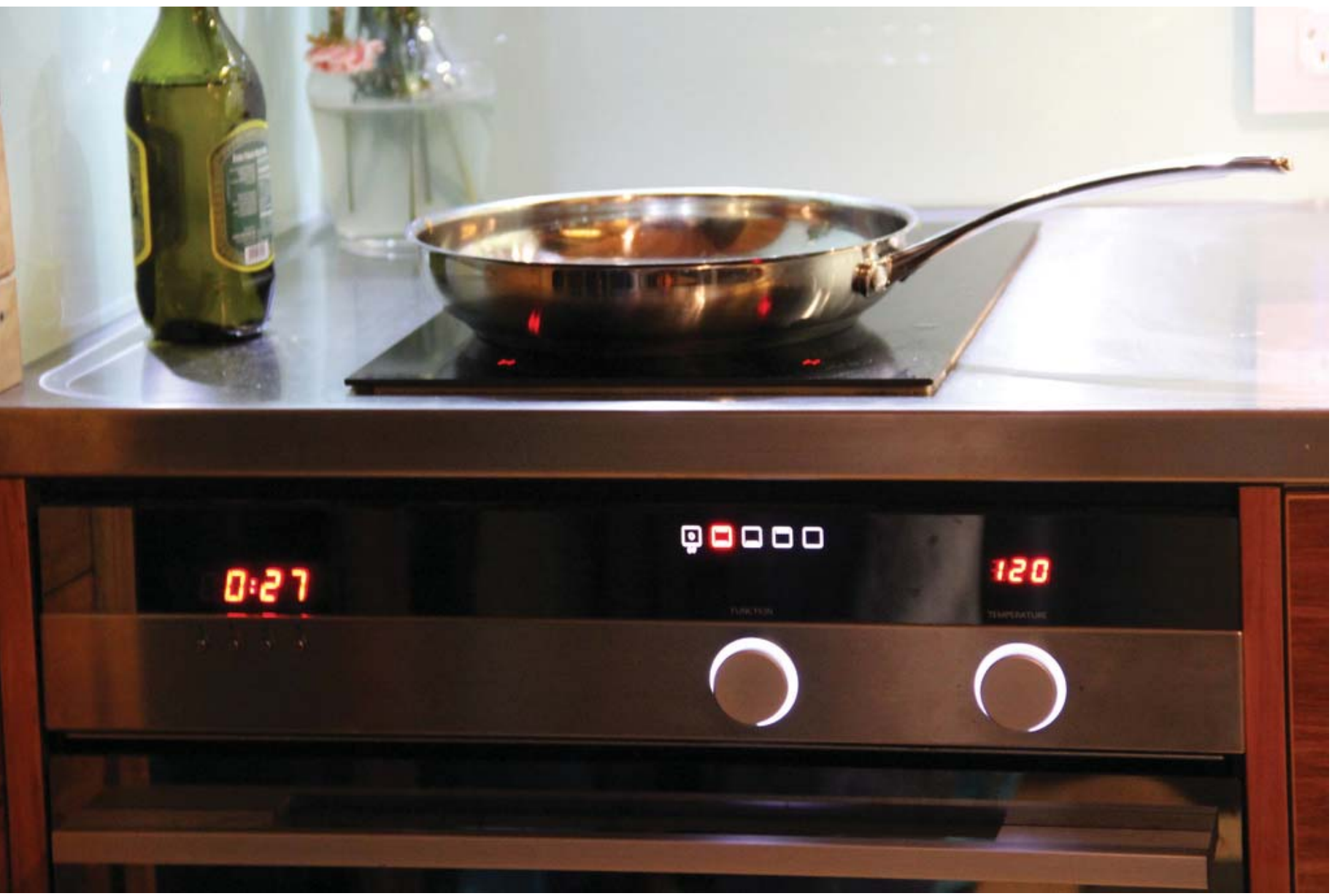

Figure 70: Fisher and Paykel applainces 


\subsection{Home entertainment}

\begin{tabular}{ll} 
Home Entertainment & $\mathbf{3 2 . 3 4 \mathbf { k W h }}$ \\
\hline Lighting & $\mathbf{6 . 1 2 k W h}$ \\
Induction Hob (Cooking) & $\mathbf{7 . 7 8 k W h}$ \\
Rangehood & $\mathbf{0 . 4 0 k W h}$ \\
Dinner Party 1 & $\mathbf{8 . 4 3 k W h}$ \\
Dinner Party 2 & $\mathbf{4 . 7 7 k W h}$ \\
TV & $\mathbf{2 . 2 8 k W h}$ \\
Computer & $1.58 \mathbf{k W h}$ \\
Movie Night & $1.00 \mathbf{k W h}$
\end{tabular}

Table 17: Estimated energy use for Home entertainment contest

As with the appliances contest, home entertainment was almost entirely an objective contest where full points were gained by turning on the lights, tv and computer and boiling a certain amount of water during the specified periods. As with the appliances contest it was essential that everything in the house was appropriately selected for the competition and was low energy. From tests, an induction hob was the most efficient way of boiling water, the oven incorporated extra insulation to reduce heat loss, the tv and computer were both energy star appliances selected specifically for the project, and LED lighting throughout the entire house ensured an enhanced lighting experience although using less energy than with conventional lighting, as might be found in a traditional kiwi bach. Within the home entertainment contest there were also 15 points out of 100 allocated to a movie night and two dinner parties which were completely judged by team members from other teams. Two specialty 'low energy' meals were designed to showcase New Zealand cuisine and culture (Appendix F). 


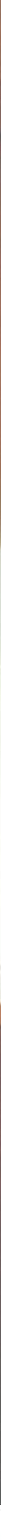




\subsection{Total energy use}

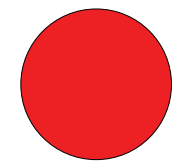

Comfort Zone,

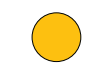

Applainces,

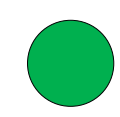

Home entertainment,

Hot Water,

\begin{tabular}{|c|c|c|}
\hline Comfort Zone & & 98.78kWh \\
\hline Appliances & & $10.35 \mathrm{kWh}$ \\
\hline Home entertainment & Totalectimentedenercusco & $32.34 \mathrm{kWh}$ \\
\hline Hot Water & lolal esilmaled energy use & $3.00 \mathrm{kWh}$ \\
\hline
\end{tabular}

Table 18: Total Estimated energy use of the First Light house during the competition

Once all of the load data was input into the schedule of events during the 10 days the total energy consumption of the home could be calculated. The graph below shows the house's energy use per day throughout the contest week. The total contest power use of $145 \mathrm{kWh}$ would be used to calculate the size of the PV array (Appendix G). As expected, out of all four of the measured contests, the comfort zone requires the largest amount of energy consuming $68 \%$ of the house's total energy (Figure 73). Based on a worst case scenario this figure highlights the effect of having to maintain such a strict comfort zone on the house's total energy

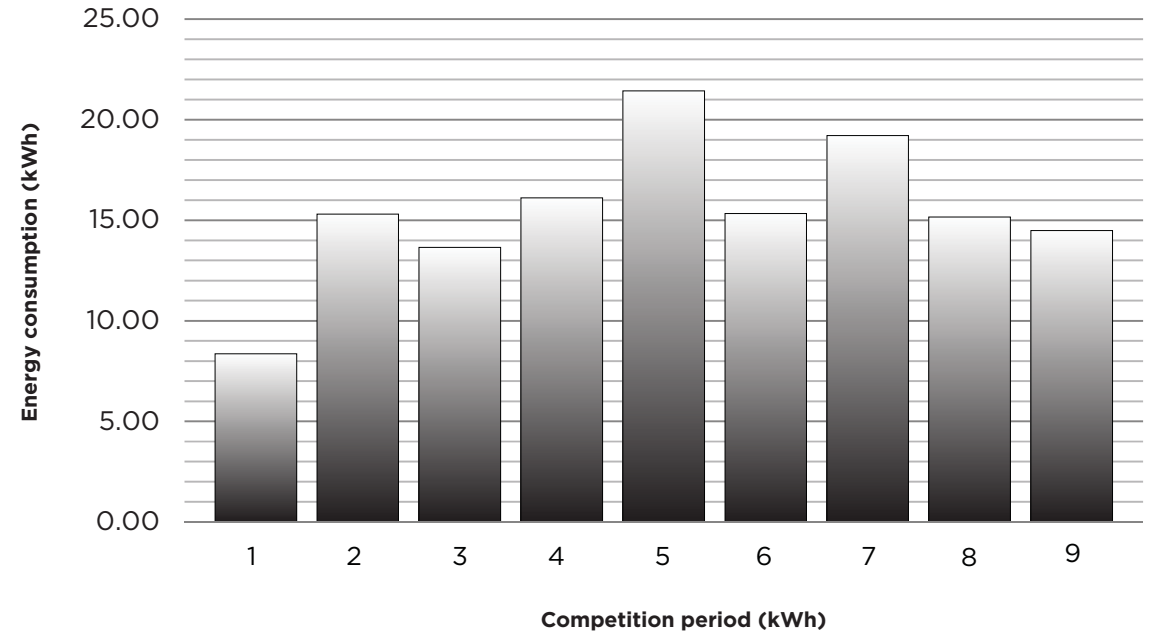

Figure 72: Energy use per day during the competition period 
use. Every effort has been made in the First Light house to optimize the passive performance of the house to reduce the reliance on mechanical heating and cooling. Even with a design that has such a high focus on the passive approach, having to meet such a narrow comfort band is unachievable without using large amounts of energy. In a competition that aims to demonstrate the highest levels of energy efficiency it is ironic that such a narrow comfort band must be maintained.

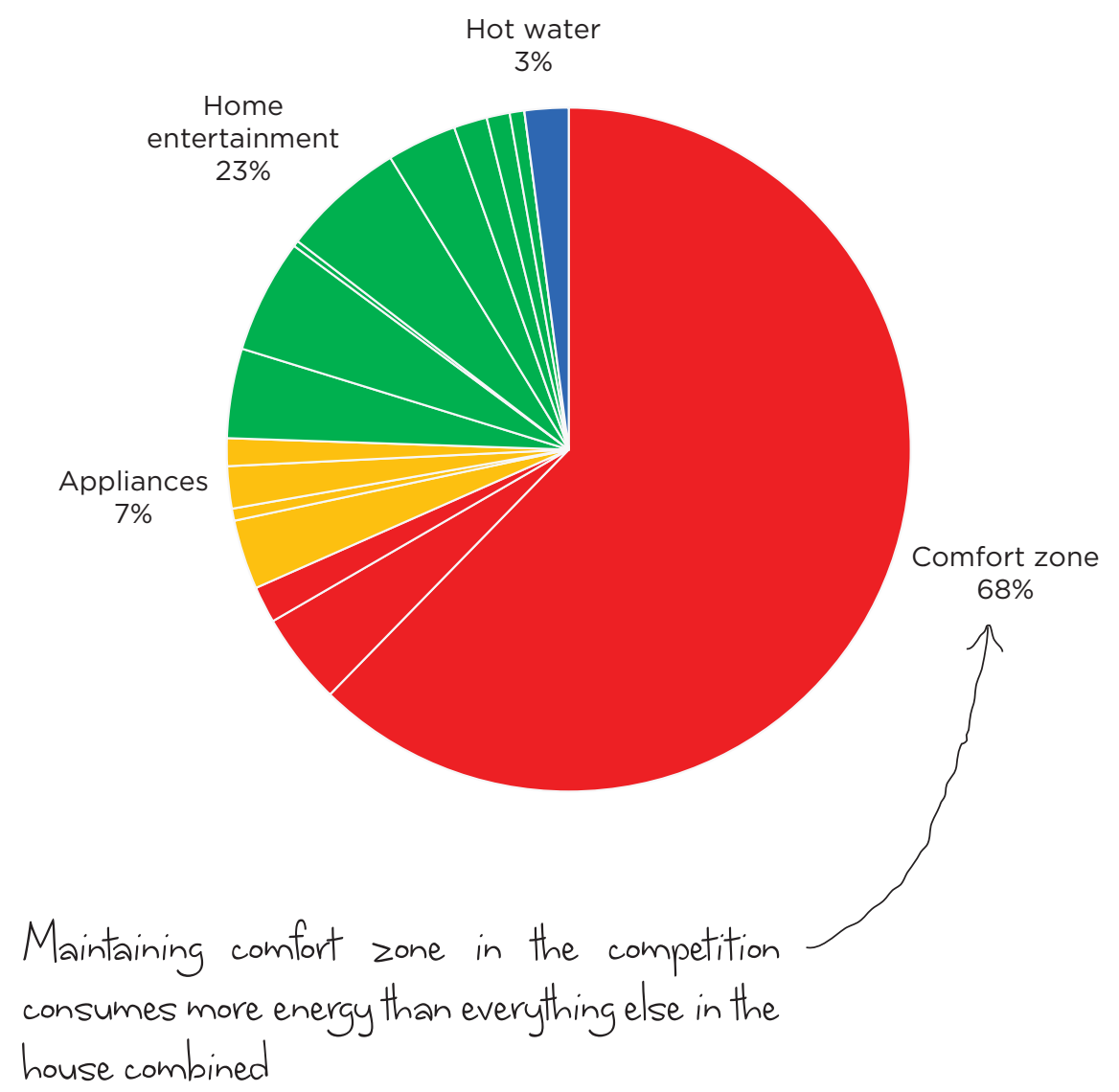

Figure 73: Pie graph of energy use during competition

To determine the energy use of the house over an entire year it was assumed that the occupant maintained a similar schedule for cooking, cleaning, and entertaining as for the competition. This was expanded over an entire year and added to the energy consumption data for space heating in New Zealand. This calculation found that the First Light house would consume only 3226kWh per year (Figure 74). 


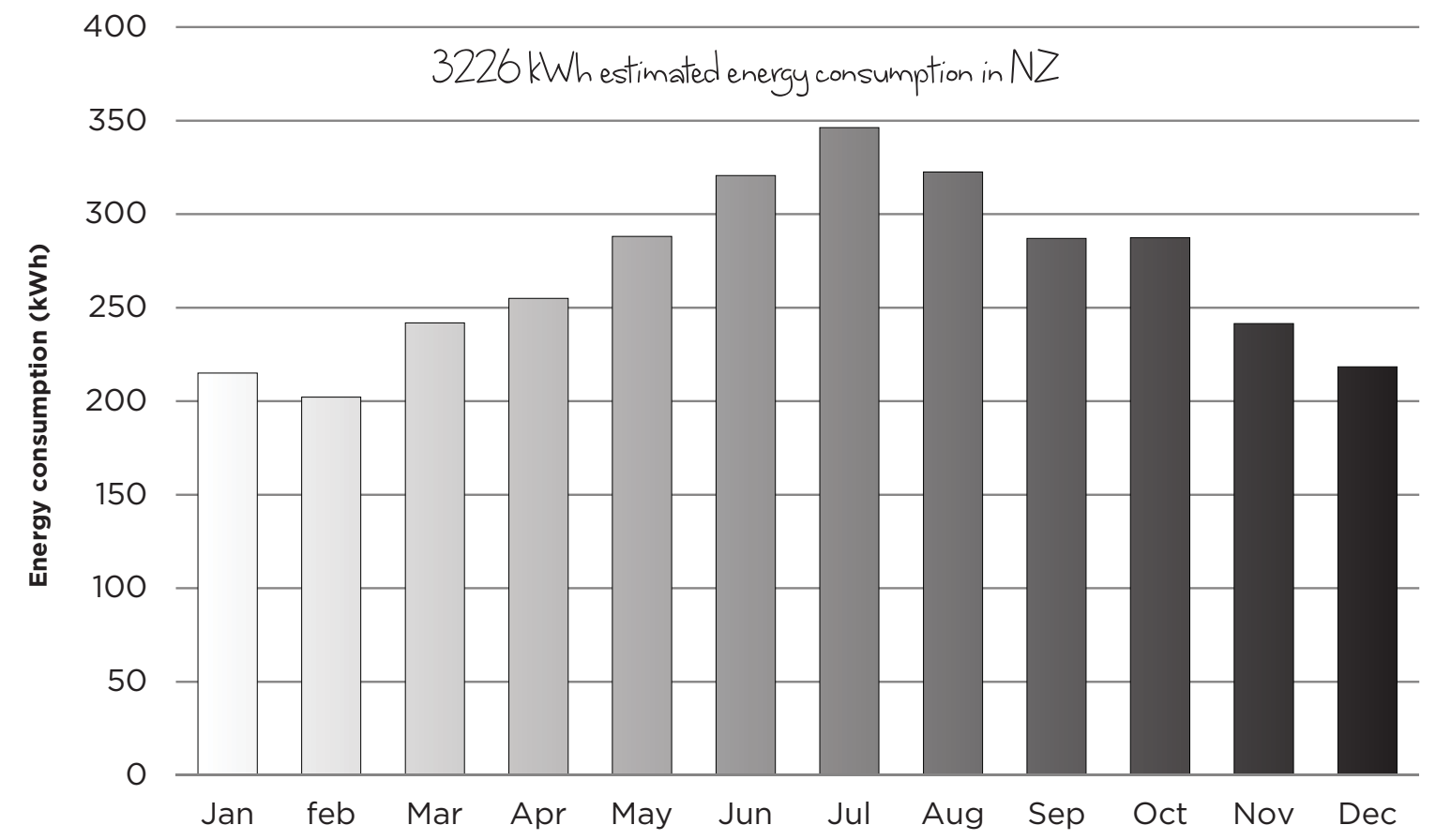

Figure 74: Graph of the monthly energy consumption (kWh) of the First Light house throughout year in New Zealand 


\section{CHAPTER 10 Energy generation}

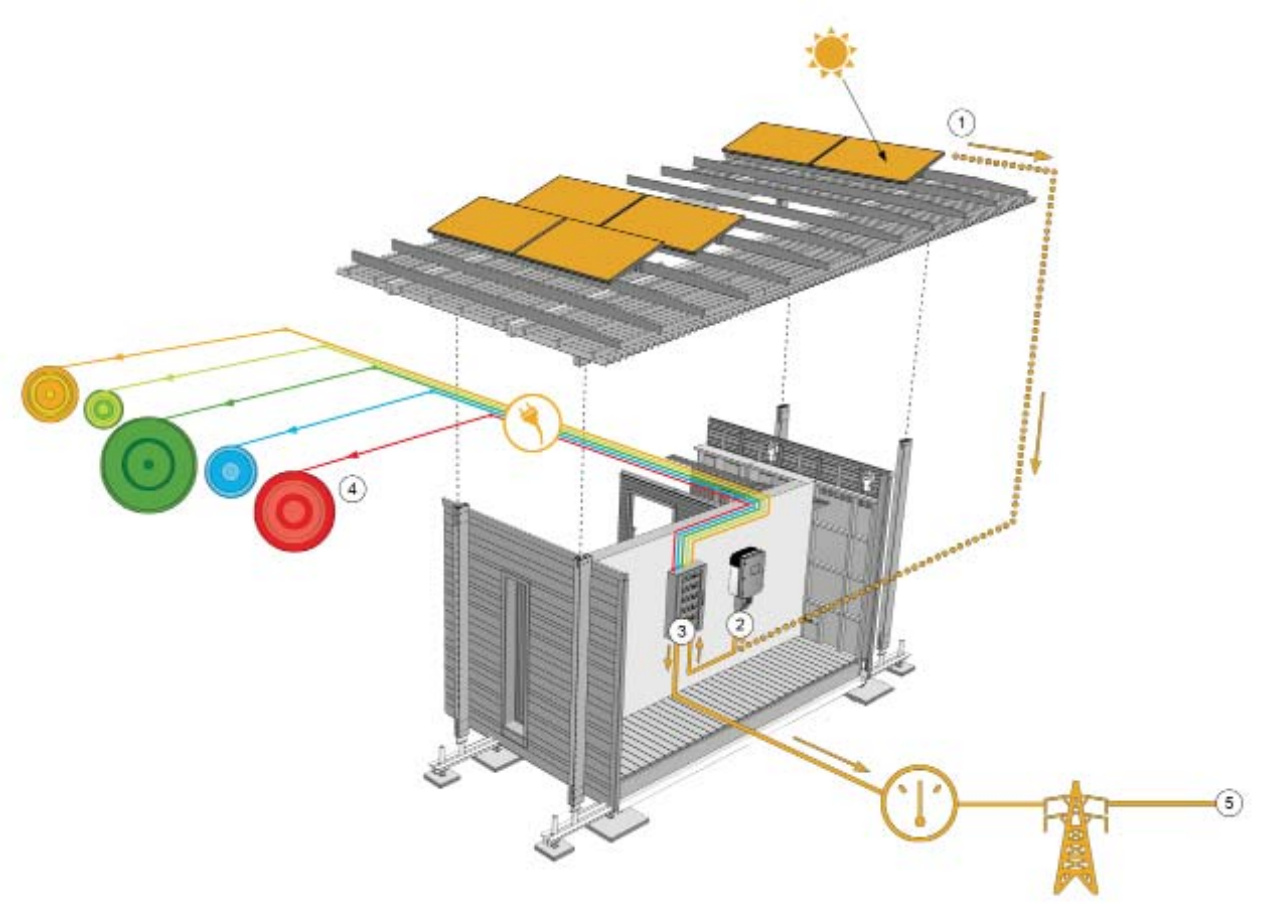

Figure 76: Schematic diagram of First Light electrical system

The energy use data as calculated above was used in combination with solar radiation data for sizing the photovoltaic ( $P V)$ array. Now that the worst case scenario energy use for the 10 days was established, the size and type of solar panels that were needed to generate this energy could be estimated. Energy generation was based on a grid connected PV system rather than use of batteries. A bi-directional utility meter ${ }^{2}$ measured the energy that was drawn from and fed back into the competition micro grid.

2 The design of the electrical system in the First Light house was different from the other teams in the competition, due to the differences in electrical systems between New Zealand and the United States. Rather than using a bidirectional electricity meter the house's supply and generation ran through two separate meters. The house was supplied with $230 \mathrm{~V} 5 \mathrm{OHz}$ (as per New Zealand standard) via a 40kVa voltage frequency converter. All of the power produced by the photovoltaic modules was supplied via a US inverter through a separate meter to the micro grid at $120 \mathrm{~V} 6 \mathrm{OHz}$ (as per the United States standard). For the competition this supply system was completely independent of the electrical system in the house. Upon return to New Zealand the US inverter would be replaced with New Zealand inverters $(240 \mathrm{~V} 5 \mathrm{OHz})$, that would feed into the distribution board, in place of the competition micro grid, as per a standard, grid linked PV system. 
To be eligible for full points, this meter had to read net zero or positive energy over the course of the competition. As this was a grid-connected PV system sizing, rather than a stand-alone system, the method used for sizing the First Light system was based on the total energy consumption over the course of the competition.

Due to the extreme variability in solar radiation levels, the amount of sunshine that the panels were exposed to and therefore the amount of energy they would produce was difficult to predict. Despite this uncertainty, the probability that the panels would be able to produce a certain amount of energy could be determined. Using a similar method to that used for creating weather files for sizing the HVAC system, a statistical analysis was performed on historic solar radiation data for Washington D.C. to determine the probability that the PVs would produce a certain amount of energy.

The last 15 years of solar radiation data was analyzed and the average amount of energy produced was determined along with the standard deviation. The average solar radiation data was found to be $3.7 \mathrm{kWh} / \mathrm{kWp} /$ day in September. The standard deviation was $0.59 \mathrm{kWh} / \mathrm{kWp} /$ day. Using the average and standard deviation, a probability density function was generated (refer to Equation 1).

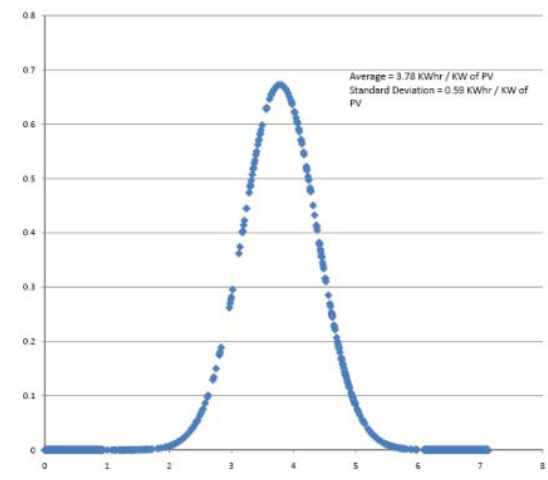

Figure 77: Probability density function

$$
\begin{aligned}
& Z=\frac{X-U}{\sigma} \\
& \text { Where: } \\
& X=k W h / \mathrm{m}^{2} / \text { day where } 0<X \leq \infty \\
& U=\text { average }=3.78 \mathrm{kWh} / \mathrm{m}^{2} / \text { day } \\
& \sigma=\text { standard deviation }=0.59 \mathrm{kWh} / \mathrm{kW} \text { of } P V
\end{aligned}
$$

Equation 1: Standard deviation formula 
Using the average solar radiation data, standard deviation, a z-table and Equation 1, the probability that the energy produced would be at or above a certain level was determined. Given the importance in the competition of designing a net zero energy house, it was decided to design to the $5 \%$ worst case scenario. From the calculation it was determined that if the solar array was to be sized based on $2.8 \mathrm{kWh} / \mathrm{kWp} /$ day there was a $95 \%$ chance that enough energy would be generated over the course of the competition to remain net zero energy.

Total contest power use $=144.47 \mathrm{kWhTotal}$ power use plus $10 \%$ contingency $(P)=158.91 \mathrm{kWh}$

Solar radiation $(S)=2.8 \mathrm{~kW} / \mathrm{kWp} /$ daySystem size $=(P / S) / 9($ days of comp $)$

$=6.3 \mathrm{kWN}$ umber of $225 \mathrm{~W}$ panels $=\frac{6.3 \mathrm{~kW}}{225 \mathrm{~W}}=28 \longrightarrow$ Number of panels required

Equation 2: Calculation of number of solar panels required for competition

Using this data for solar radiation and energy consumption during the competition a solar array of $6.3 \mathrm{~kW}$ was needed to achieve net zero energy. The panels that were selected to generate this energy were $225 \mathrm{Wp}$, polycrystalline silicon photovoltaic modules, from Mitsubishi electric (PVUJ225GA6). These panels were chosen because they had a relatively high power rating per module and unlike most panels, were rated highly for use in coastal areas, which was important for the 'kiwi bach' upon return to New Zealand. To achieve the necessary consumption, 28 panels were needed, arranged in 2 strings of 14 modules on the solar canopy of the First Light house. (Equation 2) 
The maximum collection of solar radiation occurs when the panel is perpendicular to the direct beam radiation. Since the sun moves both daily and annually, and as the solar panels would be fixed, both the angle and the spacing of the panels had to be optimized to ensure maximum solar collection and to ensure that there was no shading of the panels. It was calculated that if the panels were mounted at a $20^{\circ}$ angle, the optimum spacing for Washington DC in September to ensure there was no shading of the modules would need to be $1210 \mathrm{~mm}$.

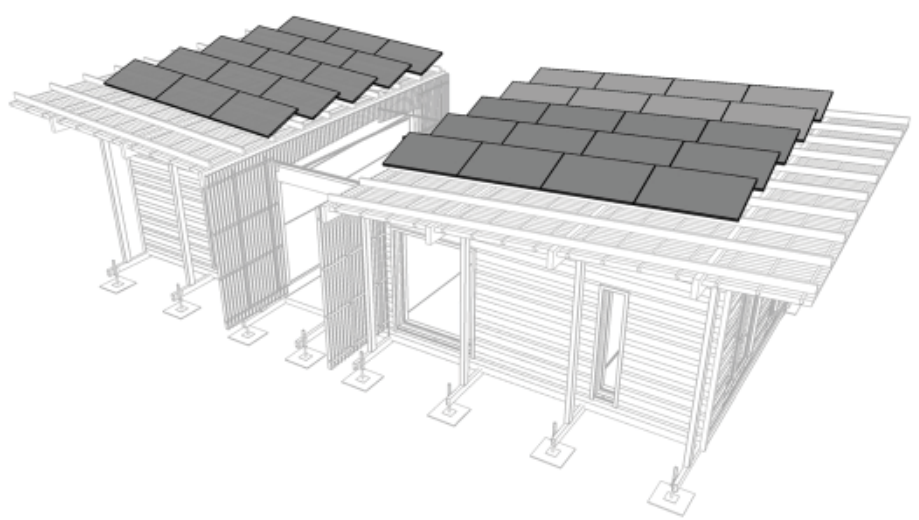

Figure 78: Diagram of intial panel layout and spacing on canopy

With 28 panels needed on the canopy and with only limited space on which to put them the maximum spacing which could be practically achieved was $1400 \mathrm{~mm}$. Using this spacing, a simulation was performed in PVSYST v5.20, a computer software designed for simulating the performance of PV arrays. The simulation tested the energy generation of the panels at varying angles of $10^{\circ}, 15^{\circ}$ and $20^{\circ}$ (Figure 79). It was found that during the competition period mounting the panels at $20^{\circ}$ degrees generated the most energy. Over an entire year in NZ, during the winter months the steeper angle shaded the panels behind for large periods of the day, reducing the array's total generation. In July, with the panels mounted at $20^{\circ}$ degrees the array generated $223 \mathrm{kWh}$ in total throughout the month, as opposed to $273 \mathrm{kWh}$ at a $10^{\circ}$ angle. The $50 \mathrm{kWh}$ difference across the month, especially in winter when consumption was high, was a significant difference in energy. Aware that the energy generation during the competition was the focus, an angle of $15^{\circ}$ was selected as a balance between an optimum competition angle and the optimum for a full year in NZ. (Appendix H)

As a final test and a check for the sizing of the solar array and the house's 


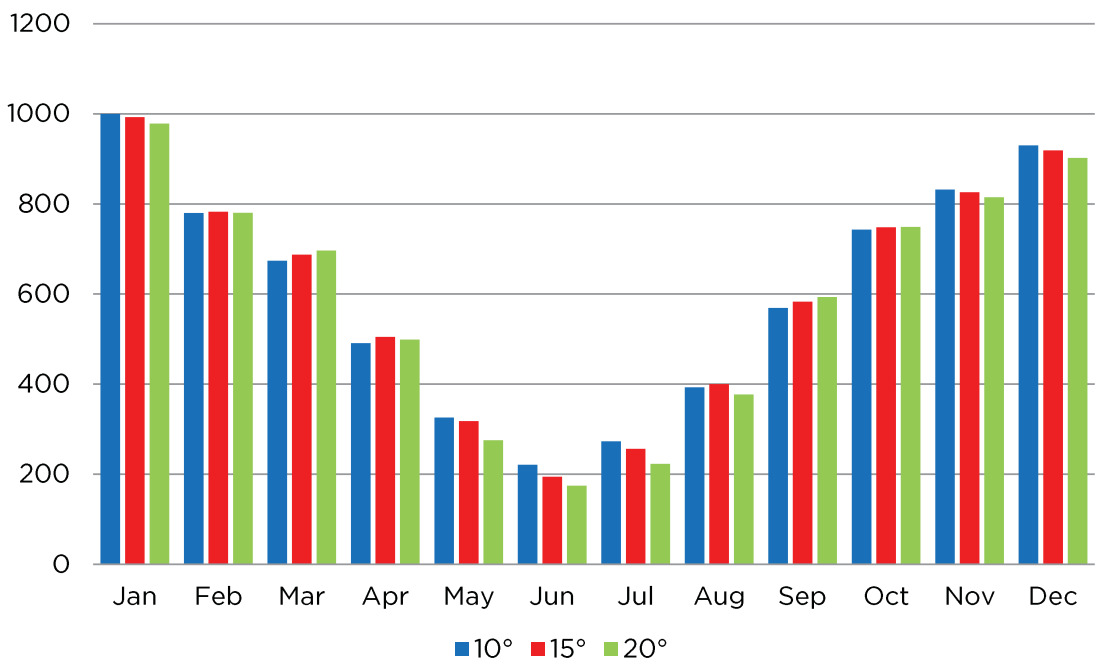

Figure 79: Energy generation of solar array at different angles throughout the year in Wellington

performance a simulation was undertaken using real life weather data from the 2005 Solar Decathlon. Figure 80 shows energy consumption versus generation for the First Light house throughout the 2005 competition. Despite low levels of solar radiation the First Light house remained net zero energy, generating $8 \mathrm{kWh}$ more than the total used during the 10 days.

$\begin{array}{ll}\text { Consumption } & \text { Generation } \\ 139.07 \mathrm{kWh} & 147.24 \mathrm{kWh}\end{array}$

Table 19: Estimated energy generation versus consumption during the 2005 competition

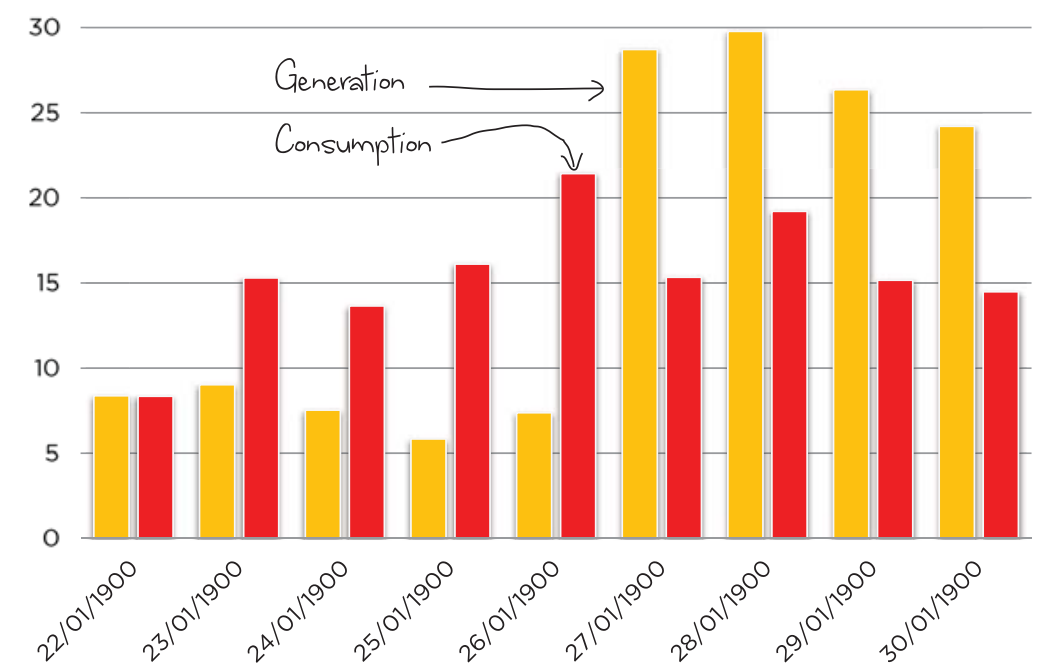

Figure 80: Simulated energy consumption vs generation using weather data from September 2005 
Energy Consumed

\begin{tabular}{lll}
\hline January & 214.9 & 992.7
\end{tabular}

February

March

April

May

June

July

August

September

October

November

December

Total
202.2

241.9

255.0

288.1

320.6

346.3

322.4

286.9

287.4

241.5

218.4

$3226 k W h$
Energy Generated

992.7

783

687.7

504.9

317.9

194.2

256.4

400.2

582.9

748.3

826

919.1

7213.3kWh

Table 20: Total monthly energy generation versus consumption in Wellington

The First Light house generates over twice as much energy as what it consumes in a year

Because the system was sized based on a $5 \%$ worst case scenario for Washington DC the system is oversized for a New Zealand climate. Throughout the year the $6.3 \mathrm{~kW}$ array generates $7213 \mathrm{kWh}$, over twice as much as would be consumed in a year (Table 20). Being a grid connected system this is not a problem and when the house returns to New Zealand will result in a pay-back over time for the new owner. What is interesting from Figure 81 is that despite the size of the PV array being at least twice as large as is needed, the house still consumes more energy than it generates during the months of June and July when there are very low levels of sunshine. Being a grid connected system this is not a problem as the extra energy that is needed can be drawn from the grid. But if the house was to move to an off grid set up in NZ a back-up energy source (e.g a battery) would be needed to provide electricity at night and during period of low sunshine.

Sizing the solar array was the last step in a long series of energy simulations that analyzed the performance of the First Light house. From a theoretical point of view solar energy is the most abundant, inexhaustible primary energy source available. At present solar technology is still relatively under-utilized in New Zealand with the majority of its uptake in stand alone, off-grid systems used in remote locations. The average rooftop in 
New Zealand of $150 \mathrm{~m}^{2}$ collects 20 times more solar radiation than the house's total energy use throughout the year (EECA 2001). The amount of solar energy available in New Zealand is comparable to Australia and much higher than European countries like Germany, who are at the forefront of the implementation of domestic solar energy technologies. The potential for the uptake of solar energy in New Zealand is high with the major barrier being the cost compared with grid electricity prices. As solar technology prices reduce in the future (and grid based energy prices rise) it is important that the public are exposed to projects like the First Light house to raise awareness about the potential of renewable energy technologies. Now that the design was completed construction of the First Light house could begin. In order to showcase the house to the public in Wellington it was decided that the house would be set up and displayed in Frank Kitts Park, a prominent site on the Wellington waterfront.

Because of low levels of solar radiation in wellington during June and July the house consumes more power than it

1200 generates, evan though it has a 6.3kW array

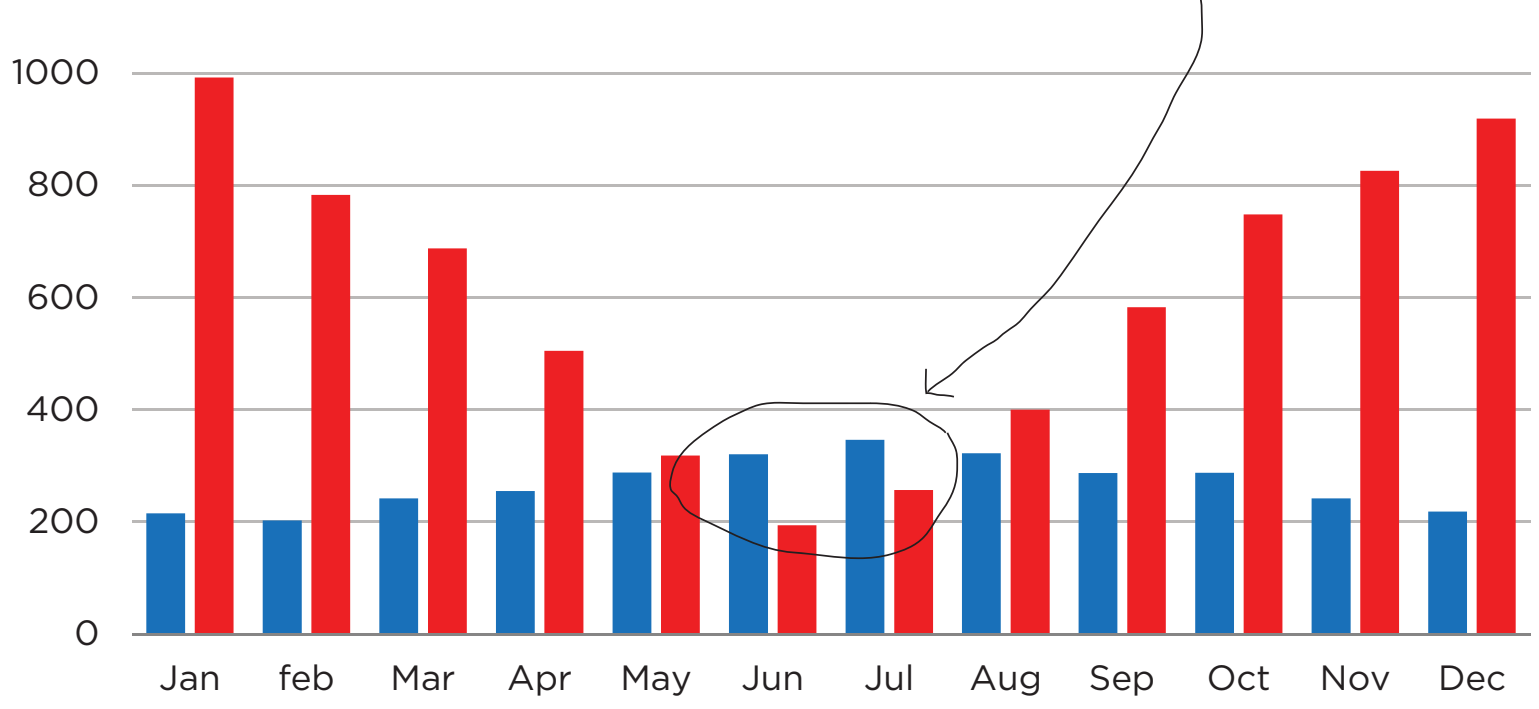

घnergy Consumed घnergy Generated

Figure 81: Energy consumption vs generation throughout year in New Zealand 


\subsection{Conclusion}

Throughout the design process the focus of the design was on the performance of the First Light house during the competition in Washington

DC. However, when presenting the design and its performance to the public, or more importantly to the judges, the focus was on how it was designed for New Zealand and optimized to perform in a Wellington climate. It is ironic that every effort has been made to showcase a New Zealand house on the world stage that has ultimately been designed for Washington DC in September. Looking at the passive design of the house every effort was made to design a home that performs as optimally as possible in both climates. But when it comes to the active side of the design this is more difficult to justify. Both the HVAC system and the solar array have been dramatically oversized for New Zealand due to the competition requirements. Comprehensive simulation went into designing a home that would maintain a comfortable and healthy internal environment with little or no energy. But, in order to meet the comfort zone requirements of the competition, this small $75 \mathrm{~m}^{2}$ 'kiwi bach' was designed with an HVAC system twice as large as it needs, and one that could condition a small office building. Throughout the process the team stressed the importance of being net zero energy and matching energy consumption with production. But a $6.3 \mathrm{~kW}$ solar array annually generates well over double the energy the house needs to run it.

One of the goals of the Solar Decathlon is to "demonstrate to the public the opportunities of energy efficient construction and appliances". Oversizing the HVAC system to maintain the comfort zone and adding a large PV array to account for the extra energy are not what the US Department of Energy was trying to achieve with the competition. Increasing insulation, adding double glazing, focusing on the passive design of the home, on the other hand, is, although there is little or no incentive within the competition to do these things. Over $50 \%$ of the points are allocated during the competition based on the performance on site in Washington DC in September. Any team going into the competition to win, would be senseless not to oversize the solar array to make sure enough energy is 
generated. In the competition only $25 \%$ of the engineering contest, 25 points out of 1000, takes account of the simulated performance of the house in its home climate. The addition of the affordability competition in the 2011 slightly changed the focus of the competition from houses that were more akin to power stations to houses people might want to live in. Unfortunately, despite the nobility of the intention, the limits set by the affordability competition are unreachable by the majority of New Zealand people, as $\$ 250,000$ U for a $75 \mathrm{~m}^{2}$ one bedroom house, without a site, is an unrealistic amount of money for the majority of the population. How can the Solar Decathlon demonstrate the potential of energy efficient design to the public if it is too expensive to achieve and its focus is not on the success of the design but the technologies that are needed to achieve a quite specific set of requirements in a DC Climate? The competition has inspired tremendous knowledge and inspiration and has exposed the public to the future of solar energy, but the benefits of the competition could be exponentially more successful if the inconsistencies of climate, location and budget could be reexamined.

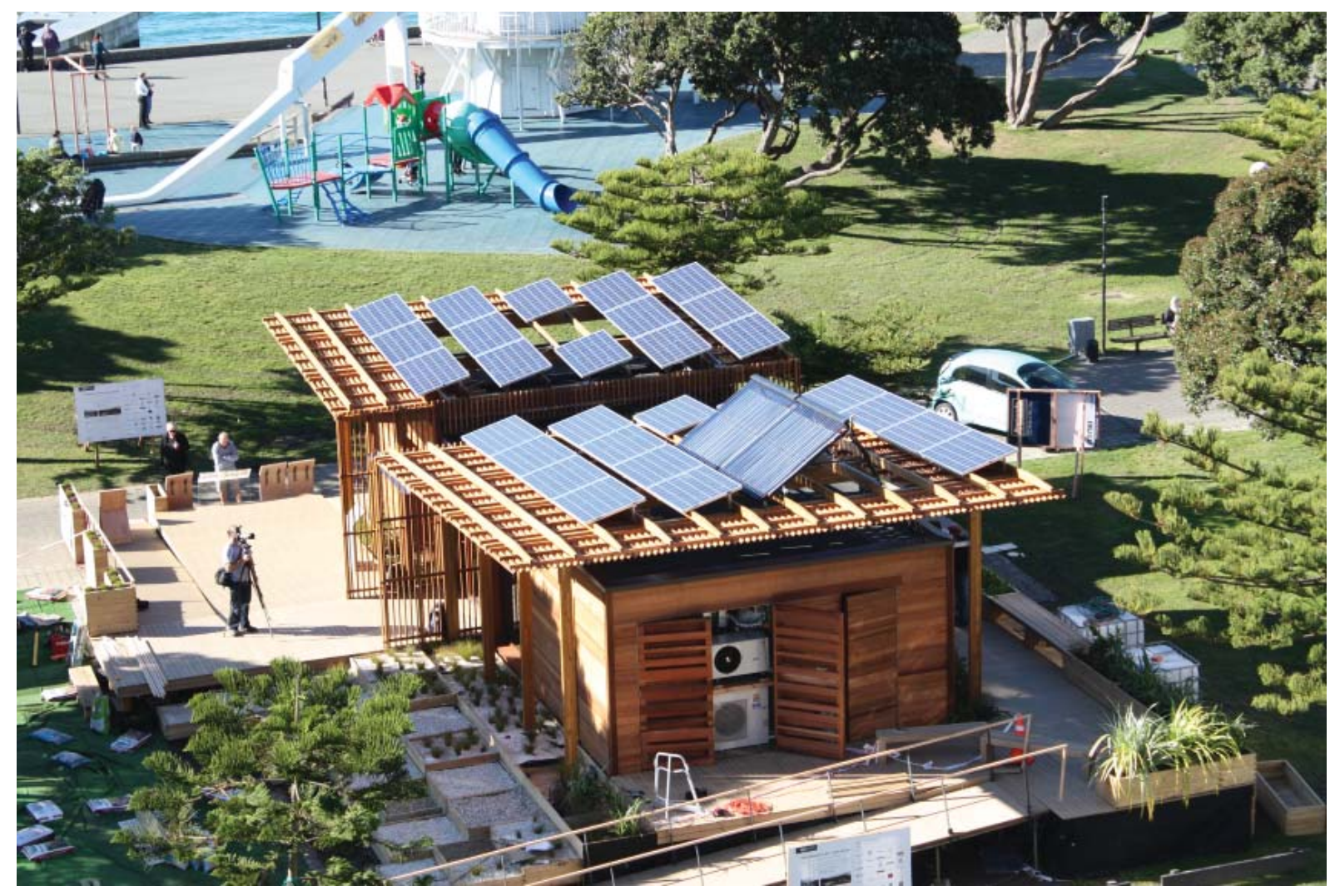

Figure 82: First Light house on Frank Kitts park from above 


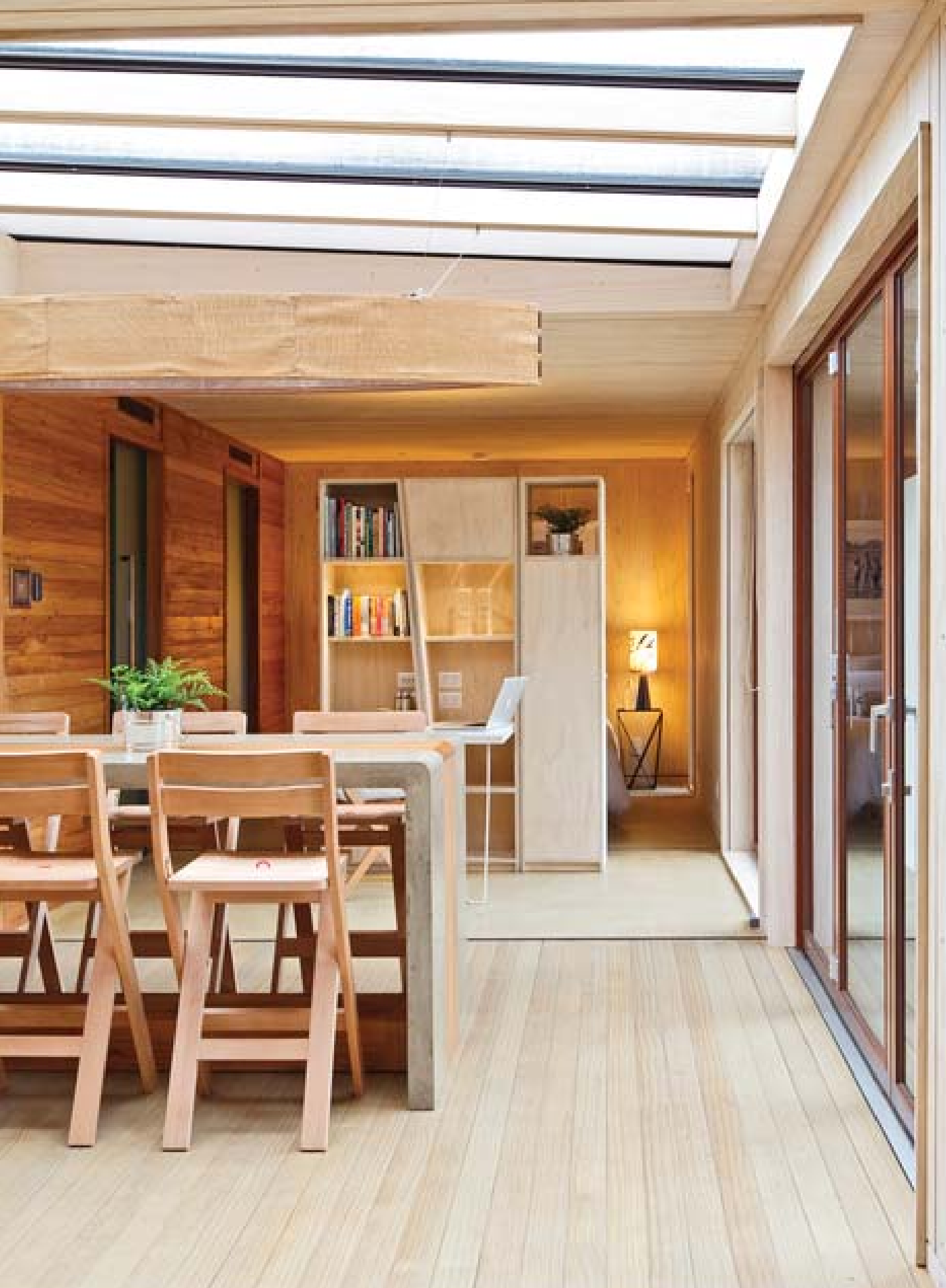




\section{Results}

\subsection{Frank Kitts Park}

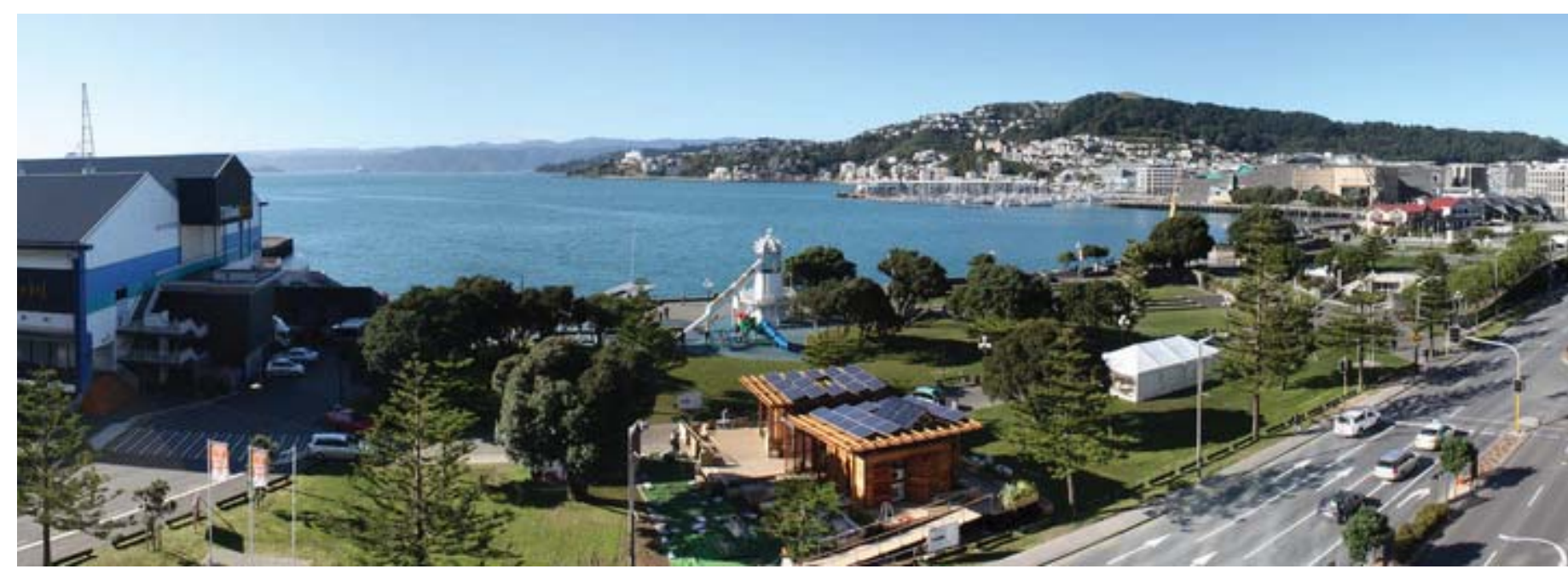

Figure 84: Panoramic image of First Light house on Frank Kitts Park

Once the design was finalised the house was first constructed in a warehouse in Wellington. Before it was packed up and shipped to Washington DC it was moved to Frank Kitts Park where it was constructed and tested under the same conditions it would have during the competition. With only seven days to construct the house it gave the team a chance to practice and perfect its assembly and to resolve any problems that arose. Once the house was constructed it was on display and open to the public for three weeks and was tested and monitored throughout, making sure that it was performing as designed. Having never competed in the Solar Decathlon this practice run was the most beneficial preparation that the team could have had. It gave the students a chance to understand their own individual roles in the on-site construction process, (Figure 85) which for many was the first construction experience they had had. Having the house open to the public gave the students an opportunity to practice running public tours and familiarising themselves with the house (Figure 86). But it was not just the students that benefited from the practice run of setting the house up prior to the competition. Having the house displayed to the public for such a long period of time on such a prestigious site in Wellington was a unique opportunity to showcase the potential of solar energy and energy efficient design and construction to the people of New 


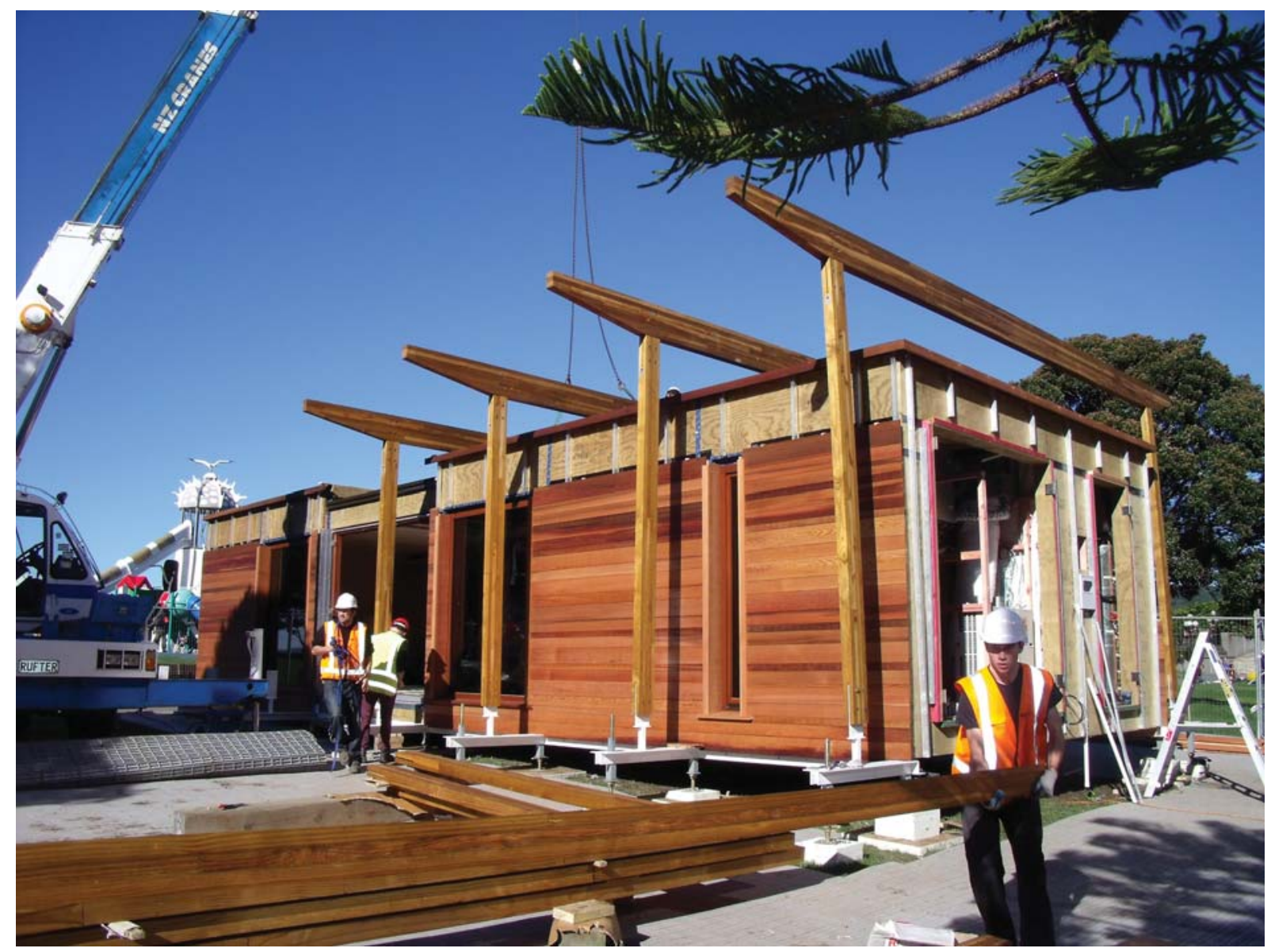

Figure 85: Student construction on Frank Kitts park

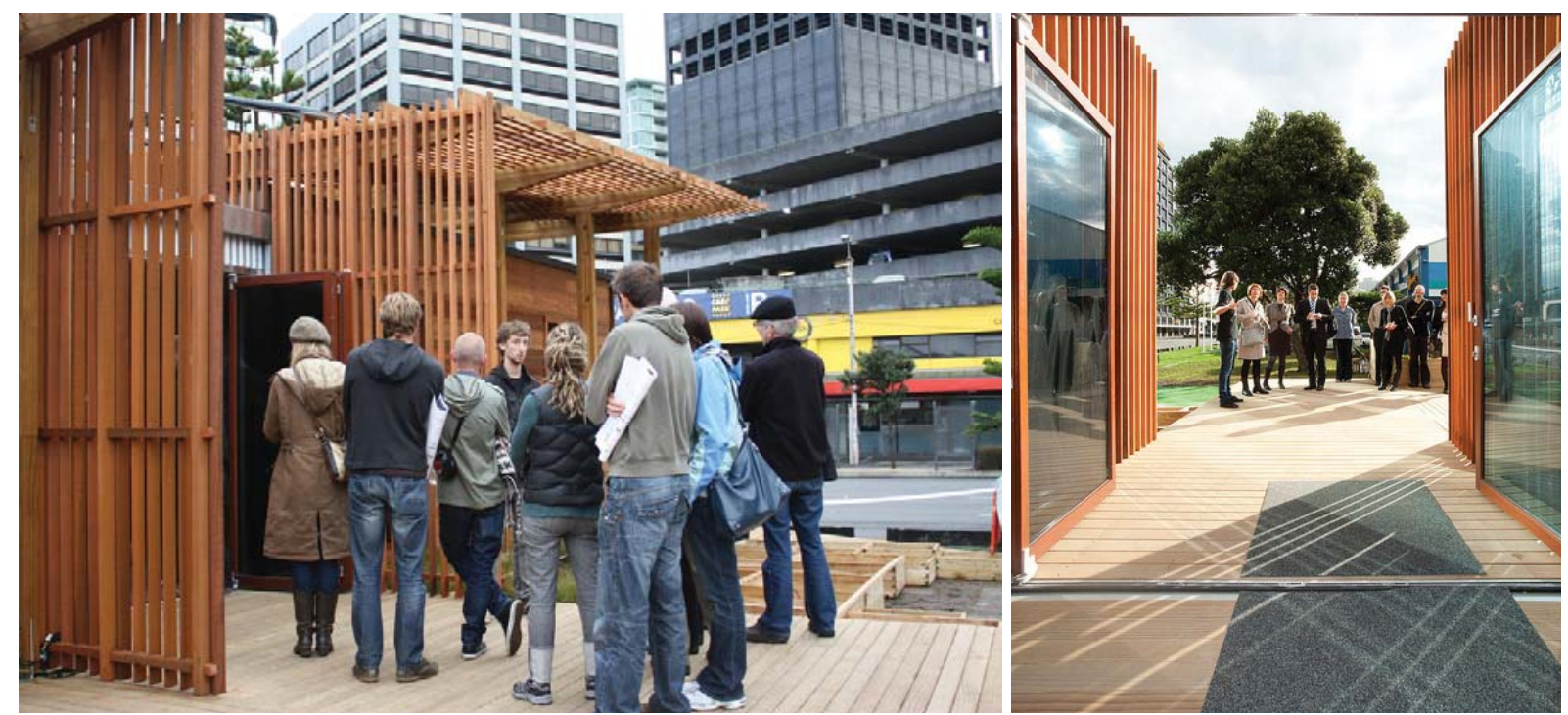

Figure 86: Students giving public tours through the house 
Zealand (Figure 87). The house was a culmination of two years of design, research, and collaboration between the university and industry in New Zealand. It represented a unique prototype for the future of housing that the people of Wellington could walk through and experience. It was a great occasion for showing that this type of housing was achievable in New Zealand, that the products and technologies were available, and that it could all be achieved without losing the essence of what it meant to live in a New Zealand house.

Setting up the house in Frank Kitts Park was also a chance to run through each of the measured contests as they would be conducted during the 10 days of the Solar Decathlon. Temperature and humidity sensors throughout the space monitored the indoor climate during the day and night. A thermal imaging camera was used to determine weaknesses in the building envelope and a blower door test was undertaken to calculate the air tightness of the house. (Figure 88 and 89) This was extremely beneficial as a number of weaknesses were found in the envelope including a poor seal on the bi folding doors, the poor air tightness of the ventilation system components, and a gap between one of the module joins. Once the passive performance was established the HVAC system was commissioned in order to get it running as efficiently as possible. From the tests, the logic for the control system was designed specifically

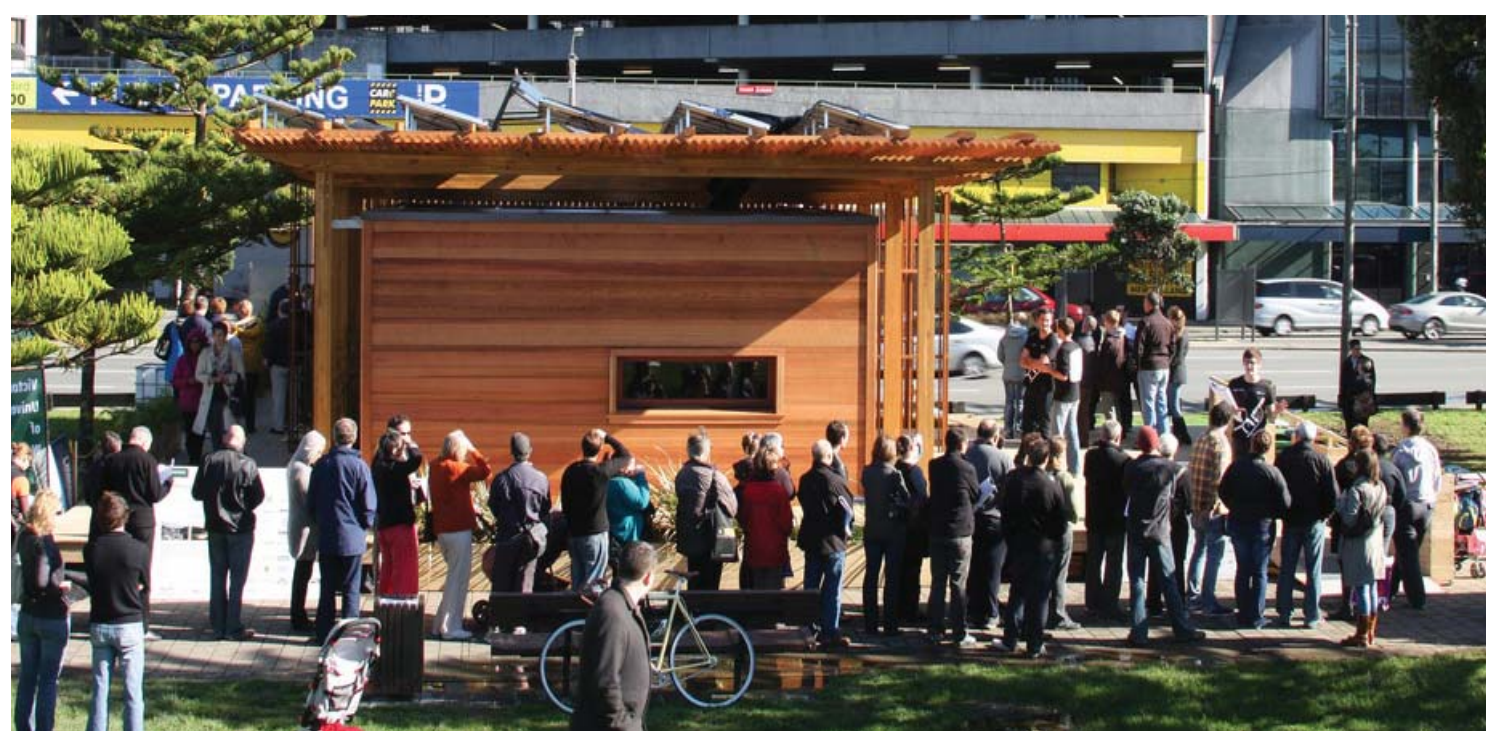

Figure 87: Lines of people waiting to view the house 


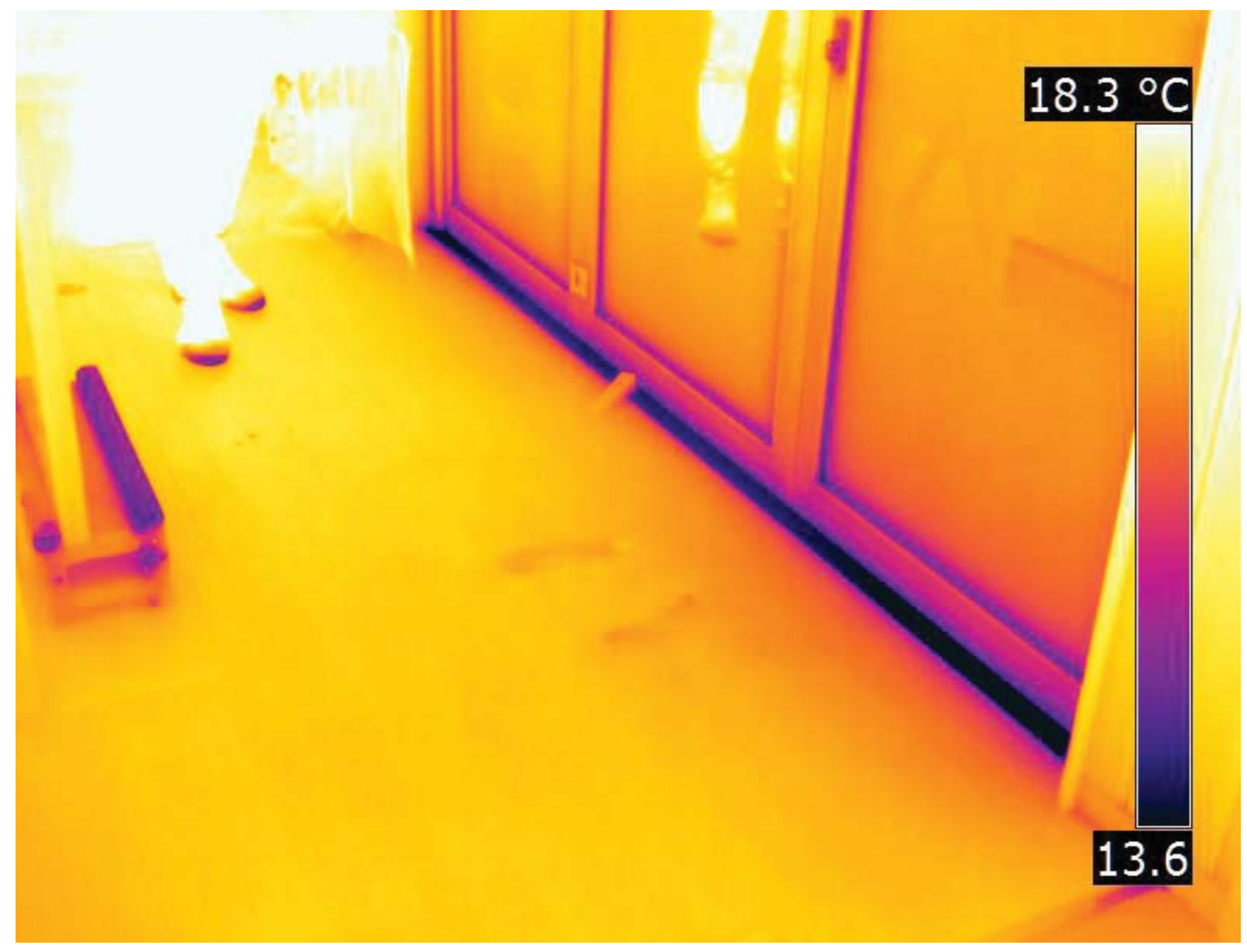

Figure 88: Faulty seal at the base of the bifold doors (Source: Image courtesy of BRANZ)

for the house to maintain the required comfort band for the competition. The appliances were all tested including the drying cupboard and the actual energy use monitored throughout. The hot water system including the evacuated tubes and the back-up heat pump were commissioned and optimized for the competition requirements.

Data was collected throughout the testing and monitoring of the house when it was on display. This was stored and used in the following weeks while the house was being shipped to develop a strategy for the competition based on the house performance under different conditions. This period of monitoring was extremely beneficial for understanding the strengths and weaknesses of the house in preparation for the Solar Decathlon. It also pinpointed areas in the design that needed further improvement before it was assembled for the competition. For the team this practice run was one of the best planning decisions that was made 

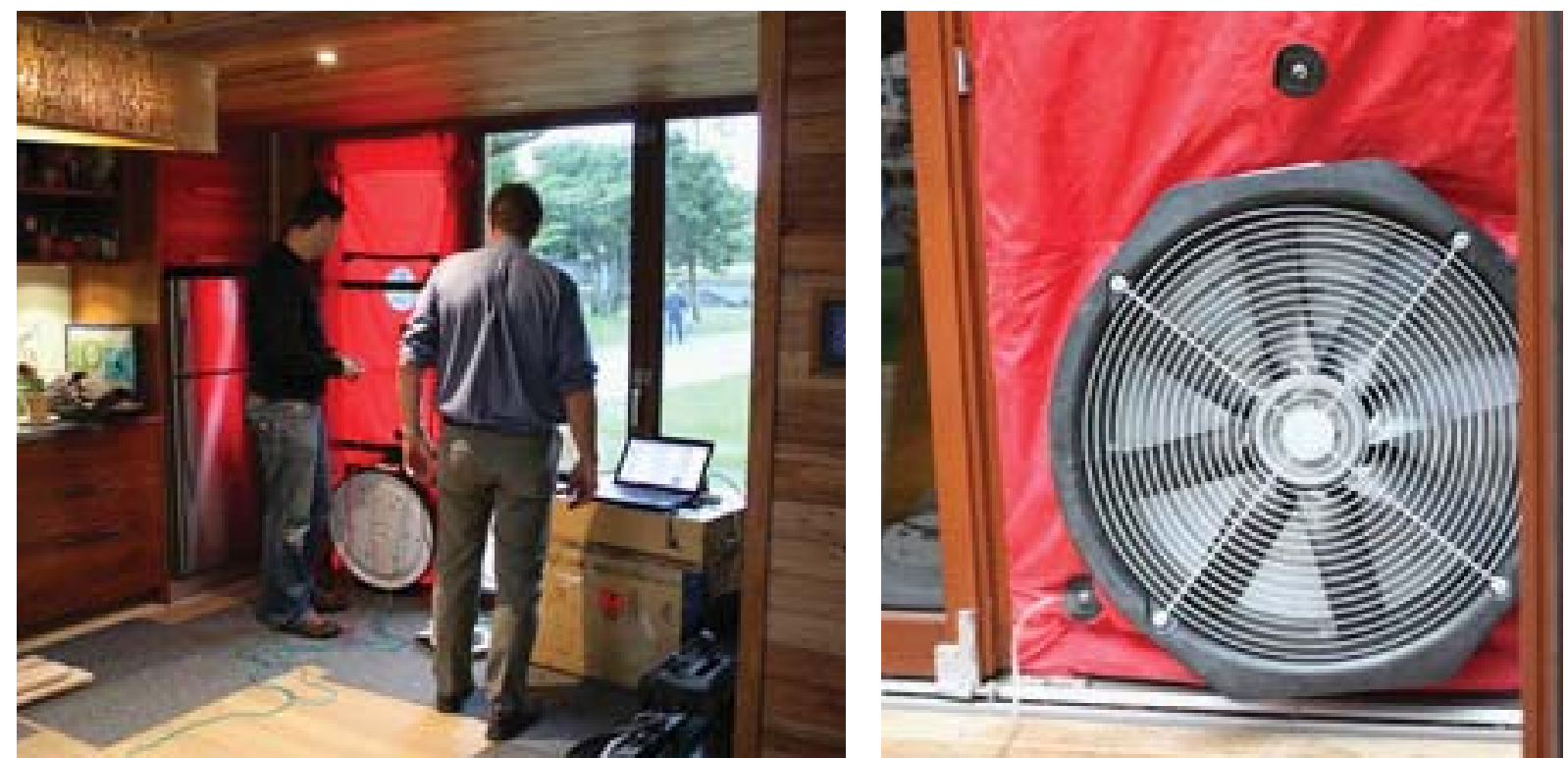

Figure 89: Blower door test on the First Light house

during the project and contributed greatly to its success.

\section{Competition results}

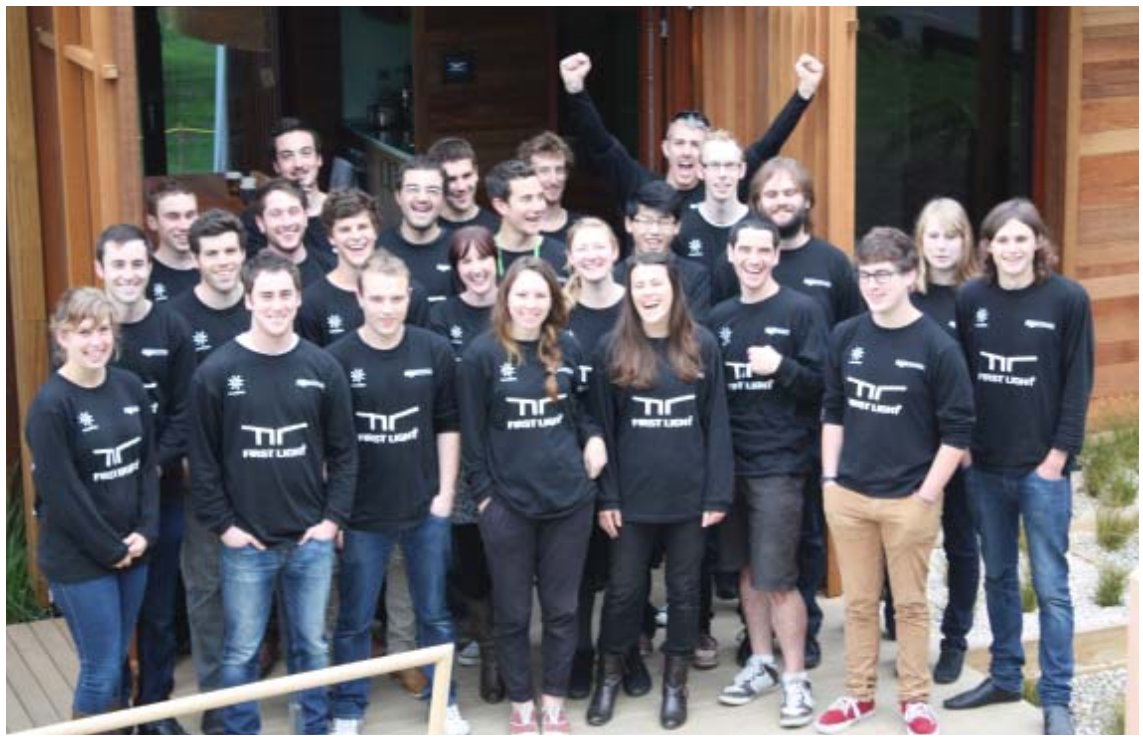

Figure 90: Final team photo before the house was shipped to DC for the competition 
Once the seven day construction period in Washington was complete there was a single day of rest before the competition phase of the project began. Each team was allocated an observer who would monitor and perform the measured tests throughout the contest period. (Figure 95) The contests that required constant measurements, including the temperature, humidity and energy balance, were based on a data logger inside each house that stored the information and constantly uploaded it to a scoring engine where the live data could be viewed. It was the observer's job to make sure that the equipment was in place during the periods of the measured competitions. This information could be viewed live by the decathletes through the scoring engine, making it possible to make on site adjustments to the house and how it was operating. It also allowed decathletes to monitor the performance of other teams, which by the end of the competition became very interesting as tactics and strategy became important. During the other contests that required on site monitoring, like the hot water draw offs, washing and drying, and the cooking contest, the observer would document each test and a score would be given based on the criteria outlined in the Solar Decathlon rules. (Appendix 1) These scores were uploaded to the scoring engine at the end of each day.

Five students or decathletes from the First Light team who were familiar with the measured tests and how the house functioned were nominated to lead this phase of the competition. To make sure that everyone in the team participated in this phase they were teamed up with one of the five leaders. Together they would perform the tests required by the observer in the rules. For some of the tests like the lighting competition, where to be eligible for full points all the lights in the house needed to be on during the specified period, it was the job of the decathletes involved to make sure the lights were on. For other tests like the hot water draw off (Figure 94) it was a little more complicated. Here the decathletes would have to connect a flow meter to the shower and make sure that a certain amount of water was drawn off and that it maintained a certain temperature. While these tests were being run the temperature and humidity in the house were constantly being monitored. It was the job of the decathletes to make sure the doors remained closed, the HVAC system was on, and they were not inside the house, adding unnecessary internal gains. During the competition running the house was a bit like sailing a boat. Instead of wind, it was the sun that was powering the vessel. As the race progressed, 
tactical decisions were made about where to save power in order to ensure the house generated more energy than it used. At the end of each day the points were tallied up and the progress of each team was analysed, and the tactics for the following day were decided upon.

The following journal accounts are for the period of the competition and the performance of the house throughout. The details of each of the 10 days including the weather, the events that were monitored, the temperature, humidity, and the energy balance as well as the total points are presented here.

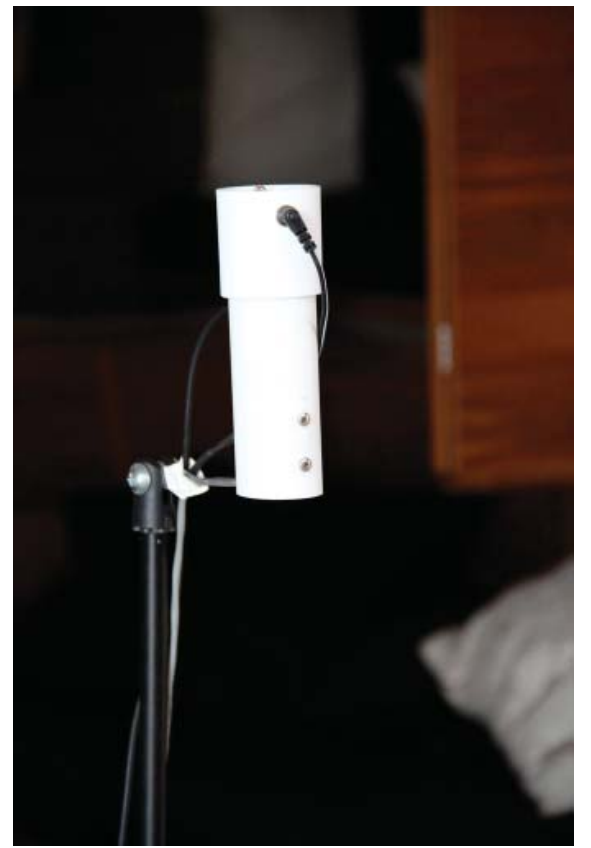

Figure 92: Temperature and Humidity sensor

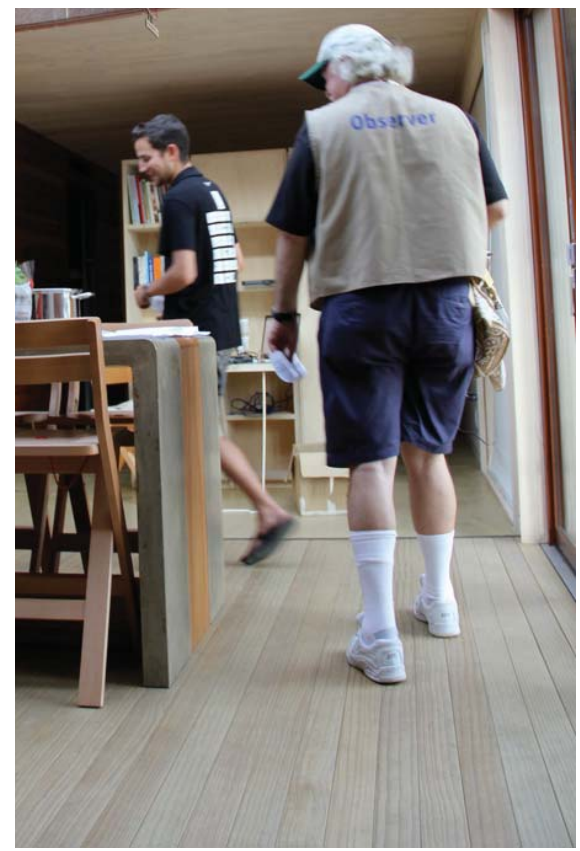

Figure 93: Observer preforming spot check of sensors 


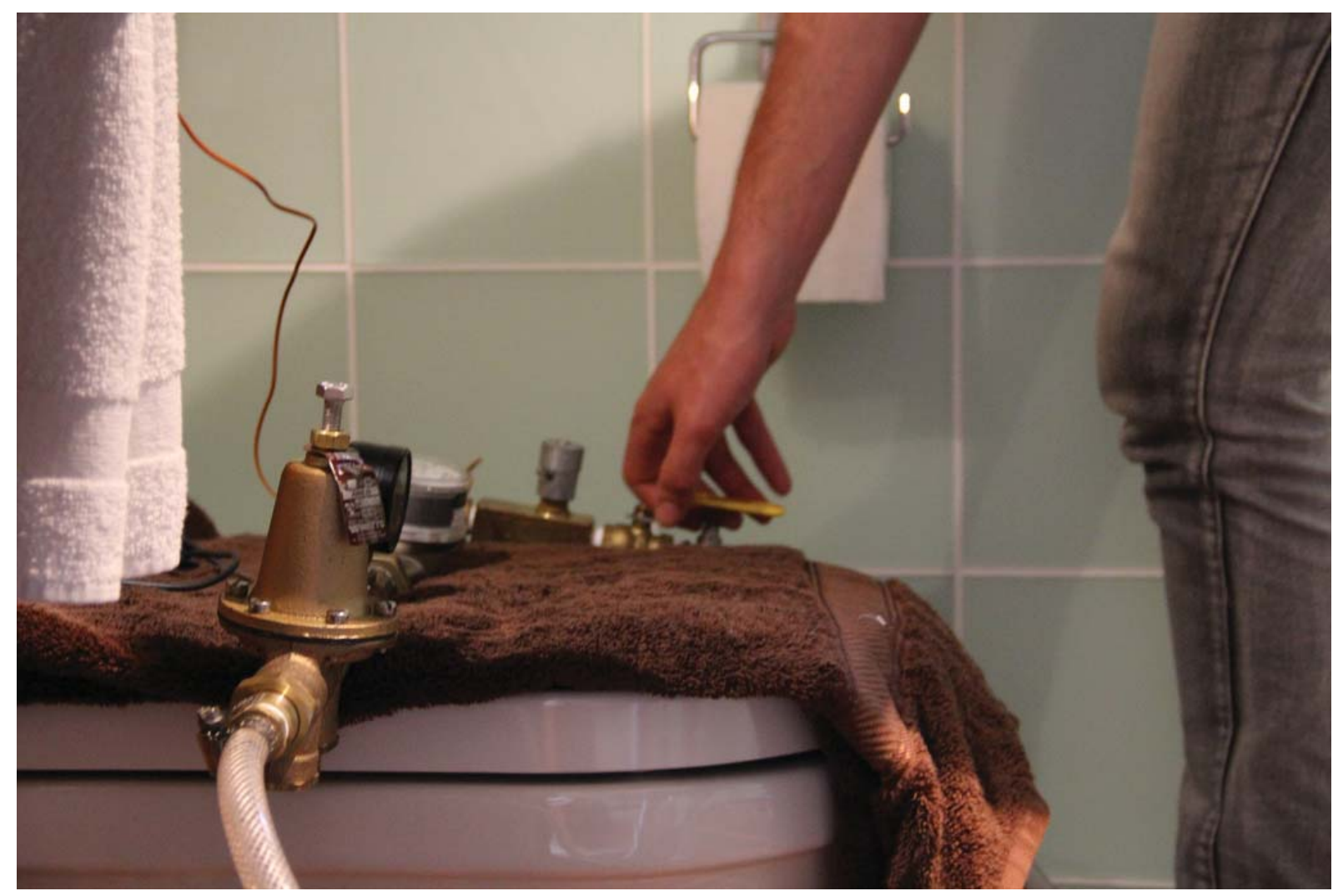

Figure 94: Decathlete reading flow meter while preforming a hot water draw off

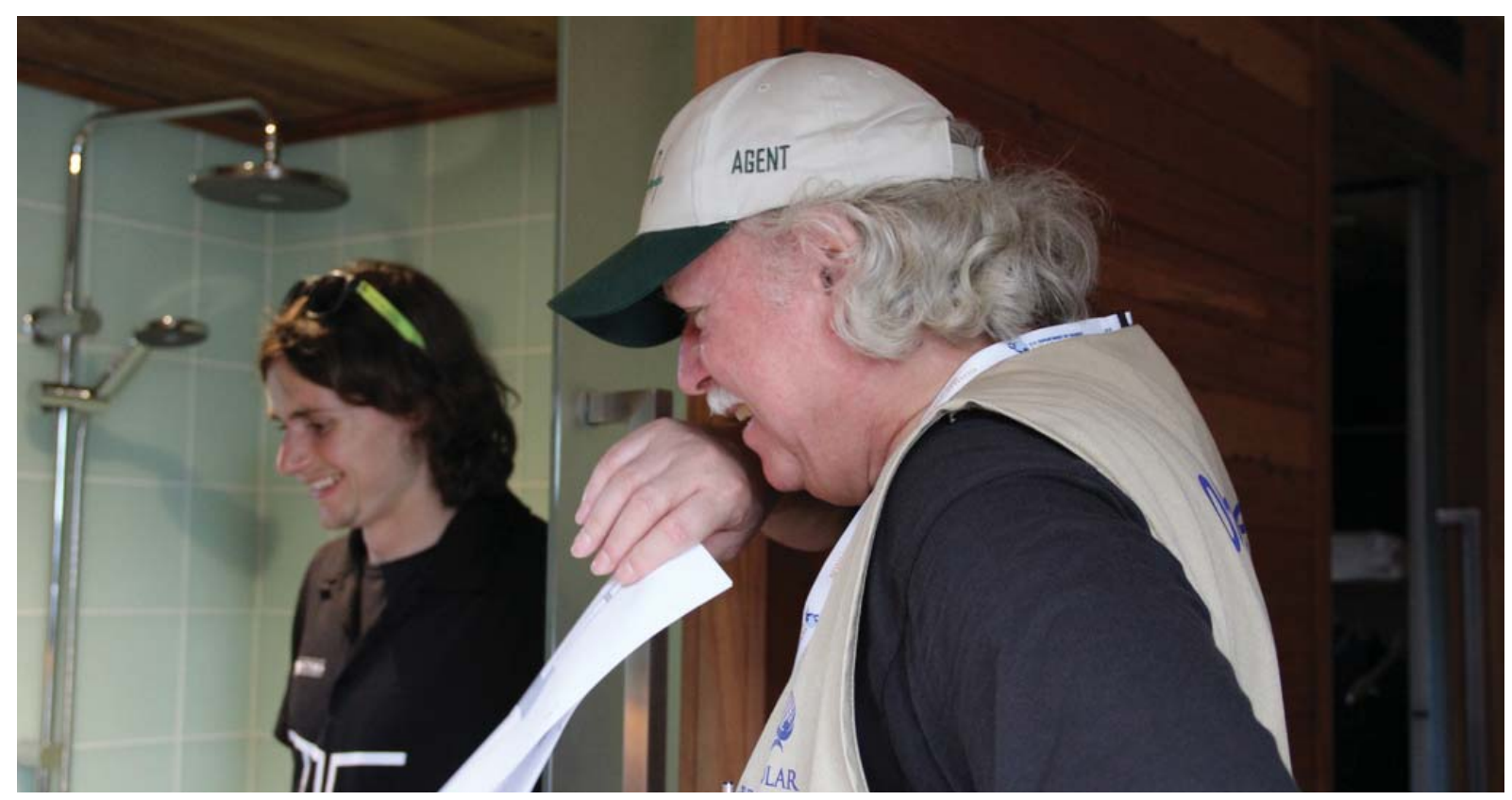

Figure 95: Observer monitering hot water draw off 


\section{DAY 1}

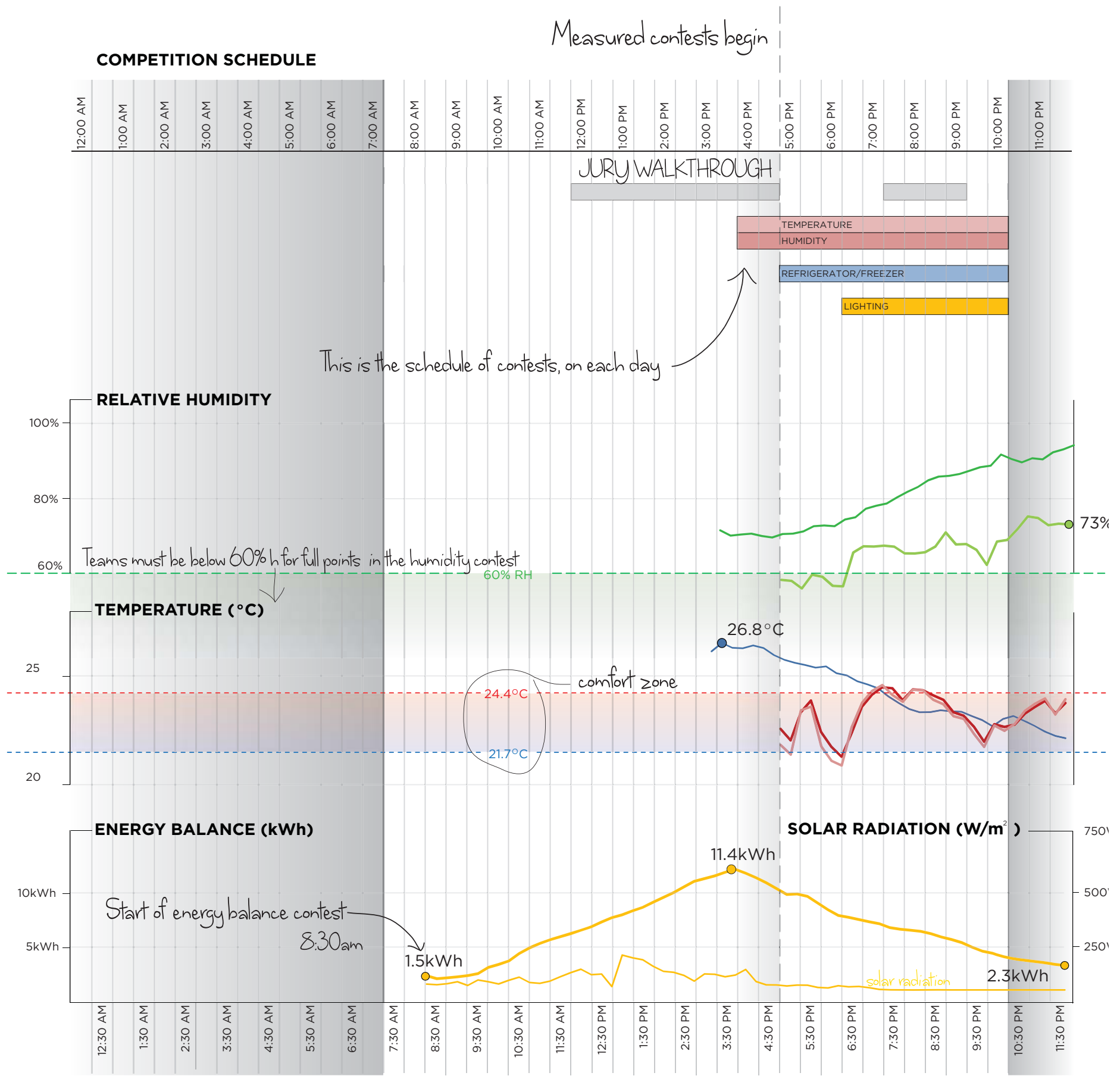

Figure 96: September 22 peformance anaylsis

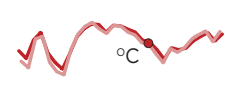

INTERIOR TEMPERATURE

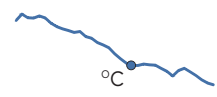

EXTERIOR TEMPERATURE

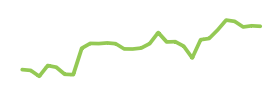

INTERIOR RELATIVE HUMIDITY

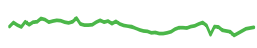

EXTERIOR RELATIVE HUMIDITY

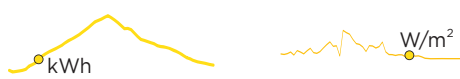

ENERGY BALANCE GLOBAL HORIZONTAL SOLAR RADIATION 


\subsection{Day 1: 22nd September}

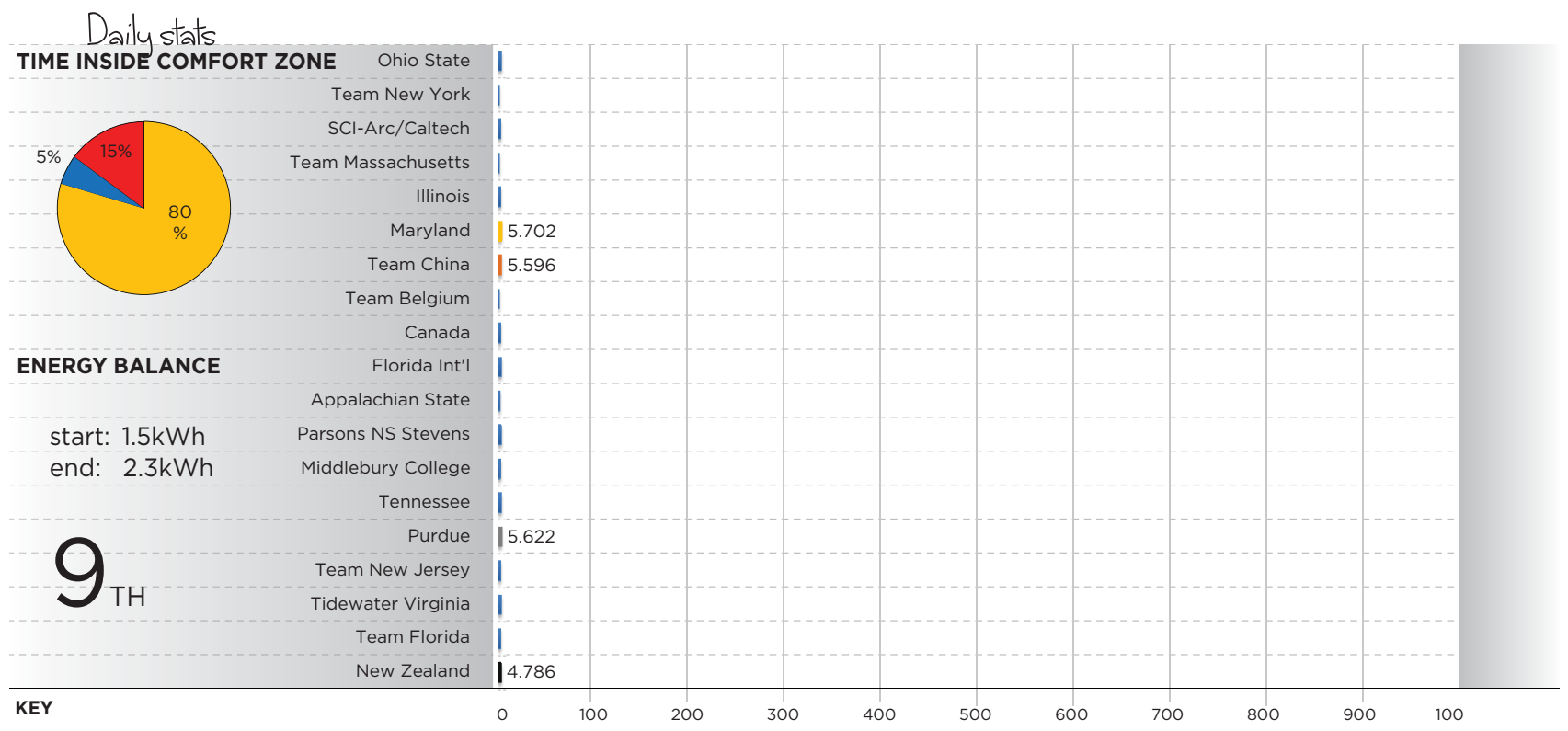

Figure 97: Team scores at the end of Day 1 of the competition

With the energy balance competition beginning at 8:30am there was the potential for a full day's sunshine before the house was turned on and the first energy was drawn off at $5 \mathrm{pm}$. This was a chance to start the competition with a positive energy balance. For the first time in Solar Decathlon history all nineteen teams ${ }^{3}$ had passed inspections and were ready to begin the competition. Unfortunately the weather was not, with grey skies that stretched across the entire Washington Mall throughout the entire day. It was not a great day for energy generation with the First Light house generating only $10.4 \mathrm{kWh}$, less than the estimated worst case scenario for the period. At least, though, all teams were in a similar situation. Even teams like Ohio State and Tennessee, both with solar arrays over $10 \mathrm{~kW}$, struggled with the low levels of solar radiation. By the time the measured contests began in the afternoon the majority of the teams had only generated between 10 and 15kWh (Figure 99.)

With only limited time to commission the HVAC system before the competition, and given it was the first time it was run through the building

3 In the months leading up to the competition Team Hawaii pulled out, leaving only nineteen houses left to compete in Washington DC 
management system, it took a period of monitoring and adjustment to get the house within the comfort range. For the first few hours the temperature bounced from 'too cold' to 'too hot' slipping outside the comfort range on a number of occasions and stabilising just before the house was closed off at 11pm. (Figure 96) Apart from getting the system up and running, and with the outside temperature below the comfort band for most of the period, the house performed as expected and maintained the required temperature for the majority of the time. But with 95\% relative humidity outside the house and no real method of reducing the humidity inside it was soon apparent that the higher than expected humidity for this period in September was going to be a challenge to overcome. Having lost points due to the high humidity the team ended the day in $9^{\text {th }}$ position, with a positive energy balance of $2.5 \mathrm{kWh}$.

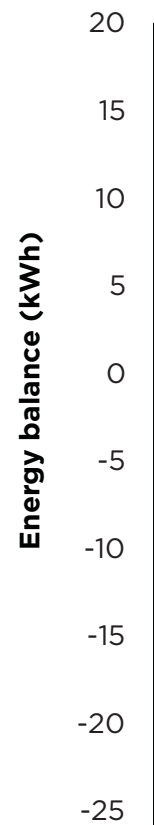

$$
\text { Energy }
$$
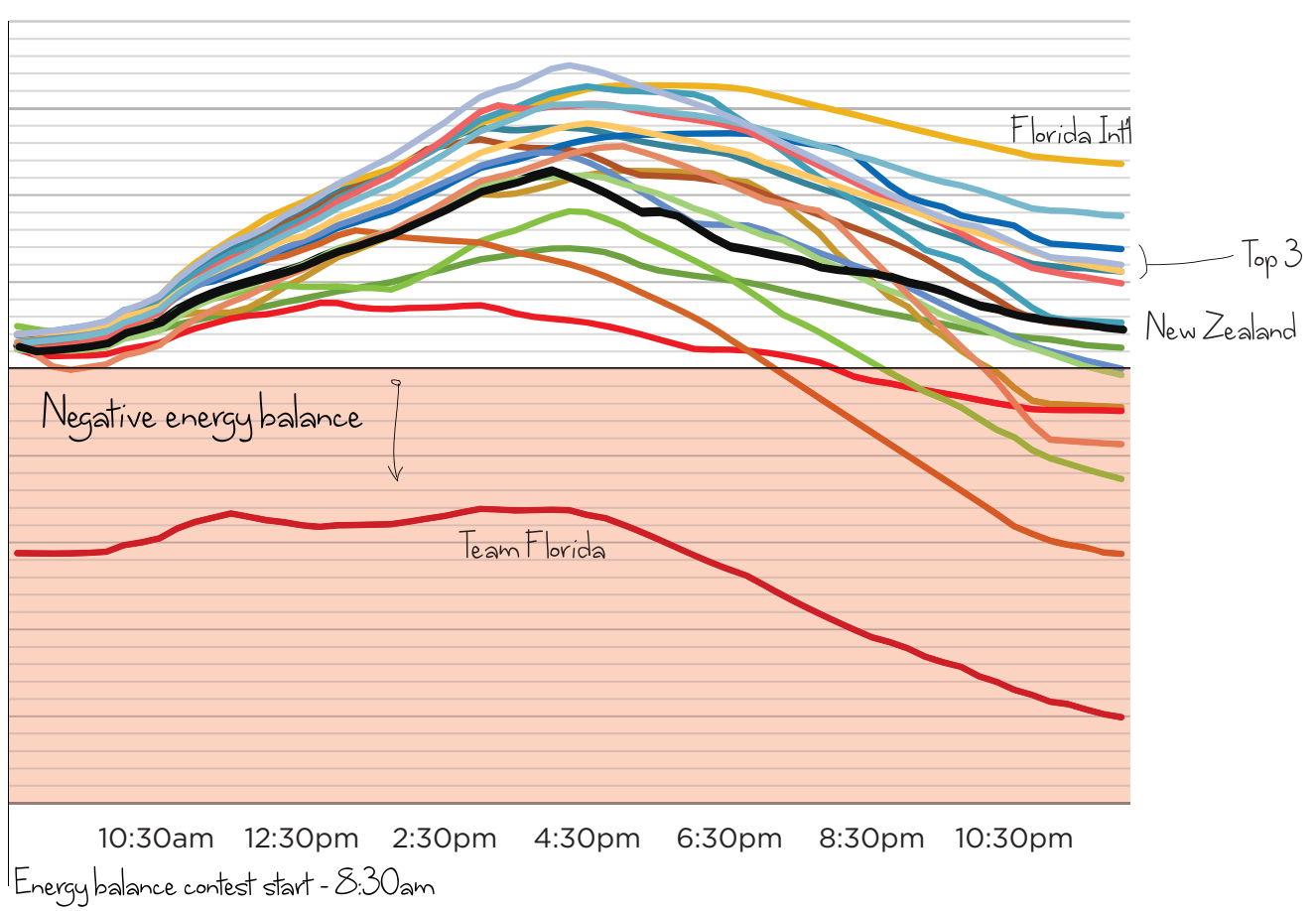

Hours during day

Figure 99: Energy use of all 20 teams throughout on the 22 September, the first day of the competition 


\section{DAY 2}

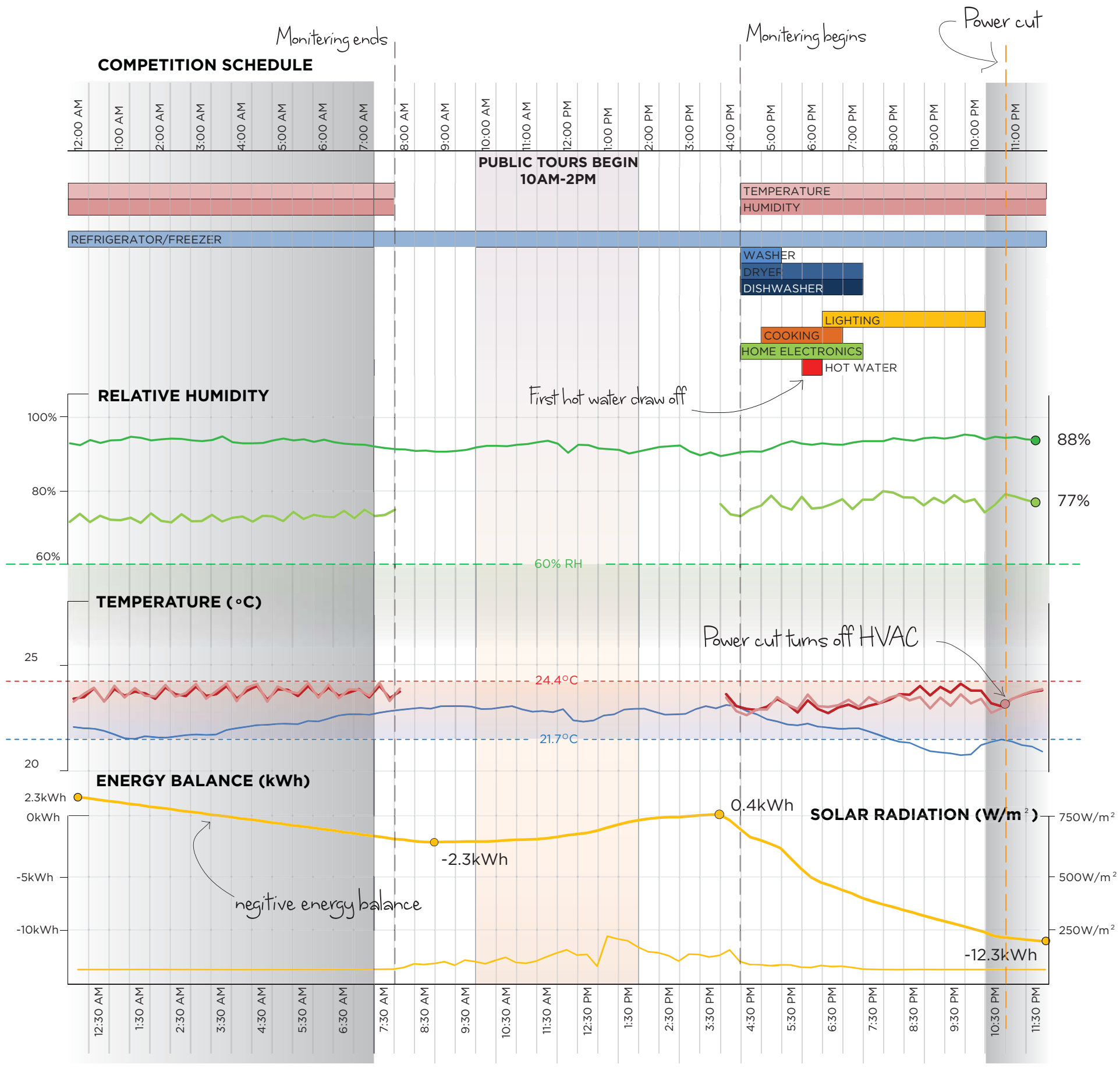

Figure 100: September 23 peformance anaylsis

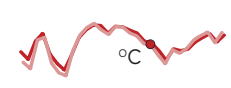

INTERIOR TEMPERATURE

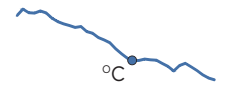

EXTERIOR TEMPERATURE

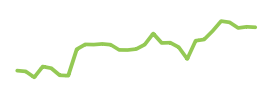

INTERIOR RELATIVE HUMIDITY

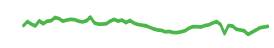

EXTERIOR RELATIVE HUMIDITY

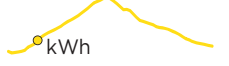

$\mathrm{W} / \mathrm{m}^{2}$

ENERGY BALANCE GLOBAL HORIZONTAL SOLAR RADIATION 


\subsection{Day 2: 23rd September 23}
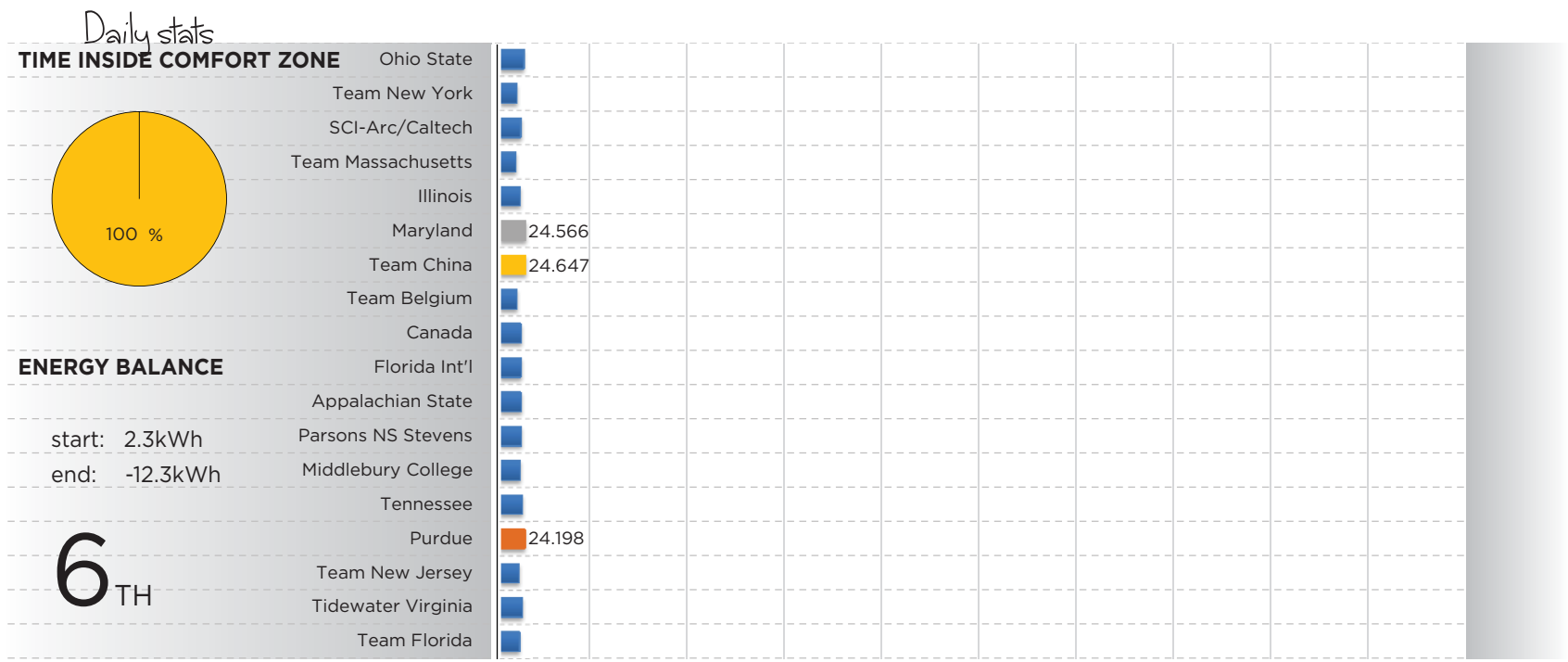

Figure 101: Team scores at the end of Day 2 of the competition

Throughout the night the house sat with a $1^{\circ} \mathrm{C}$ temperature range within the comfort band. To maintain such a strict temperature the HVAC system was running at $0.5 \mathrm{~kW}$ and consumed a total of $4.2 \mathrm{kWh}$ before the house was opened in the morning. (Figure 100) From the mechanical side of the project this was extremely positive, showing that not only was the equipment working and the system functioning as expected but all the time and effort that had gone into simulating, testing and programming the BMS to maintain such strict comfort controls had been successful. Figure 102 compares the performance of the First Light house to the teams that were leading the comfort zone contest. All remain within the comfort zone for the competition throughout the night and all consume energy at a similar rate to the First Light house for the same period. With well-designed building envelopes, large HVAC systems and no internal gains it is no surprise that these houses had no trouble maintaining the comfort zone. For the First Light house, this was the last time that the HVAC system would be run throughout the night.

When the sun came up on the $23^{\text {rd }}$ of September it was hidden behind another sky filled with grey clouds. The weather was worse than the day before with $25 \mathrm{~mm}$ of rain falling throughout the day. Despite the rain, for 


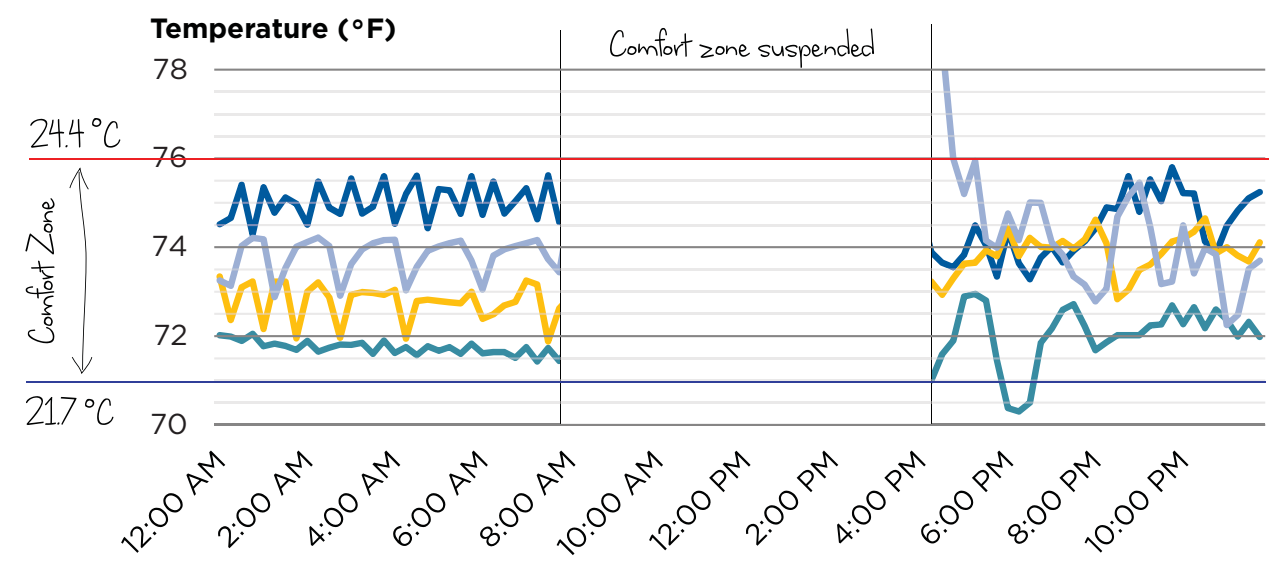

23rd September

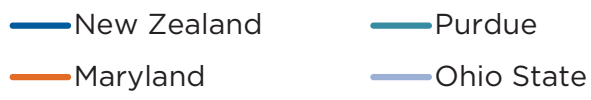

Figure 102: Temperature of New Zealand house compared with the three leading teams in the comfort zone contest

the first time the competition site was opened up between 10am and $2 \mathrm{pm}$ for public tours. The rain did not stop people coming to visit the houses and despite the best efforts of the team to reduce the amount of water that was brought inside by the incoming guests, by the end of the day the timber floor was saturated and there was water everywhere. Once public tours had finished there were two hours to remove as much water as possible and get the house back within the temperature range. It was soon apparent that the timber inside the house had soaked up so much water throughout the day that even with the drying function of the HVAC system running, the house would not drop below $60 \% \mathrm{RH}$ and no points would be gained. Looking at the top seven teams in the competition it

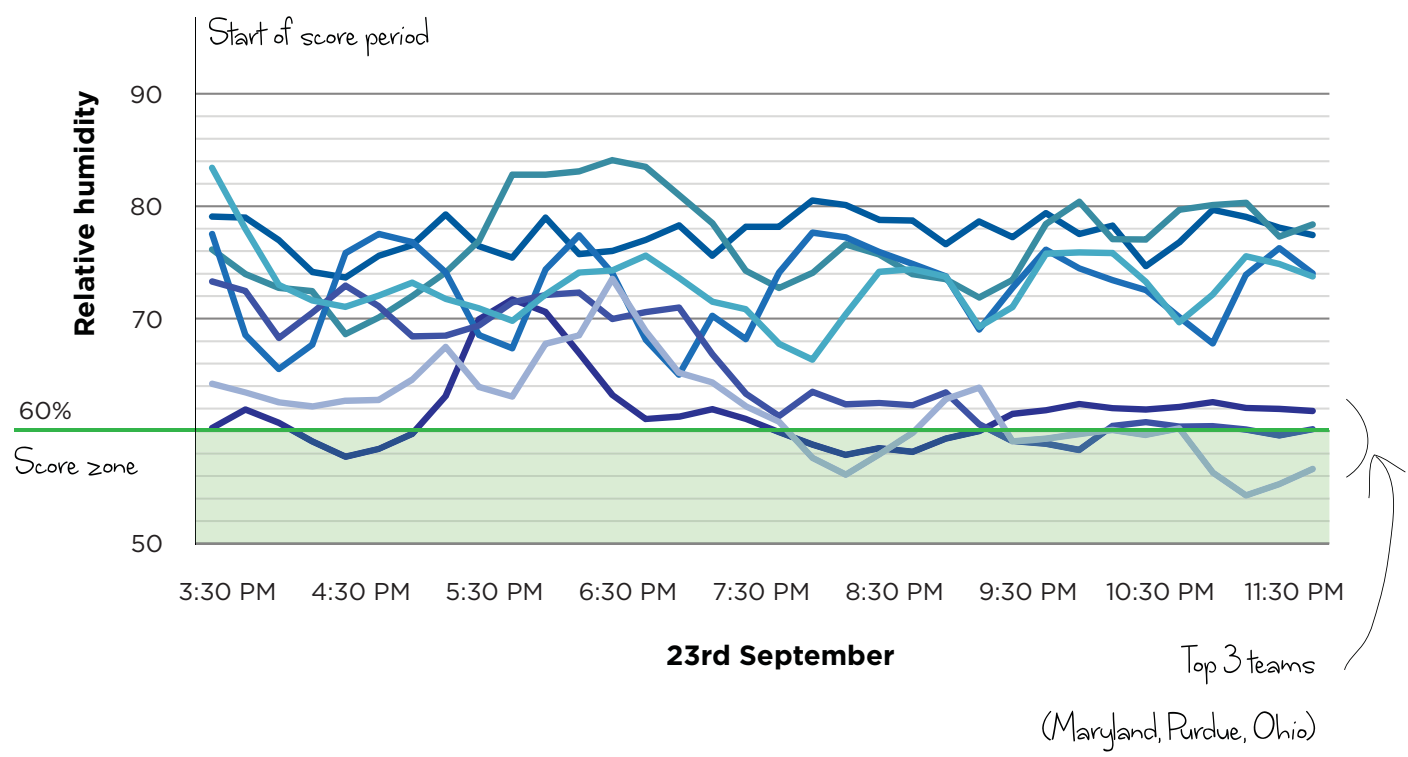

Figure 103: Relative humidity of the top 7 teams during the scoring period of the 23 September 
seemed that everyone was struggling with humidity with only one team consistently falling within the scoring range (Figure 103). By forfeiting the points in humidity it was imperative that full points were gained for temperature in order to stay in touch with the leaders.

Once public tours were over it was interesting to see how each house came back within the comfort range and to monitor the difference in temperature maintained once the internal gains from appliances and home entertainment were applied. Throughout the monitored tests live scoring data for every team was available on site. This meant that teams could not only monitor the performance of their own house but every other house on the competition site. This made interesting viewing throughout the week as tactics changed. At this stage of the competition every team was struggling with the humidity, so maintaining the comfort zone and gaining full points in each of the other measured contests was critical. In order to do this and having only generated $2.77 \mathrm{kWh}$, meant consuming energy and moving into a negative energy balance in the hope for sunshine later in the week. Starting the day in the positive the First Light house ended with a negative energy balance of $12.2 \mathrm{kWh}$ (Figure 104). With a good performance in all of the measured contests and achieving full points in temperature the team had jumped into $6^{\text {th }}$ position, not too far behind the leaders.

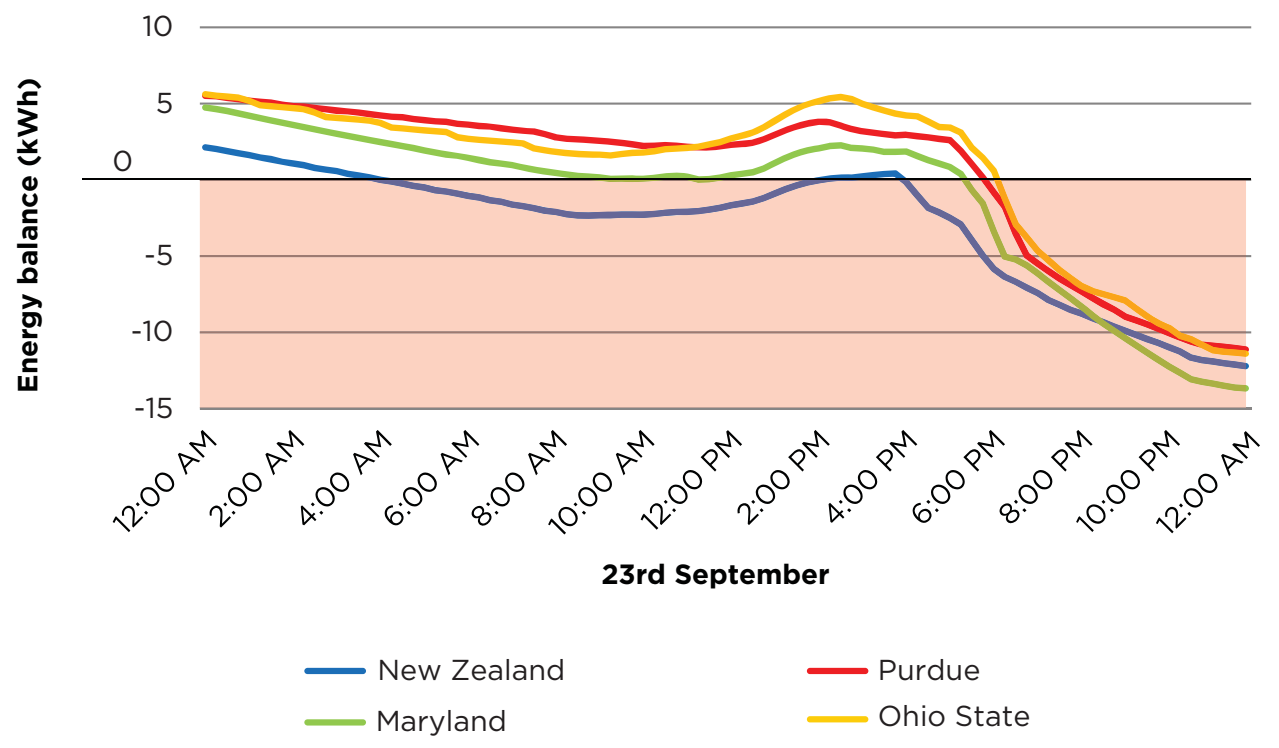

Figure 104: Energy balance of New Zealand compared with the top three teams by the end of the $23^{\text {rd }}$ of September 


\section{DAY 3}

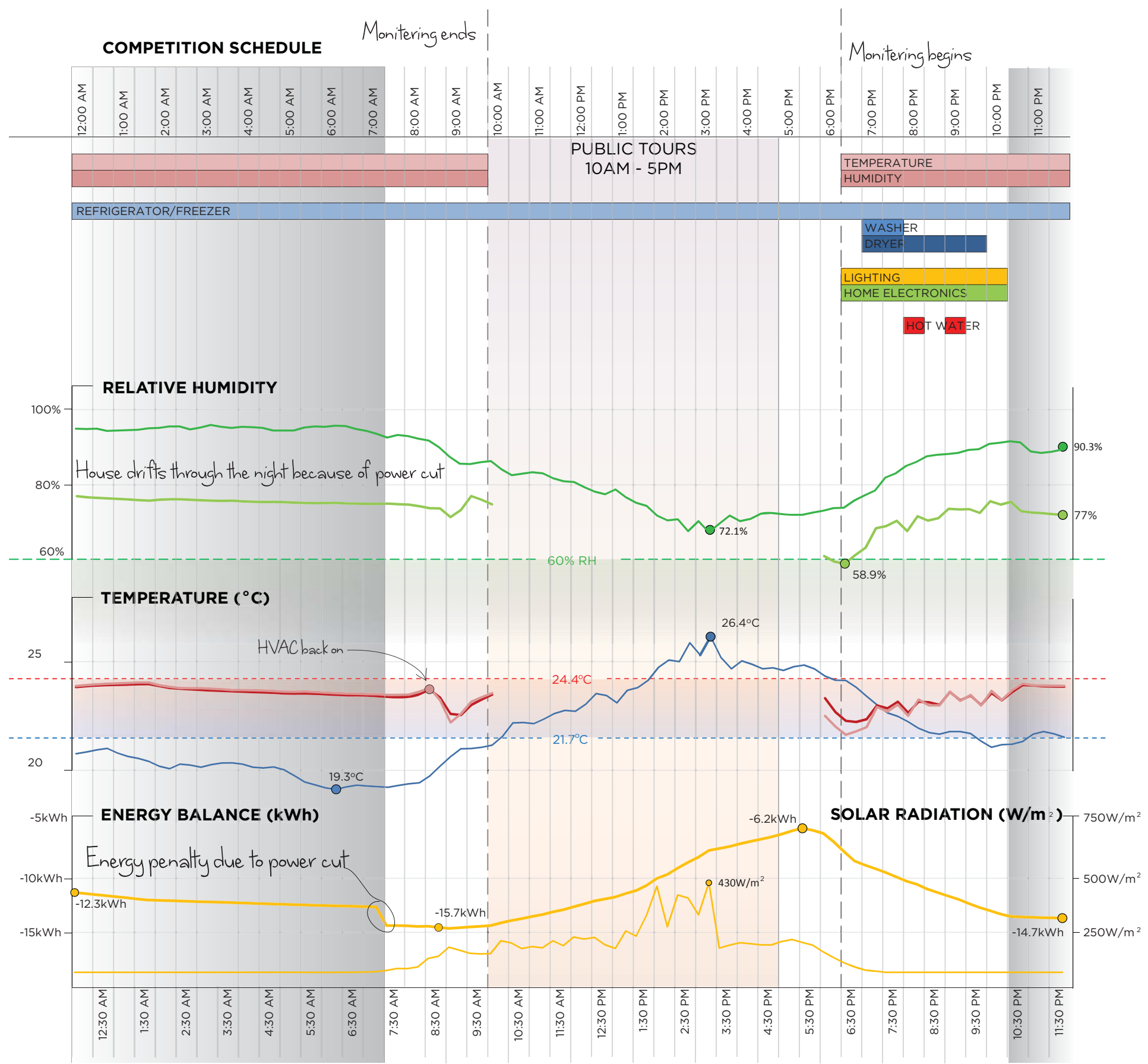

Figure 105: September 24 peformance anaylsis

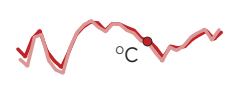

INTERIOR TEMPERATURE

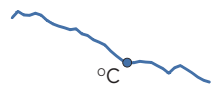

EXTERIOR TEMPERATURE

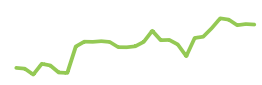

INTERIOR RELATIVE HUMIDITY

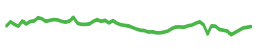

EXTERIOR RELATIVE HUMIDITY

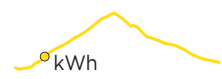

$\mathrm{W} / \mathrm{m}^{2}$

ENERGY BALANCE GLOBAL HORIZONTAL SOLAR RADIATION 


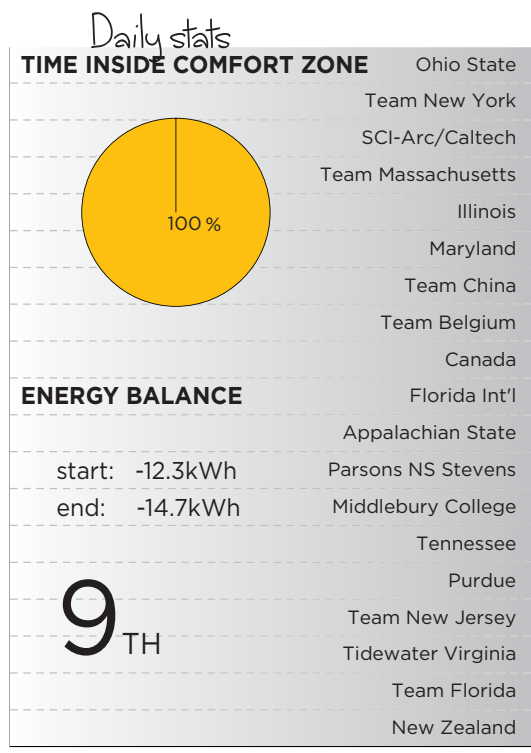

KEY

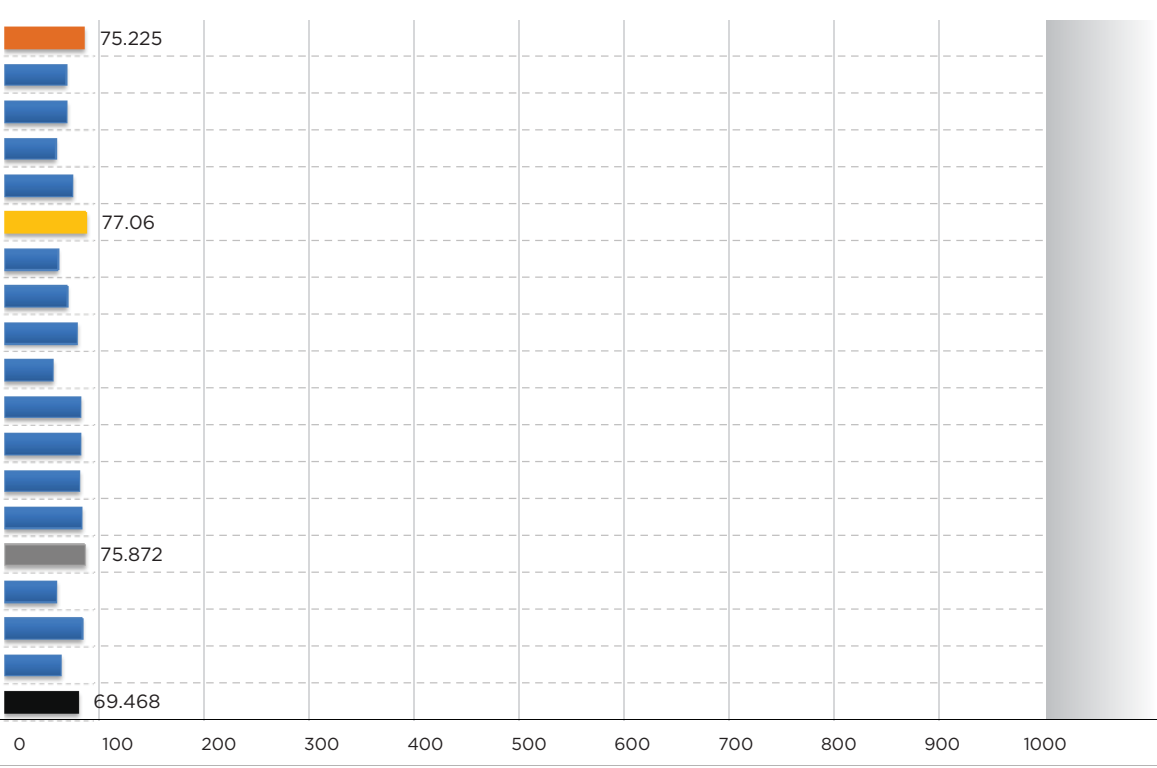

Figure 106: Team scores at the end of Day 3 of the competition

At 11pm the previous night, just after the houses had been closed up for the night, there was a power cut on the $230 \mathrm{v}, 50 \mathrm{HZ}$ power grid affecting all of the international teams. For the First Light house it shut off the HVAC system, meaning that the house drifted throughout the night without any mechanical heating or cooling (Figure 105) It took a while to realise this had occurred as no points had been lost due to the malfunction. The house had done what it was designed to and maintained a constant temperature passively. In fact the temperature inside the house dropped less than a degree throughout the night. This highlighted how well the house had been designed and that it could perform without the mechanical system as the simulations had shown. All the effort that was put into simulations early in the design process had been forgotten leading up to the competition. Focusing on the strict comfort requirements had led to an unnecessary reliance on the HVAC system. It was lucky this had occurred early on in the competition otherwise it was likely the house would have continued to be run with the HVAC system, at a dramatic cost to the team's energy balance. The organizers of the competition realised the advantage this had given the First Light house and added 2.5kWh to our total energy use in place of the energy that would have been consumed by the HVAC system had the power cut not occurred. 
The new day bought more clouds with similar humid weather. Throughout the day the average humidity was $87 \%$, reaching close to $95 \%$ for most of the night. It was becoming apparent that the teams that had a means of dealing with humidity were gaining a strong points advantage over the teams that did not. After the public tours the aim was to try the drying function of the HVAC system in order to reduce the humidity inside the house. For the first hour the house remained below $60 \% \mathrm{RH}$ but as this was achieved the temperature dropped to the bottom end of comfort zone. This setting had not been tested before and was not a part of the programming that had been done in the BMS. Maintaining a much larger temperature range made it difficult to maintain both the comfort zone requirements of temperature and humidity. Using the drying function also consumed large amounts of energy. During the one hour period where the humidity was below $60 \%$ while in drying mode the house consumed over $3 \mathrm{kWh}$. It was decided to sacrifice the points allocated for humidity in order to gain full points for temperature, which was worth more over the course of the competition. Looking at Figure 107 comparing the humidity of the top three teams during the scoring period on the $24^{\text {th }}$, the difference was their ability to maintain the humidity below $60 \%$.

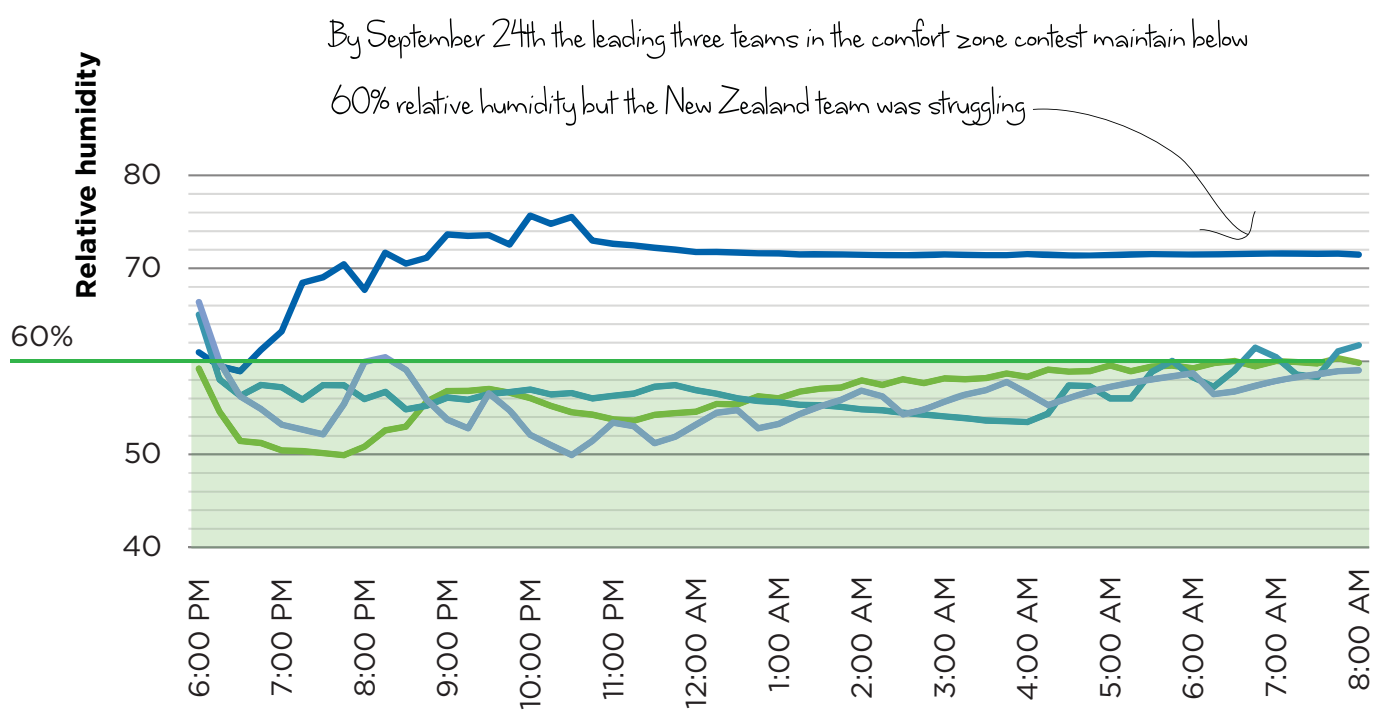

24th September

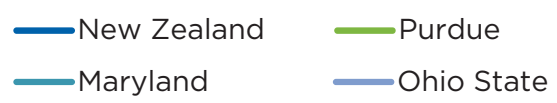

Figure 107: Graph of top three teams humidity during score period compared with New Zealand 
The humidity was not just causing problems for the comfort zone. The design of the hydronic drying cupboard meant bringing in air from the outside that was heated by the hot water heat exchanger. The problem was that the system was trying to dry six bath towels using humid outside air. When designing the drying cupboard the team had overlooked the potential for high humidity's at this time of the year in Washington DC and had not allowed for this in the design. This was also compounded with low hot water temperatures due to the low levels of solar radiation from the previous three days, and meant that the team could not achieve full points in the drying category. In 2 hours and 15minutes the dryer was only able to remove $95 \%$ of the water in the towels, meaning that only 2.5 points out of the possible 5 were gained. This, added to the loss in points in the comfort zone, meant that the team lost points and dropped to $9^{\text {th }}$ by the end of the day
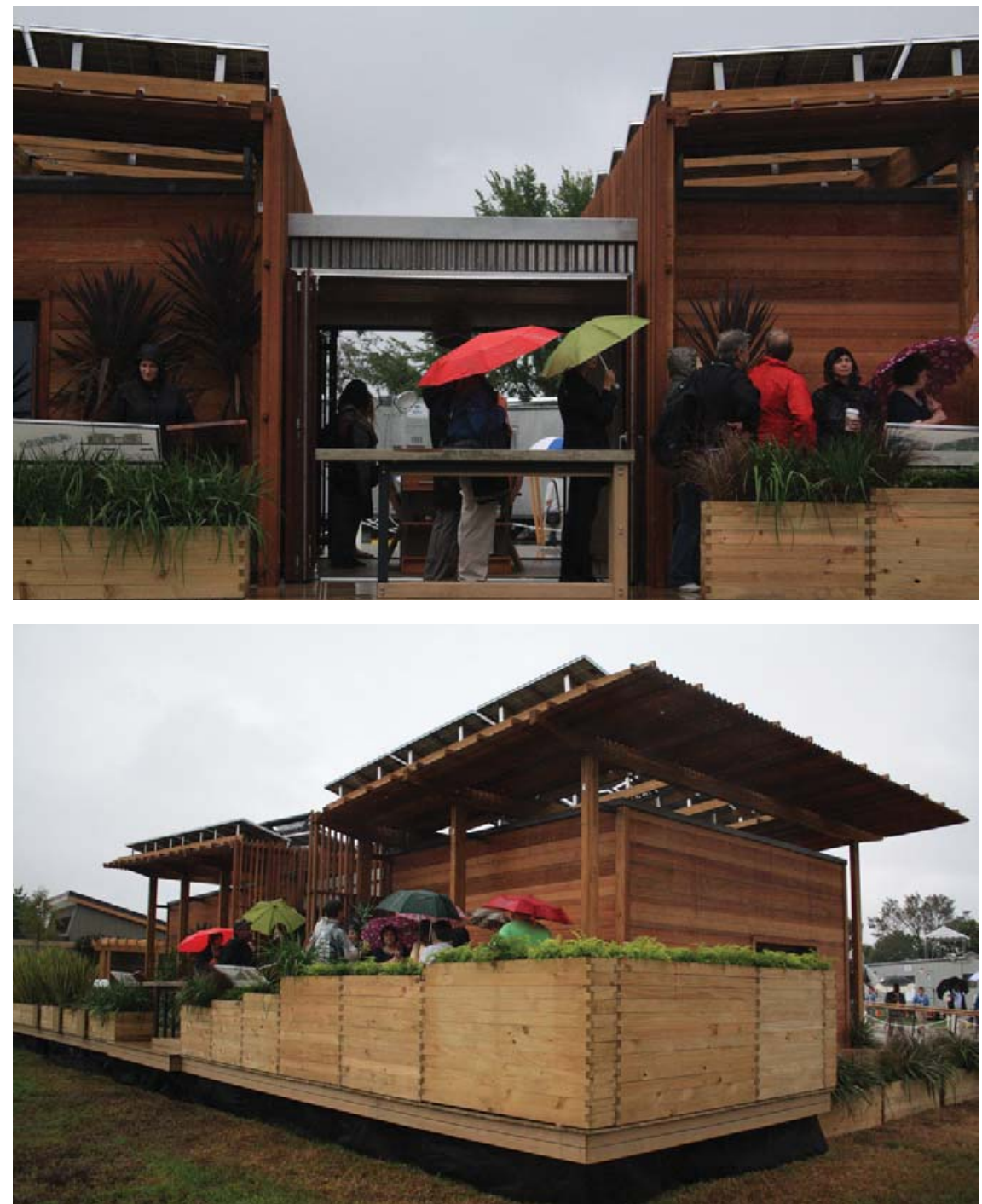

Figure 108: Public lining up to view the house despiet the rain 


\section{DAY 4}
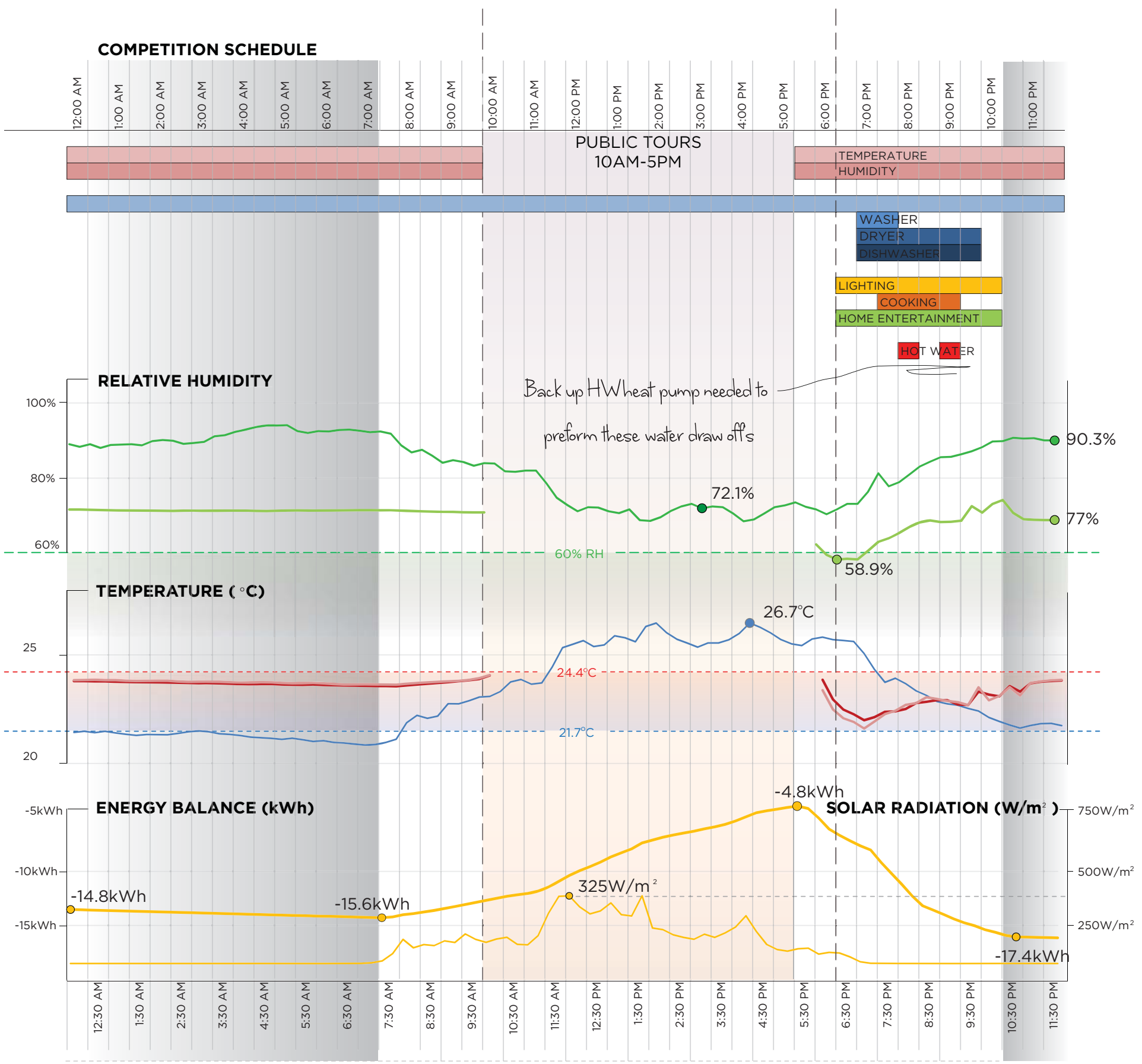

Figure 109: September 25 peformance anaylsis

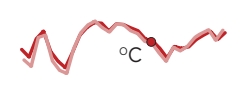

INTERIOR TEMPERATURE

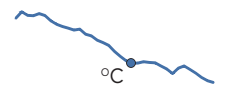

EXTERIOR TEMPERATURE

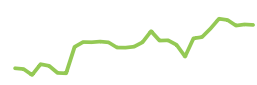

INTERIOR RELATIVE HUMIDITY

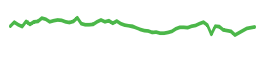

EXTERIOR RELATIVE HUMIDITY

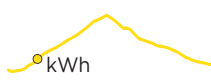

$\underset{0}{W} / m^{2}$

ENERGY BALANCE GLOBAL HORIZONTAL SOLAR RADIATION 


\subsection{Day 4: 25th September}

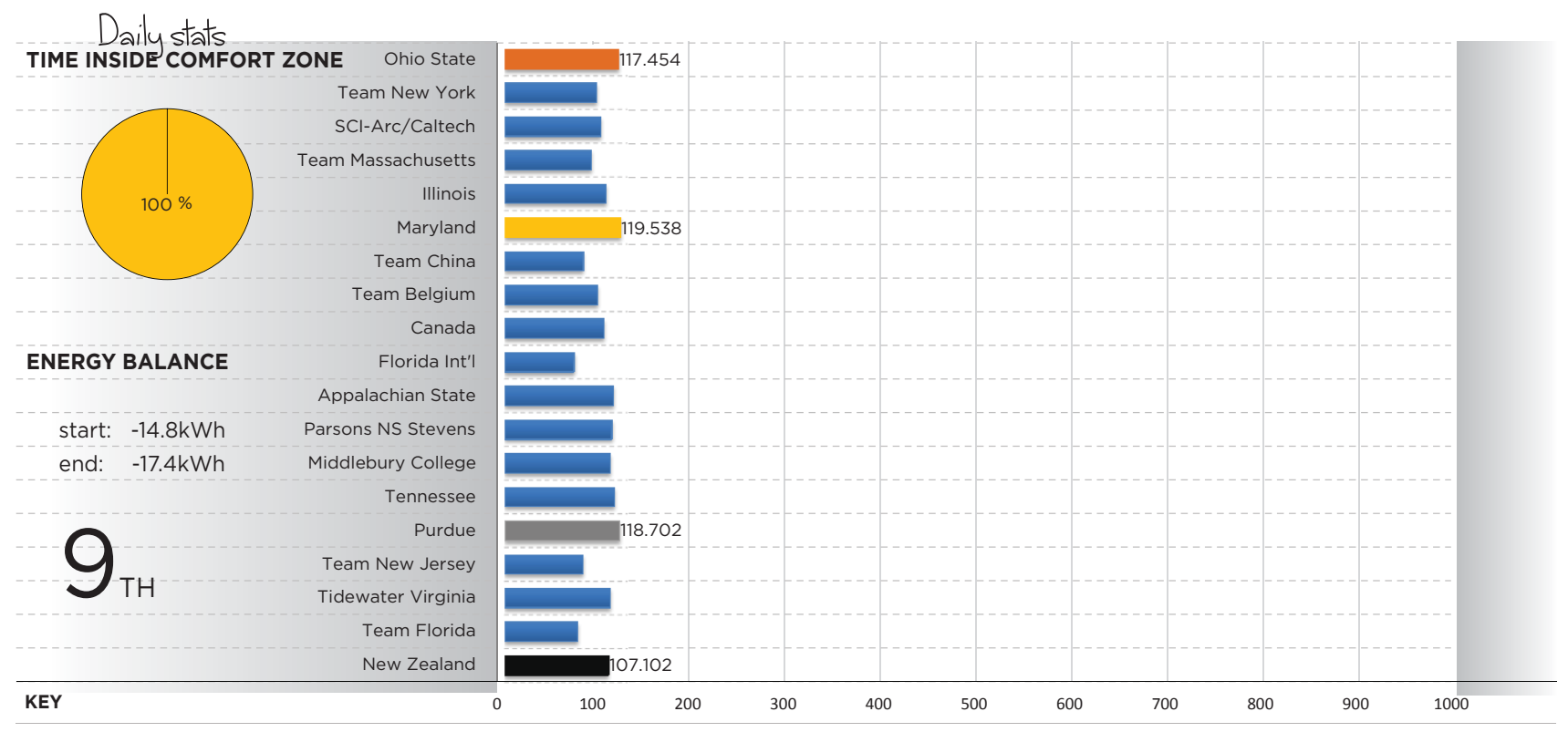

Figure 110: Team scores at the end of Day 4 of the competition

The dawn of September 25th bought yet another day of overcast skies. Low levels of solar radiation over the past few days meant that most teams were sitting on a negative energy balance but it also meant that teams with solar hot water systems could not generate any hot water. In the First Light house, the temperature in the tank for the past few days was sitting below $50^{\circ} \mathrm{C}$. This meant that the heat pump back up had to be employed in order to get the water temperature hot enough to complete the water draws and run the dryer. In the energy budget performed prior to the competition the use of the hot water heat pump was not allowed for, as the evacuated tubes were expected to generate enough hot water, even in cloudy conditions. With the points being lost due to the humidity there was no choice but to use this back up to guarantee full points in the hot water contest and hope for sun later on in the week.

The house was consuming more energy than expected due to the period of bad weather but in comparison with the other teams was still in a strong position. By the end of the day, the house sat in a similar situation to the leaders on $-17.5 \mathrm{kWh}$. There were only two teams in a better position with the majority of teams having consumed well above 20kWh more than they had generated (Figure 112). 


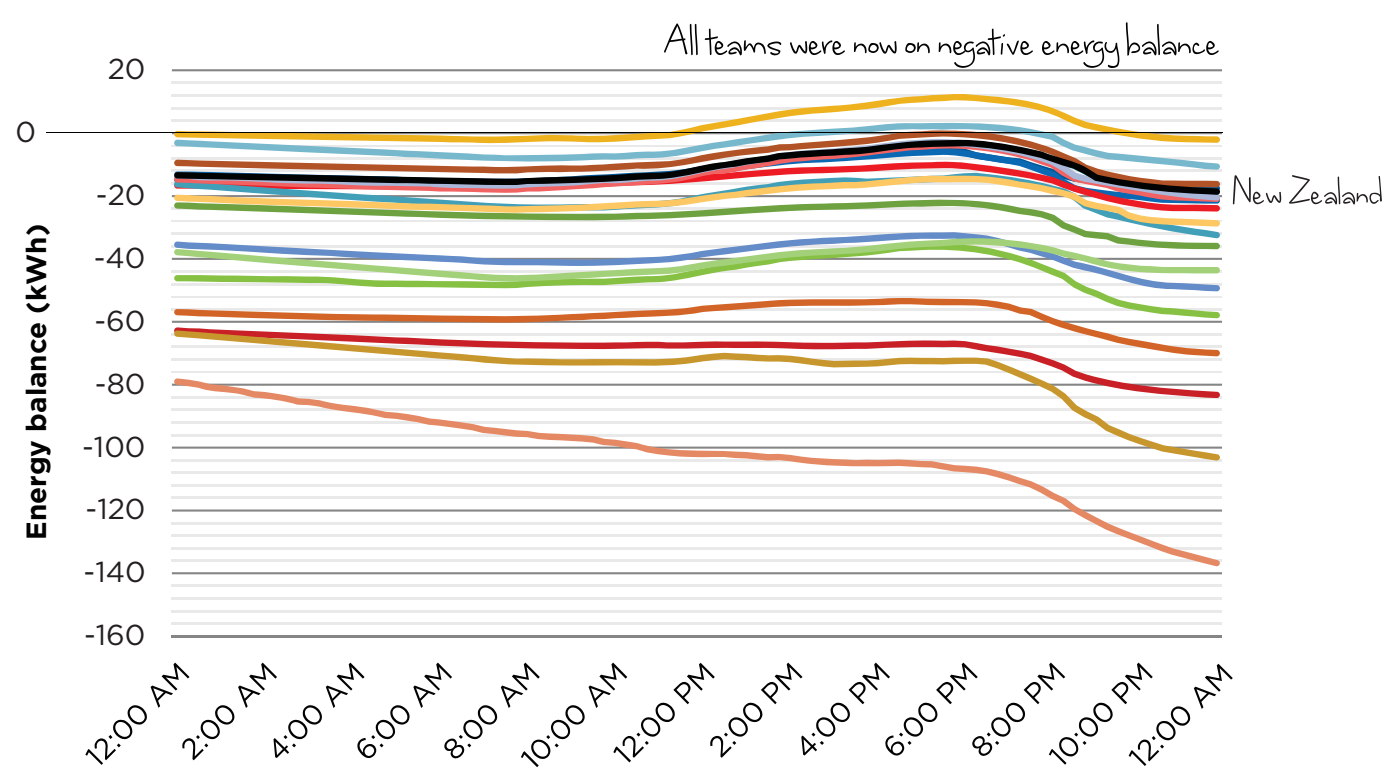

25th September

Figure 112: Energy balance of all teams on day 4

Among the teams that were sitting on a similar energy balance, the First Light house consumed less energy, especially with the tactical decision to turn off the HVAC system over night. Even with the other measured contests the First Light house was consuming at least $5 \mathrm{kWh}$ less than its rivals per day because of the extremely energy efficient lighting and appliances and the hydronic drying cupboard. The problem was that despite the house being more energy efficient than its rivals, all of the top five teams had larger solar arrays and their generating potential on a sunny day was far greater. The weather, which had already been a key factor in this competition, was looking as if it might have a major bearing on the winner of the competition.
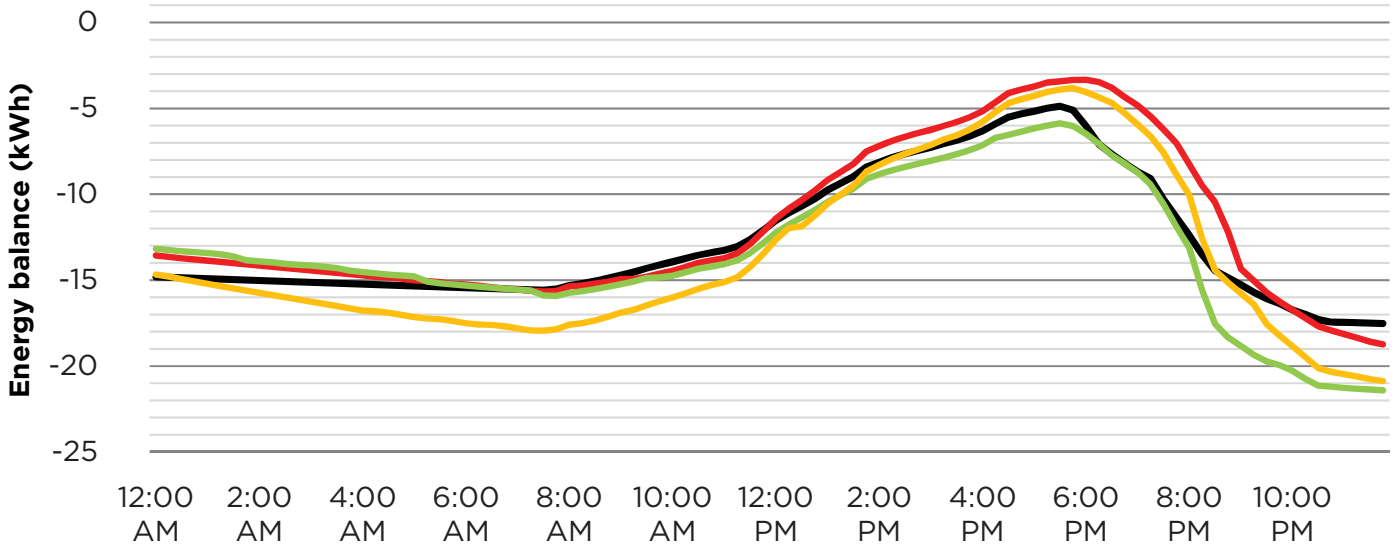

25th September

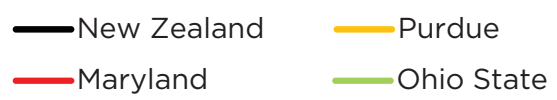

Figure 113: New Zealand's energy balance compared with top three teams on September 24th 


\section{DAY 5}

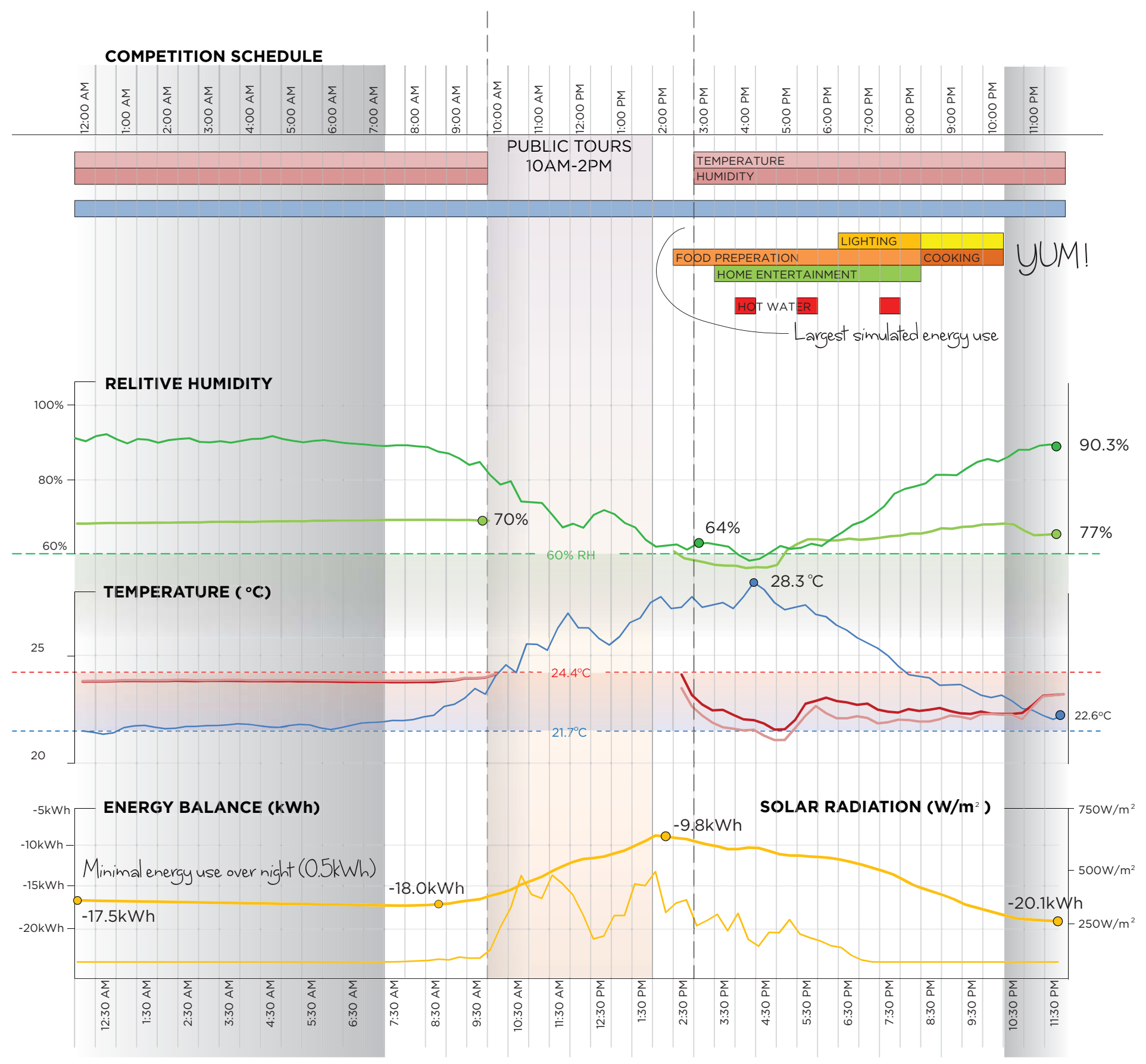

Figure 114: September 26 peformance anaylsis

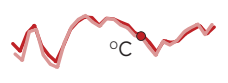

INTERIOR TEMPERATURE

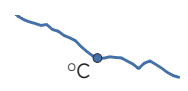

EXTERIOR TEMPERATURE

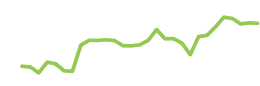

INTERIOR RELATIVE HUMIDITY

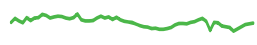

EXTERIOR RELATIVE HUMIDITY

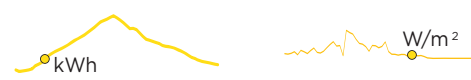

ENERGY BALANCE GLOBAL HORIZONTAL SOLAR RADIATION 


\subsection{Day 5: 26th September}

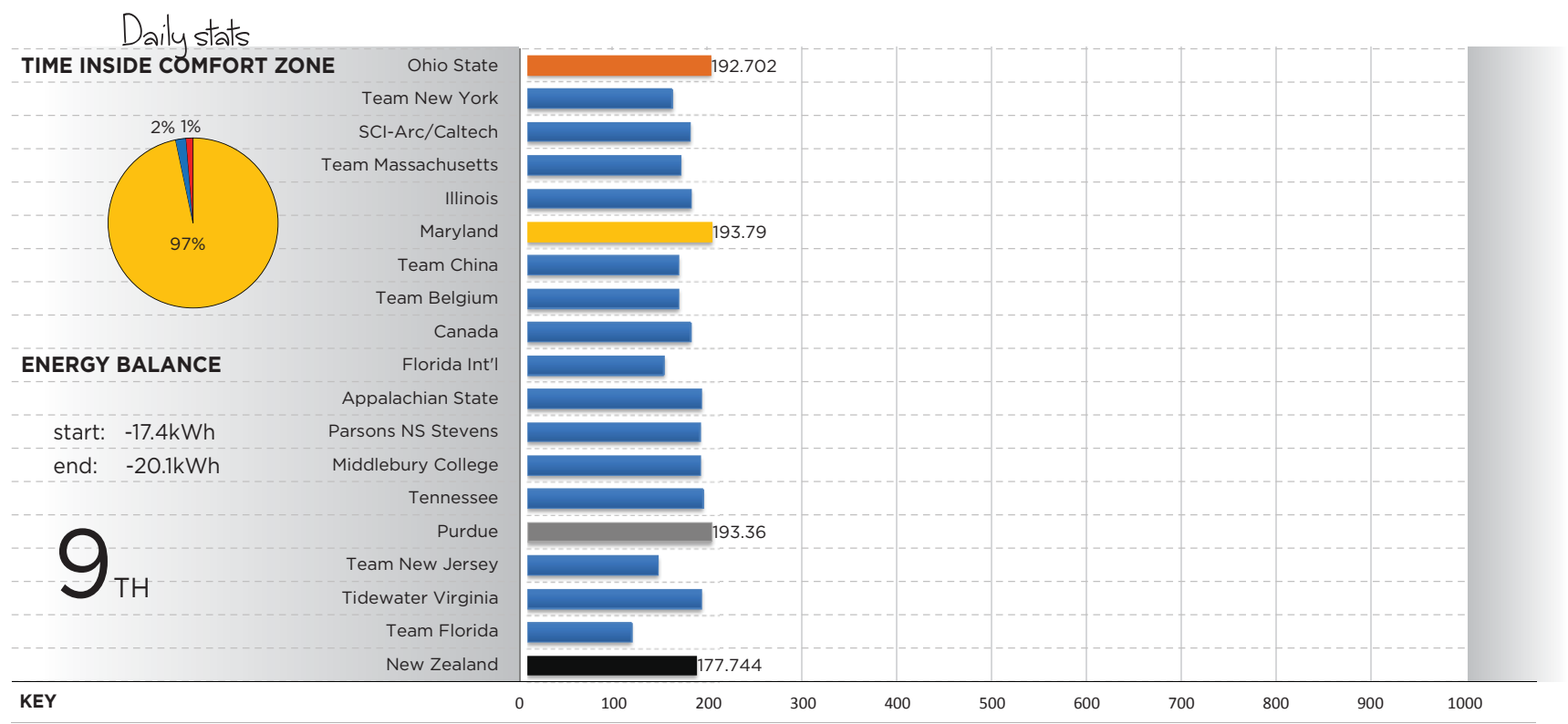

Figure 115: Team scores at the end of Day 5 of the competition

For the first five days of the competition the energy generation had been below the designed $10 \%$ worst case scenario. With less than $10 \mathrm{kWh}$ generated throughout the competition there was a strong possibility that all of the teams would drift further into negative energy balance. From the energy simulations day 13 was predicted as the day with the largest energy consumption. (Figure 72) With this in mind and the thought of continued grey weather it was looking increasingly more difficult to achieve a positive energy balance. The forecast was for more cloudy weather in the coming days and with the first of two dinner parties to be held in the evening an interesting situation developed from an energy perspective. The dinner party was a chance to entertain and cook a meal for guests from other teams. It was an opportunity to show off the house, New Zealand culture and cuisine, and celebrate the common achievements of those involved. The guests would judge the quality of the meal and the ambiance and a score would be given. But at this stage in the competition the five points allocated for the dinner party had to be weighed against the need to save energy, especially if the weather was set to continue. Cooking is often a very energy intensive operation especially for up to ten guests. Two meals had been designed for the competition with energy in mind. (Appendix F) This was fortunate as the energy use of the top eight teams was very high 


\section{DAY 6}

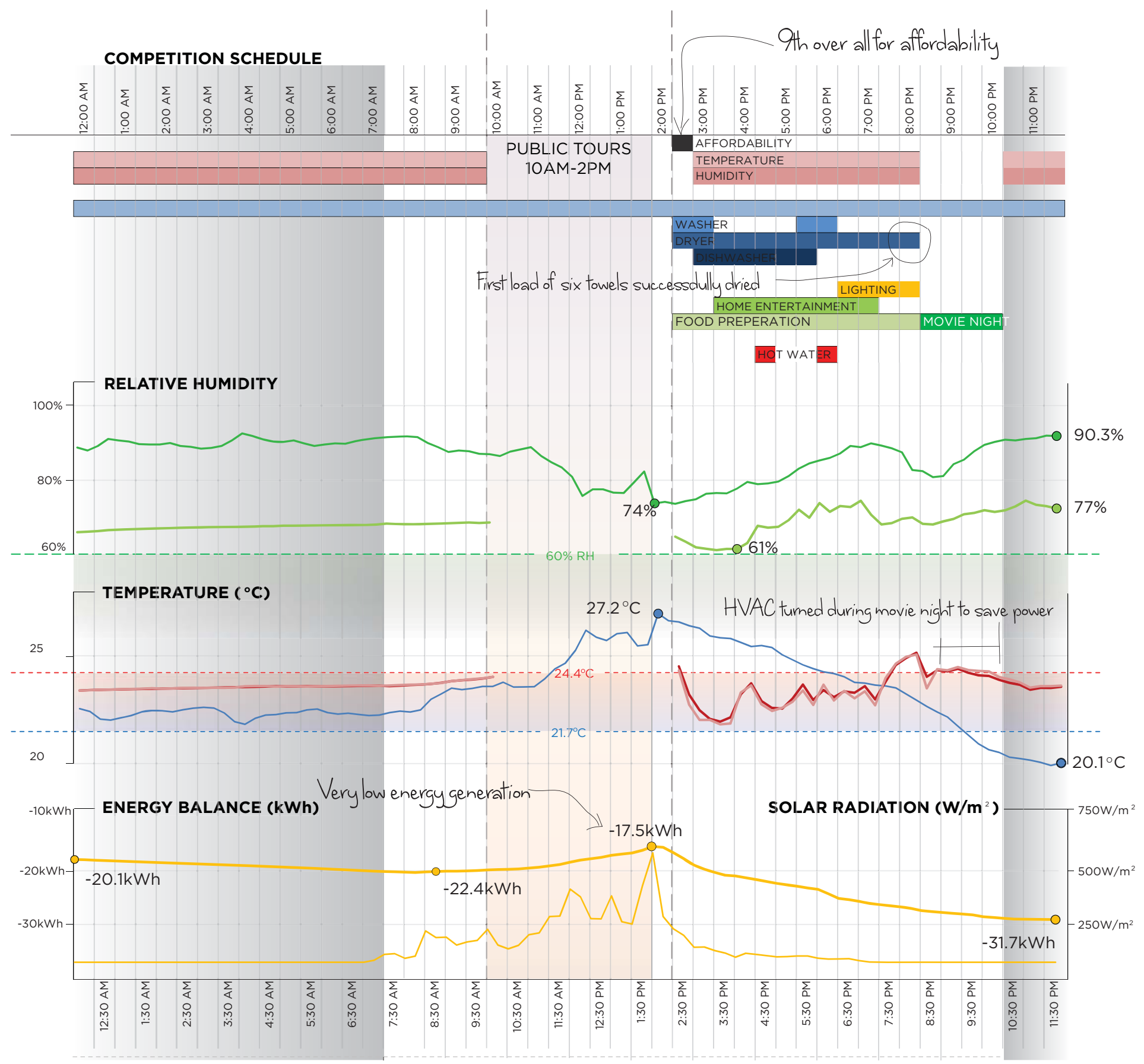

Figure 116: September 27 peformance anaylsis

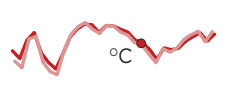

INTERIOR TEMPERATURE

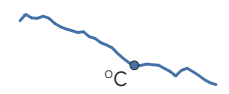

EXTERIOR TEMPERATURE

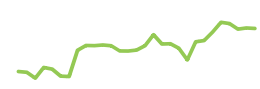

INTERIOR RELATIVE HUMIDITY

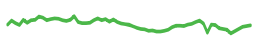

EXTERIOR RELATIVE HUMIDITY

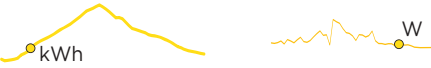

ENERGY BALANCE GLOBAL HORIZONTAL SOLAR RADIATION 
and having very energy efficient meals could make a significant difference. On top of the energy demand of the dinner party the comfort zone had to be maintained throughout. Ten bodies and ten meals have the potential to generate a lot of heat, especially in a well-insulated, air tight box. With such an effective HVAC system the temperature was maintained, again within $1^{\circ} \mathrm{C}$ throughout the evening, only dropping below the comfort band due to cooling the house before the guests arrived. (Figure 114) For the dinner party First Light were ranked second, which moved the team to first in the home entertainment contest but still $9^{\text {th }}$ overall.

\subsection{Day 6: 27th September}

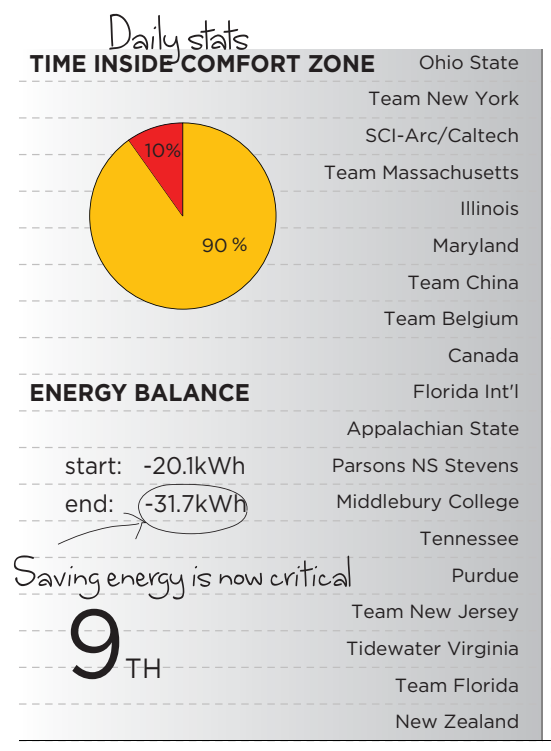

KEY

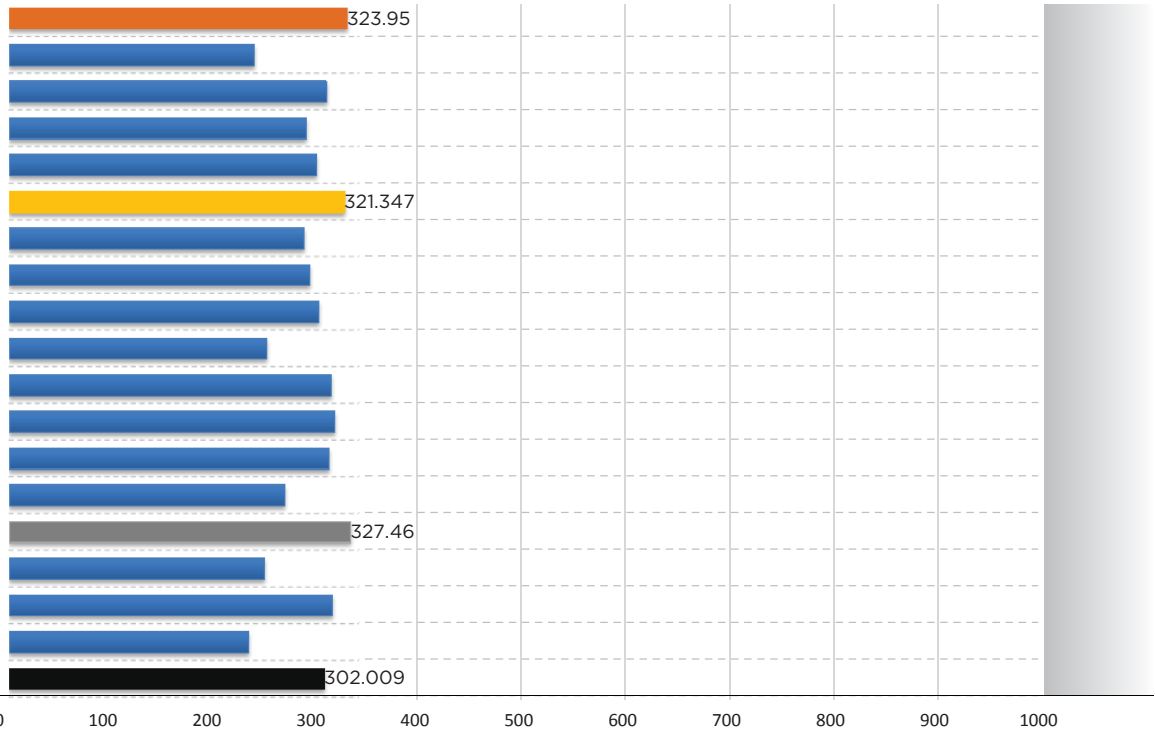

Figure 117: Team scores at the end of Day 6 of the competition

The first of the judged competitions was announced on day six which led to a real buzz around the solar village. Up until this point the teams that were dominating the competition were those that could maintain the comfort zone. With the first announcement being the affordability competition it was interesting to see some of the top teams drop down in the overall points because of the cost of the technology within the home that was gaining them so many points in the measured contests. Team Tennessee, $4^{\text {th }}$ at the beginning of the day, received only 46 points for affordability and dropped them down to $15^{\text {th }}$ place. New Zealand gained 94 points for affordability but the team were only $9^{\text {th }}$ overall in the affordability competition, showing how close the competition was. 
The plan for day six was to save power. Starting the day with an energy balance of $-20 \mathrm{kWh}$ was not helped by yet another day with less than $10 \mathrm{kWh}$ of energy generation. (Figure 116) Today, with two hot water draws and two drying cycles, the backup heat pump was needed yet again. For the first time during the competition the dryer managed to successfully dry one load of towels. Unfortunately by the time the second load went in the temperature in the tank had dropped to just above $40^{\circ} \mathrm{C}$, not enough to dry six large bath towels and the system could only manage to remove 93\% of the water. Humidity was again forfeited and temperature was moved to manual control, only turning on the heat pump intermittently. The plan was to entertain guests in the house for the movie night with the large bi fold doors open and the HVAC off to save power, with the hope that the outside temperature would be sufficient to keep the temperature within the range. Unfortunately the doors were opened when the sun was setting and the temperature outside was above the range meaning the house crept outside the comfort zone for a small period of time. Just before the guests arrived a burst of cooling from the heat pump helped to get the house within the range where it remained for the rest of the night. By the end of the day the energy balance was negative $31.6 \mathrm{kWh}$. This was nearing the limit of what the system could generate in a single day, provided there was a full day of sunshine. With only three days left in the competition and the forecast for continued cloudy weather with patches of sunshine, net zero energy was beginning to look like a distant target. 


\section{DAY 7}

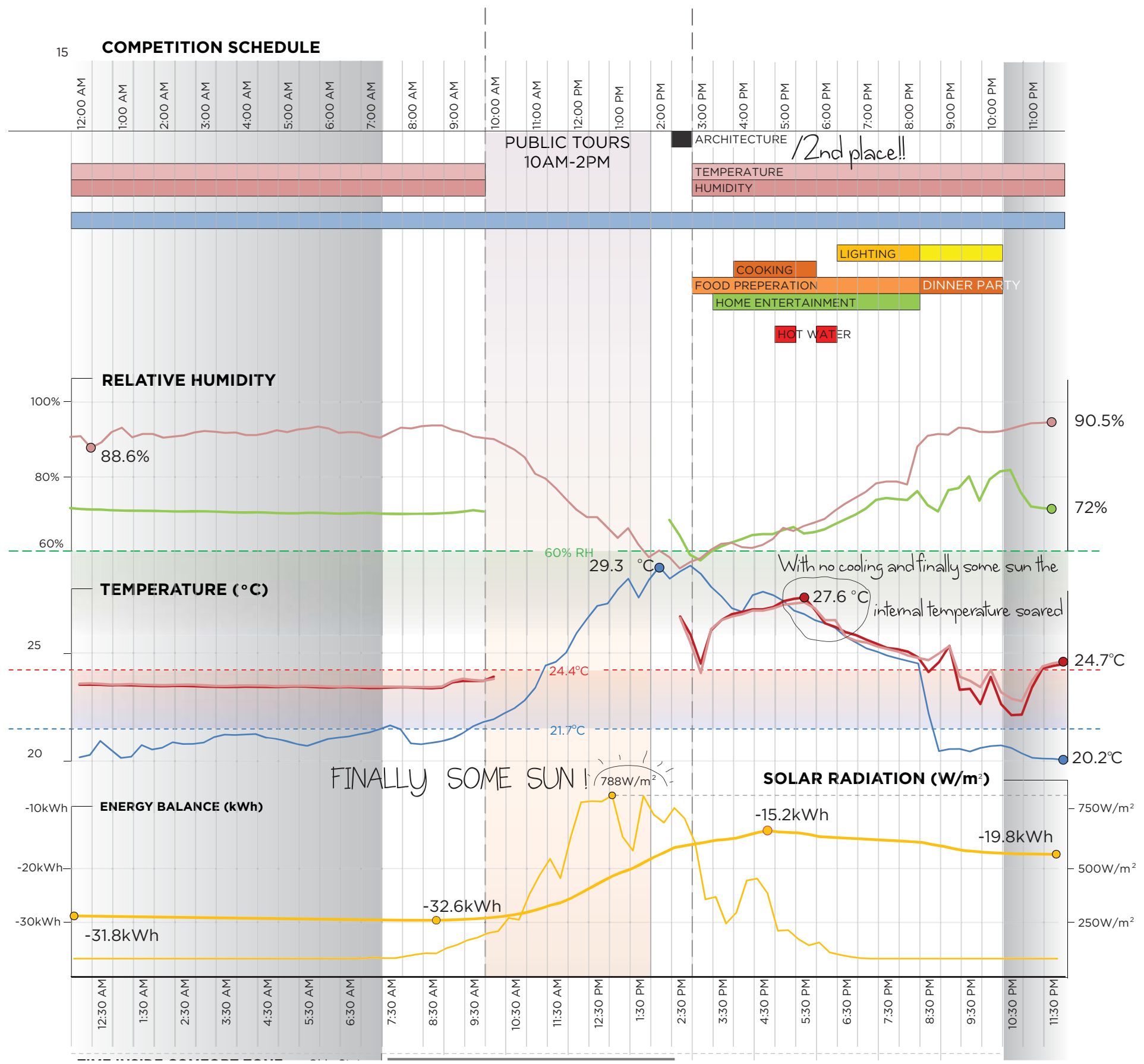

Figure 119: September 28 peformance anaylsis

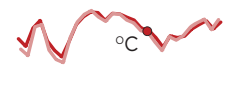

INTERIOR TEMPERATURE

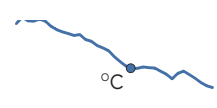

EXTERIOR TEMPERATURE

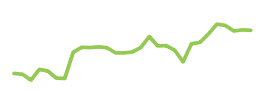

INTERIOR RELATIVE HUMIDITY

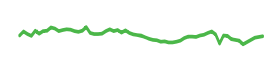

EXTERIOR RELATIVE HUMIDITY

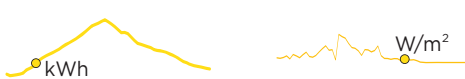

ENERGY BALANCE GLOBAL HORIZONTAL SOLAR RADIATION 


\subsection{Day 7: 28th September}

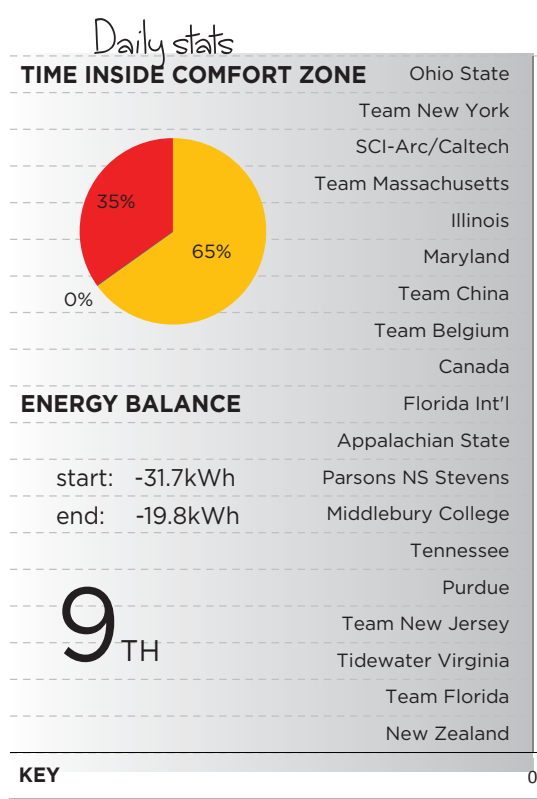

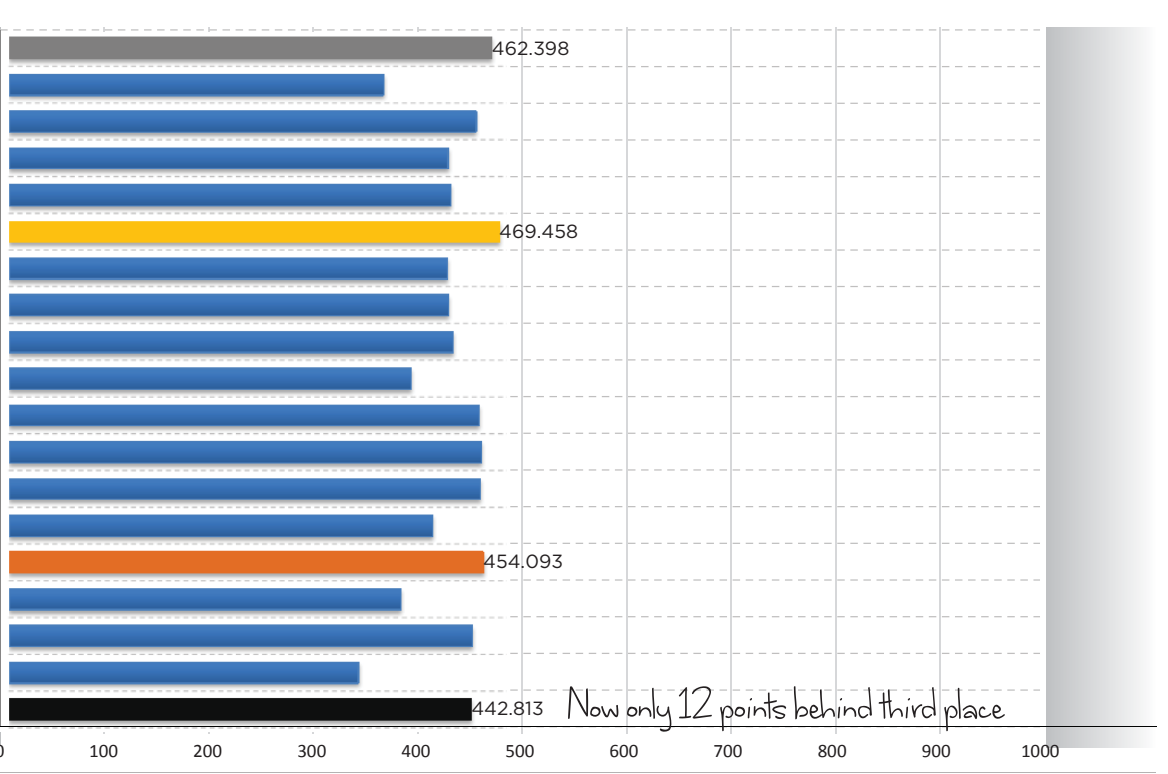

Figure 120: Team scores at the end of Day 7 of the competition

The morning of the $28^{\text {th }}$ brought rain, thunderstorms and more dark skies. As the team arrived at the solar village for public tours there was an air of apprehension at the thought of another day of no sunshine and dropping further away from the target of net zero energy. For the first few hours it continued to rain but as 10:00am arrived and public tours began, for the first time since the contests had begun, the sun peeked out from behind the clouds and shone down on the competition site all afternoon. This was a great relief for all of the teams as they watched their energy balance rise throughout the day, but today was special for another reason. Today was the announcement of the architecture awards. Throughout the entire design process the quality of the architecture was integral to the success of the project. More than any other contest it governed the design decisions that were made and shaped the First Light house. To the New Zealand team the Solar Decathlon was an architecture competition and how the house met the requirements of the other nine contests was a result of the success of the architecture. With this philosophy there was great anticipation surrounding the announcement of the awards with the hope of a much needed points boost.

At the end of the ceremony the First Light house had been placed second 
behind Maryland with 95 points. (Figure 121)At first this brought great excitement and pride at what had been achieved but this was soon washed away by frustration at the points allocation that had rendered the architecture contest irrelavant to the final result. The points differential between first place and last place was only sixteen points. This was the same number of points that the First Light house had already lost against the top three teams due to the humidity, one of five measured contests. To win the Solar Decathlon these results gave no incentive to focus on the quality of the architecture. Instead, the design of a well-insulated air tight box, artificially heated and cooled with a large solar array that met the requirements of the other measured contests could easily win the Solar Decathlon with very little thought put into the architecture. The contests clearly favour technological solutions over passive design strategies imbedded in good architecture and yet the Solar Decathlon challenges teams to showcase 'sustainable design'. It is frustrating that the architecture contest is only worth $10 \%$ of the competition overall points but even more frustrating that a team can gain last place in architecture and still be only sixteen points behind the winner, effectively making the architecture contest worthless in the overall competition. Because of this Purdue (last in architecture) who were in first place the day before, only dropped to third place in the competition and New Zealand $\left(2^{\text {nd }}\right.$ in architecture) stayed in $9^{\text {th }}$.

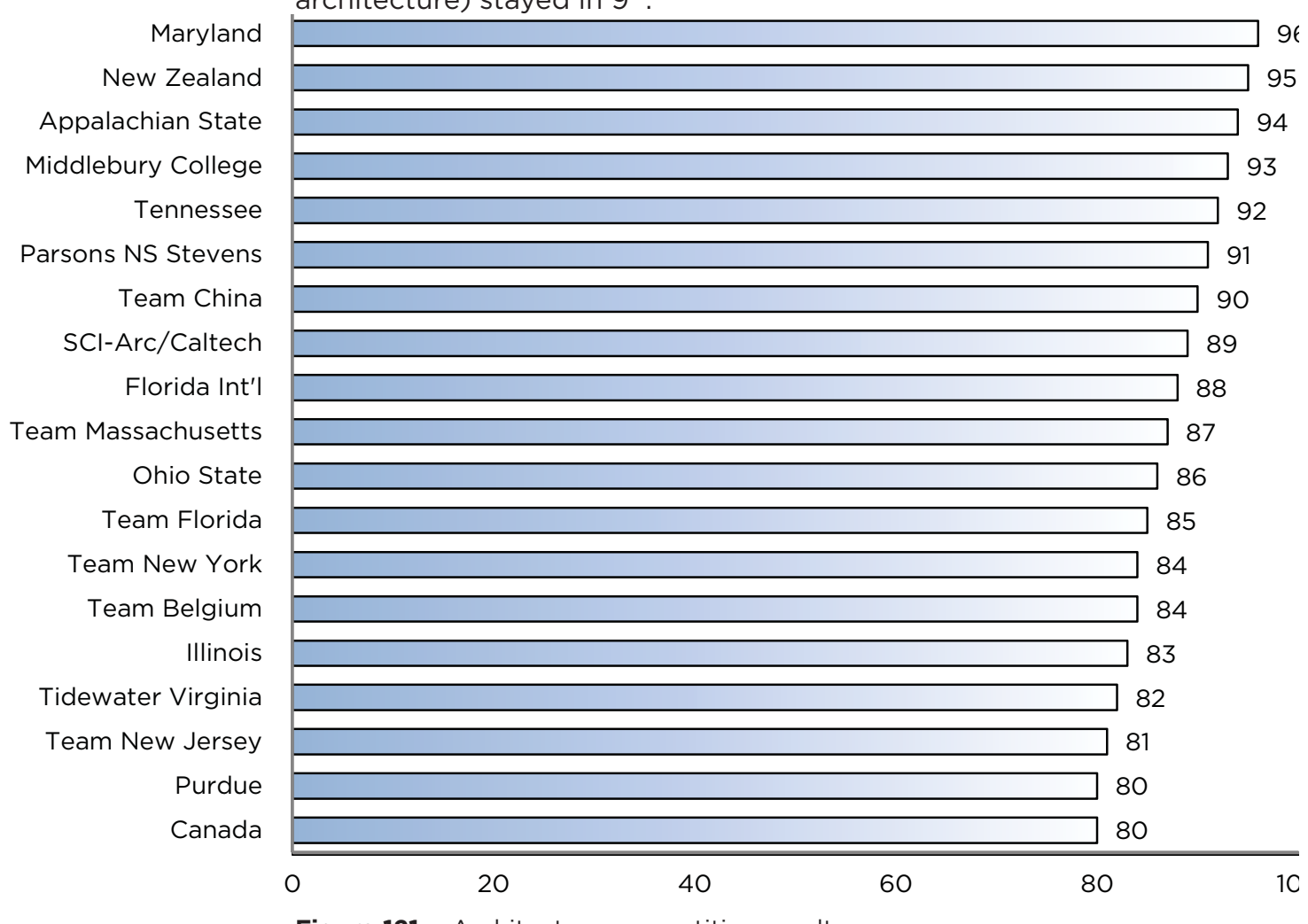

Figure 121: Architecture competition results 
These results, although disheartening, put the focus back on the measured contests. Reassessing the strategy the focus moved on to the energy balance competition. The forecast was for more bad weather and with all teams struggling with energy balance there was an opportunity to make up a large amount of points, provided the First Light house reached zero and the other teams did not. In the energy balance every kWh in negative was worth two points. As half of the teams in the competition were sitting on an energy balance of below $-50 \mathrm{kWh}$, and the rest below $-20 \mathrm{kWh}$, the strategy was to conserve power. The HVAC system remained off for the entire night and the doors were opened. The hot water had received enough energy from the day's sunshine to perform the water draw offs. All pumps were turned off and the BMS was switched to energy saving. Luckily the fish that was being served for dinner did not need a lot of energy to cook and chips and dips were served as an entrée. Every measure to conserve energy was taken as a strategic decision to gain a separation between the First Light house and its rivals. The strategy seemed to work and by the end of the day there was a $5 \mathrm{kWh}$ difference between First Light and Purdue, currently in $3^{\text {rd }}$, and a $15 \mathrm{kWh}$ difference between the leaders Maryland, and 20kWh between Ohio and Middlebury, both ahead on points. (Figure 122) With two days left the team was hopeful that if the weather stayed in its favour this advantage could be expanded.

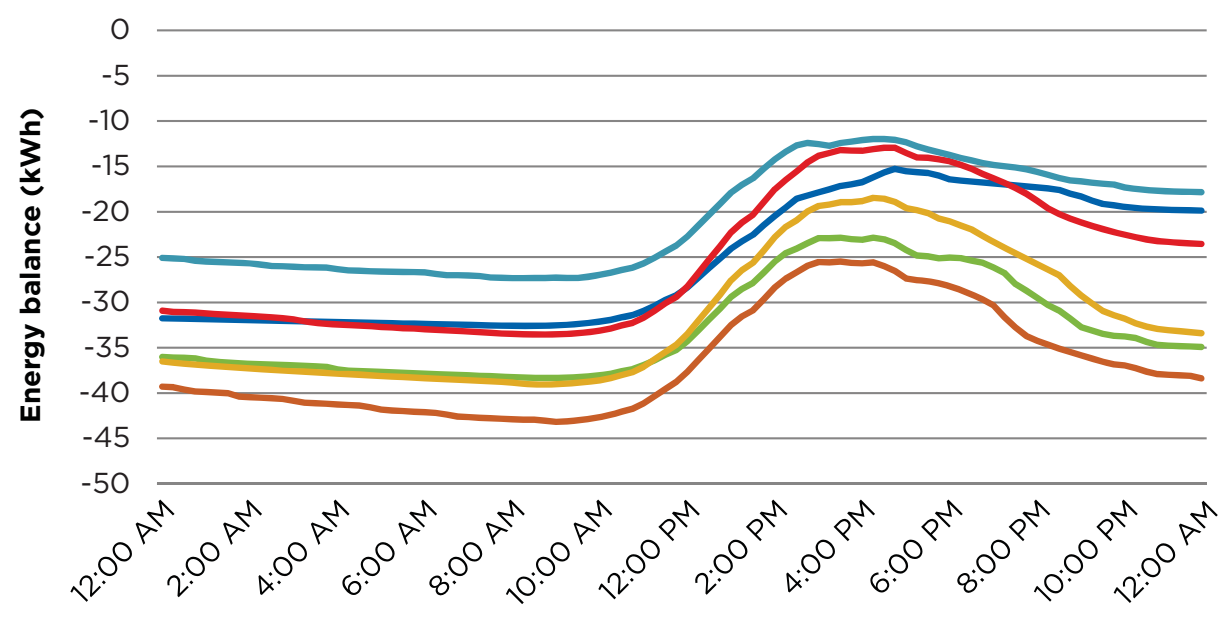

28th September
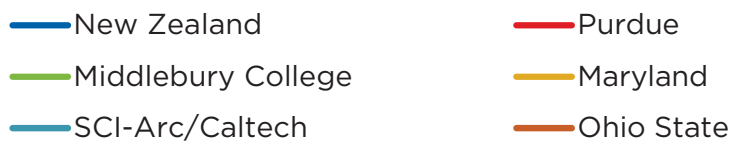

Figure 122: Energy balance on 28th September of top six teams 


\section{DAY 8}

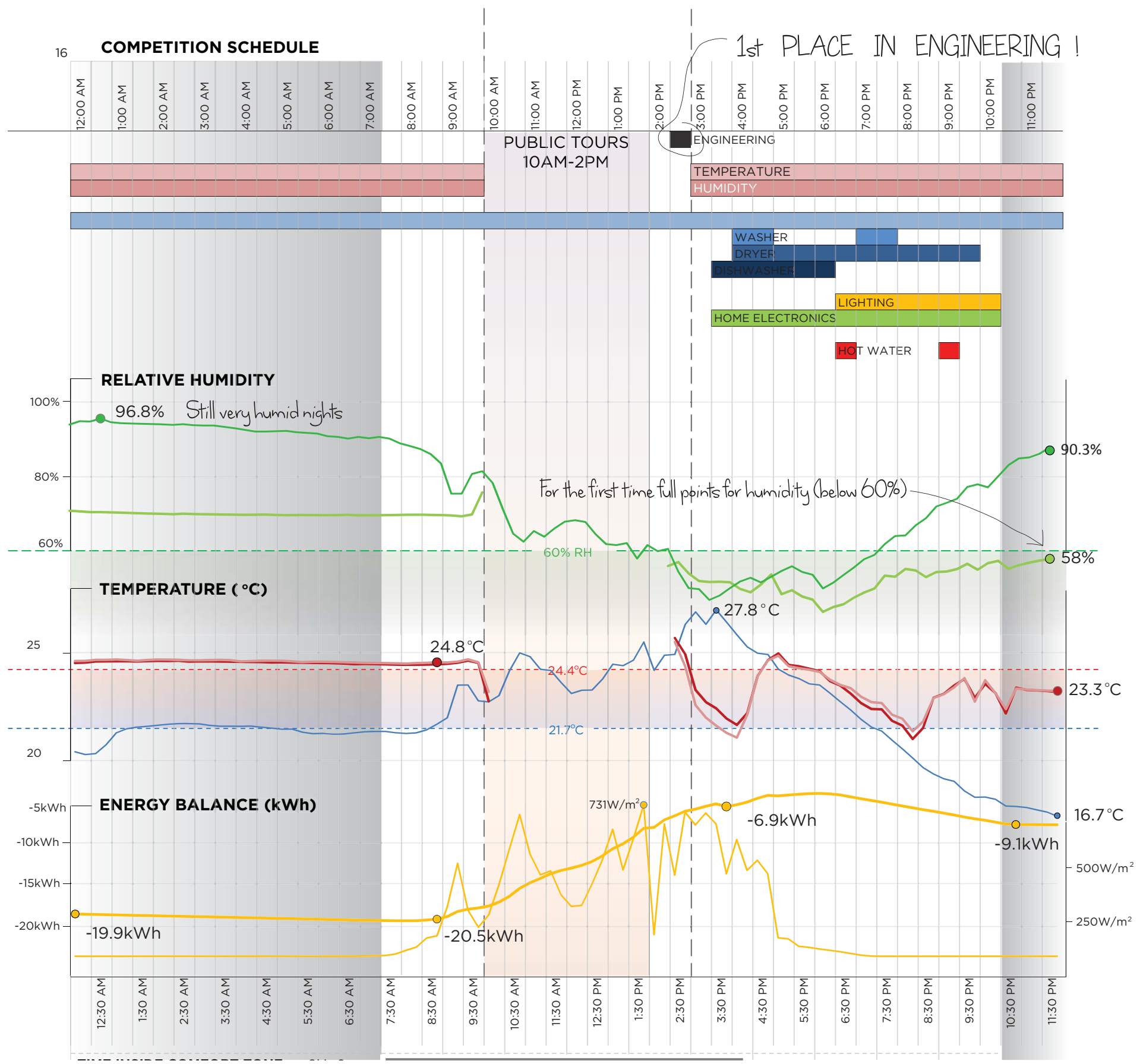

Figure 123: September 29 peformance anaylsis
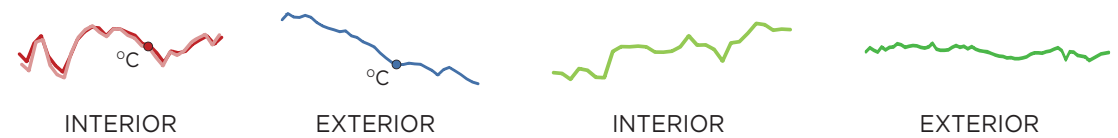

INTERIOR
TEMPERATURE

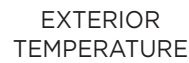

INTERIOR
RELATIVE HUMIDITY

EXTERIOR RELATIVE HUMIDITY

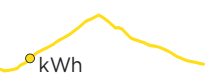

ENERGY BALANCE

GLOBAL HORIZONTAL SOLAR RADIATION 


\subsection{Day 8: 29th Spetember}

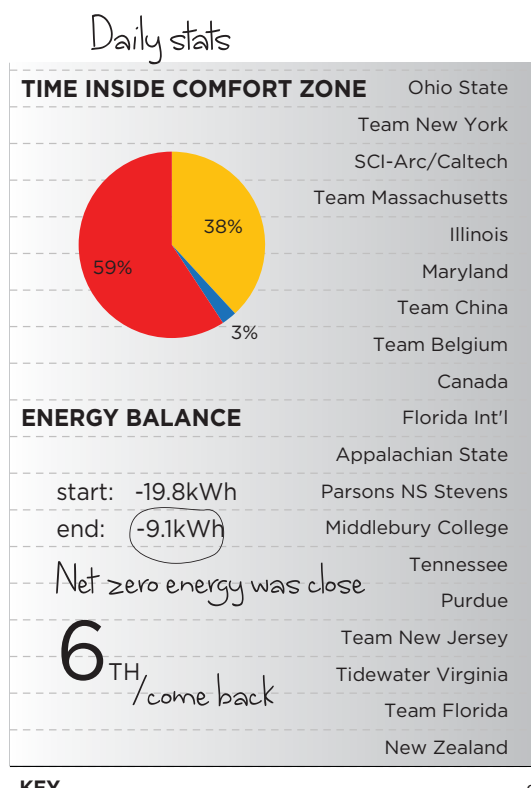

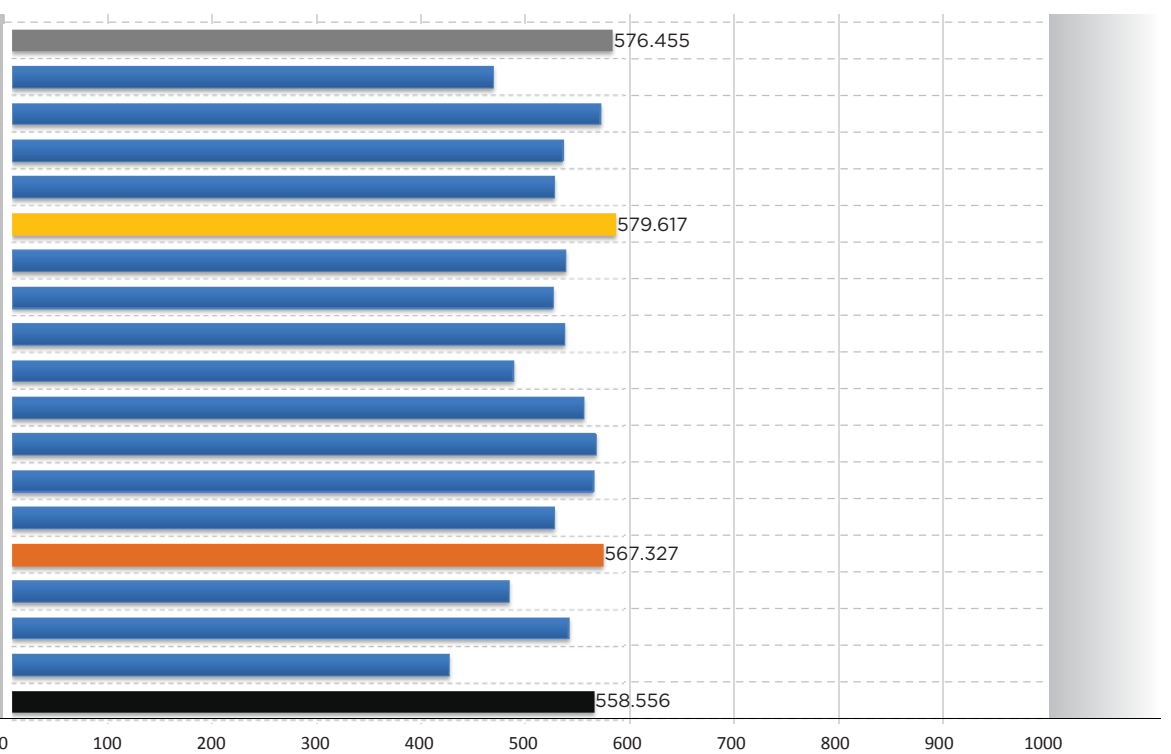

Figure 124: Team scores at the end of Day 8 of the competition

In the past the solar decathlon has been a technologically dominated competition which showcased cutting edge and innovative engineering. With over half the points in the competition allocated to the on site performance of the house, its engineering is an integral part of the potential success of a house in the Solar Decathlon. In a competition dominated by engineering universities this particular competition is passionately contested by all teams. The winner is determined by a team of judges who analyse each team's documentation and give a score based on a house's efficiency, reliability, functionality and of course innovation. Going into the competition the team expected to do well in the engineering but thought it would be unlikely to be placed in the top three against houses that, in terms of technology, were far superior. The strength of the First Light house was an integrated approach to the architecture and engineering, with a focus on the simplicity of the technology in a home that was easy to use and understand. The focus was not on complex home automation or high tech systems but on simple technologies that reduced the energy consumption of the house and blended with the architecture. To the team's great surprise this was also what the judges were looking for and New Zealand was named first in engineering. (Figure 125) Their comments focused on the integration of the architecture and engineering 
in a seamless and beautiful manner. The First Light house was described as a meticulous mechanical shed, with its comprehensive energy modelling and documentation that proved the performance of the systems both in New Zealand and in Washington DC. (Comments in all judged contests can be viewed in Appendix 10) It was a result that went against the trend in the past which was to award high technology and innovation. Instead the judges focused their attention on functionality and the reliability of the systems, calling for a simple but efficient design that was easy to use. It was a result that lifted the spirits of the team, and one that had a fairer distribution of points compared with the architecture competition.

After a full day of sunshine and a great result in engineering the weather finally became more reminiscent of what had been predicted in the simulations. Lower temperatures, sunshine, and finally lower humidities meant for the first time the drying cupboard worked as designed, successfully drying two complete loads of washing. The house sat below $60 \%$ relative humidity for the entire afternoon and if it was not for the temperature full points would have been gained in all measured contests. Strategically saving power at this stage in the competition was critical, and with only small periods where the cooling was running the house drifted outside the temperature band.
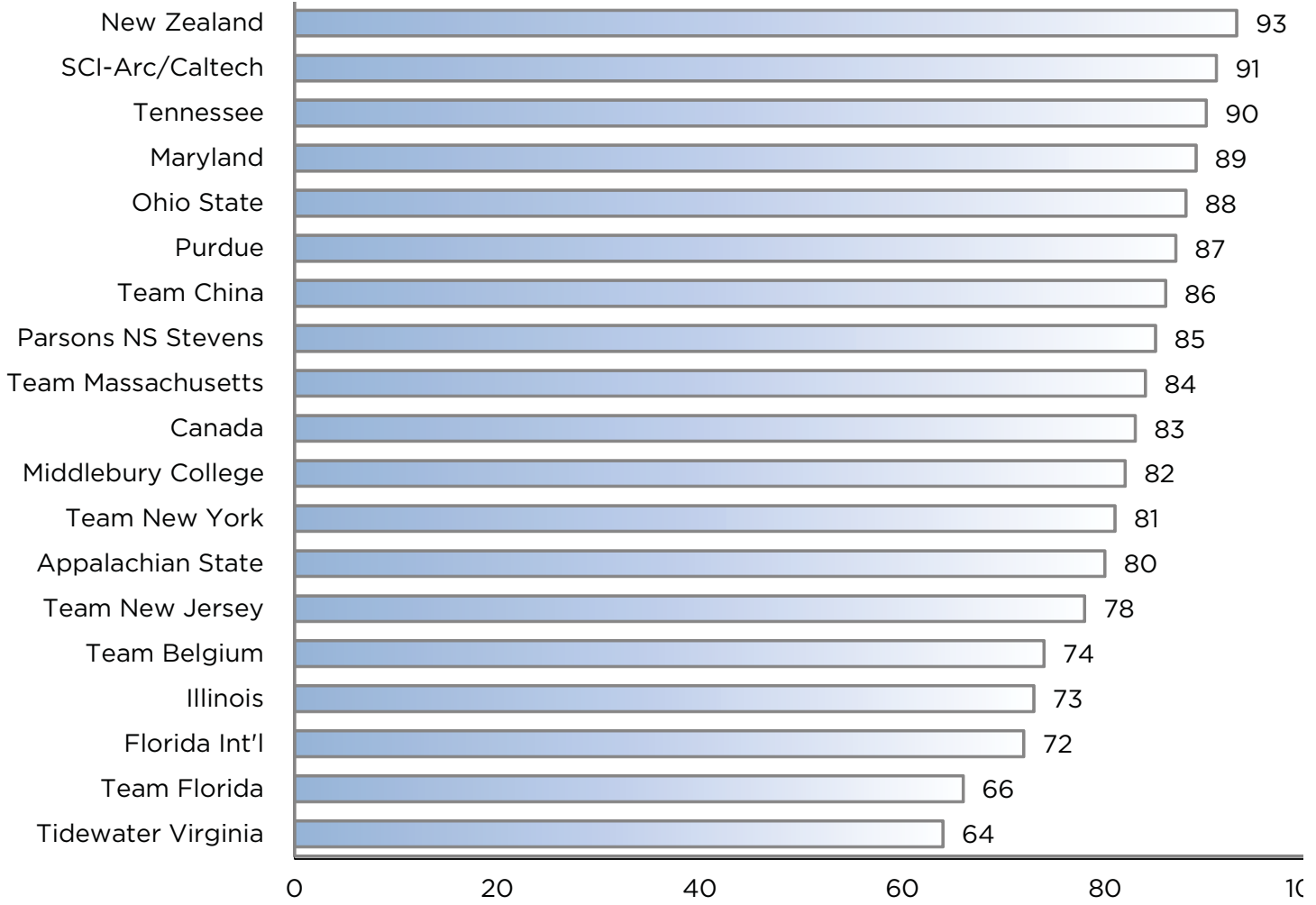

Figure 125: Architecture competition results 
These good results had pushed the team into sixth place behind Maryland, Ohio State, Purdue, Sci-ARC/Caltech and Parson Stevens and closely followed by Middlebury, whose strengths were market appeal and communications, competition results still to come. Of these teams only Sci-ARC/Caltech was on a greater energy balance by the end of the day, (Figure 126) although after the first full day of energy generation the teams with the larger solar arrays had made up some of the deficit that had been gained from the day before. It seemed Sci-ARC/Caltech was also tactically saving power realising the importance of achieving net zero. By the end of the day the First Light deficit was $9 \mathrm{kwh}$, which would need to be made up with one day of generation remaining. In order to complete all of the required tests on the final day of competition and remain net zero energy the house would need to reach at least $10 \mathrm{kWh}$ in positive. To achieve this another day like the present would be required. But with the teams above First Light on points all having larger solar arrays the risk was that a full day of sunshine would be enough for these teams to make up the deficit and the points advantage would be lost.

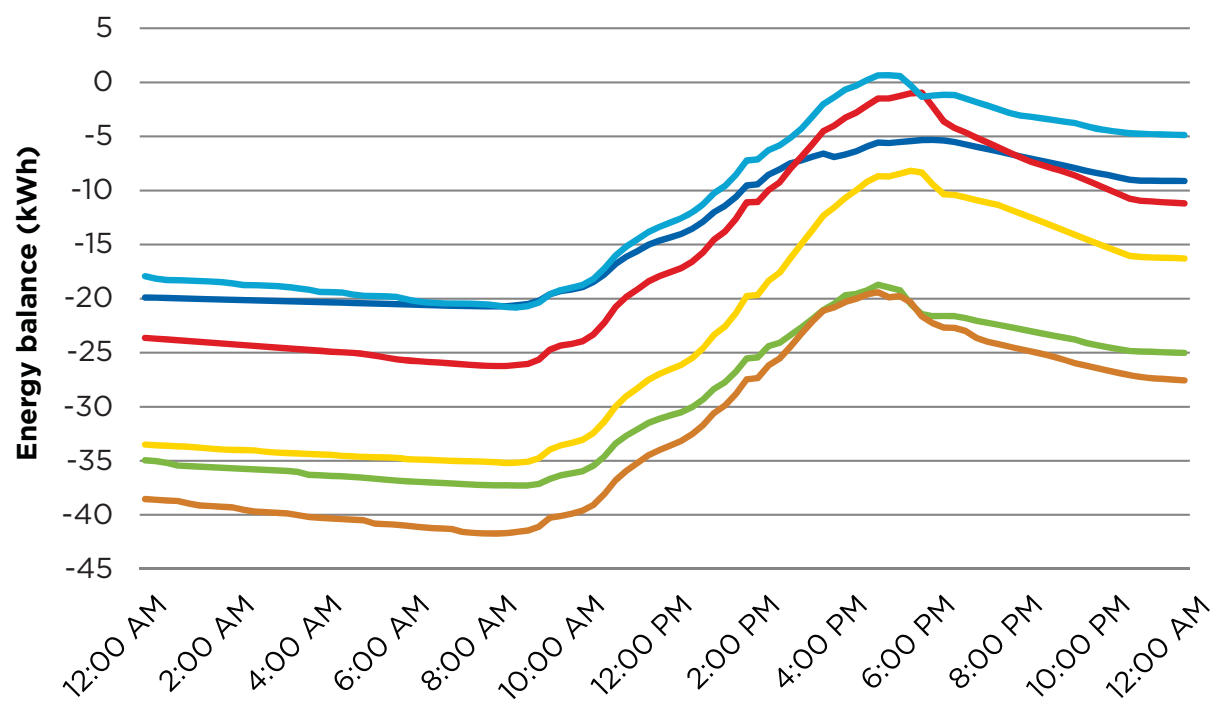

28th September
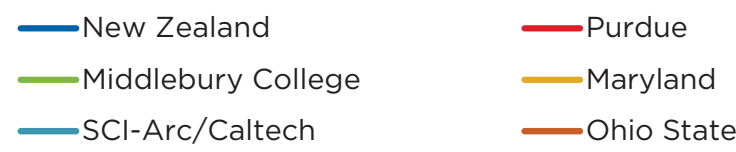

Figure 126: Energy balance on 28th September of top six teams 


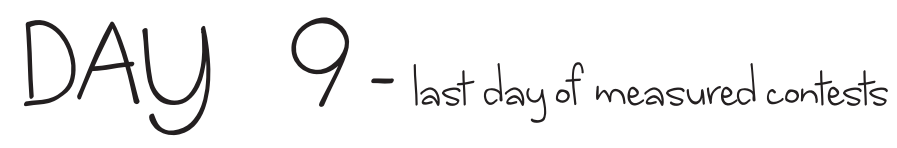

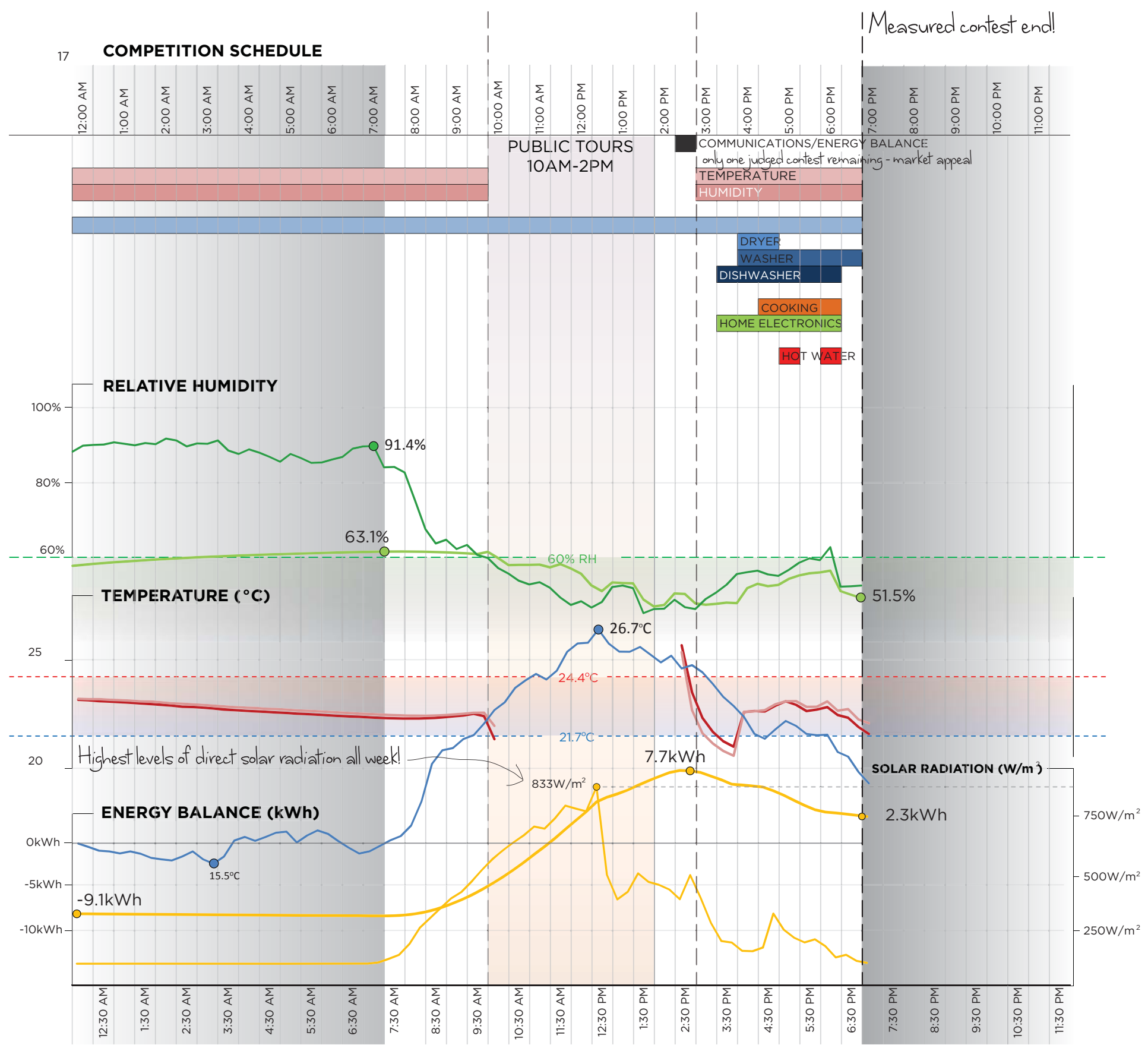

Figure 127: September 30 peformance anaylsis

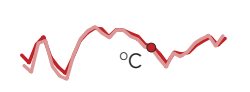

INTERIOR

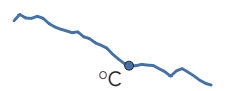

EXTERIOR

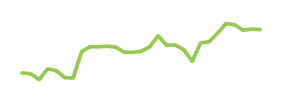

INTERIOR

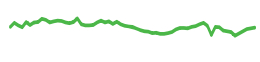

EXTERIOR

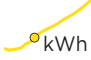

$\mathrm{W} / \mathrm{m}^{2}$ 


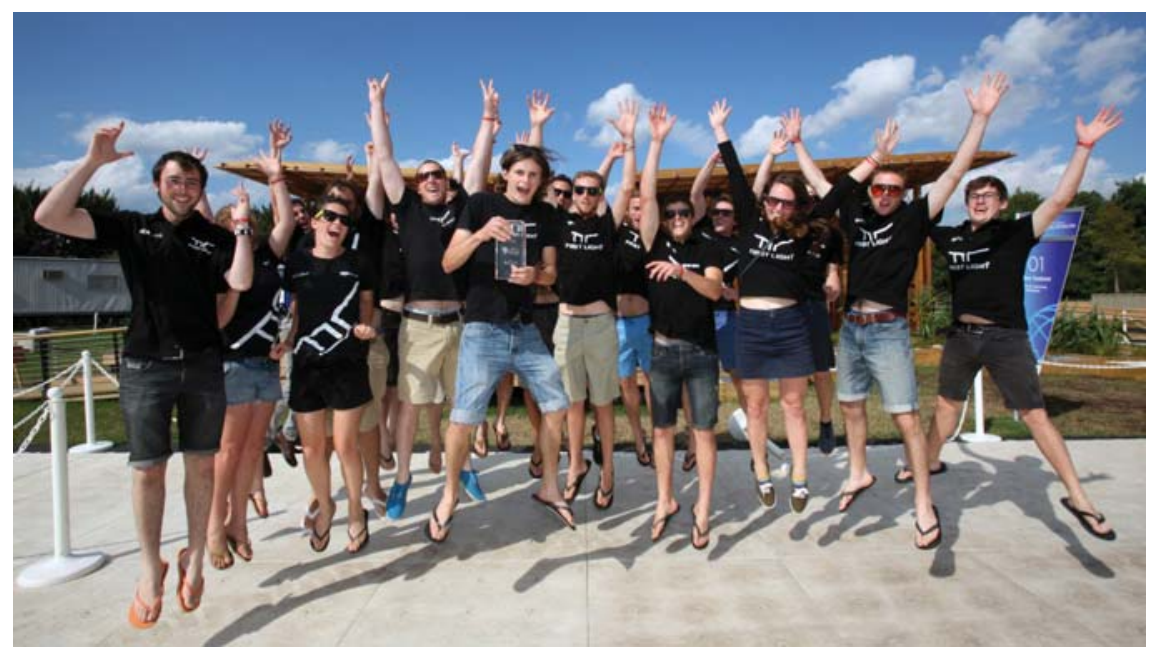

Figure 128: Celebration after winning engineering contest

\subsection{Day 9: 30th September}

\section{Dailystats}
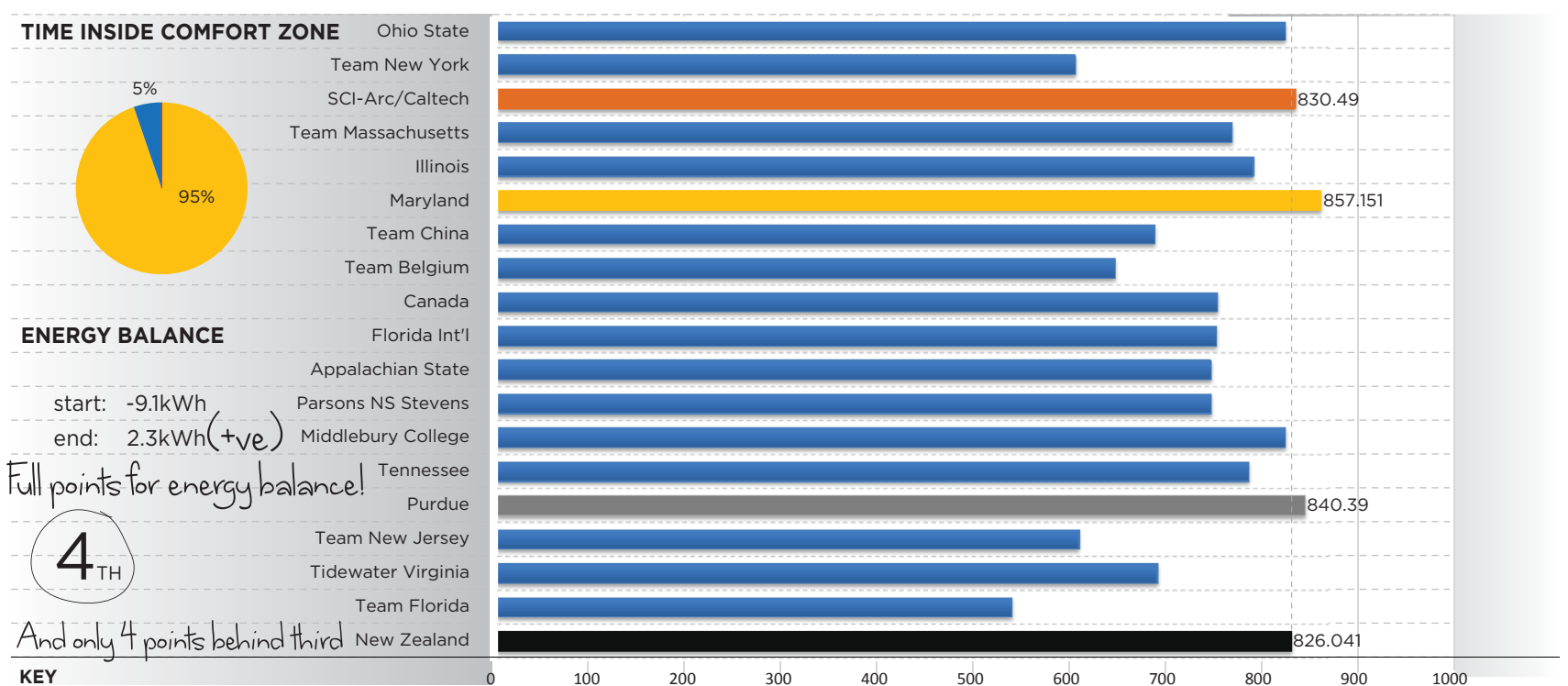

Figure 129: Team scores at the end of Day 9 of the competition

The final day of the competition was an exciting race to the finish with the top eight teams desperate to move into positive energy balance, all aware of the significance of the milestone. The competition was so close that any team that failed to do would be pushed down the competition ladder. The script had been set for a perfect finale. The solar village was bathed in full sunshine all morning and looking at Figure 131 showing the days energy generation it seemed that all seven of the top teams would reach net zero energy. At 12:30 the direct solar radiation peaked at the highest it had been in the entire competition with over $800 \mathrm{~W} / \mathrm{m}^{2}$ falling on the 


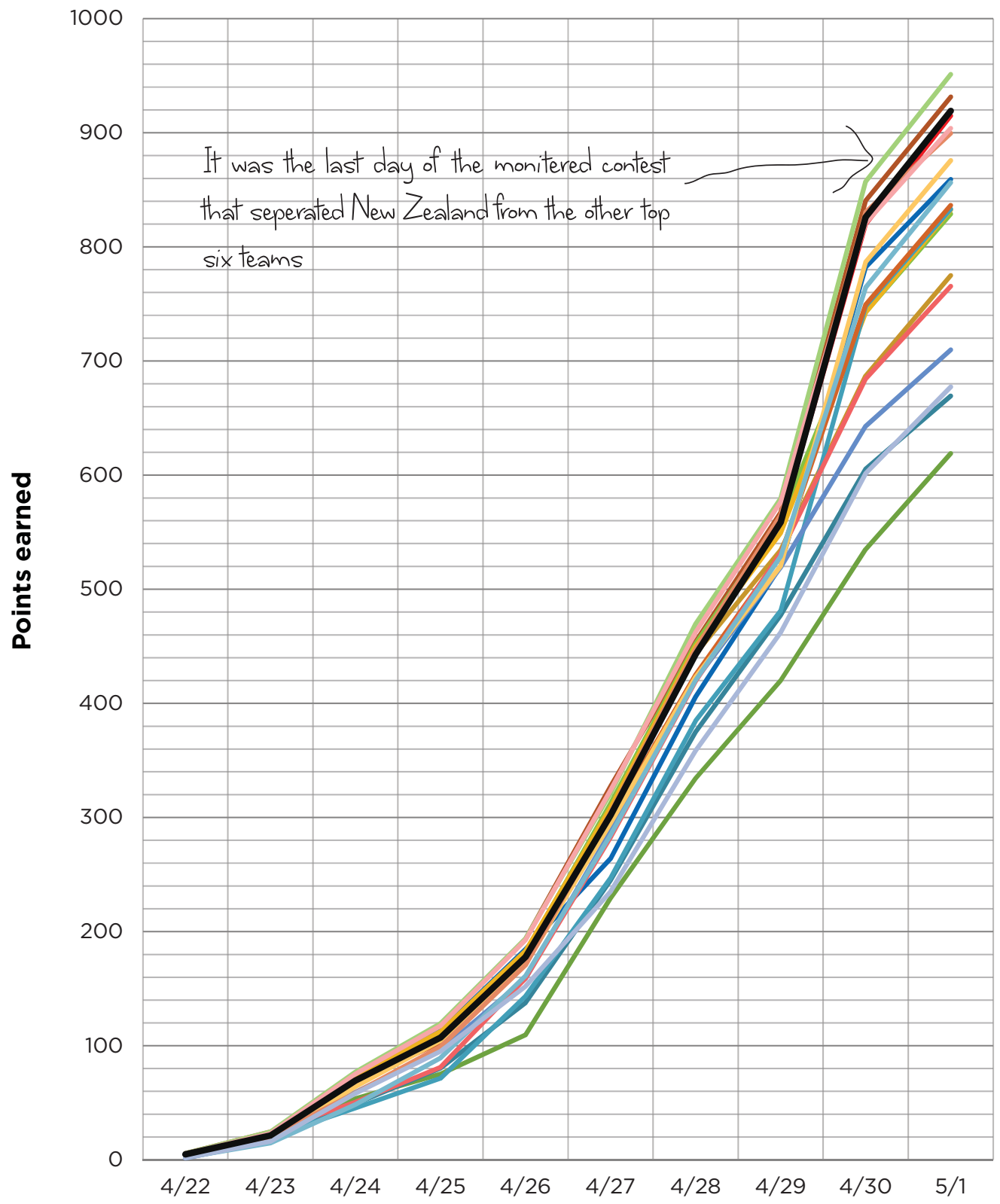

\section{Competition period}

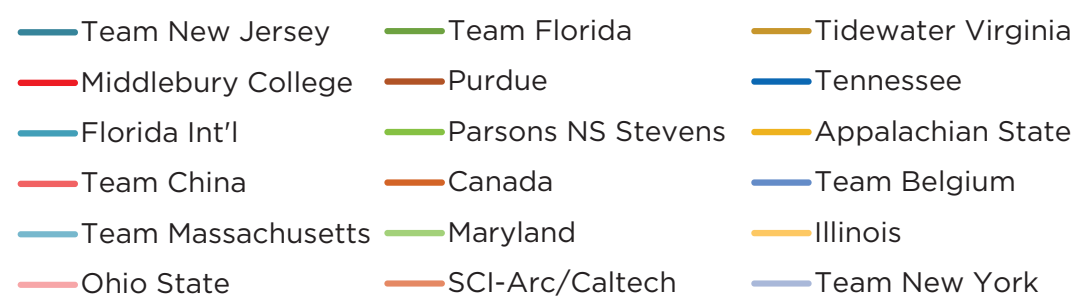

$\longrightarrow$ New Zealand

Figure 130: Graph of the accumulation of points throughout competition 
competition site. For those teams that had large solar arrays there was the potential for significant energy generation which would push them into the positive. Fortunately for the First Light house soon after this peak the clouds rolled in again and put an end to this generation. By the time the sun disappeared Maryland, Purdue, Sci-ARC/Caltech and New Zealand had all moved into positive and the small amount of solar radiation that leaked through the clouds was enough for all four teams to compete in the final tasks and end on a positive energy balance. Ohio State, Middlebury and Parsons Stevens, who were all still below zero, could not afford to consume any more energy. At that stage in the competition every $\mathrm{kW}$ in negative was two points lost. If the sun had stayed out all afternoon it was very likely that Ohio State and Middlebury would have reached net zero and the standings in the competition would have been quite different. Both teams had not only dropped over 10 points in energy balance but had forfeited over 20 points in the other measured competitions to save energy. (Figure 130) Because of this and another strong placing in communications First Light jumped into $4^{\text {th }}$ position only 4 points behind third place and 14 points behind second with one judged competition still remaining. The decision to save energy early in the week had worked in the team's favour and pushed First Light into a strong position with a real chance of a placing in the top 3.

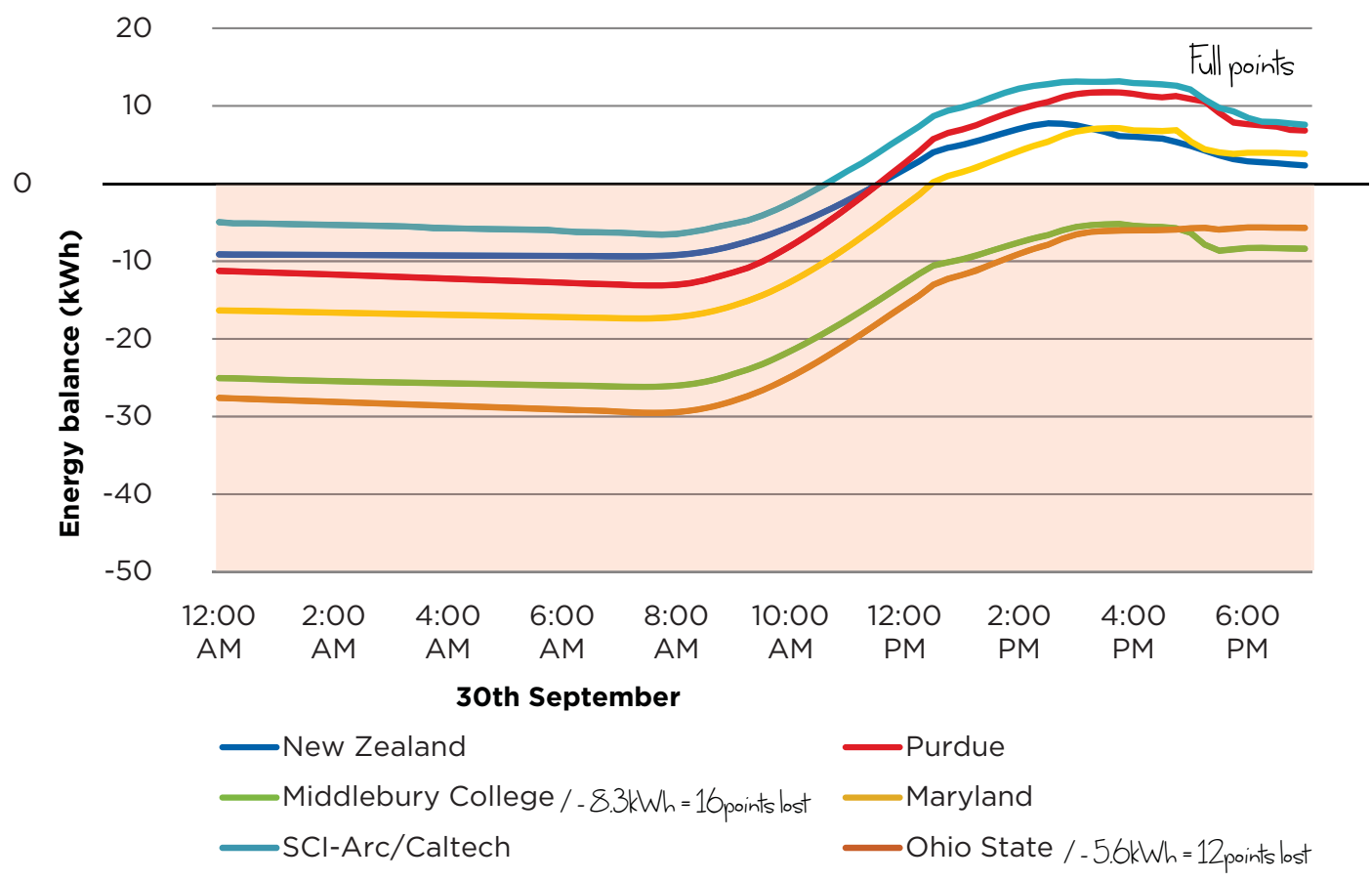

Figure 131: Final energy balance of top 6 teams 


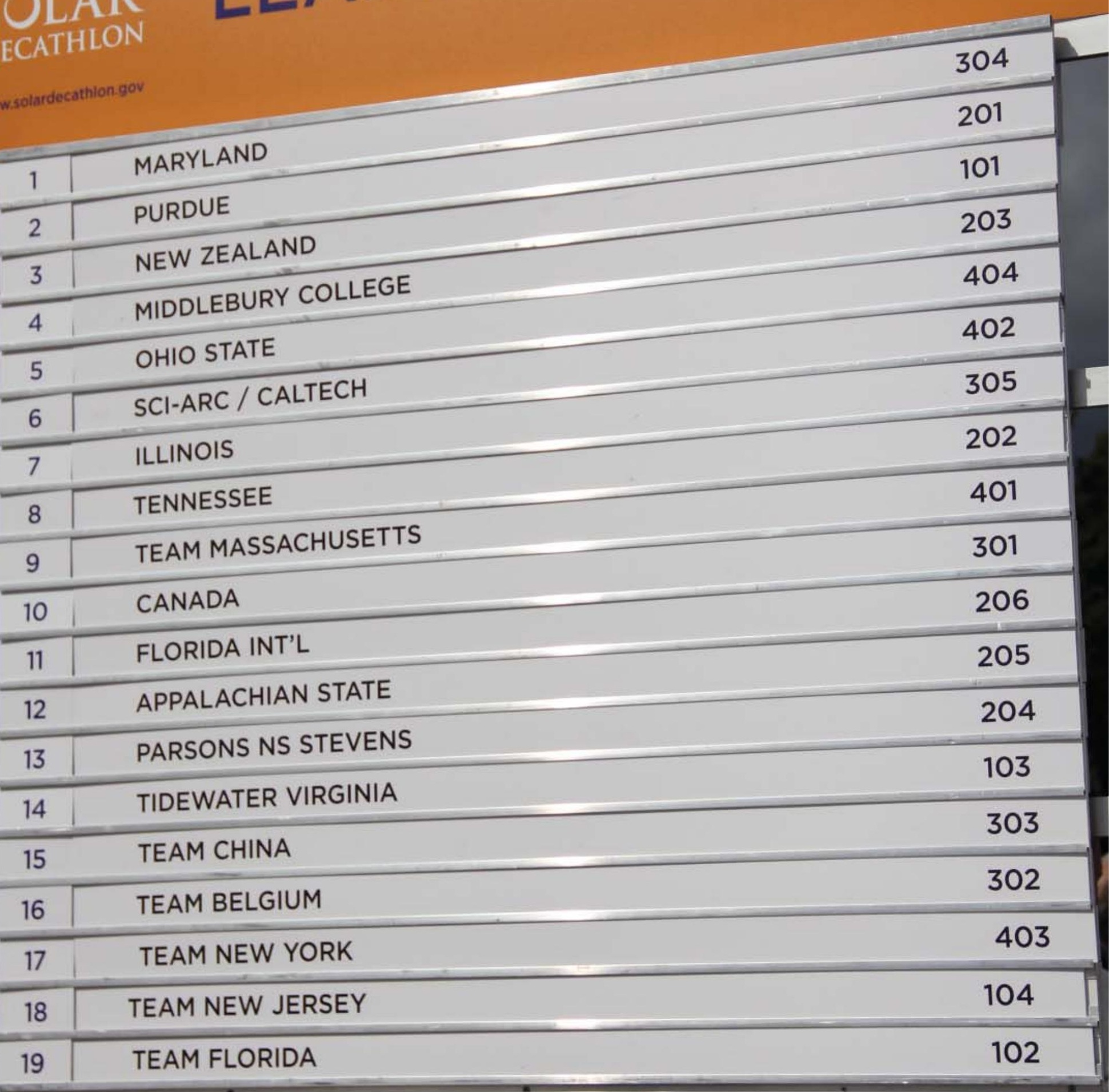




\subsection{Day 10: 1st October}

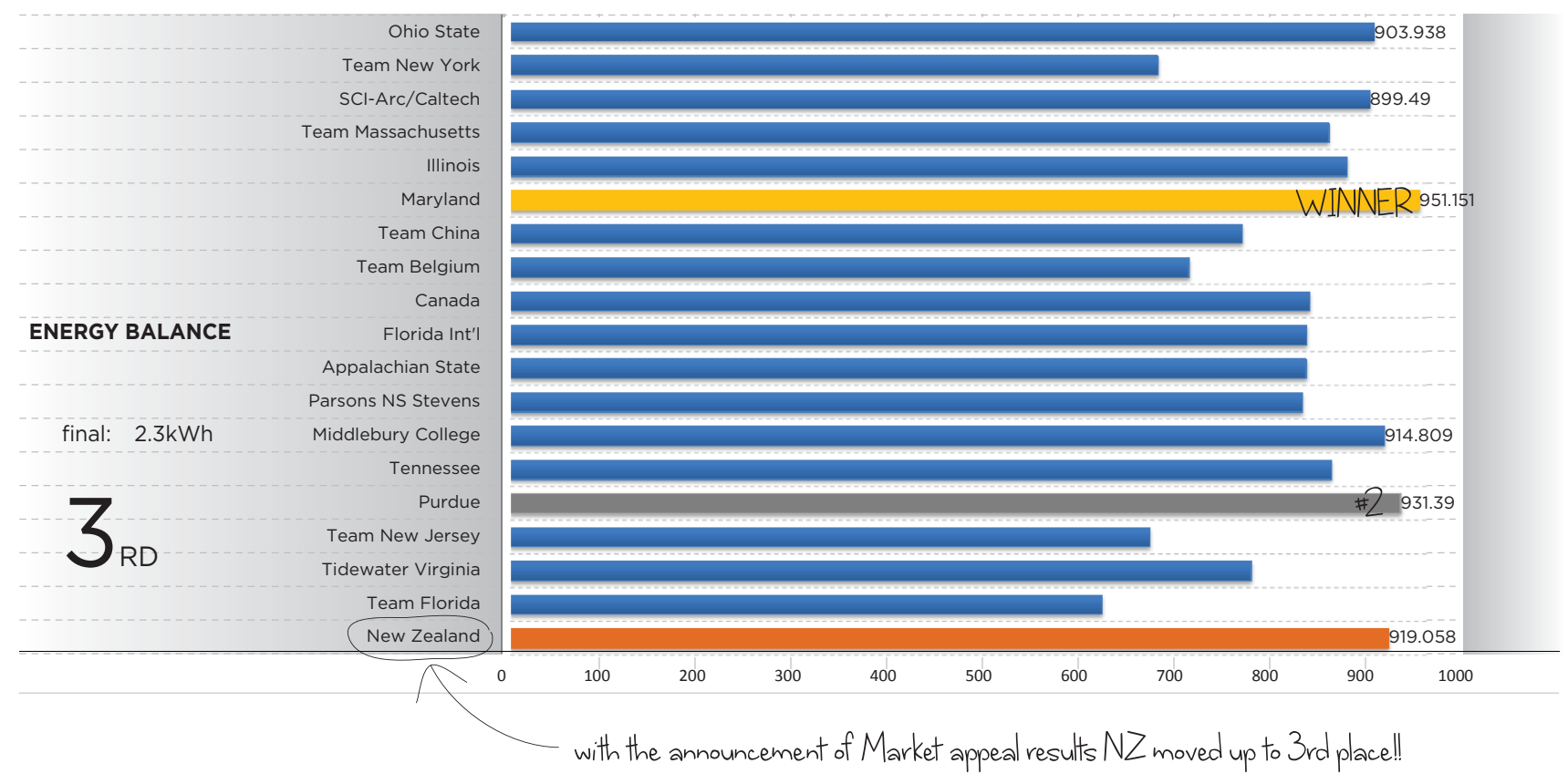

Figure 133: Team scores at the end of Day 9 of the competition

Being only four points behind $\mathrm{SCl}$ Arc/Caltech there was a good opportunity to move into third position with a good performance in the market appeal contest. The energy balance contest had shuffled teams around and had shown how important it was to reach net zero energy over the course of the ten days. It was fitting that the market appeal contest was the last to be announced as it was the hardest contest to predict how the judges would place teams. With all the performance and ceremony that came with the Solar Decathlon, the top teams in the market appeal category were announced with New Zealand placed third, Maryland second and Middlebury first. At this stage teams did not know the allocation of points so when the overall winners were announced it was still a surprise when New Zealand's First Light house was declared in third place. In the end only 12 points separated New Zealand and Purdue who was second. (Figure 133) But the outright and overall champions of the 2011 solar decathlon were Maryland University. They had led for the majority of the competition and had gained the most points in the measured contests. They had performed well across all of the 10 contests 
and had proven that they were the best house in the Solar Decathlon.

It was an exciting moment for them but also for New Zealand who had fought back from ninth with a good performance in all of the judged contests, some intelligent tactical decisions along the way and some luck with the weather to finish in the top three.

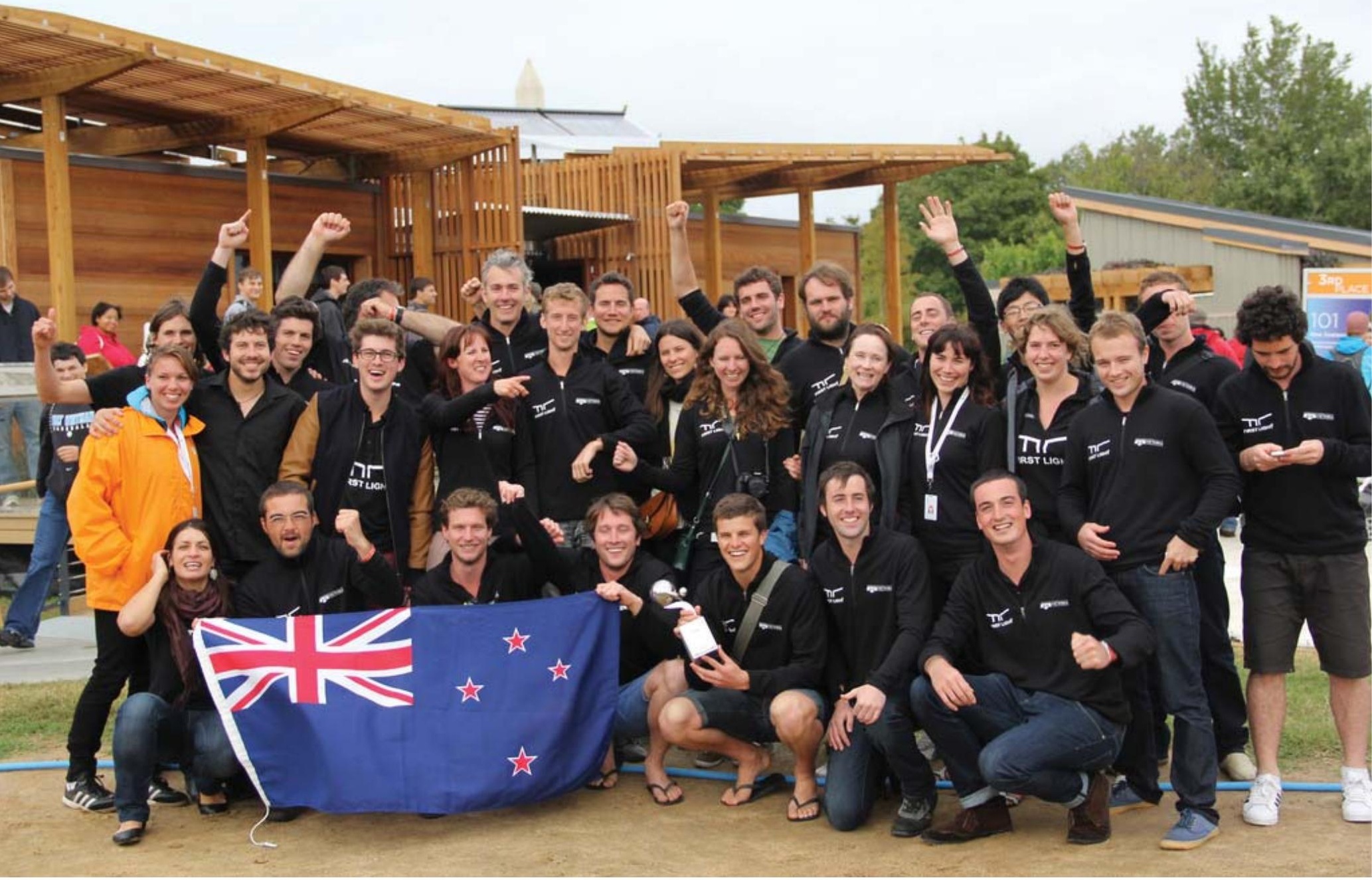

Figure 134: Team Celebrations after finishing in third place 


\subsection{Summary}

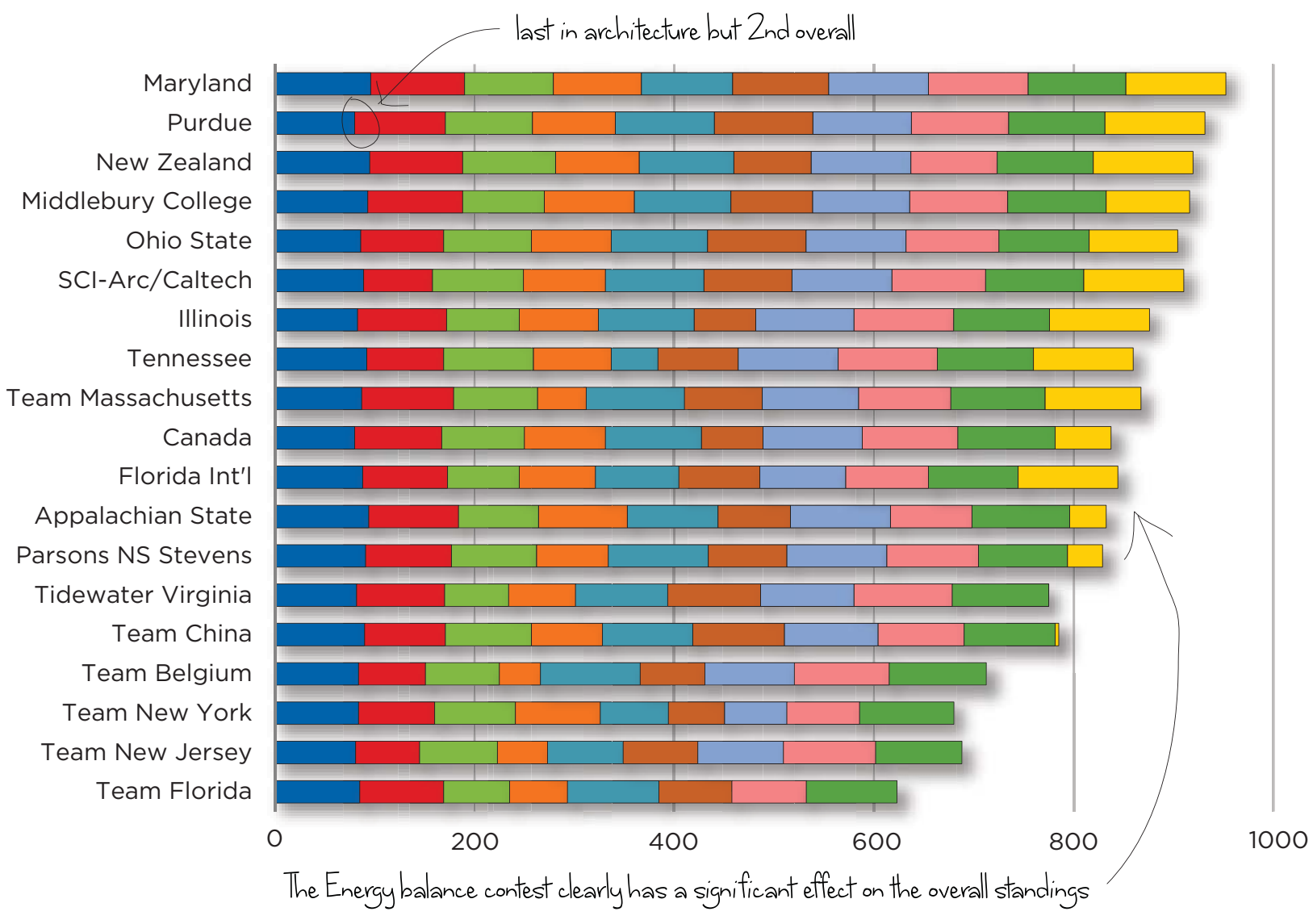

Total points

$\square$ Architecture $\square$ Market Appeal $\quad$ Engineering $\square$ Communications
$\square$ Affordability $\quad$ Comfort Zone $\quad$ Hot Water $\quad$ Appliances
$\square$ Home Entertainment

Figure 135: Summary of Final results

Going into the competition it would seem that the strengths of the First Light house would have been the judged contests. Led by four architectural students the holistic design of the house was at times more important than maximising its thermal performance. The inclusion of the skylight was a perfect example of this. It is an element that adds tremendous architectural and spatial benefits to the home but has a negative effect on the comfort in the space and the overall energy use. In the competition the First Light house was up against other teams with different mind-sets that were more orientated towards performance and efficiency than design and spatial delight. Going into the competition the judged contests were the team's strength and so were their major focus 
for winning the Decathlon. By the end New Zealand had gained 459.6 points out of 500 for the judged contests, more than any other team. The house had performed extremely well in each of the five judged categories, as expected, winning engineering, and placed second in architecture and third in market appeal. In the measured contests, though, the house had performed even better. Scoring 459.9 points, among the top five of all teams, the house had exceeded all expectations gaining full points for energy balance and hot water. This result was a testament to the holistic design of the First Light house.

From the engineering side of the project the result showcased the importance of simulation. The team had focused on passive strategies and had designed a house that consumed very little energy. Finishing with a net zero energy balance showcased how energy efficient the house was and well balanced the sizing of the system had been for the competition. (Figure 136) Out of the teams that finished on net zero energy balance the average size of the solar array was $8.3 \mathrm{~kW}$ and among these teams the First Light house had the smallest system at only 6.3kW. Despite such a small solar array and with such low levels of sunshine throughout the

10

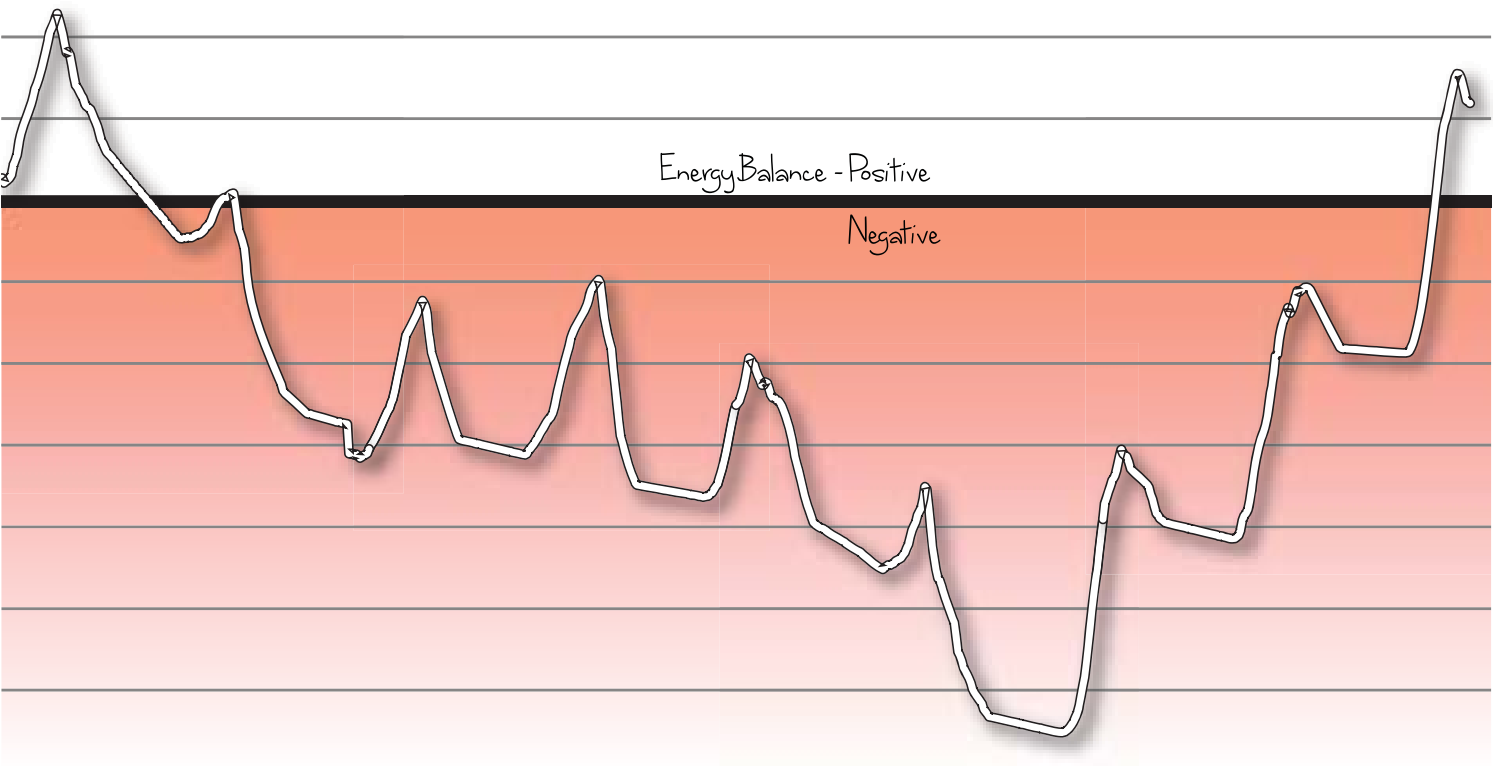

Day 1

For most of the competition the house was negative energy balance but some sunshine later in the competition helped push it into the positive

\section{Competition period}

New Zealand, Cumulative Energy (kWh)

Figure 136: New Zealand's cumulative energy use throughout the competition period 
week the house still finished on a positive energy balance at the end of the 10 days and gained the full 100 points.

Throughout the competition the house remained inside the temperature requirements for $95 \%$ of the monitoring period. Through accurate thermal simulation the house had been designed and the system had been sized to stay within a $2.7^{\circ} \mathrm{C}$ comfort range. Unfortunately, higher than expected humidity during the competition had a significant impact on the house's overall performance in the comfort zone contest. In all of the simulations very little time was spent on the effect of humidity on the space. Being unfamiliar with the Washington climate the team overlooked Washington DC's high humidity and the bearing it would have on the competition. It not only affected comfort but also the performance of the drying cupboard. Figure 137 shows the actual points earned in each contest against the potential points. From the measured contests the two areas where significant points were lost were the drying of towels and maintaining humidity. In saying this, the humidity was above average for this period and all the teams in the competition struggled with it. The comfort zone was always going to be a challenge for all teams involved as it means adapting the design of houses for their own home climates to the unpredictable weather of Washington DC in September.

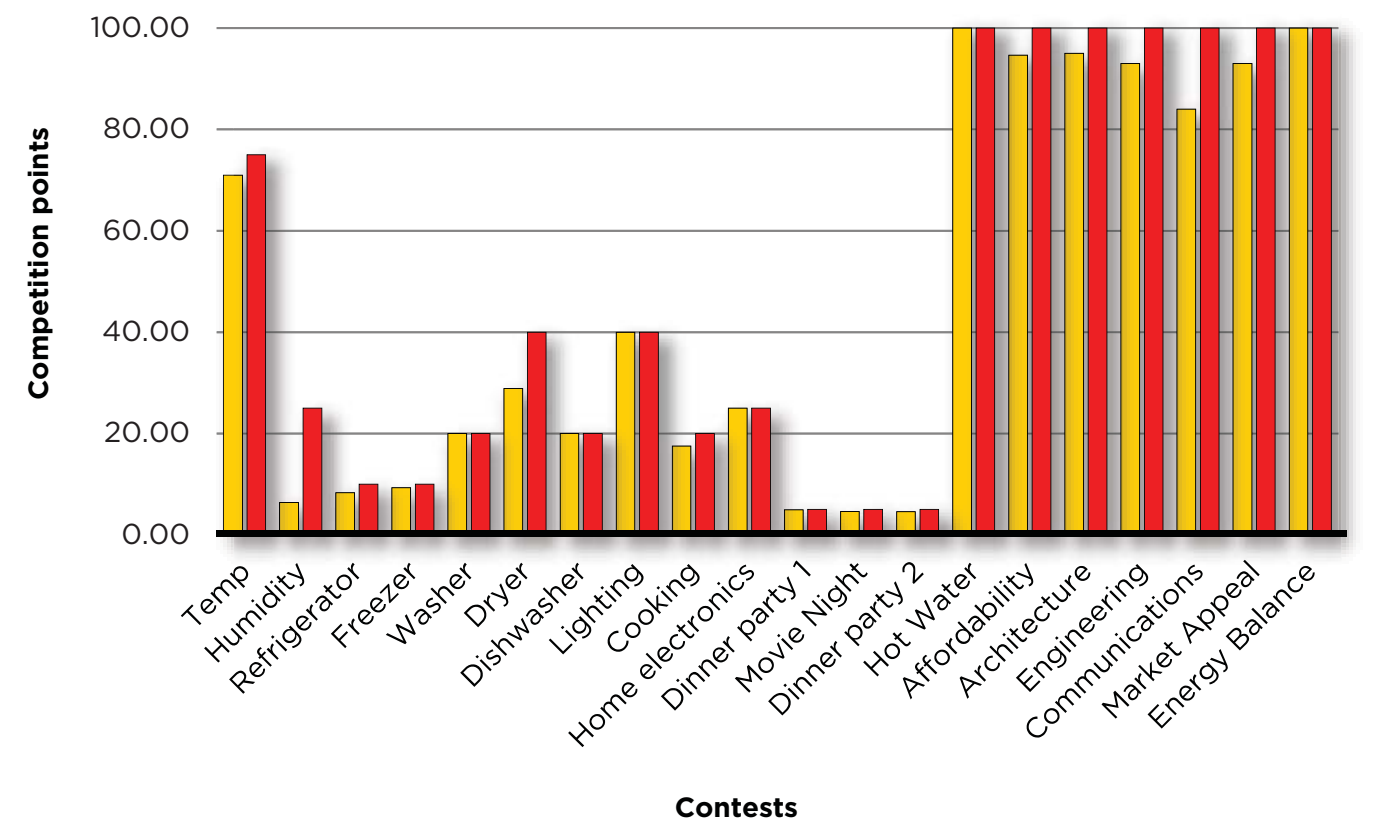

- Actual points earned - Potential points earned

Figure 137: Actual points earned versus potential points for each individual contest 


\section{Conclusion}

A lot has been discussed about the structure of the competition and the allocation of points. The format for the 2011 Solar Decathlon gave equal weighting to each of the ten categories. Half of the points were subjective, judged contests and half were based on measured performance data during the competition. One of the major critiques of the competition is the contradictory relationship between these two sides of the competition. An aspect that makes the Solar Decathlon interesting is the unique design, engineering and construction of each house based on the location for which each building was designed. The public gets an opportunity to view twenty different projects that have been designed for twenty different climates. In the 2011 competition these varied immensely from Belgium to China. Even within the US the climatic conditions in Florida differ completely from those in Illinois. For all these houses the climate has a major effect on the design. The climate creates challenges that bring opportunities for creative solutions that are showcased in each design and make each house unique. How well each team addresses these elements are judged in the competition in the architecture, engineering, communications, market appeal, and affordability contests. The location for which each house is designed is critical to a team's success in each of these five contests.

The other half of the contest on the other hand, contradictorily is based on the performance in Washington DC in a brief period in September. For each team hours of time and effort are made to design a house that is appropriate for its location and this is presented to the judges. But the winner of the Solar Decathlon is not the house that best meets these design requirements, it is the house that performs best in a completely different climate for only a ten day period. In the 2011 competition all of the top 10 teams, except for New Zealand, performed better in the measured competitions. (Figure 139) This trend matched results from previous years where the teams that do the best are those houses that perform in the measured competitions. Interestingly, the team that won the competition in 2011 was the University of Maryland, the institution closest to the location of the competition. The team's first-hand knowledge of the 
climate, the culture and the place inevitably influenced their design and their subsequent success in the measured contests. It seems appropriate and fitting that a house designed for a Washington DC climate should perform the best in the Solar Decathlon. The question is whether there is another way to perform a quantitative analysis of the houses that better represents the success of the design to meet a particular set of guidelines for a particular location?

For the first two years of the Solar Decathlon the architecture competition was worth 200 points, but in 2009 it was reduced to 100 points, the same as the appliances and home entertainment contests. A panel of judges made up of 'respected architects' judged each house based on a range of criteria including its holistic design, inspiration, and delight. In this year's architecture contest, the difference between the winner and the team that was placed last was only sixteen points, making it worthless in the overall competition. In the end this rating of points had a significant impact on the final results in the Solar Decathlon. If the allocation of points had been similar to the other four judged competitions the team in last place would have received only 60 points, or less in comparison with the communications competition. Instead of Purdue scoring 80 , they would have received at least 20 points fewer than they did, dropping them into fourth position overall, behind New Zealand and Middlebury. Teams with an architecture focus like Middlebury and New Zealand are already

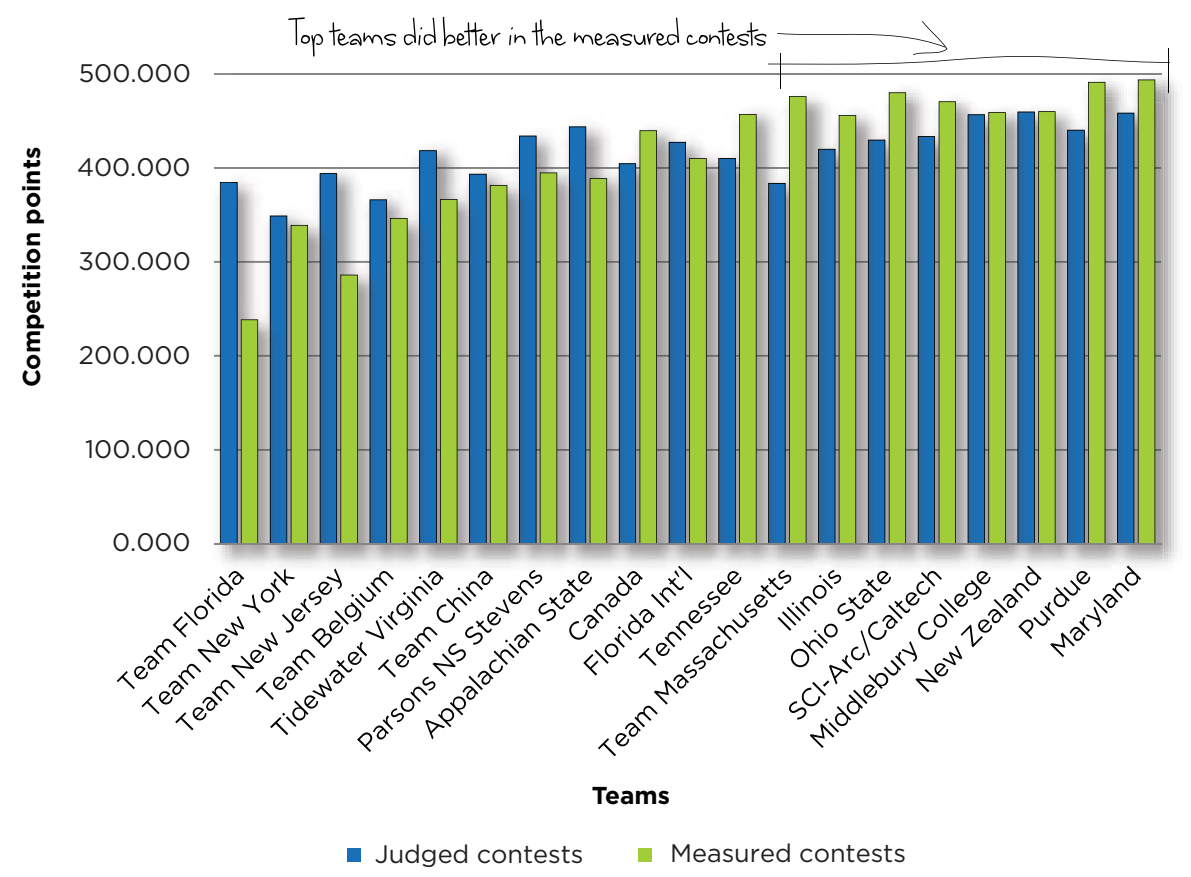

Figure 139: Measured contest scores versus judged contests 
at a disadvantage with the points allocation in the competition. Rating architecture as having the same importance as home entertainment and then not distinguishing or awarding teams who have achieved highly, does not encourage good design and is a weakness of the competition.

It is not just the allocation of points but the entire set up of the architecture competition that is being critiqued here. In the Solar Decathlon the need to maintain thermal comfort with a minimal use of energy is just as important for the design elements as the idea of holistic design, inspiration and delight. But the passive design elements used to achieve this are barely mentioned in the marking criteria of the architectural competition. Many of the criticisms of the Solar Decathlon are directly related to the comfort zone contest. The unrealistic limits set by this contest mean that every team must incorporate a large, oversized mechanical system to ensure they meet the temperature and humidity requirements. The engineering competition is structured towards teams largely based on these oversized and redundant mechanical systems. To generate the energy required to run these systems and meet the net zero energy requirements of the competition teams incorporate large solar arrays. In 2011 the average solar array was $7.7 \mathrm{~kW}$. Because of the focus on these excessive active technologies the houses are expensive and the limits of the affordability competition have to be unrealistically high.

The comfort zone has a dramatic effect on the design of the Solar Decathlon houses and the overall winner of the competition. Its major weakness is not recognizing the link between the comfort zone and architecture. If the temperature limits of the comfort zone contests were widened there would be a significant change in the design of the houses. In fact from the thermal simulation performed on the First Light house for the period in September in Washington DC it is not unrealistic to design a house that could maintain a wider comfort band without a mechanical system. Imagine the change to the competition and the design of houses if there was a limit to the size of the HVAC system, or it was not allowed at all. The innovation would move from a focus on technologies to a focus on simple, passive design systems that use the climate to maintain comfort. The quality of the architecture would improve, the size of the solar arrays would reduce, and the houses would be cheaper. All of a sudden the public, at whom the US Department of Energy aim the Solar Decathlon, would have access to ideas and technologies that are finally within their budget. 
Figure 140: Brendan, Eli and Nick with Joe outside the teams HQ during the competition 
According to Richard King, the founder the Solar Decathlon "the aim of the competition is to raise awareness's of the energy saving benefits of highly efficient home design and renewable energy technologies." It is difficult to believe that a competition that is established based on this philosophy does not give any specific award for teams that use passive design. The competition gives the DOE and NREL an objective set of requirements for judging the competition but does not fully judge the design of a home. The design of a home is many of things tested in the competition, it is about human comfort and energy efficiency, just as it is about delight and space. But these qualities cannot be measured by a $2.7^{\circ} \mathrm{C}$ comfort band or a hot water draw off. The organizers fail to recognise the importance of the architecture instead putting the focus on technology. For the First Light house it is important that it showcases the potential of the energy saving benefits of passive design. Largely due to the thermal simulations, the house has been optimized to meet the competition requirements of the 10 contests but it had to be run as conscientiously as a sailing vessel to meet these requirements. The question is whether comfort is better left to the individual to adjust rather than requiring a team of 'experts' constantly to monitor and change how the house is running. Given the bach approach, it is the former way of reaching comfort that is at the heart of a design to meet human comfort in New Zealand. The 'active' performance of the house during the Washington DC climate has been tested and proven. When the house returns to New Zealand and is constructed for the fourth and final time it can finally be operated passively, as it was designed. When it is finally constructed the next owner of the First Light house will have a chance to run the house in New Zealand and to discover the true energy saving benefits of highly efficient home design and renewable energy technologies. 


\section{Bibliography}

ASHRAE Standard. Thermal Environmental Conditions for Human Occupancy. Atlanta: American Society of Heating, Refrigerating and Air-Conditioning Engineers, Inc, 2003.

Breuer, D R. Desgn for the Sun -Vol 1: Resedential design Guidlines for New Zealand. Southwestern publishing Company Ltd, 1994.

EECA. Solar Energy use and Potential in New Zealand. Wellington: EECA, 2001.

Guzowski, Mary. Zero Energy Architecture. London: Laurence King Publishing Ltd, 2010.

Isaacs, Nigel. "Thermal Insulation." BUILD, November/December 2007: 110-111.

Isaacs, Nigel, Michael Camilleri, Lisa Burrough, and Andrew Pollard. Energy use in new Zealand Households, Final report on the Household Energy End-use Project (HEEP). Judgeford, New Zealand: BRANZ Ltd, 2010.

John, Goulding R, Lewis Owen, and Theo C Steemers. Energy in Architecture: The European Passive Solar Handbook. London: B.T. Batsford limited, 1986.

Lechner, Norbert. Heating, cooling, Lighting: Sustainable Design Methods for Architects. New Jersey: John Wiley \& sons, Inc, 2009.

Pollard, Andrew. "Turning solar for water heating." BUILD, August/ September 2008: 58-59.

Stein, Richard. Architecture and Energy. New York: Anchor Press, 1977. 
Szokolay, Steven V. Introduction to Architectural Science: The basis of sustainable design. Oxford: Architectural Press, 2004.

The German Solar Energy Society. Planning and Installing Photovoltaic Systems: A guide for Installers, Architects and Engineers. London: Earthscan, 2005.

The German Solar Energy Society. Planning and Installing Solar thermal Systems: A guide for Installers, Architects and Engineers. London: Earthscan, 2005.

Vale, Brenda, and Robert Vale. The New Autonomous House. London: Thames \& Hudson Ltd, 2000.

Vale, Brenda, and Robert Vale. The self-Sufficient house: D/Y techniques for saving fuel, heat and money. London: Macmillan London Ltd, 1980.

WHO. Health impact of Low IndoorTemperatures: Report on a WHO Meeting. Copenhagen. Copenhagen: WHO, Reginal office for Europe, 1987.

Zaretsky, Michael . Precedents in Zero-Energy Design: Architecture and Passive design in the 2007 Solar Decathlon. New York: Routledge, 2010.

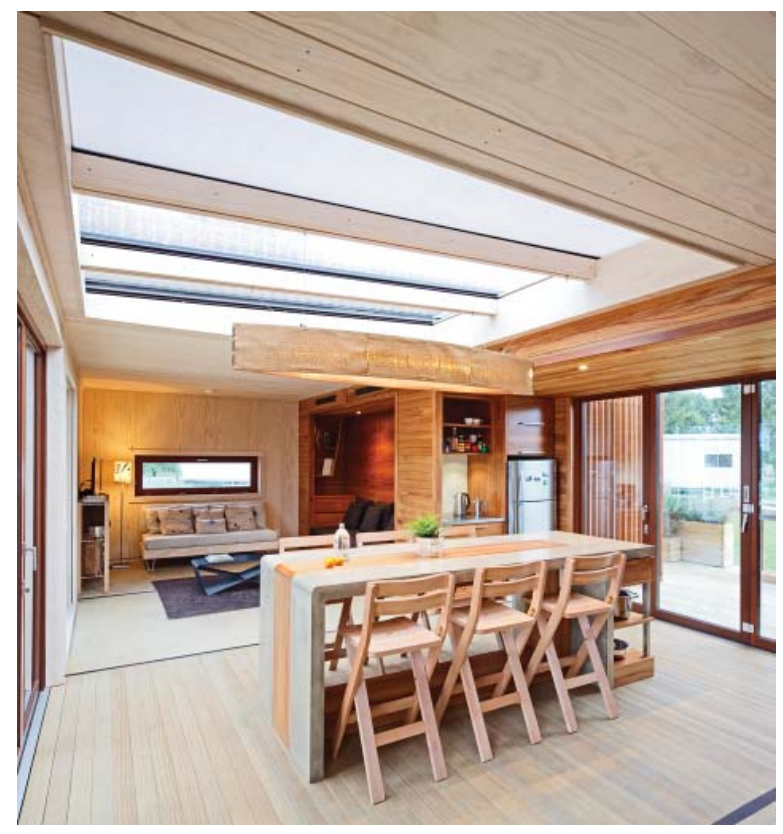

Figure 141: Final interior image 


\section{Appendix A - Contest rules}

\section{Contest 1. Architecture}

A jury of architects shall assign an overall score for the design's architectural merit and implementation by reviewing the team's drawings, construction specifications, and audiovisual architecture presentation (see Appendix D), and by performing an on-site evaluation of the competition prototype (see Appendix B). The jury shall consider the following specific criteria in its evaluation:

\section{Design and implementation}

- Was the team effective in its use of architectural elements including, but not limited to: scale and proportion of room and facade features, indoor/outdoor connections, composition, and linking of various home elements?

- Did the team create a holistic design that will be comfortable for occupants and compatible with the surrounding environment?

- Are the lighted spaces rich and varied? Do they have adequate light for tasks? Do they have good color rendition? Do the luminaires properly distribute light? Is the admission of direct and diffuse sunlight effectively controlled?

- Will the overall architectural design offer a sense of inspiration and delight to Solar Decathlon visitors?

Documentation

- Did the drawings, construction specifications, and audiovisual architecture presentation enable the jury to conduct a preliminary evaluation of the design prior to its arrival at the competition site?

- Did the drawings, construction specifications, and audiovisual architecture presentation accurately reflect the constructed project as assembled on the competition site?

\section{Contest 2. Market Appeal}

A jury of professionals from the homebuilding industry shall assign an overall score for the house's market appeal by reviewing the team's drawings, construction specifications, and audiovisual sales presentation (see Appendix D), and by performing an on-site evaluation of the competition prototype (see Appendix B).

The jury shall consider the following specific criteria in its evaluation of the responsiveness of the design to the characteristics and requirements of a team-defined target client (see Table 3 for examples of target client characteristics and requirements).

\section{Livability}

- Does the design offer the occupant(s) a safe, functional, convenient, comfortable, and enjoyable place to live (see Table 4 for examples of livability considerations)?

- Is the operation of the house's lighting, entertainment, and other controls intuitive?

- Are the unique needs and desires of the target client met by the design? 


\section{Marketability}

- Does the house demonstrate curb appeal, interior appeal, and quality craftsmanship?

- Do the house's sustainability features and strategies make a positive contribution to its marketability?

- Does the house offer a good value to potential homebuyers?

\section{Buildability}

- Are the drawings and construction specifications of sufficient quality and detail to enable a contractor to generate an accurate, detailed construction cost estimate?

- Are the drawings and construction specifications of sufficient quality and detail to enable a contractor to construct the building as the design team intended it to be built?

- Are all the house's materials and equipment commercially available, such that the house can be immediately built in the private sector?

Table 3: Examples of target client characteristics and requirements

\begin{tabular}{|l|l|l|l|}
\hline Characteristic or Requirement & Example \#1 & Example \#2 & Example \#3 \\
\hline Location of permanent site & New Orleans, LA & Folsom, CA & Boston, MA \\
\hline Housing type & Emergency relief & Single family & $\begin{array}{l}\text { Investment property in an } \\
\text { urban college setting }\end{array}$ \\
\hline \# of occupants & 2 & 3 & 1 \\
\hline Client demographic & $\begin{array}{l}\text { Middle-aged married } \\
\text { couple }\end{array}$ & $\begin{array}{l}\text { Mid-30s married couple with } \\
\text { infant }\end{array}$ & Graduate student \\
\hline Client annual income & $\$ 35,000$ & $\$ 100,000$ & $\$ 75,000$ \\
\hline \# of bedrooms & 1 & 2 & 1 \\
\hline
\end{tabular}

Notes:

1. These examples show the minimum required level of detail for the target client characteristics and requirements.

2. The target client characteristics and requirements shall be included in a prominent location in the audiovisual sales presentation (see Appendix D-5)

3. Other examples of housing types include, but are not limited to, the following: retirement cottage, vacation retreat, university housing, home office/studio, studio apartment, mobile home, barracks, penthouse, and loft. 


\section{Contest 3. Engineering}

A jury of engineers shall assign an overall score for the design's engineering merit and implementation by reviewing the team's drawings, construction specifications, energy analysis results and discussion, and audiovisual engineering presentation (see Appendix D), and by performing an on-site evaluation of the competition prototype (see Appendix B).

The jury shall consider the following specific criteria in its evaluation:

\section{Functionality}

- Do the systems function as intended?

- Does the HVAC system maintain indoor air quality via contaminant control, fresh air ventilation, or both?

- Does the HVAC system maintain uniform thermal comfort conditions via temperature control, humidity control, air movement, and a successful distribution system design?

\section{Efficiency}

- Relative to conventional systems, how much energy will the systems save over the course of an entire year?

- Do the HVAC and lighting controls facilitate a reduction in energy consumption during an entire year of operation?

\section{Innovation}

- Were any unique approaches used to solve design challenges?

- Do the proposed innovations have true market potential?

\section{Reliability}

- How long are the systems expected to operate at a high level of performance?

- How much maintenance is required to keep them operating at a high level?

\section{Documentation}

- Did the drawings, construction specifications, energy analysis results and discussion, and audiovisual engineering presentation enable the jury to conduct a preliminary evaluation of the design prior to its arrival at the competition site?

- Did the drawings, construction specifications, energy analysis results and discussion, and audiovisual engineering presentation accurately reflect the constructed project as assembled on the competition site?

\section{Contest 4. Communications}

The goal of Contest 4: Communications is to ensure that all communications materials educate consumers about the project and topics relevant to the project.

A jury of communications professionals will evaluate and assign an overall score to the following team communications products: final Web site (see Appendix E-1), public exhibit materials (see Appendix E-6), public exhibit presentation (see Appendix B-3), and video walkthrough (see Appendix E-3).

For each product evaluated, the jury will consider the following specific criteria:

\section{Final Web site}

- Was the site submitted by the deadline?

- Is the design appealing (graphics, photos, colors, and typography)?

- Is the information architecture easy to use, consistent, and comprehensible? Does it present a logical hierarchy of information?

- Are graphical elements easy to use, consistent, and well integrated with content and design? 
- Does the Web site meet minimum coding requirements?

- Is the Web site usable by people of all abilities?

- Does the team communicate its messages appropriately to online audiences?

- Does the team employ original and creative methods to capture users' interests and engage online visitors?

- Does the site comply with rules 10-2 and 10-3?

\section{Public exhibit materials}

- Do the on-site communications materials (signage and handout) comply with rules 10-2 and 10-3?

- Did the house pass all on-site inspections in time to be opened to the public during required public hours?

- Are messages communicated appropriately?

- Do materials use correct spelling and grammar?

- Do the handout and signage demonstrate originality?

- Do materials both educate and engage audiences?

\section{Public exhibit presentation}

- Does the team adequately offer two presentations for the jurors' evaluation: one that represents a comprehensive, personalized "tour" appropriate for times when visitors are few and another that represents a fast, yet informative, self-guided exhibit that accommodates large crowds and long lines?

- Are both on-site presentations for the public informative? Interesting? Accessible by people of all abilities?

- Has the team planned original and creative methods to control lines and wait times and to engage visitors waiting in line during public hours? Are these methods effective?

- Are the team messages appropriate for the public?

\section{Video walkthrough}

- Does the walkthrough provide viewers with interesting and informative video of the team's house?

- Does the walkthrough include an audio narrative that explains to viewers what they're seeing and describes the philosophy behind the design?

- Does the video walkthrough closely represent the as-built house on the competition site?

- Has the team followed formatting requirements?

- Has the team provided a verbatim transcript to meet Section 508 Accessibility standards?

\section{Contest 5. Affordability}

A professional cost estimator shall assign an estimated construction cost to each project. All available points are earned for achieving a target construction cost of $\$ 250,000$ or less.

a. Reduced points are earned for a construction cost between $\$ 250,000$ and $\$ 600,000$. No points are earned for a construction cost at or above $\$ 600,000$. Reduced points are scaled linearly, as shown in Figure 2.

b. When information necessary for completing a thorough, accurate estimate is missing, the estimators will err on the conservative (high) side.

c. Each team is required to declare the target construction cost of its design by a specified deadline. The team's target construction cost shall be within $\pm 20 \%$ of the professional cost estimator's final estimated construction cost.

d. The cost of organizer-provided walkway material up to a limit specified by the Site Operations Manager will not be included in the estimate.

e. A file describing the estimator's methodology is posted in the "/Files/Rules/Affordability Contest" folder on the Yahoo Group. 


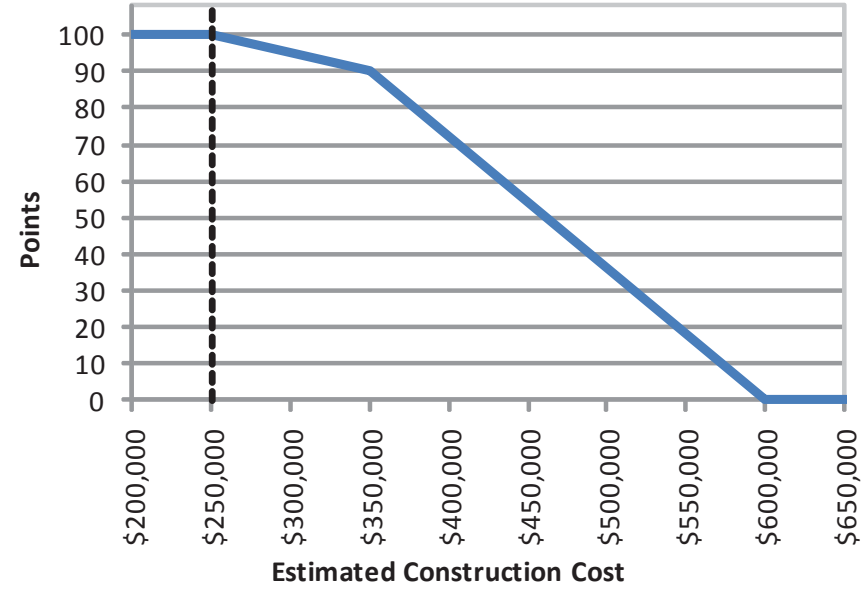

Figure 2: Scoring function for the Affordability Contest
Full Points:

Cost $\leq \$ 250,000$

Reduced Points (shallow): $\$ 250,000<$ Cost $\leq \$ 350,000$

Reduced Points (steep): $\$ 350,000<$ Cost $<\$ 600,000$

No Points:

Cost $\geq \$ 600,000$

\section{Contest 6. Comfort Zone}

\section{6-1. Temperature}

All available points are earned at the conclusion of each scored period by keeping the time-averaged interior drybulb temperature between $71.0^{\circ} \mathrm{F}\left(21.7^{\circ} \mathrm{C}\right)$ and $76.0^{\circ} \mathrm{F}\left(24.4^{\circ} \mathrm{C}\right)$ during the scored period. See Appendix A-3 for the schedule of scored periods and for the number of available points per scored period.

a. Reduced points are earned if the time-averaged interior dry-bulb temperature is between $67.0^{\circ} \mathrm{F}\left(19.4^{\circ} \mathrm{C}\right)$ and $71.0^{\circ} \mathrm{F}\left(21.7^{\circ} \mathrm{C}\right)$ or between $76.0^{\circ} \mathrm{F}\left(24.4^{\circ} \mathrm{C}\right)$ and $80.0^{\circ} \mathrm{F}\left(26.7^{\circ} \mathrm{C}\right)$. Reduced point values are scaled linearly, as shown in Figure 3.

b. The zone temperature deviating farthest from the target temperature range is the zone temperature of record. The organizers will identify at least two thermal zones in each house and measure the temperature of each zone.
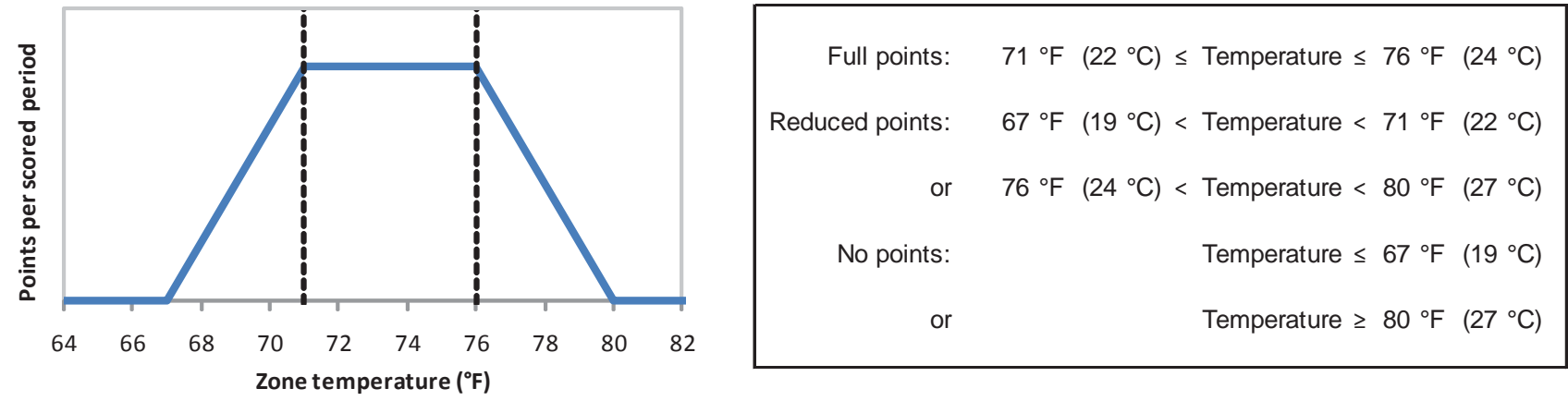

Figure 3: Scoring function for the Temperature Subcontest

\section{6-2. Humidity}

All available points are earned at the conclusion of each scored period by keeping the time-averaged interior relative humidity below $60.0 \%$ during the scored period. See Appendix A-3 for the schedule of scored periods and for the number of available points per scored period.

a. Reduced points are earned if the time-averaged interior relative humidity is between $60.0 \%$ and $70.0 \%$. Reduced point values are scaled linearly, as shown in Figure 4.

b. In multi-zone houses, the zone humidity deviating farthest from the target humidity range is the zone humidity of record. 

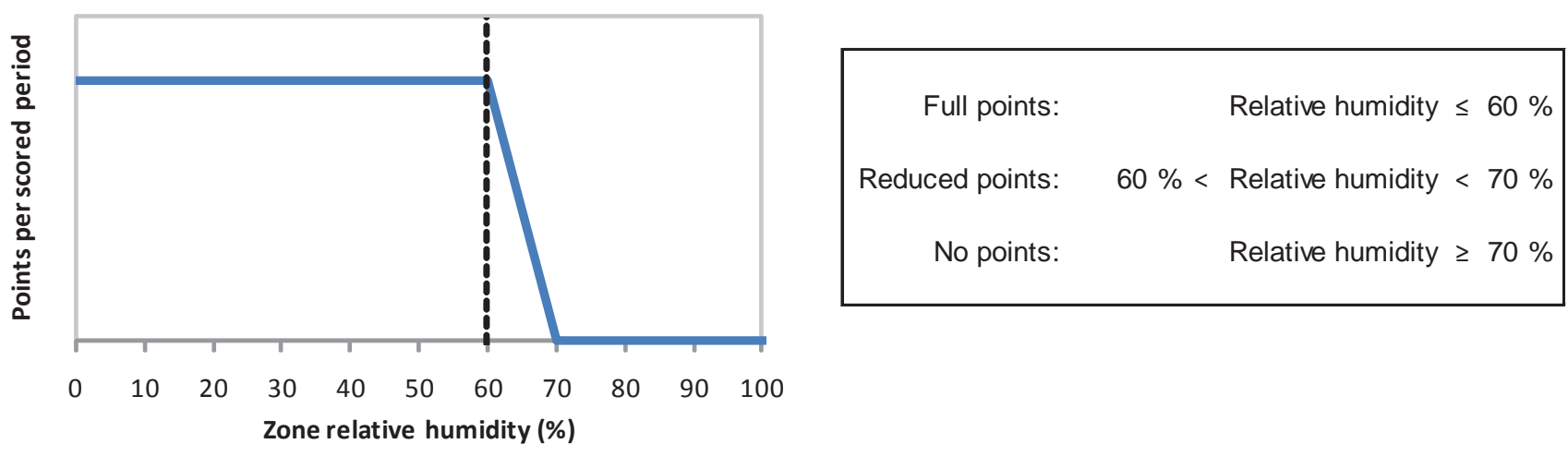

Figure 4: Scoring function for the Humidity Subcontest

\section{Contest 7. Hot Water}

Hot water draws will occur at the approximate times specified in Appendix A-3. For each draw, at least 15 gal $(56.8 \mathrm{~L})$ of hot water shall be delivered in no more than 10 minutes to qualify for points. All available points are earned by delivering an average temperature of at least $110^{\circ} \mathrm{F}\left(43.3^{\circ} \mathrm{C}\right)$. An average temperature below $100^{\circ} \mathrm{F}$ $\left(37.8^{\circ} \mathrm{C}\right)$ earns no points. For temperatures between $100^{\circ} \mathrm{F}\left(37.8^{\circ} \mathrm{C}\right)$ and $110^{\circ} \mathrm{F}\left(43.3^{\circ} \mathrm{C}\right)$, points are scaled linearly, as shown in Figure 5.

a. These hot water draws are designed to simulate most of the washing and bathing tasks that would take place in a typical day. Note: The dishwashing task is not simulated by these hot water draws because it belongs to a different contest.

b. The schedule for hot water draws will most likely vary from one day to the next, just as it does in a typical home.

c. The maximum number of hot water draws for one day will not exceed three, but they may occur consecutively.

d. For fairness, all teams will be drawing hot water on nearly identical schedules.

e. Hot water will be drawn from the shower. Teams shall replace their showerhead with an organizer-supplied fitting prior to the start of the contest. If a house has multiple showers, the shower expected to be used most frequently by the occupants will be used for the hot water draws.

f. Teams shall provide a male $1 / 2$ " National Pipe Thread Tapered Thread (NPT) to accept the Organizer equipment outlined in Table 8.".
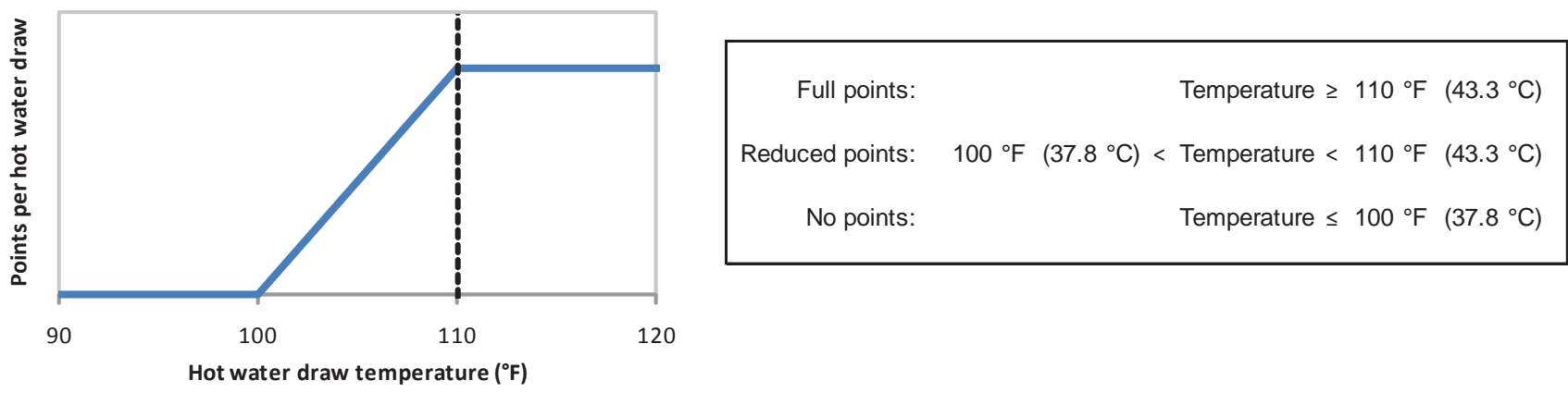

Figure 5: Scoring function for the Hot Water Contest 


\section{Contest 8. Appliances}

\section{8-1. Refrigerator}

All available points are earned at the conclusion of each scored period by keeping the time-averaged interior temperature of a refrigerator between $34.0^{\circ} \mathrm{F}\left(1.11^{\circ} \mathrm{C}\right)$ and $40.0^{\circ} \mathrm{F}\left(4.44^{\circ} \mathrm{C}\right)$ during the scored period. See Appendix A-3 for the schedule of scored periods and for the number of available points per scored period.

a. Reduced points are earned if the time-averaged interior refrigerator temperature is between $32.0^{\circ} \mathrm{F}\left(0.00^{\circ} \mathrm{C}\right)$ and $34.0^{\circ} \mathrm{F}\left(1.11^{\circ} \mathrm{C}\right)$ or between $40.0^{\circ} \mathrm{F}\left(4.44^{\circ} \mathrm{C}\right)$ and $42.0^{\circ} \mathrm{F}\left(5.56^{\circ} \mathrm{C}\right)$. Reduced point values are scaled linearly, as shown in Figure 6.

b. The refrigerator volume published in the manufacturer's specifications shall be a minimum of $6.0 \mathrm{ft}^{3}(170 \mathrm{~L})$.

c. The refrigerator may be used to store food and beverages.
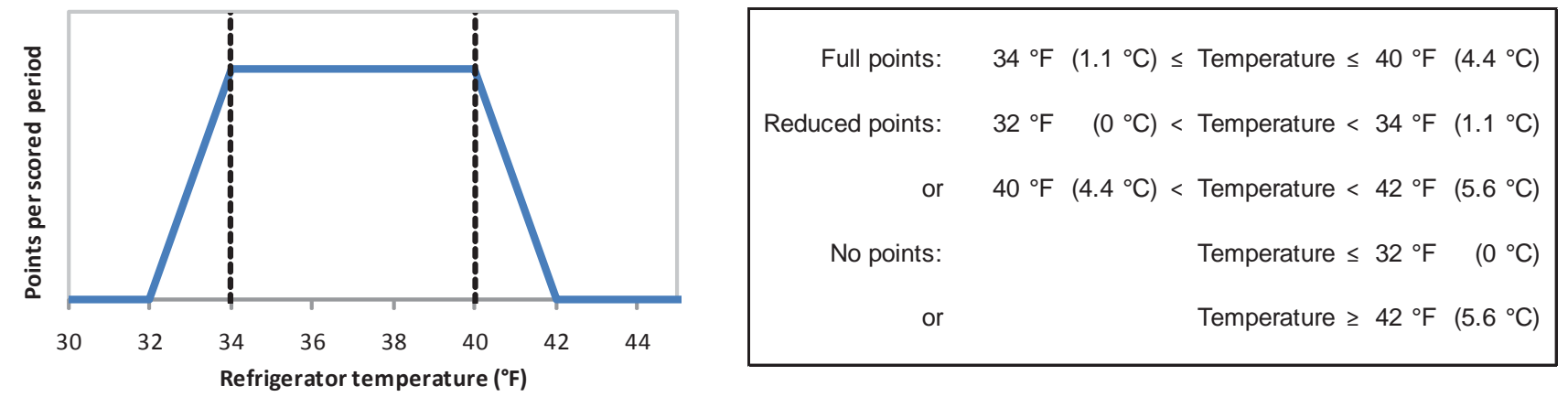

Figure 6: Scoring function for the Refrigerator Subcontest

\section{8-2. Freezer}

All available points are earned at the conclusion of each scored period by keeping the time-averaged interior temperature of a freezer between $-20.0^{\circ} \mathrm{F}\left(-28.9^{\circ} \mathrm{C}\right)$ and $5.0^{\circ} \mathrm{F}\left(-15.0^{\circ} \mathrm{C}\right)$ during the scored period. See Appendix A-3 for the schedule of scored periods and for the number of available points per scored period.

a. Reduced points are earned if the time-averaged interior freezer temperature is between $-30.0^{\circ} \mathrm{F}\left(-34.4^{\circ} \mathrm{C}\right)$ and $-20.0^{\circ} \mathrm{F}\left(-28.9^{\circ} \mathrm{C}\right)$ or between $5.0^{\circ} \mathrm{F}\left(-15.0^{\circ} \mathrm{C}\right)$ and $15.0^{\circ} \mathrm{F}\left(-9.44^{\circ} \mathrm{C}\right)$. Reduced points are scaled linearly, as shown in Figure 7.

b. The freezer volume published in the manufacturer's specifications shall be a minimum of $2.0 \mathrm{ft}^{3}(57 \mathrm{~L})$.

c. The automatic defrost function may be disabled.

d. The freezer may be used to store food and only enough ice to fill the freezer's ice bin.

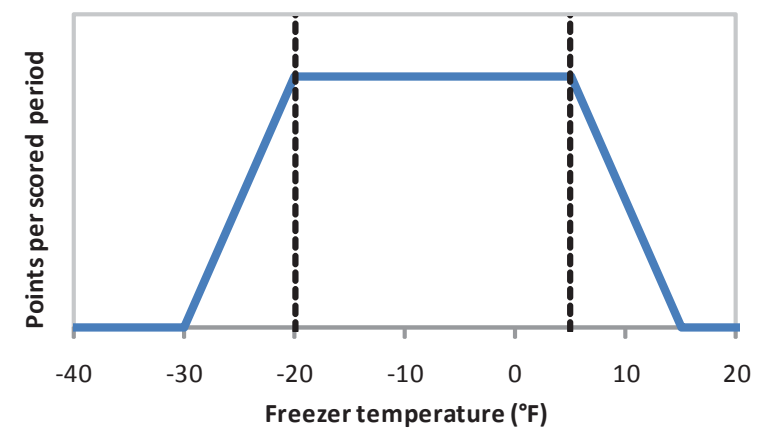

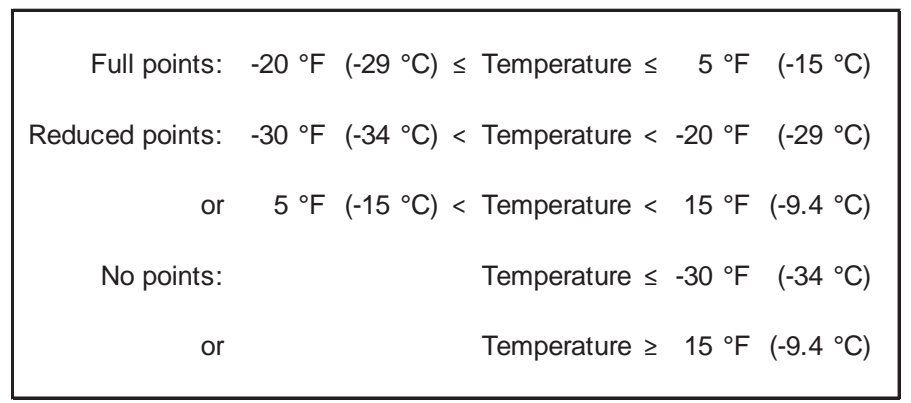

Figure 7: Scoring function for the Freezer Subcontest

\section{8-3. Clothes Washer}

All available points are earned for washing laundry by running a clothes washer through one or more complete, uninterrupted, "normal" (or equivalent) cycle(s) within a specified period of time. See Appendix A-3 for specific details regarding the number of points per clothes-washing task and the time periods designated for clotheswashing tasks. 
b. For redundancy, two temperature sensors shall be placed in the dishwasher for each test. The higher of the two readings is the temperature of record, unless it is determined that the sensor with the higher reading is defective, in which case the lower of the two readings is the temperature of record.

c. The dishwasher shall operate automatically, have at least one wash and rinse cycle, and have a minimum capacity of six place settings according to the manufacturer's specifications.

d. If the dishwasher has a heated drying option, this option shall be disabled.

e. Cycle "interruption" includes the adjustment of supply temperature or flow in a manner not anticipated by the manufacturer or addressed in its operation manual.

f. Cycle completion shall be confirmed by the observance of an audible or visible signal.

g. The organizers will consult the operation manual to identify appropriate cycle settings. "Normal" or "regular" settings shall be selected, if available. Otherwise, settings most closely resembling typical "normal" or "regular" settings shall be selected.

h. The dishwasher may be run empty, partially loaded, or fully loaded; the load may be soiled or clean.

\section{Contest 9. Home Entertainment}

\section{9-1. Lighting}

All available points are earned for keeping all interior and exterior house lights on during specified periods of time. See Appendix A-3 for specific details regarding the number of points per house lighting task and the time periods designated for house lighting tasks.

Exception: Lights located within manufactured residential appliances such as a refrigerator, clothes dryer, microwave, and oven that are intended to illuminate the interior of the appliance are not required to be illuminated.

a. All dimmers shall be adjusted to their highest positions and all other lighting control equipment shall be disabled or overridden so that the controlled lamps are fully and continuously on during the specified periods.

b. Partial credit will be awarded for partial compliance.

\section{9-2. Cooking}

All available points are earned by using a kitchen appliance to vaporize $5.000 \mathrm{lb}(80.00 \mathrm{oz}$ or $2.268 \mathrm{~kg})$ of water within a specified period of time. See Appendix A-3 for specific details regarding the number of points per cooking task and the time periods designated for cooking tasks.

a. Reduced points are earned if between $1.000 \mathrm{lb}(16.00 \mathrm{oz}$ or $0.454 \mathrm{~kg})$ and $5.000 \mathrm{lb}(80.00 \mathrm{oz}$ or $2.268 \mathrm{~kg})$ are vaporized. Reduced point values are scaled linearly, as shown in Figure 9.

b. Any kitchen appliance may be used, but it must operate in its normal configuration as it is vaporizing the water.

c. The water shall be vaporized in a single pot and the starting water weight shall be at least $96.00 \mathrm{oz}(2.721$ $\mathrm{kg})$.

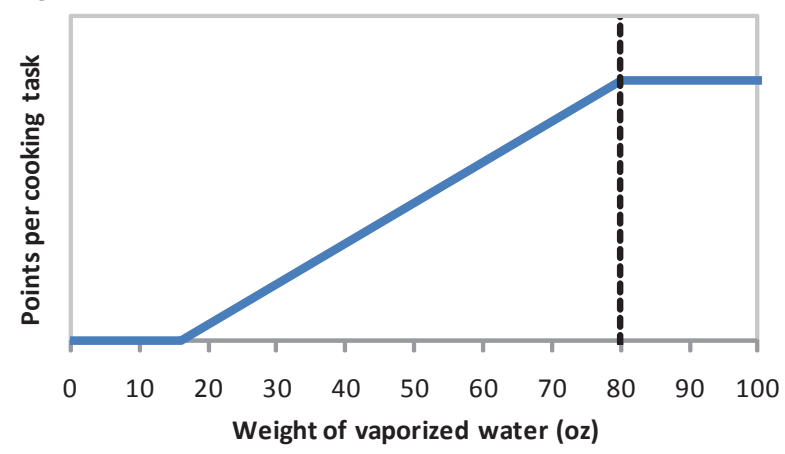

Full points:

Reduced points:

No points:
Weight $\geq 80 \mathrm{oz}(2300 \mathrm{~g})$

$16 \mathrm{oz}(450 \mathrm{~g})<$ Weight $<80 \mathrm{oz}(2300 \mathrm{~g})$

Weight $\leq 16 \mathrm{oz} \quad(450 \mathrm{~g})$

Figure 9: Scoring function for the Cooking Subcontest 


\section{9-3. Dinner Party}

Each team shall host two dinner parties for its neighbors during contest week. See Appendix A-3 for the dinner party schedule and the number of available points per dinner party. Dinner parties will feature a pair of guest decathletes from each of three neighboring houses, and each pair of guest decathletes shall assign a score to the host team after each dinner party. The quality of the meal, ambiance, and overall experience shall be considered in the evaluation.

a. To maintain consistency among the juried contests and subcontests, guest teams shall use the scoring methodology described in the "Phase 3: Deliberation" section of Appendix B-1. Each of the three pairs of guest decathletes shall submit three percentage integer scores, i.e., one score for quality of the meal, one score for ambiance, and one score for overall experience, to the contest officials by 10:45 p.m. These nine scores will be averaged and multiplied by the maximum available points in the scoring server to generate a final score for each dinner party. Percentage integer scores may range from $0 \%$ (lowest possible score) to $100 \%$ (highest possible score).

b. The village will be organized into five small "neighborhoods." Each neighborhood consists of four neighboring houses. The guest list for the dinner party shall be limited to eight people-two people from each of the three neighboring houses and up to two VIP guests. VIP guests may include organizers, media, government employees, family members, or other individuals approved by the organizers to attend the dinner parties.

c. See rule 11-1d for house occupancy rules during the dinner party.

d. Each host team shall prepare dinner for exactly eight people — six decathlete guests and two host team members or VIP guests. Guest decathletes are encouraged to deduct points if too much or too little food is prepared. Guest decathletes of the second dinner party are strongly encouraged to deduct points if the second meal is similar to or the same as the first meal. The intent of this subcontest is to serve a unique meal at each dinner party.

e. Host team decathletes in the house during the dinner party must be performing one or more of the following three functions: 1) eating the meal; 2) cooking/preparing the food; 3) operating the house during scheduled Contest 7, 8, or 9 activities.

f. Non-decathletes are prohibited from preparing the meal or instructing decathletes in any way on the competition site.

g. Teams shall prepare and cook all food and beverages in the house during the period of time indicated in Appendix A-3. A file describing eligible and ineligible ingredients is posted in the "/Files/Rules/Dinner Party" folder on the Yahoo Group.

h. The meal shall be served and eaten in the conditioned space at the eating area designated in the drawings.

i. Before and after the dinner portion of the party, the host team is permitted, but not required, to serve hors d'oeuvres and/or beverages, which may be served outside.

j. Teams are required to submit detailed dinner party menus to the organizers. The organizers will review each menu for compliance. If corrective actions are required to meet all safety requirements, a team must submit an updated version of the menu. Guest decathletes are encouraged to deduct points if the meal isn't consistent with the menu.

(i). Teams shall submit a single, bookmarked PDF file (see Appendix G-2 for PDF formatting and filenaming requirements) containing a restaurant-style menu, cookbook-style recipes, and comprehensive ingredient list for each dinner party.

(ii). Revised menus may be submitted to the subcontest official by noon on the day of the dinner party. Teams are responsible for providing these revised copies to guest decathletes. Guest decathletes are encouraged to deduct points for inconsistencies between the revised menus and the original menu submission.

k. Teams hosting dinner parties shall comply with the following safety requirements:

(i). The use of flames, including candle flames, is prohibited during contest week (see rule 8-2b).

(ii). No alcoholic beverages may be stored in the house, used in meal preparation, served, or part of a meal in any way.

(iii). All water used for cooking and drinking shall be drinking water purchased in sealed containers. 
(iv). All dishes and cookware shall be washed with hot water and soap and rinsed prior to use.

(v). Normal domestic wastewater may go into the wastewater tank.

(vi). All beverages and food must be stored properly and according to the instructions on the packaging, e.g., beverages and foods marked "refrigerate after opening" must be refrigerated appropriately after opening.

(vii). To help prevent allergic reactions among dinner party guests, teams shall create a list of ingredients for each of the items being served at each meal. Common food allergies include milk/dairy products, eggs, peanuts, tree nuts (walnuts, cashews, pecans), fish, shellfish, soy, and wheat.

(viii). Outdoor cooking and grilling equipment may be incorporated into the competition prototype, but the use of such equipment is prohibited on the competition site.

\section{9-4. Home Electronics}

All available points are earned for operating a TV and computer during specified periods of time. See Appendix A-3 for specific details regarding the number of points per home electronics task and the time periods designated for home electronics tasks.

a. The TV display shall be a minimum of 19 in. $(48.3 \mathrm{~cm})$ according to the manufacturer's stated display size. The computer display shall be a minimum of $17 \mathrm{in} .(43.2 \mathrm{~cm})$ according to the manufacturer's stated display size. The computer may be a laptop or desktop computer. The TV and computer displays shall be able to be operated simultaneously and controlled independently of each other.

b. The organizers will supply content that must be shown on the TV display during the home electronics tasks. On the Yahoo Group, the team shall declare its desired format for the supplied content. There is no required volume setting, but the brightness of the display shall be set to at least $75 \%$ of maximum. Observers will conduct spot checks to verify that the TV is showing the supplied content and that the brightness is at the required level.

c. The organizers will supply content that must be shown on the computer display during the scored periods. On the Yahoo Group, the team shall declare its desired format for the supplied content. A decathlete may temporarily suspend the supplied content to use the computer for other practical purposes, but the playing of supplied content shall be resumed whenever the computer is not being used for other practical purposes. The brightness of the display shall be set to at least $75 \%$ of maximum. Observers will conduct spot checks to verify that the computer is either showing the supplied content or is being used by a decathlete, and that the brightness is at the required level.

\section{9-5. Movie Night}

Each team shall host a movie night for its neighbors during contest week. See Appendix A-3 for the movie night schedule and the number of available points for movie night. Each guest team shall assign a score to each host team after the movie. The quality and design of the home theater system, ambiance, and overall experience shall be considered in the evaluation.

a. To maintain consistency among the juried contests and subcontests, guest teams shall use the scoring methodology described in the "Phase 3: Deliberation" section of Appendix B-1. Each of the three guest teams shall submit three percentage integer scores, i.e., one score for the quality and design of the home theater system, one score for ambiance, and one score for overall experience, to the contest officials by 10 p.m. These nine scores will be averaged and multiplied by the maximum available points in the scoring server to generate a final score for movie night. Percentage integer scores may range from $0 \%$ (lowest possible score) to $100 \%$ (highest possible score).

b. The village will be organized into five small "neighborhoods." Each neighborhood consists of four neighboring houses. One or more decathletes from each neighboring house shall spend at least 15 minutes during the movie in each of their neighbors' houses.

c. The Comfort Zone Contest is suspended during movie night. Therefore, the occupancy rule, rule 11-1, is not in effect on movie night. 
d. Whereas take-out and prepared over-the-counter food items are permitted to be served as snacks, movie night guests are encouraged to assign higher scores to teams that use fresh ingredients to prepare the snacks and those that prepare and cook the snacks entirely in the house.

e. Prior to the event, team members signed up for the Yahoo Group will have the option to vote for one of three movies selected by the organizers. The movie receiving the most votes shall be provided by the organizers on the day of movie night and shall be the movie shown in all houses on movie night. The selected movie shall be available in several of the most popular video formats, so that each team may request the format most suitable for its home theater system.

f. The audio/visual equipment settings to be used on movie night shall be declared to a designated organizer prior to movie night. Observers or a small team of organizers, or both, will verify that these settings are maintained on movie night. Guests are encouraged to evaluate the usability of the home theater system and its controls, but the host team is responsible for returning the equipment back to the declared settings after the guests have finished their evaluation(s).

\section{Contest 10. Energy Balance}

All available points are earned at the conclusion of the specified energy balance period (see Appendix A-3 for the energy balance schedule) for a net electrical energy balance of at least $0 \mathrm{kWh}$. A positive net electrical energy balance indicates net production; a negative net electrical energy balance indicates net consumption.

a. Reduced points are earned for a net electrical energy balance between $-50 \mathrm{kWh}$ and $0 \mathrm{kWh}$. Reduced points are scaled linearly, as shown in Figure 10.
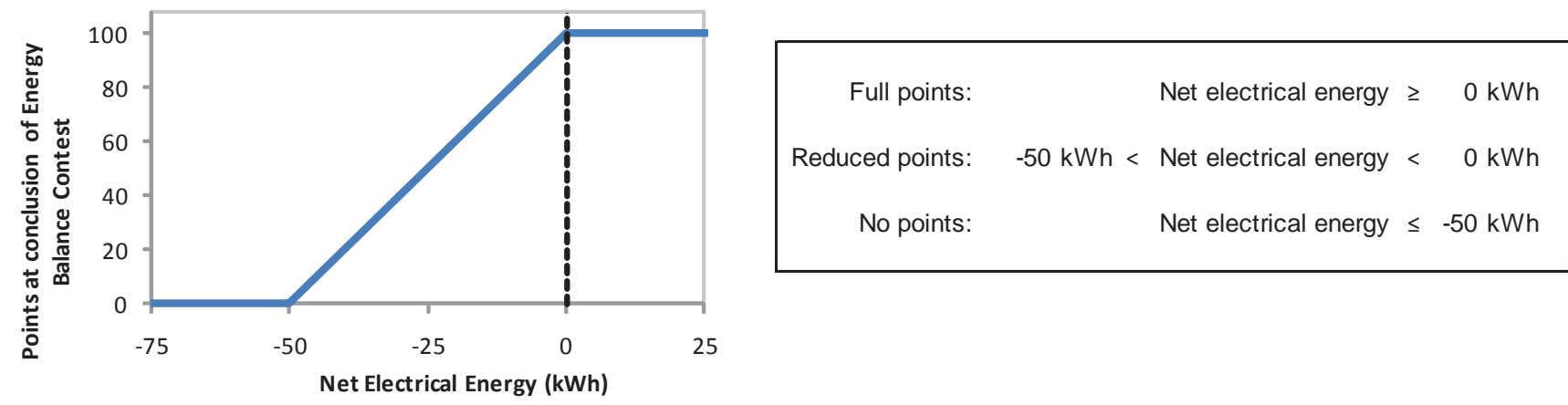

Figure 10: Scoring function for the Energy Balance Contest 


\section{Appendix B: Calculation of $\mathrm{R}$ value}

The following provides information on the method of calculation of the construction $\mathrm{R}$ value for building elements of the First Light house. The calculation follows the method described in NZS 4214(int):2002. Each construction element has been separated into individual layers (Fig 1) and the thermal resistance has been calculated for each. The total thermal resistance of the building component is then calculated from the sum of all of the homogeneous layers and surface layers as described in NZS 4214 (int):2002.

\begin{tabular}{|c|c|}
\hline Building Element & Construction R-value $\left(\mathbf{m}^{2} \cdot{ }^{\circ} \mathbf{C} / \mathbf{W}\right)$ \\
\hline Roof & 6.48 \\
\hline Wall & 5.77 \\
\hline Concrete Floor & 5.46 \\
\hline Timber Floor & 5.88 \\
\hline Glazing & 1.11 \\
\hline Door & - \\
\hline Skylight & 1.11 \\
\hline
\end{tabular}

Table 21: Thermal resistance of individual building elements

In order to calculate the thermal resistance of each building element it was broken down into layers perpendicular to the heat flow. The total thermal resistance of these elements has been calculated using the following expression (Taken from NZS 4214(int):2002)

$R_{T}=R_{s i}+R_{1}+R_{2}+\ldots+R_{n}+R_{s e}$

Where

$R_{T} R_{T} \quad$ is the total thermal resistance

$R_{s i} R_{s i} \quad$ is the internal surface resistance $=\quad 0.09$

$R_{1}, R_{2}, \ldots R_{n}, R_{1}, R_{2}, \ldots R_{n}$, are the thermal resistances of each layer, including bridged layers 
$R_{s e}, R_{s e} \quad$ is the external surface resistance $\quad=\quad 0.03$

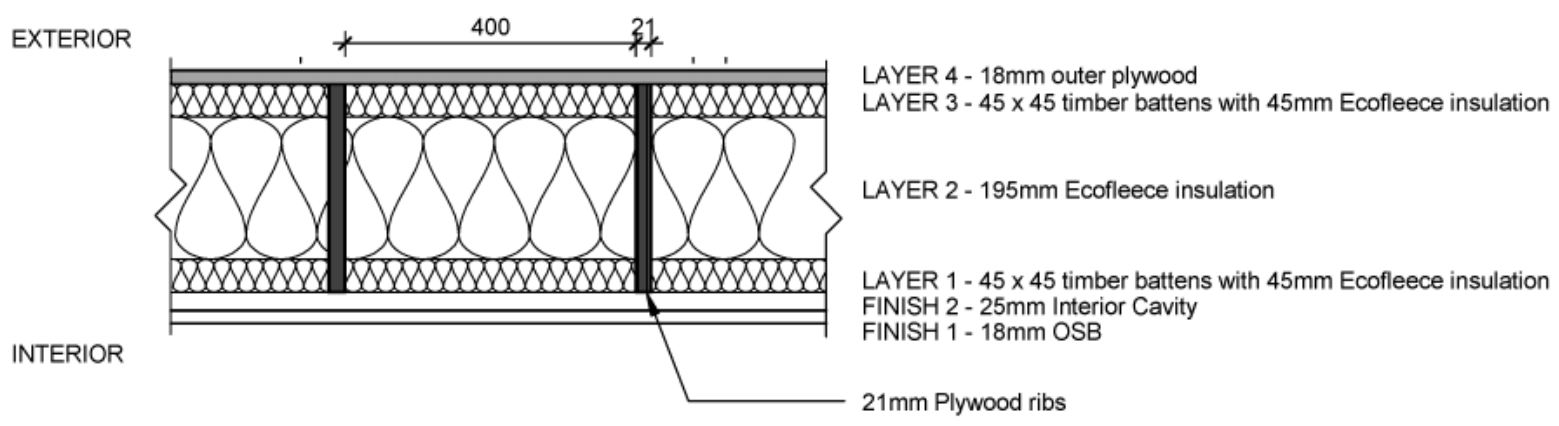

\subsection{Roof construction}

NOTE: The drawings shown in this section are schematic diagrams to understand the breakdown in layers for the thermal resistance calculation. Please refer to the detail drawings included in the drawing set for further information on the detail design of each element

\begin{tabular}{|c|c|c|c|}
\hline & TABLE 1: & $\begin{array}{l}\text { R Value of First Light Roof } \\
\text { Building Element }\end{array}$ & $R$ Value \\
\hline$R_{-i}$ & Interior & Internal Surface Resistance & 0.09 \\
\hline$R_{1}$ & Finish 1 & $18 \mathrm{~mm}$ OSB & 0.14 \\
\hline$R_{2}$ & Finish 2 & $25 \mathrm{~mm}$ Interior Cavity & 0.00 \\
\hline$R_{3}$ & Layer 1 & Wall layer 1 - Ecofleece $45 \mathrm{~mm}$ & 0.93 \\
\hline$R_{4}$ & Layer 2 & Wall Layer 2 - Ecofleece 195mm & 4.36 \\
\hline$R_{5}$ & Layer 3 & Wall Layer 3 - Ecofleece 45mm & 0.79 \\
\hline$R_{6}$ & Layer 4 & $18 \mathrm{~mm}$ outer plywood & 0.14 \\
\hline \multirow{2}{*}{$\begin{array}{l}R_{-.} \\
R_{s e}\end{array}$} & Exterior & External Surface Resistance & 0.03 \\
\hline & & Total R Value of roof construct & \\
\hline
\end{tabular}

Table 22: Breakdown of the layers within the roof construction and their $R$ values 
$R_{\tau}=6.48$

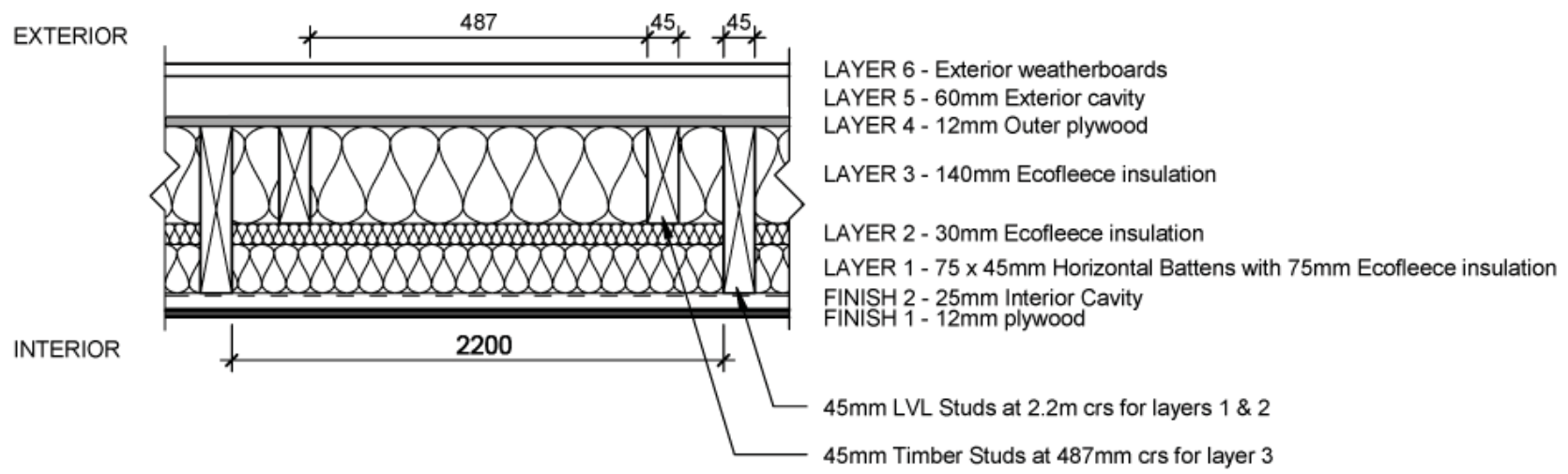

\subsection{Wall construction}

The following provides information on the method of calculation of the construction $\mathrm{R}$ value for the Roof of the First Light house. The calculation follows the method described in NZS 4214(int):2002.

\begin{tabular}{|l|lll|}
\hline & TABLE 2 & R VALUE of First Light Wall construction \\
Building Element & R Value \\
\hline$R_{\sim i}$ & Interior & Internal Surface Resistance & \\
$R_{\sim i}$ & & Interior Lining 12mm Plywood & 0.09 \\
$R_{7}$ & Finish 1 & Interior Cavity 25mm & 0.09 \\
$R_{g}$ & Finish 2 & Wall layer 1 - Ecofleece 70mm & 0.00 \\
$R_{10}$ & Layer 1 & Wall Layer 2 - Ecofleece 30mm & 1.43 \\
$R_{11}$ & Layer 2 & Wall Layer 3 - Ecofleece 140mm & 0.72 \\
$R_{12}$ & Layer 3 & 12mm outer plywood & 3.18 \\
$R_{13}$ & Layer 4 & 60mm Cavity & 0.14 \\
$R_{14}$ & Layer 5 & Exterior Cladding & 0.00 \\
$R_{15}$ & Layer 6 & & 0.09
\end{tabular}




\begin{tabular}{|c|c|c|c|}
\hline \multirow[t]{2}{*}{$R_{s e}$} & Exterior & External Surface Resistance & 0.03 \\
\hline & & Total R Value of building component & 5.77 \\
\hline
\end{tabular}

Table 23: Breakdown of the layers within the wall construction and their $\mathrm{R}$ values

$R_{T}=0.09+0.09+1.43+0.72+3.18+0.14+0.09+0.03$

$R_{T}=5.77$

\subsection{Concrete floor construction}

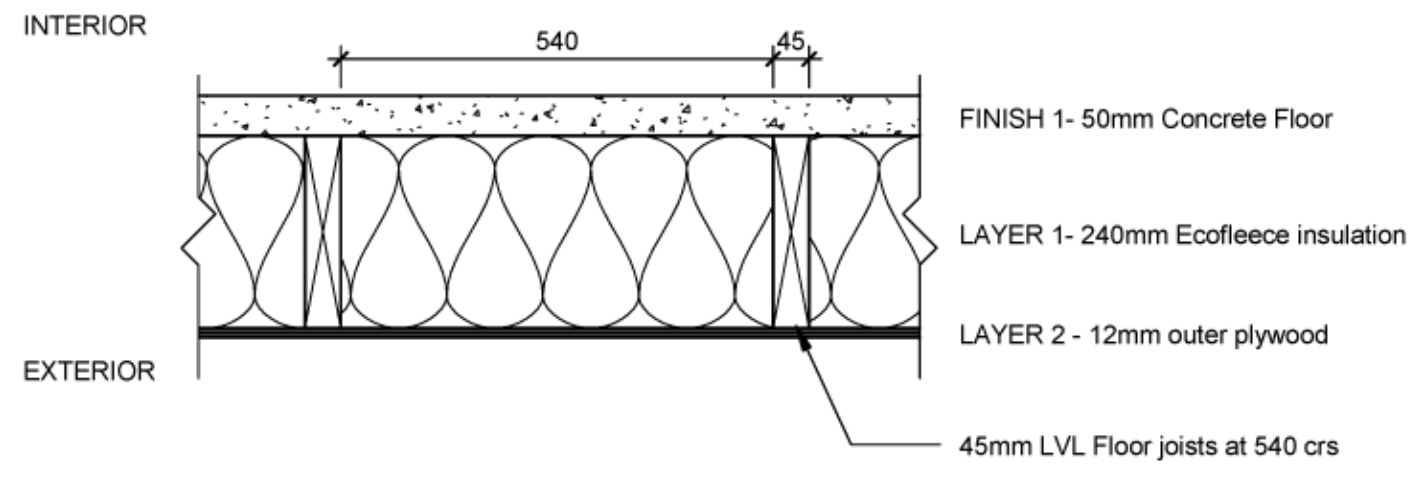

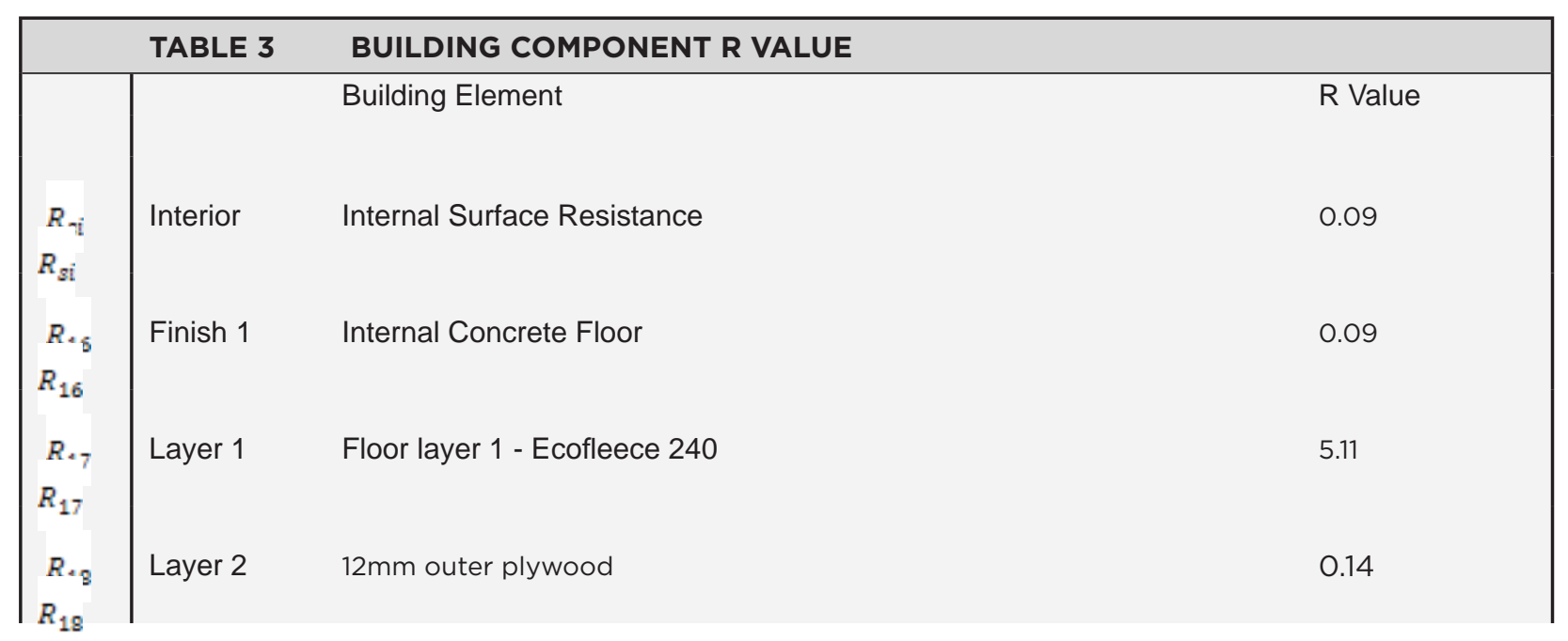




\begin{tabular}{|l|l|l|}
$R_{s e}$ & Exterior & External Surface Resistance \\
& Total R Value of building component & 0.03 \\
\hline
\end{tabular}

Table 24: Breakdown of the layers within the floor construction and their $\mathrm{R}$ values

$R_{T}=0.09+0.09+5.11+0.14+0.03$

$R_{T}=5.46$

\subsection{Timber floor construction}

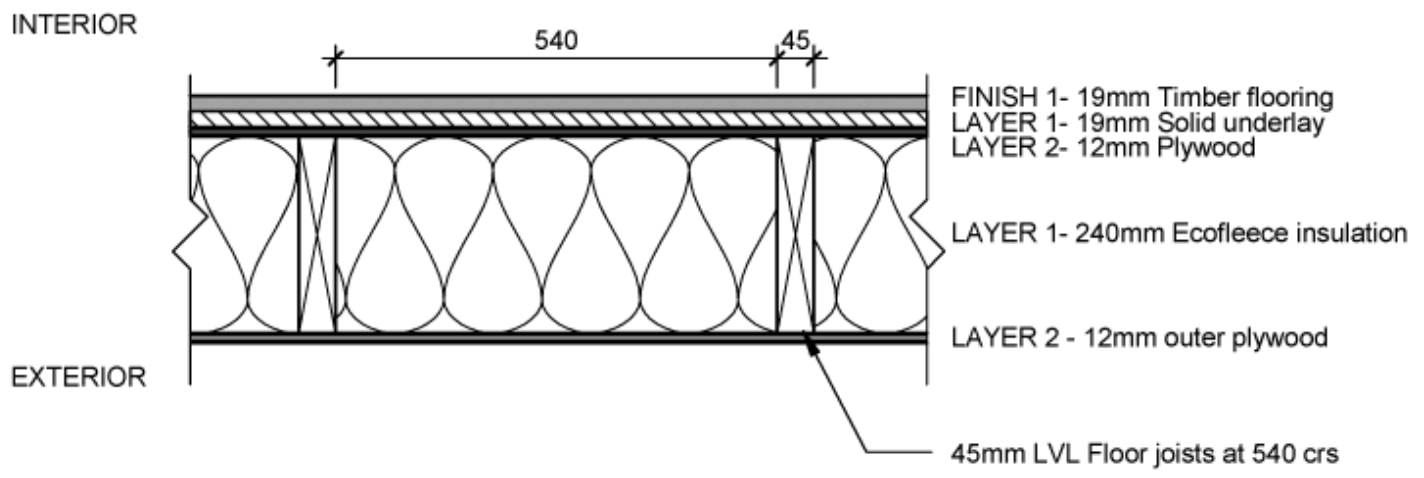

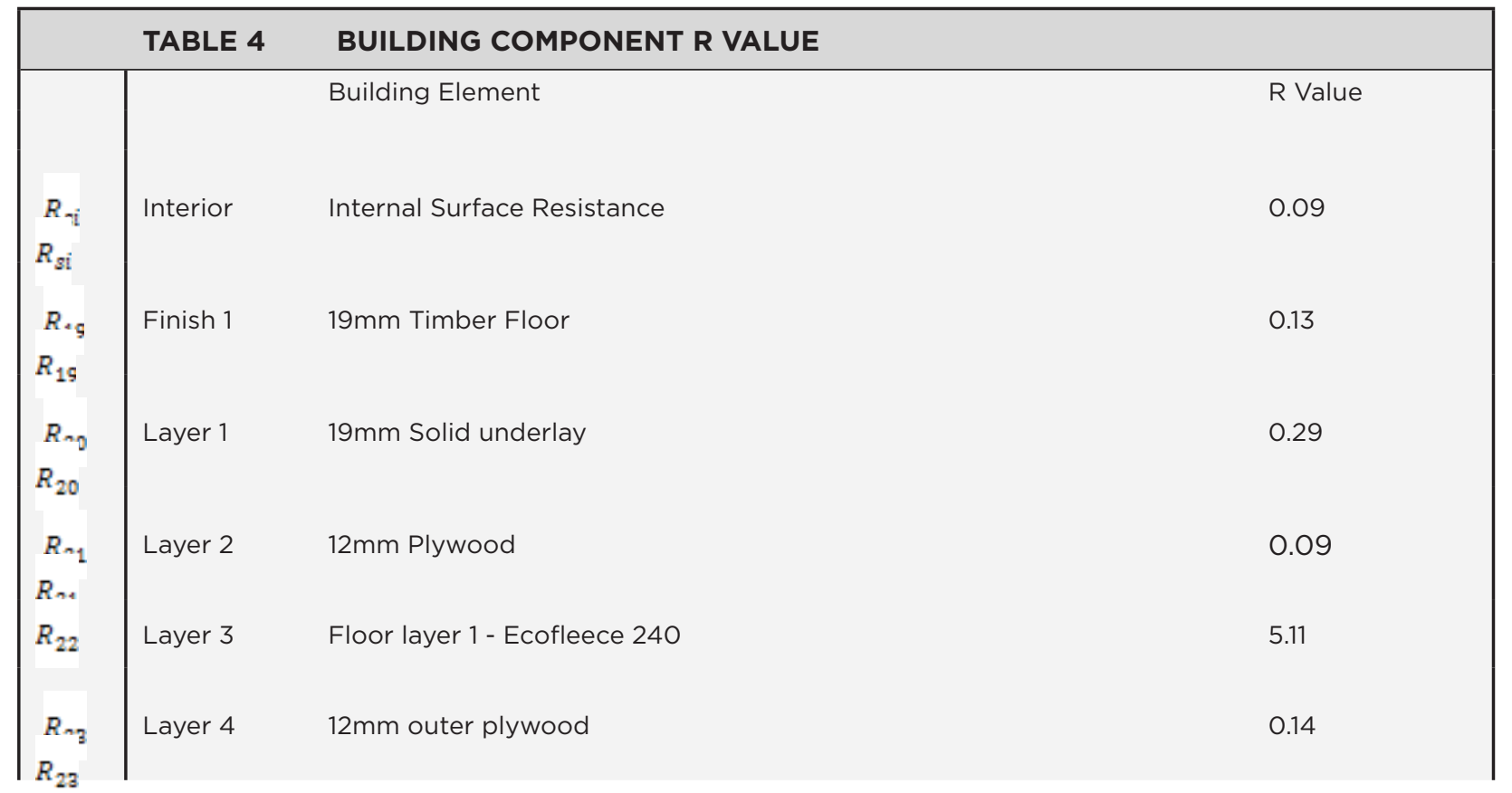


Table 25: Breakdown of the layers within the timber floor construction and their $\mathrm{R}$ values

$R_{T}=0.09+0.13+0.29+5.11+0.14+0.03$

$R_{\tau}=5.88$

\subsection{Window and Skylight}

The R Value for both the windows and the skylight have been calculated using Window 5 in accordance with 4214 G.1.1. The windows are triple glazed, argon filled, Low-e and will be supplied by Metroglass. Refer appendix 5 for further details on this calculation

$$
\begin{aligned}
& R_{T \text { window }}=1.11 \\
& R_{T \text { skylight }}=1.11
\end{aligned}
$$




\section{Appendix C: Weather file}

\begin{tabular}{|c|c|c|c|c|c|c|c|c|}
\hline & $\operatorname{ccs}$ & CWS & CCR & CWR & HCS & HCR & HWR & HWS \\
\hline Direct Solar & High $5 \%$ & High 5\% & Low 5\% & Low 5\% & High 5\% & Low $5 \%$ & Low 5\% & High 5\% \\
\hline Diffuse Solar & High 5\% & High 5\% & Low 5\% & Low 5\% & High 5\% & Low 5\% & Low 5\% & High $5 \%$ \\
\hline Wind Direction & Northerly & Northerly & Northerly & Northerly & Northerly & Southerly & Southerly & Southerly \\
\hline Wind Speed & Low 5\% & High 5\% & Low 5\% & High 5\% & Low 5\% & Low 5\% & High 5\% & High 5\% \\
\hline Temperature & Low 5\% & Low 5\% & Low 5\% & Low 5\% & High 5\% & High 5\% & High 5\% & High $5 \%$ \\
\hline Dew Point & Low 5\% & Low 5\% & Low 5\% & Low 5\% & High 5\% & High 5\% & High 5\% & High $5 \%$ \\
\hline Precipitation & Low 5\% & Low 5\% & High 5\% & High 5\% & Low 5\% & High 5\% & High 5\% & Low 5\% \\
\hline Cloud Cover & Low 5\% & Low 5\% & High $5 \%$ & High 5\% & Low 5\% & High 5\% & High 5\% & Low 5\% \\
\hline $\begin{array}{l}\text { Relative } \\
\text { Humidity }\end{array}$ & Low 5\% & Low 5\% & High 5\% & High 5\% & Low 5\% & High 5\% & High 5\% & Low 5\% \\
\hline
\end{tabular}

Table 26: Construction of weather files

- CCS (Cold, Calm and Sunny)

- CWS (Cold, Windy and Sunny)

- CCR (Cold, Calm and Raining)

- CWR (Cold, Windy and Raining)

- HCS (Hot, Calm and Sunny)

- HWS (Hot, Windy and Sunny)

- HCR (Hot, Calm and Raining)

- HWR (Hot, Windy and Raining)

- WASH (Washington weather file) 


\section{Appendix D: Schedule of contests}

The following tables are an adaption of the contest schedule that was given to each team. This schedule was used to calculate the total energy use of the house during the competition. 


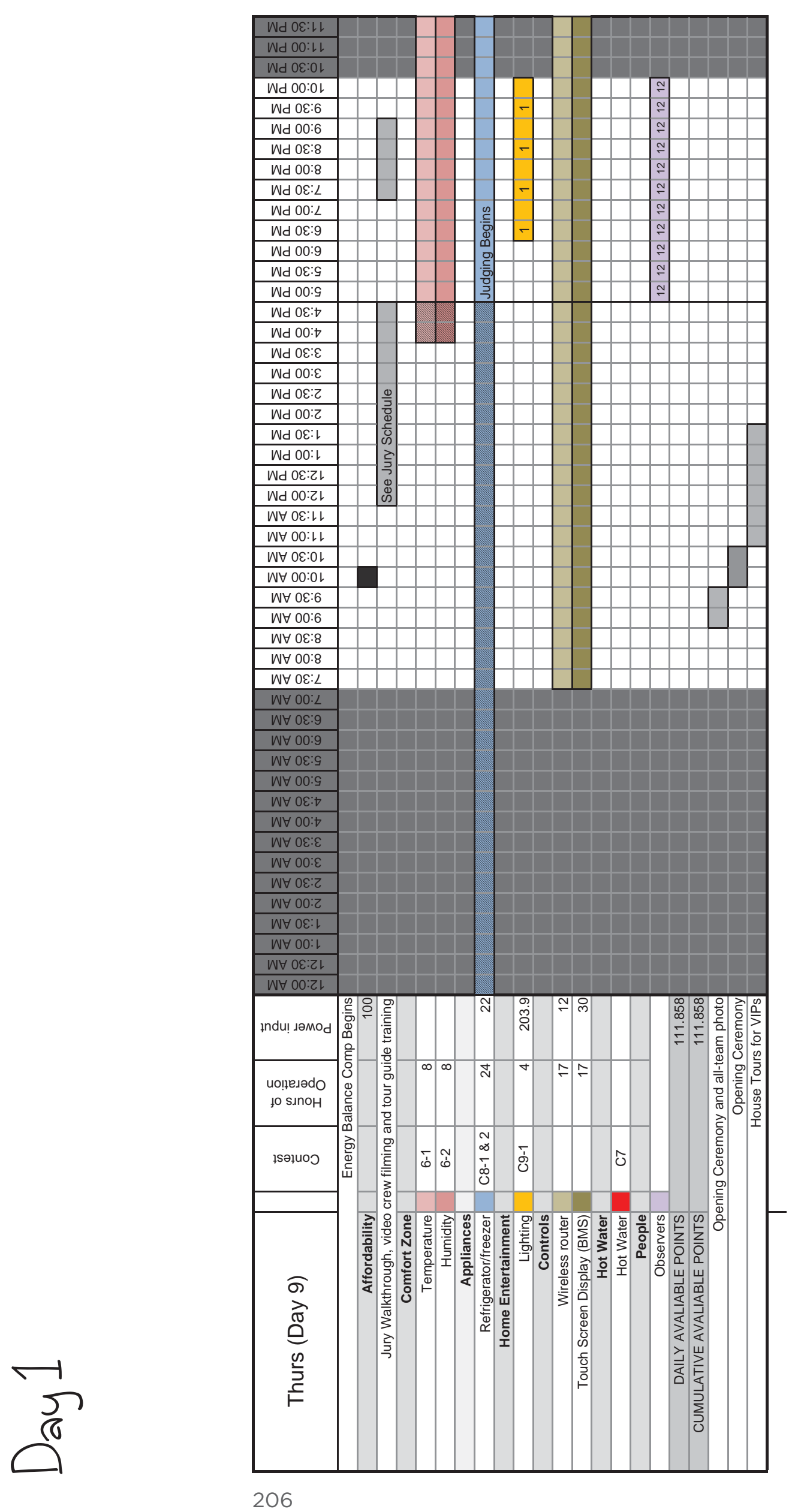




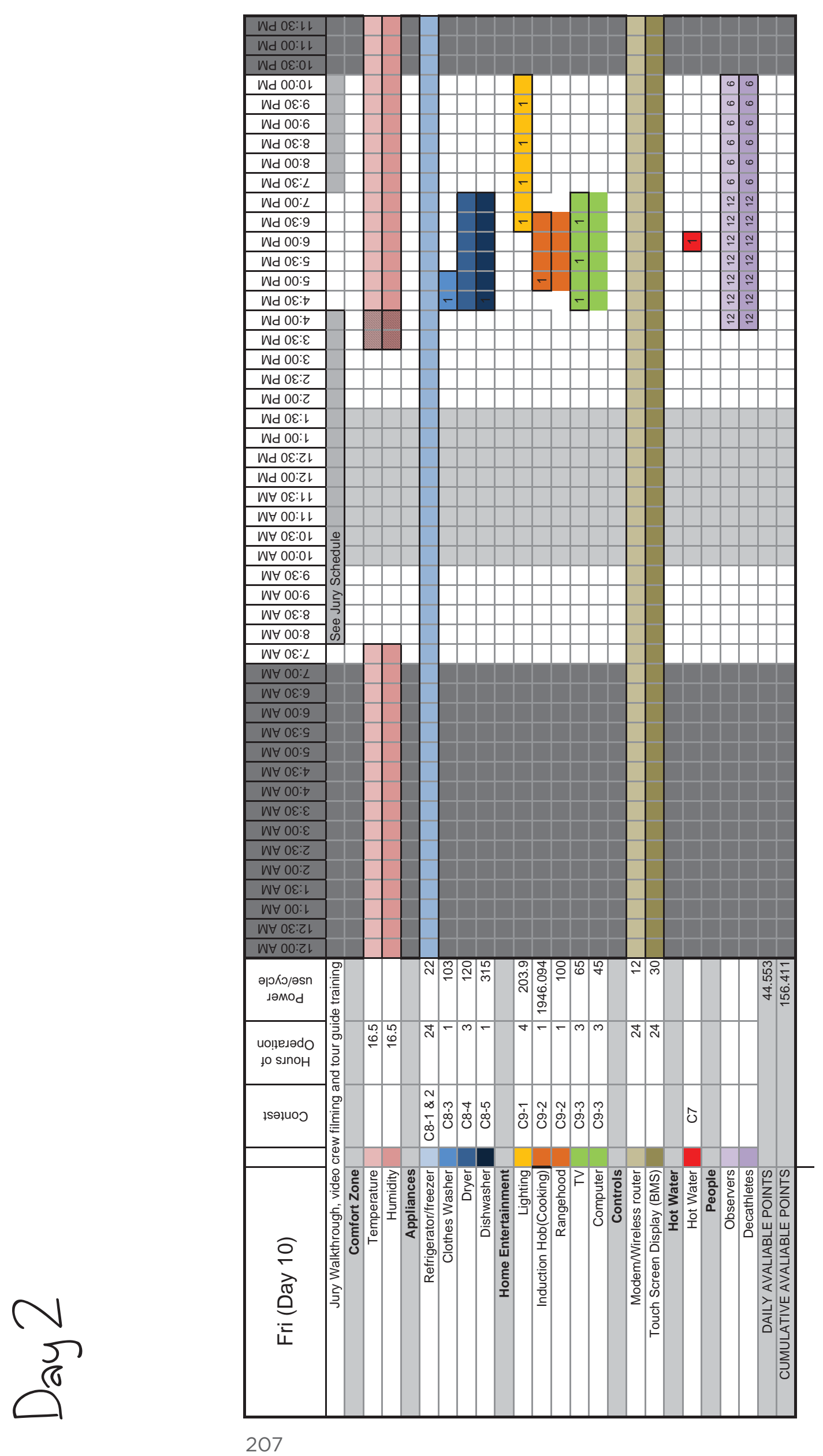




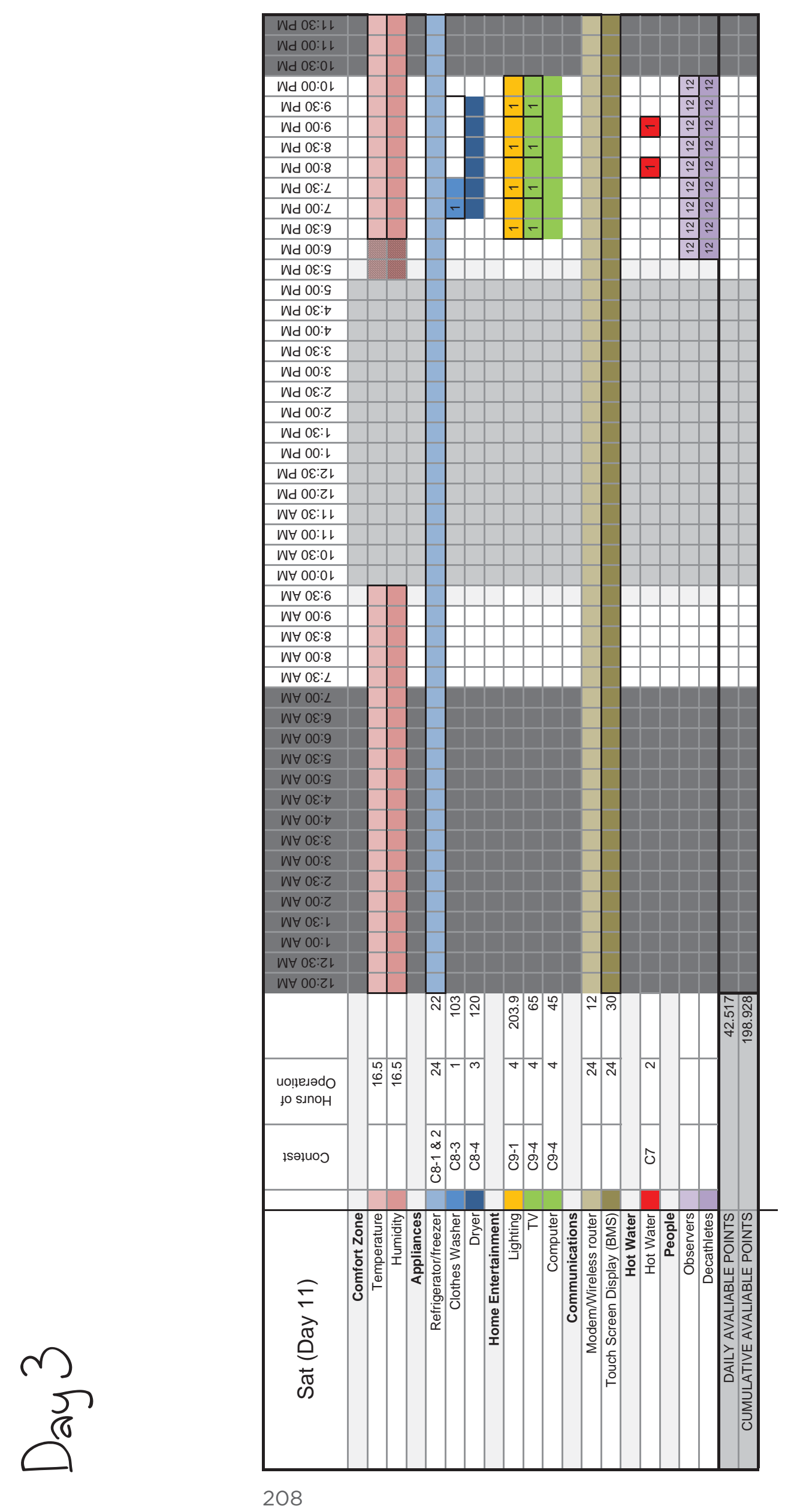




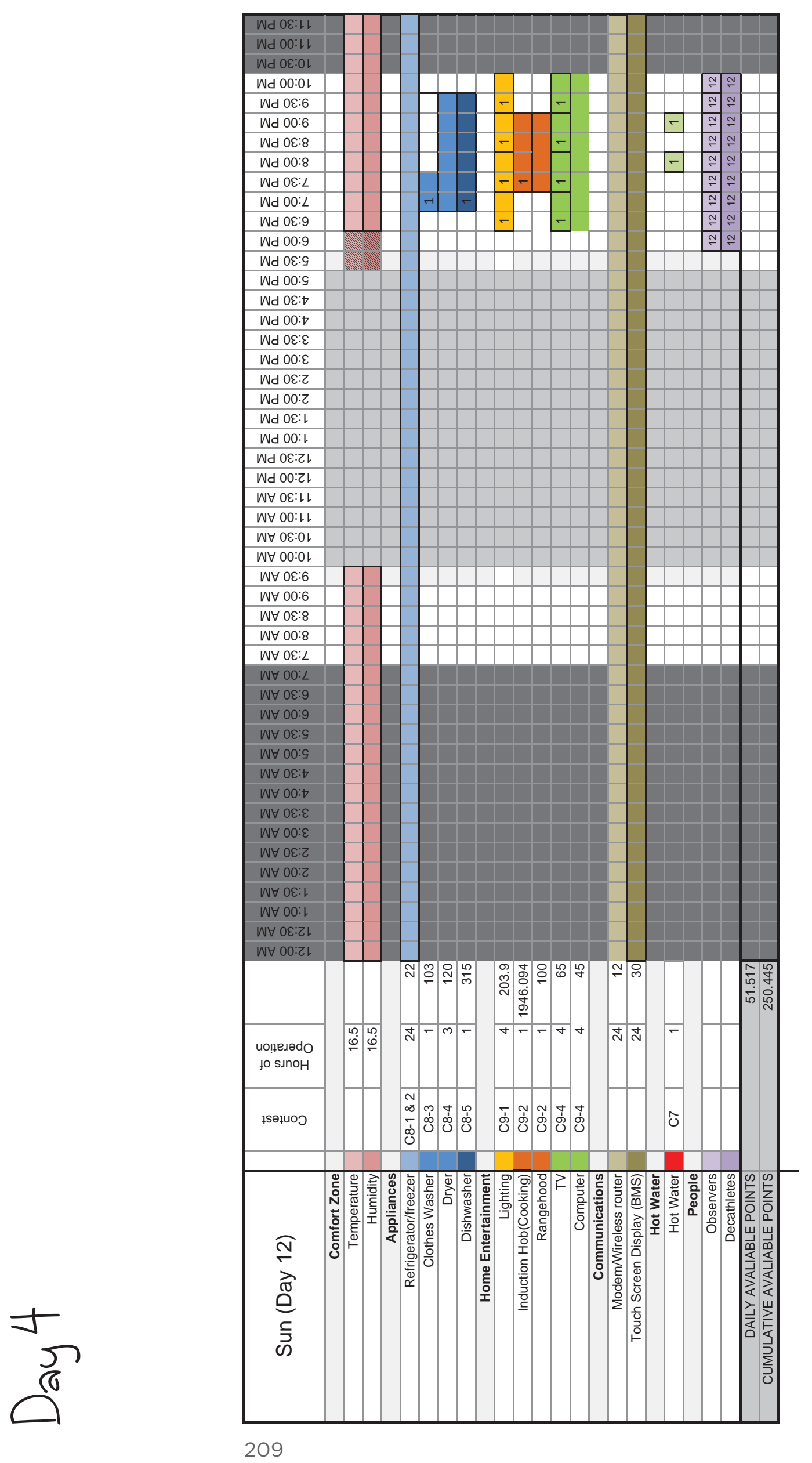




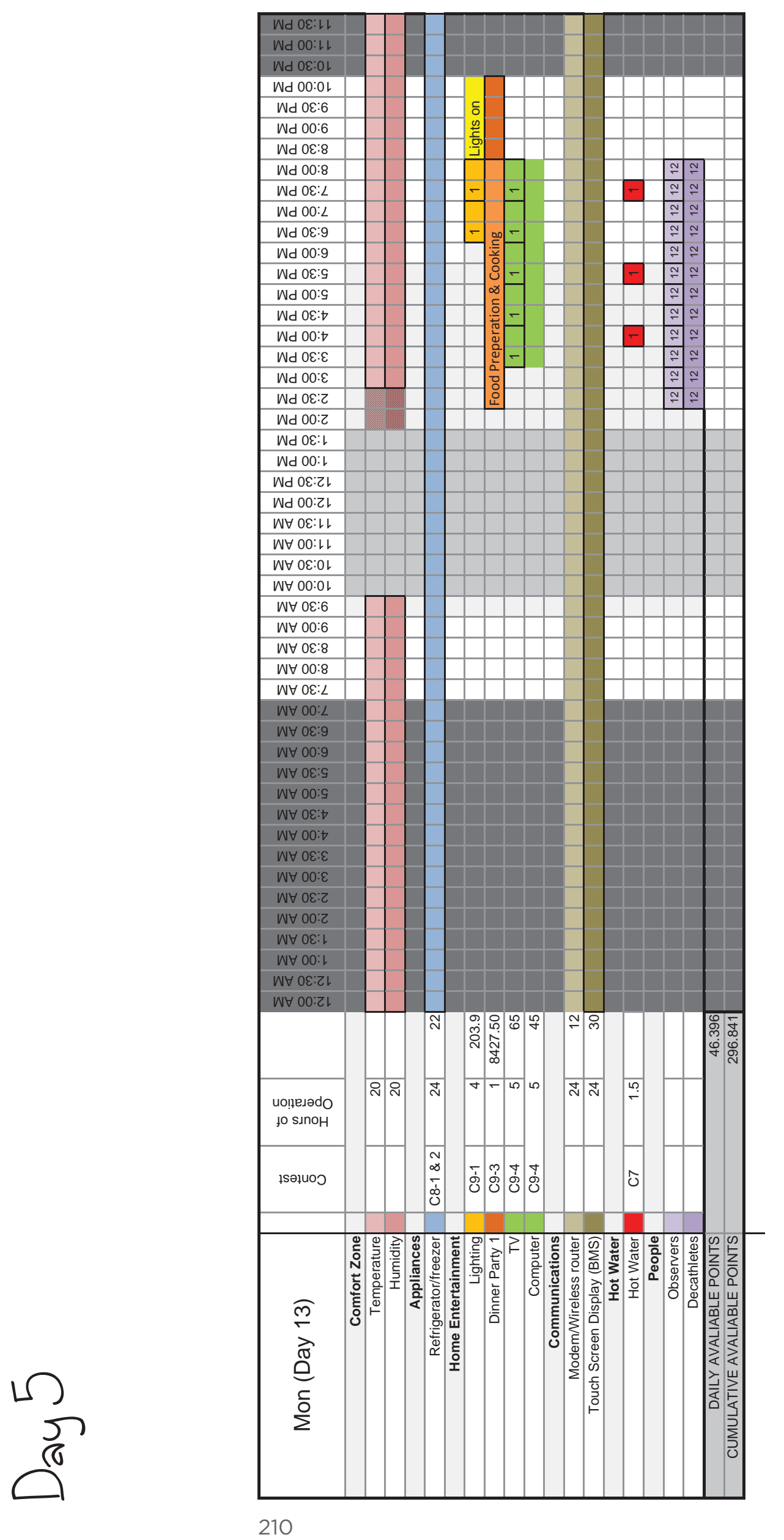




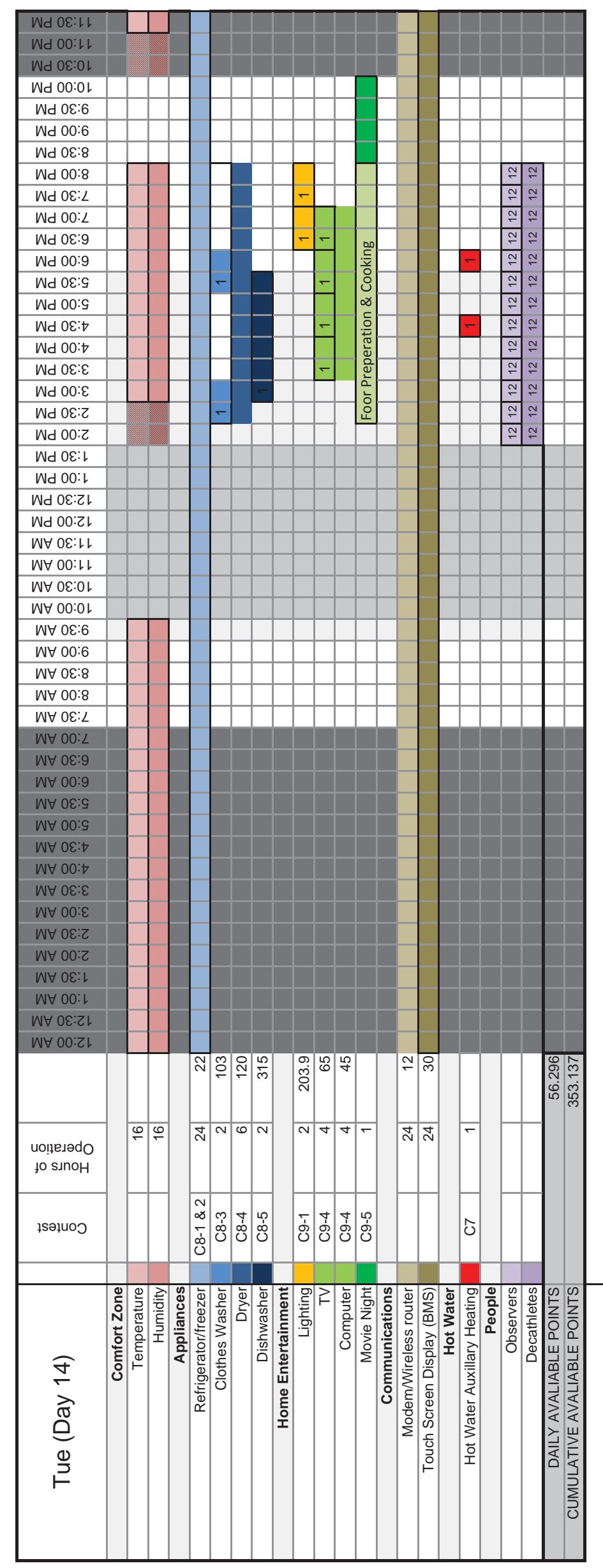




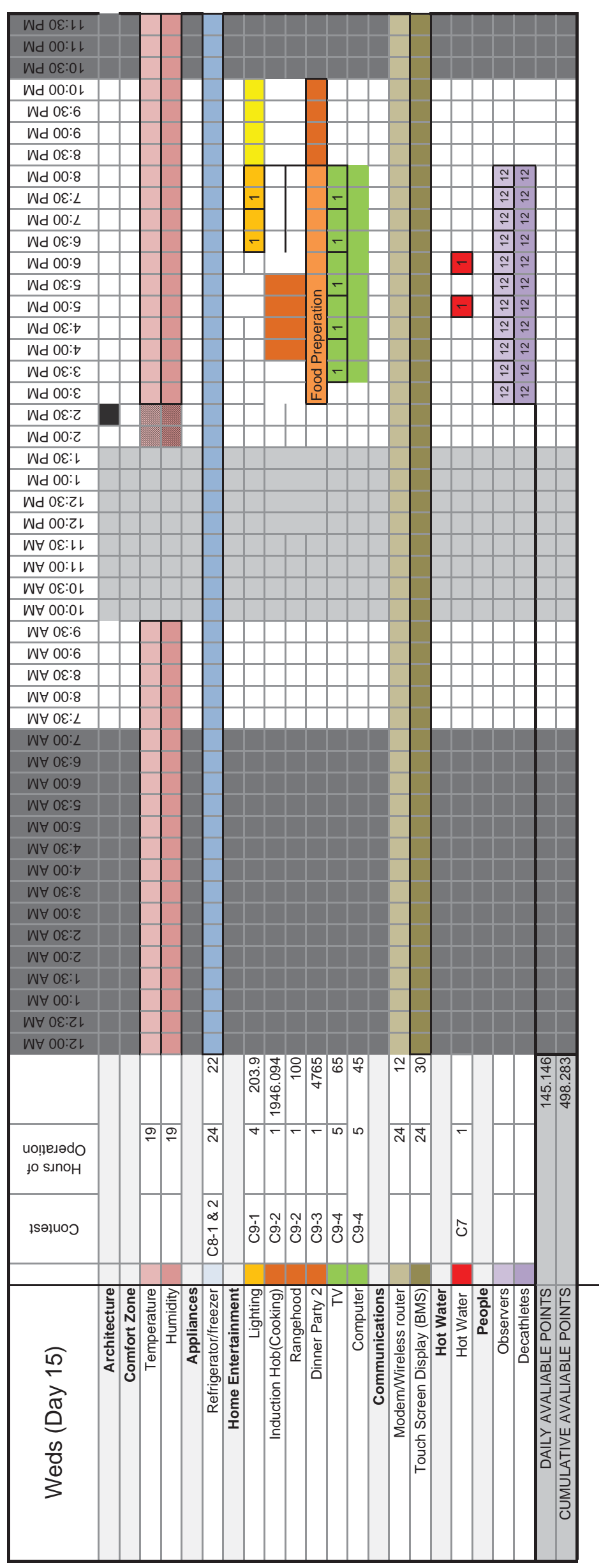




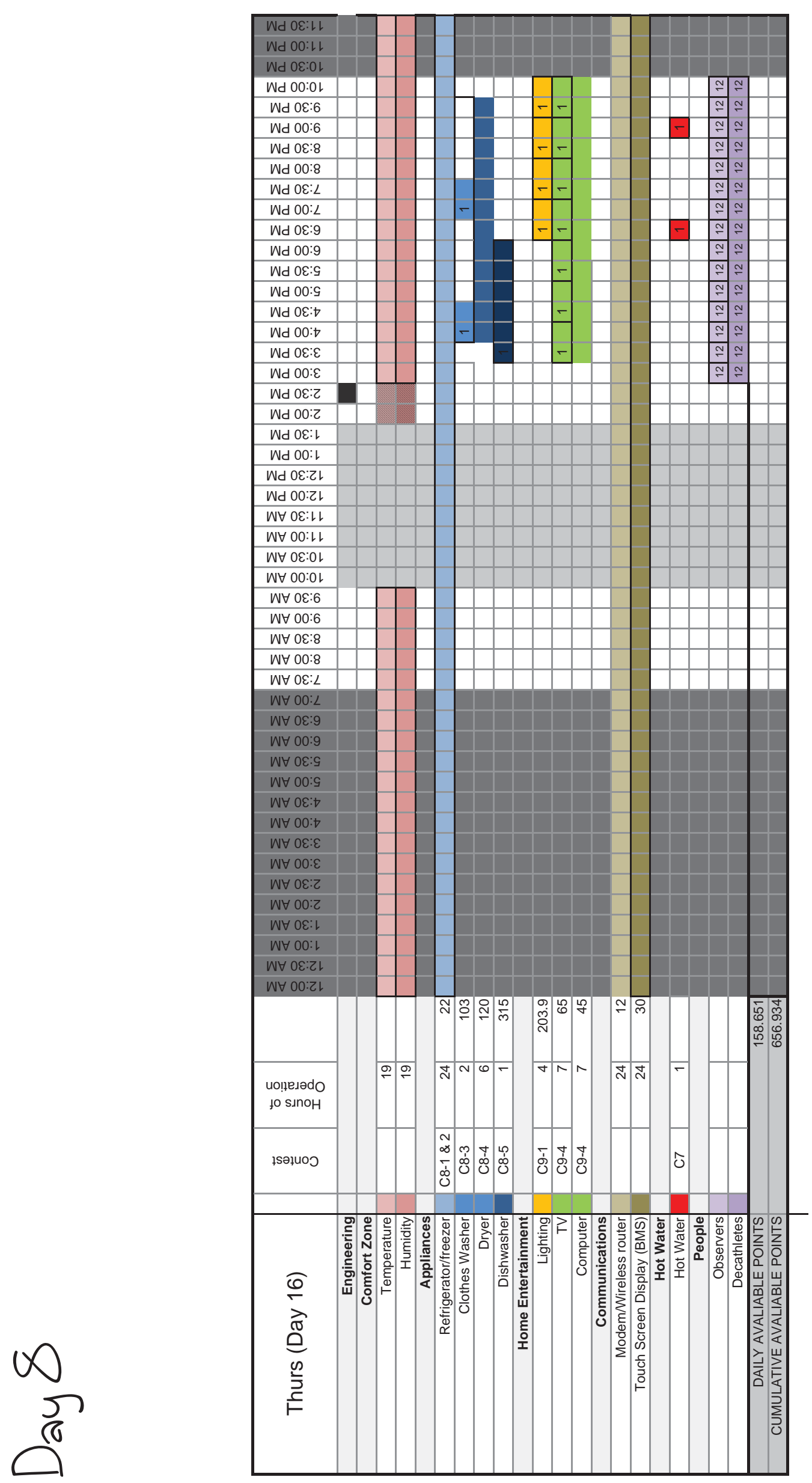




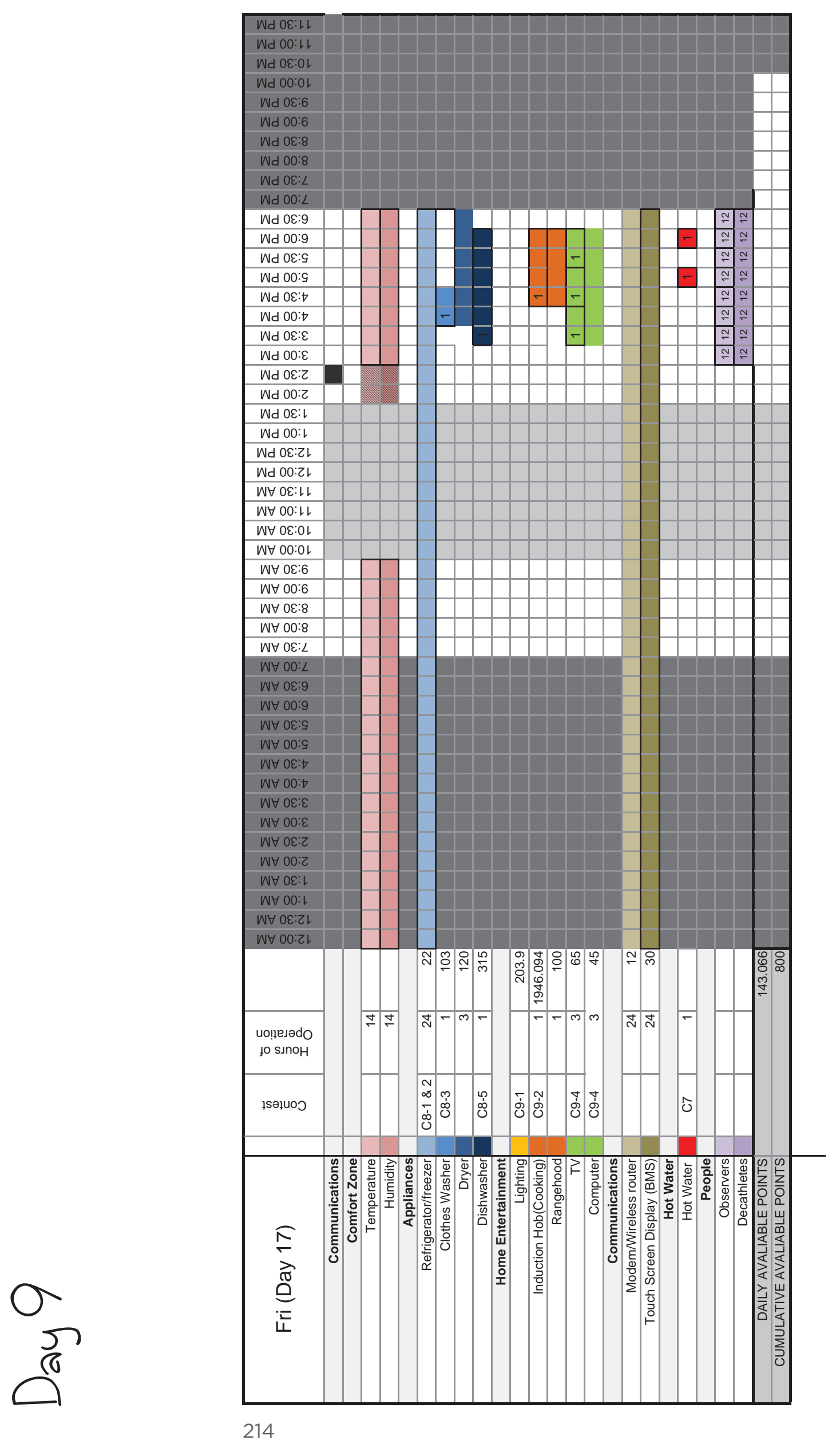




\section{Appendix E: Drying cupboard tests}

Once the prototype drying cupboard was constructed the intial testing focused on the drying time of the six bath towels required by the competition rules at different water temperatures. Presented here are is the test with the water temperature at $80^{\circ} \mathrm{C}$ and the drying time $1.5 \mathrm{hrs}$. This was was the ideal water temperature for drying in the required time frame. A test was also preformed with the water temperature at $60^{\circ} \mathrm{C}$ but these results are not presented here. At this temperature it took 2.5 hours to dry the towels.

The prototype model had no insulation and was not constructed of the highest standard. Significant improvements from these results were found when final prototype was constructed in the house in Washington DC.

The intial tests and results presented here were preformed by by Pedro Romero of Leap Australisia

\subsection{Test 1: Water temperature $80^{\circ} \mathrm{C}$}

Test Drying time: $1.5 \mathrm{hrs}$

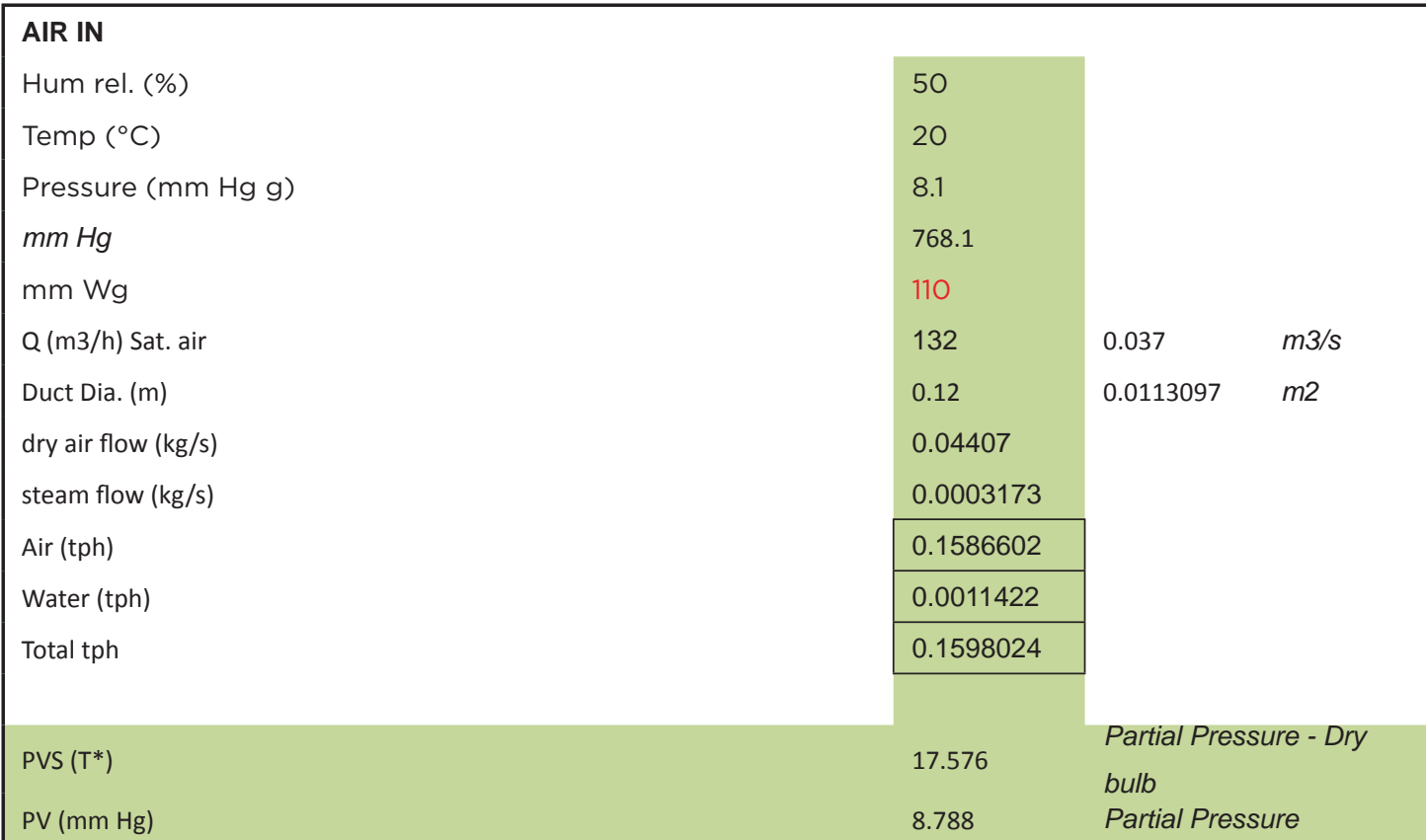




\begin{tabular}{|c|c|c|c|}
\hline W (Hum. Spec.) & 0.007 & \multicolumn{2}{|l|}{ kgv/kgas } \\
\hline V(m3ah/kgas) & 0.832 & & \\
\hline \multirow[t]{2}{*}{$\mathrm{Q}(\mathrm{m} 3 / \mathrm{h})$ Sat. air } & 132 & 2.2 & $\mathrm{~m} 3 / \mathrm{min}$ \\
\hline & & 77.6 & CFM \\
\hline Duct Dia. (m) & 0.12 & 0.0113097 & $m 2$ \\
\hline Veloc. (m/s) & 3.2 & & \\
\hline
\end{tabular}

\begin{tabular}{|c|c|c|}
\hline Towel Weight (6 units) & 5.7 & $\mathrm{~kg}$ \\
\hline$\%$ Water contained & $37 \%$ & \\
\hline Water contained & 2.100 & $\mathrm{~kg}$ \\
\hline \multirow[t]{2}{*}{ Drying Time } & 1.3 & Hrs \\
\hline & 80.1 & Min. \\
\hline Heat Input & 1.5 & $k W$ \\
\hline Water Inlet @ $80^{\circ} \mathrm{C}$ & 2.5 & $L P M$ \\
\hline$d T$ & 8.00 & ${ }^{\circ} \mathrm{C}$ \\
\hline
\end{tabular}

\begin{tabular}{|c|c|c|c|}
\hline AIR OUT & & & \\
\hline Hum rel. (\%) & 36.7 & & \\
\hline Temp $\left({ }^{\circ} \mathrm{C}\right)$ & 41.9 & & \\
\hline Pressure (mm Hg g) & 8.1 & & \\
\hline $\mathrm{mm} \mathrm{Hg}$ & 768.1 & & \\
\hline $\mathrm{mm}$ Wg & 110 & & \\
\hline $\mathrm{Q}(\mathrm{m} 3 / \mathrm{h})$ Sat. air & 132 & 0.037 & $m 3 / s$ \\
\hline Duct Dia. (m) & 0.12 & 0.0113097 & $m 2$ \\
\hline dry air flow (kg/s) & 0.04027 & & \\
\hline steam flow $(\mathrm{kg} / \mathrm{s})$ & 0.0007541 & & \\
\hline Air (tph) & 0.1449859 & & \\
\hline Water (tph) & 0.0027148 & & \\
\hline Total tph & 0.1477007 & & \\
\hline $\operatorname{PVS}\left(T^{*}\right)$ & 61.218 & \multirow{2}{*}{\multicolumn{2}{|c|}{$\begin{array}{l}\text { Partial Pressure - Dry } \\
\text { bulb } \\
\text { Partial Pressure }\end{array}$}} \\
\hline $\mathrm{PV}(\mathrm{mm} \mathrm{Hg})$ & 22.447 & & \\
\hline W (Hum. Spec.) & 0.019 & \multirow{2}{*}{\multicolumn{2}{|c|}{ kgv/kgas }} \\
\hline$V(m 3 a h / k g a s)$ & 0.910 & & \\
\hline
\end{tabular}

Table 27: Test results of prototype dryer

TEST 1

$\begin{array}{lll}\text { Room Temperature } & 20 & { }^{\circ} \mathrm{C} \\ \text { Room Humidity } & 50 & \% \\ \text { Water Temp supply } & 80 & { }^{\circ} \mathrm{C} \\ \text { Water Temp return } & 72 & { }^{\circ} \mathrm{C} \\ \text { Water flow LPM } & 2.5 & \text { LPM } \\ \text { Pump Power Required (min. speed) } & 0.045 & \mathrm{~kW} / \mathrm{hr}\end{array}$


Towels initial weight

5.7

$\mathrm{kg}$

Towels final weight 


\section{Appendix F: Dinner party energy use}

\subsection{Dinner Party 1}

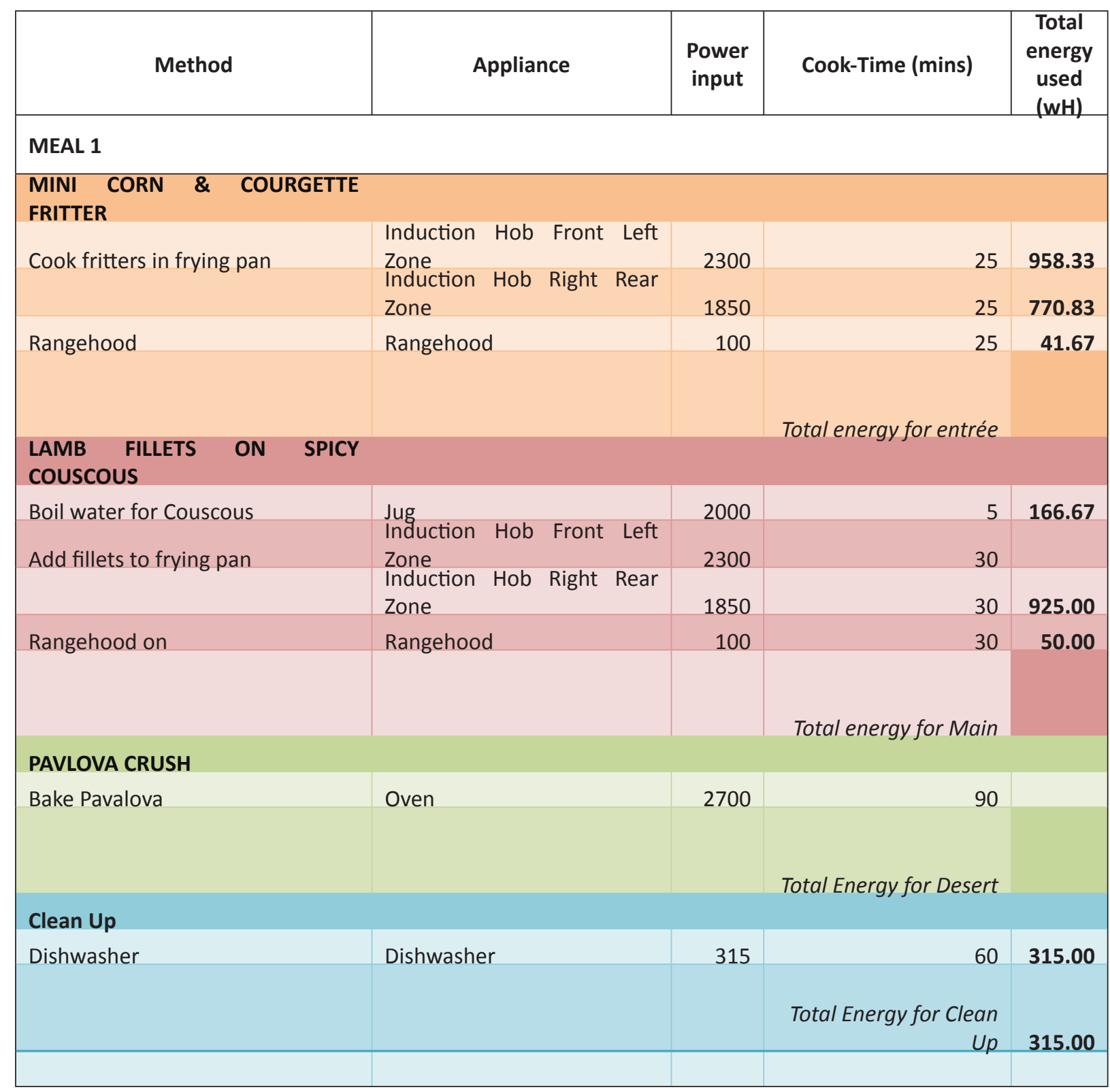

Table 28: Energy use of first dinner party 


\subsection{Dinner party 2}

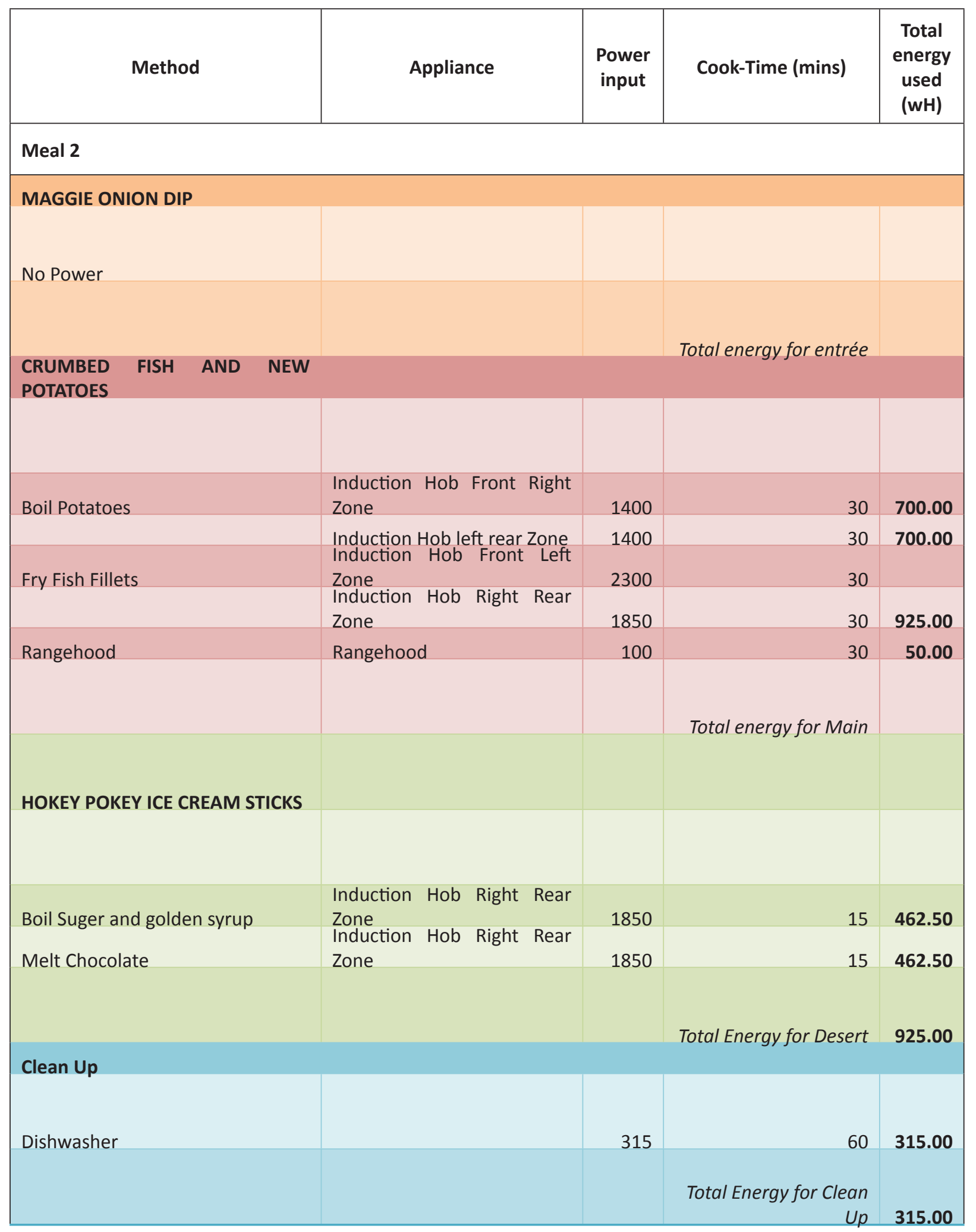

Table 29: Energy use of second dinner party 


\section{Appendix G: total house energy use}

Below is the results table used to calculate the total energy use during the competition. This was based on the contest schedule issued by the competition organizers.

The total energy use was $145 \mathrm{kWh}$ over the course of the 9 days of comeptition

\begin{tabular}{|c|c|c|c|c|c|c|c|c|c|c|}
\hline CONTEST & స్ & $\stackrel{N}{\underset{\pi}{\sigma}}$ & $\stackrel{\text { m }}{\stackrel{\text { I }}{\Delta}}$ & $\begin{array}{l}\text { बे } \\
\stackrel{\Delta}{\Delta}\end{array}$ & $\begin{array}{l}\text { n } \\
\text { đ̊ }\end{array}$ & $\begin{array}{l}\bullet \\
\stackrel{\pi}{\Delta}\end{array}$ & $\hat{\text { ๙̊ }}$ & $\begin{array}{l}\infty \\
\stackrel{\infty}{\Delta} \\
\stackrel{0}{2}\end{array}$ & $\stackrel{0}{\stackrel{0}{\sigma}}$ & Totals \\
\hline HVAC & 6.30 & 9.80 & 10.40 & 10.50 & 10.10 & 10.40 & 9.50 & 10.80 & 9.80 & 90.00 \\
\hline BMS & 0.51 & 0.72 & 0.72 & 0.72 & 0.72 & 0.72 & 0.72 & 0.72 & 0.72 & 6.27 \\
\hline House Controls & 0.20 & 0.29 & 0.29 & 0.29 & 0.29 & 0.29 & 0.29 & 0.29 & 0.29 & 2.51 \\
\hline Refrigerator/freezer & 0.53 & 0.53 & 0.53 & 0.53 & 0.53 & 0.53 & 0.53 & 0.53 & 0.53 & 4.75 \\
\hline Clothes Washer & & 0.10 & 0.10 & 0.10 & & 0.21 & & 0.21 & 0.10 & 0.82 \\
\hline Clothes Dryer & & 0.36 & 0.36 & 0.36 & & 0.72 & & 0.72 & 0.36 & 2.88 \\
\hline Dishwasher & & 0.32 & & 0.32 & & 0.63 & & 0.32 & 0.32 & 1.89 \\
\hline Lighting & 0.82 & 0.82 & 0.82 & 0.82 & 0.82 & 0.41 & 0.82 & 0.82 & 0.00 & 6.12 \\
\hline Induction Hob & & 1.95 & & 1.95 & & & 1.95 & & 1.95 & 7.78 \\
\hline Rangehood & & 0.10 & & 0.10 & & & 0.10 & & 0.10 & 0.40 \\
\hline Dinner Party 1 & & & & & 8.43 & & & & & 8.43 \\
\hline Dinner Party 2 & & & & & & & 4.77 & & & 4.77 \\
\hline Tv & & 0.20 & 0.26 & 0.26 & 0.33 & 0.26 & 0.33 & 0.46 & 0.20 & 2.28 \\
\hline Computer & & 0.14 & 0.18 & 0.18 & 0.23 & 0.18 & 0.23 & 0.32 & 0.14 & 1.58 \\
\hline Movie Night & & & & & & 1.00 & & & & 1.00 \\
\hline Hot Water & 0.00 & 0.00 & 0.00 & 0.00 & 0.00 & 0.00 & 0.00 & 0.00 & 0.00 & 0.00 \\
\hline Water pumps & & & & & & & & & & 3.00 \\
\hline Total & 8.36 & 15.31 & 13.65 & 16.12 & 21.43 & 15.34 & 19.21 & 15.16 & 14.49 & 144.47 \\
\hline
\end{tabular}

Table 30: Total competition energy use per day 


\title{
19 Appendix H: Energy generation report
}

\author{
Grid-Connected System: Simulation parameters
}

Project :

Geographical Site

Situation

Time defined as

\section{Solar Decathlon Wellington}

Wellington

Latitude $41.2^{\circ} \mathrm{S}$

Legal Time Time zone UT+12

Albedo 0.20
Country New Zealand

Longitude $174.5^{\circ} \mathrm{E}$

Altitude $6 \mathrm{~m}$

Meteo data :

Wellington, Synthetic Hourly data

\section{Simulation variant : $\quad 15^{\circ} 1500$}

Simulation date $\quad 19 / 12 / 1013 \mathrm{~h} 44$

Simulation parameters

Collector Plane Orientation

Horizon

Near Shadings

PV Array Characteristics

PV module

Number of PV modules

Total number of PV modules

Array global power

Array operating characteristics $\left(50^{\circ} \mathrm{C}\right)$

Total area

Inverter

Characteristics

PV Array loss factors

Thermal Loss factor

$=>$ Nominal Oper. Coll. Temp. (

Wiring Ohmic Loss

Module Quality Loss

Module Mismatch Losses

Incidence effect, ASHRAE parametrization
According to strings $\quad$ Electrical effect $100 \%$

Free Horizon

User's needs :

Unlimited load (grid) 


\section{Grid-Connected System: Near shading definition}

Project :

Solar Decathlon Wellington

Simulation variant :

$15^{\circ} 1500$

Main system parameters

Near Shadings

PV Field Orientation

PV modules

PV Array

Inverter

User's needs
System type Grid-Connected

According to strings

$\begin{aligned} \text { tilt } & 15^{\circ} & \text { azimuth } & 0^{\circ} \\ \text { odel } & \text { PV-UJ225GA6 } & \text { Pnom } & 225 \mathrm{Wp} \\ \text { ules } & 28 & \text { Pnom total } & \mathbf{6 . 3} \mathbf{k W p}\end{aligned}$

Model Sunny Mini Central 6000A Pnom $5.5 \mathrm{~kW} \mathrm{ac}$ Unlimited load (grid)

Perspective of the PV-field and surrounding shading scene

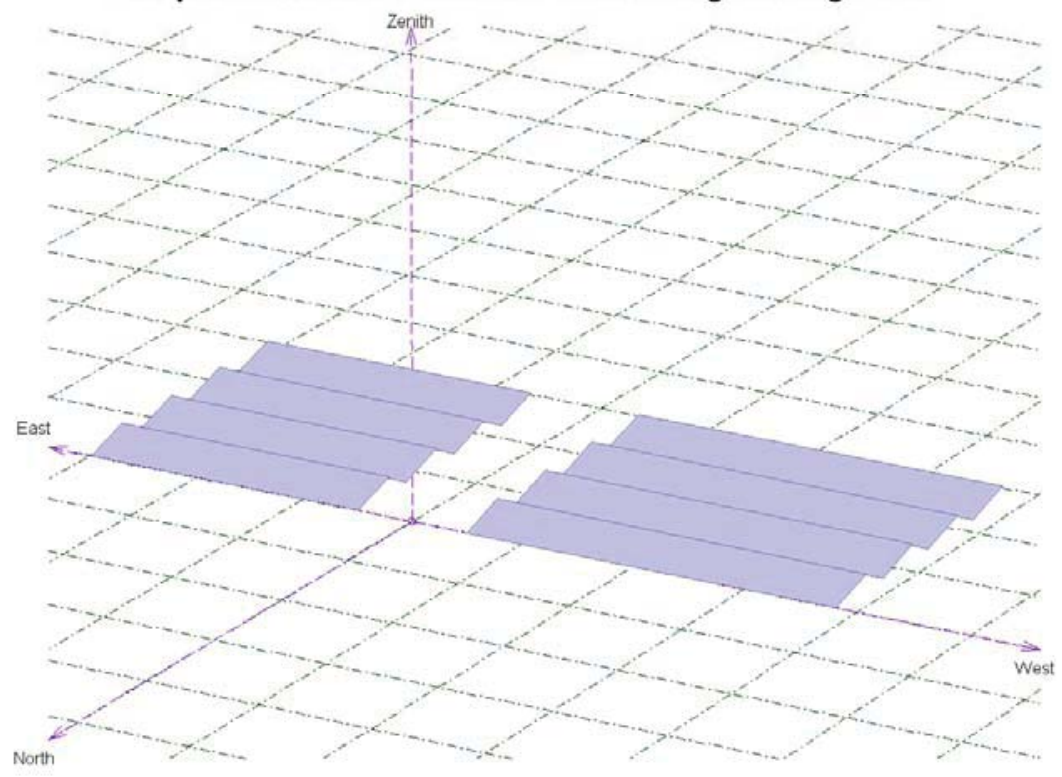

Iso-shadings diagram

Solar Decathlon Wellington: solar decathlon array layout 1500

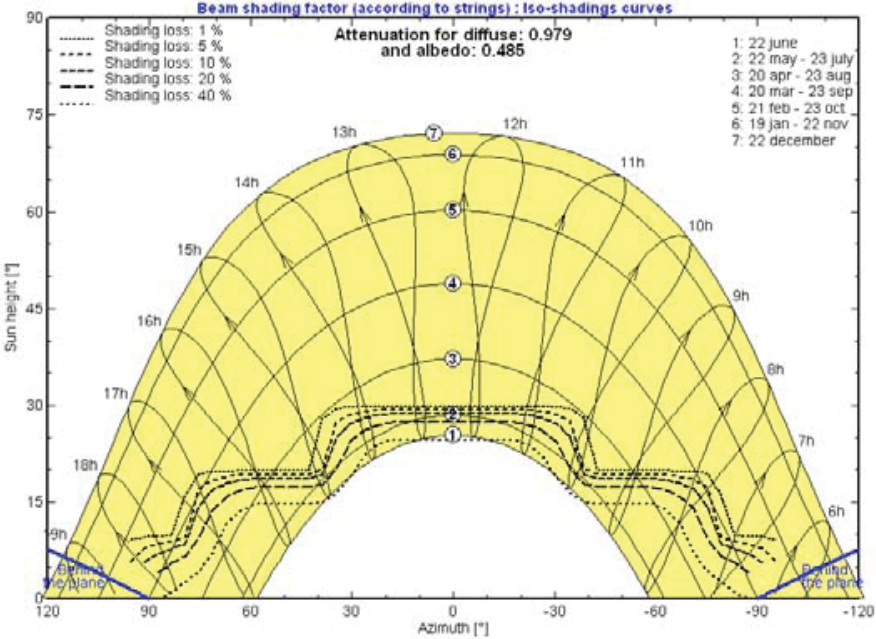




\section{Grid-Connected System: Main results}

Project :

Solar Decathlon Wellington

Simulation variant :

$15^{\circ} 1500$

Main system parameters

Near Shadings

PV Field Orientation

PV modules

PV Array

Inverter

User's needs

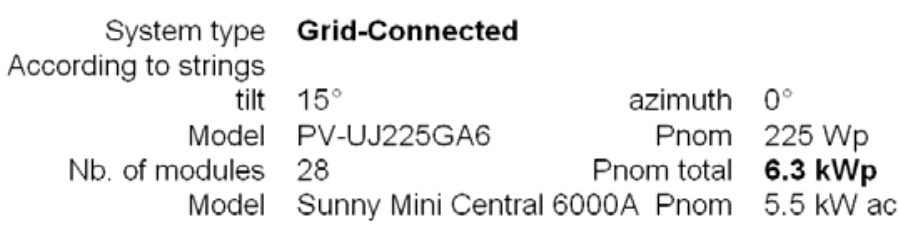

According to strings

tilt $15^{\circ}$

Model PV-UJ225GA6 Pnom 225 Wp

$\mathrm{Nb}$. of modules 28

Model Sunny Mini Central 6000A Pnom $5.5 \mathrm{~kW} \mathrm{ac}$

Main simulation results

System Production

Produced Energy $\mathbf{7 2 1 4}$ kWh/year Specific prod. $1145 \mathrm{kWh} / \mathrm{kWp} / \mathrm{year}$

Performance Ratio PR $75.3 \%$
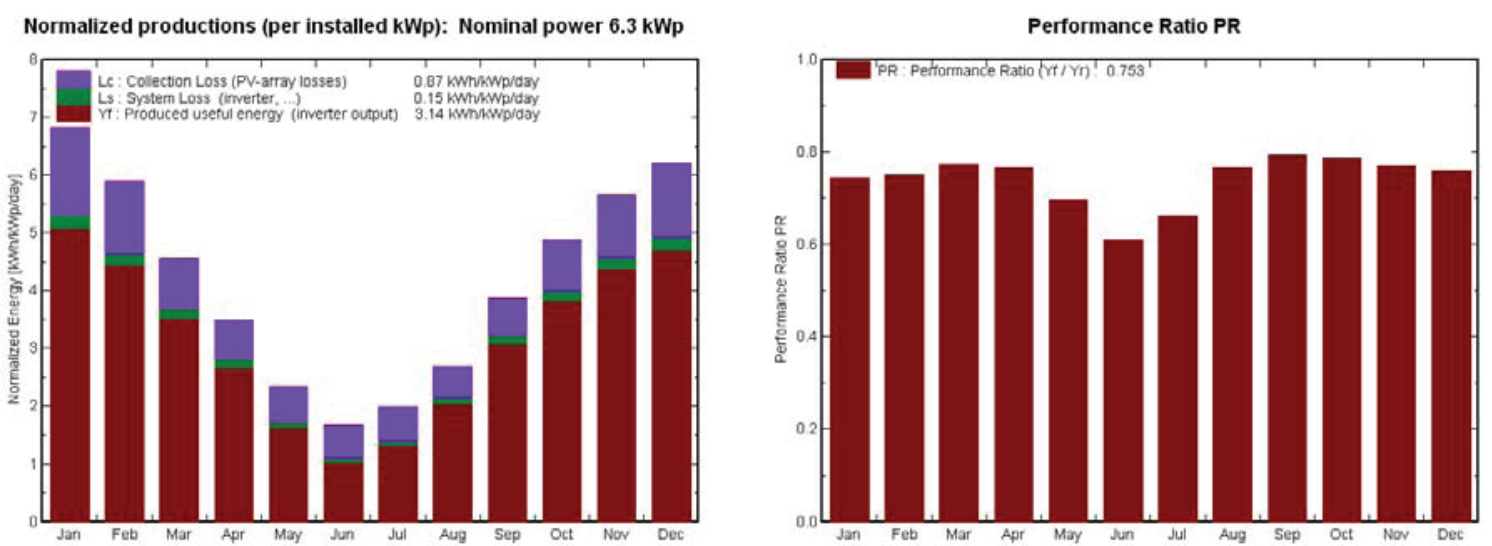

$15^{\circ} 1500$

Balances and main results

\begin{tabular}{l|l|c|c|c|c|c|c|c|c|}
\hline & $\begin{array}{c}\text { GlobHor } \\
\mathrm{kWh} / \mathrm{m}^{2}\end{array}$ & $\begin{array}{c}\mathrm{T} \text { Amb } \\
{ }^{\circ} \mathrm{C}\end{array}$ & $\begin{array}{c}\text { Globlnc } \\
\mathrm{kWh} / \mathrm{m}^{2}\end{array}$ & $\begin{array}{c}\text { GlobEff } \\
\mathrm{kWh} / \mathrm{m}^{2}\end{array}$ & $\begin{array}{c}\text { EArray } \\
\mathrm{kWh}\end{array}$ & $\begin{array}{c}\text { E_Grid } \\
\mathrm{kWh}\end{array}$ & $\begin{array}{c}\text { EffArrR } \\
\%\end{array}$ & $\begin{array}{c}\text { EffSysR } \\
\%\end{array}$ \\
\hline January & 209.7 & 18.11 & 211.5 & 203.8 & 1040 & 992.7 & 10.65 & 10.17 \\
February & 157.9 & 18.00 & 165.3 & 158.6 & 819 & 783.0 & 10.74 & 10.26 \\
March & 128.5 & 16.80 & 141.1 & 134.7 & 720 & 687.7 & 11.06 & 10.57 \\
April & 87.7 & 14.13 & 104.5 & 97.4 & 530 & 504.9 & 10.98 & 10.47 \\
May & 57.1 & 11.95 & 72.4 & 61.0 & 335 & 317.9 & 10.03 & 9.51 \\
June & 39.6 & 9.94 & 50.6 & 38.0 & 208 & 194.4 & 8.89 & 8.32 \\
July & 48.3 & 9.21 & 61.6 & 49.2 & 272 & 256.4 & 9.57 & 9.03 \\
August & 69.1 & 9.77 & 82.9 & 76.0 & 421 & 400.2 & 11.01 & 10.46 \\
September & 103.6 & 10.98 & 116.7 & 110.6 & 611 & 582.9 & 11.34 & 10.83 \\
October & 142.8 & 12.79 & 151.1 & 144.6 & 784 & 748.3 & 11.24 & 10.73 \\
November & 167.7 & 14.26 & 169.8 & 162.3 & 865 & 826.0 & 11.03 & 10.54 \\
December & 192.6 & 16.43 & 192.2 & 184.3 & 962 & 919.1 & 10.85 & 10.36 \\
\hline Year & 1404.6 & 13.51 & 1519.7 & 1420.5 & 7566 & 7213.6 & 10.79 & 10.29 \\
\hline
\end{tabular}


Grid-Connected System: Loss diagram

Project :

Solar Decathlon Wellington

Simulation variant :

$15^{\circ} 1500$

Main system parameters

Near Shadings

PV Field Orientation

PV modules

PV Array

Inverter

User's needs

\section{System type Grid-Connected}

According to strings

tilt $15^{\circ}$

$\mathrm{Nb}$. of modules $28 \quad$ Pnom total $6.3 \mathrm{kWp}$

Model Sunny Mini Central $6000 \mathrm{~A}$ Pnom $5.5 \mathrm{~kW}$ ac Unlimited load (grid)

Loss diagram over the whole year

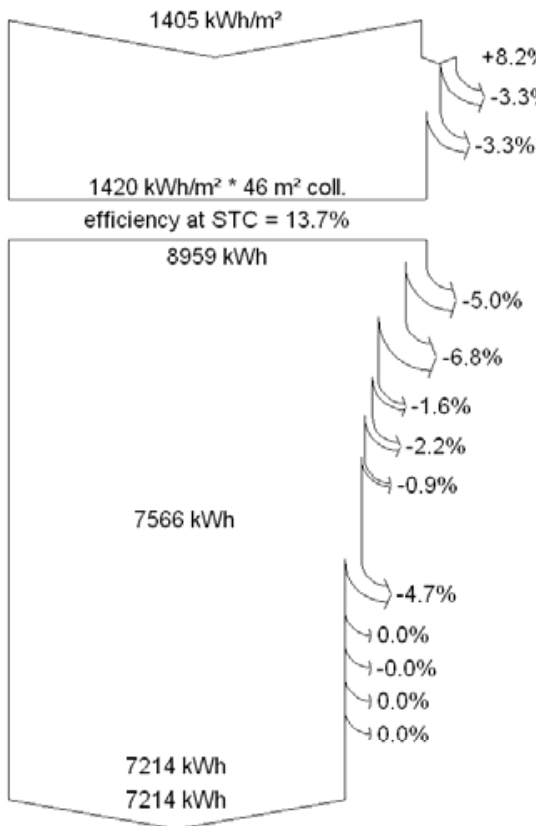

Horizontal global irradiation

Global incident in coll. plane

Near Shading Factor on global

IAM factor on global

Effective irradiance on collectors

PV conversion

Array nominal energy (at STC effic.)

$\mathrm{PV}$ loss due to irradiance level

PV loss due to temperature

Module quality loss

Module array mismatch loss

Ohmic wiring loss

Array virtual energy at MPP

Inverter Loss during operation (efficiency)

Inverter Loss over nominal inv. power

Inverter Loss due to power threshold

Inverter Loss over nominal inv. voltage

Inverter Loss due to voltage threshold

Available Energy at Inverter Output

Energy injected into grid 


\section{Appendix J: Judged contest results and comments}

\begin{tabular}{|c|c|c|c|c|c|c|}
\hline \multicolumn{7}{|c|}{ New Zealand } \\
\hline \multirow{2}{*}{\multicolumn{2}{|c|}{ ARCGARE }} & \multicolumn{4}{|c|}{ TEAM SCORE } & \multirow{2}{*}{$\begin{array}{l}\text { POI NTS } \\
\text { /100 }\end{array}$} \\
\hline & & 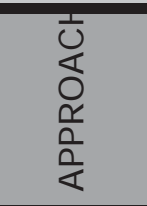 & 皆 & 岂 & 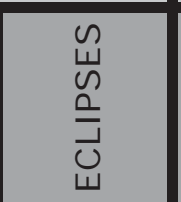 & \\
\hline \multicolumn{2}{|c|}{ CONTEST CRITERI A } & $0-60 \%$ & $61-80 \%$ & $81-90 \%$ & $91-100 \%$ & \\
\hline & DESI GN \& I MPLEMENTATI ON & & & & & \\
\hline \multirow[t]{5}{*}{1} & $\begin{array}{l}\text { Was the team effective in its use of architectural } \\
\text { elements including, but not limited to: }\end{array}$ & & & & & \\
\hline & Scale and proportion of room and façade features & & & & $x$ & \\
\hline & Indoor/outdoor connections & & & & $\mathrm{X}$ & \\
\hline & Composition & & & & $\mathrm{x}$ & \\
\hline & Linking of various home elements & & & & $\mathrm{X}$ & \\
\hline 2 & $\begin{array}{l}\text { Did the team create a holistic design that will be } \\
\text { comfortable for occupants and compatible with the } \\
\text { surrounding environment? }\end{array}$ & & & & $x$ & \\
\hline \multirow[t]{6}{*}{3} & Lighting & & & & & \\
\hline & Are the lighted spaces rich and varied? & & & & $\mathrm{X}$ & \\
\hline & Do they have adequate light for tasks? & & & $x$ & & \\
\hline & Do they have good color rendition? & & & & $x$ & \\
\hline & Do the luminaires properly distribute light? & & & $\mathrm{x}$ & & \\
\hline & $\begin{array}{l}\text { Is the admission of direct and diffuse sunlight } \\
\text { effectively controlled? }\end{array}$ & & & $\mathrm{x}$ & & \\
\hline 4 & $\begin{array}{l}\text { Will the overall architectural design offer a sense of } \\
\text { inspiration and delight to Solar Decathlon visitors? }\end{array}$ & & & & $x$ & \\
\hline B. $\mathrm{I}$ & DOCUMENTATION & & & & & \\
\hline 1 & $\begin{array}{l}\text { Did the drawings, construction specifications, and } \\
\text { audiovisual architecture presentation enable the jury to } \\
\text { conduct a preliminary evaluation of the design prior to } \\
\text { its arrival at the competition site? }\end{array}$ & & & & $x$ & \\
\hline 2 & $\begin{array}{l}\text { Did the drawings, construction specifications, and } \\
\text { audiovisual architecture presentation accurately reflect } \\
\text { the constructed project as assembled on the competition } \\
\text { site? }\end{array}$ & & & $\mathrm{X}$ & & \\
\hline \multicolumn{2}{|r|}{ Total } & & & & & 95 \\
\hline
\end{tabular}




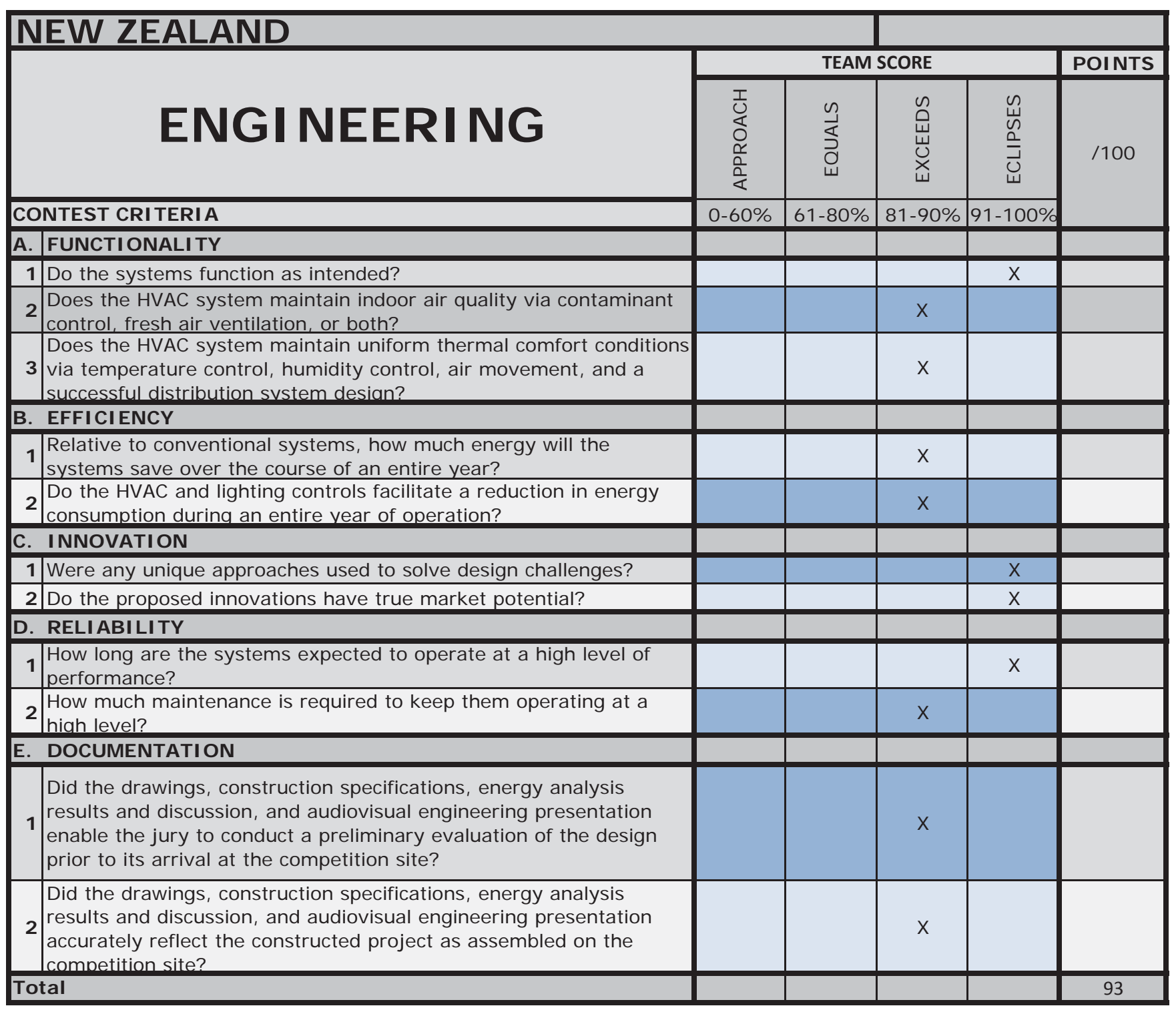




\section{New Zealand}

\section{MARKET APPEAL}

\section{CONTEST CRITERIA}

\begin{tabular}{|c|c|c|c|c|}
\hline \multicolumn{4}{|c|}{ TEAM SCORE } & POI NTS \\
\hline 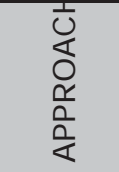 & 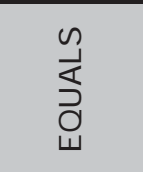 & 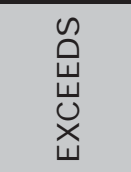 & 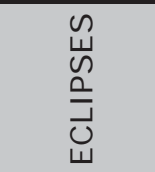 & $/ 100$ \\
\hline $0-60 \%$ & $61-80 \%$ & $81-90 \%$ & $91-100 \%$ & \\
\hline
\end{tabular}

A. LI VABI LI TY

1 Is the operation of the house's lighting, entertainment, and other controls intuitive?

2 Does the design offer the occupant(s) a safe, functional, convenient, comfortable, and enjoyable place to live

3 Are the unique needs and desires of the target client met by the design?

B. MARKETABI LITY

1

Does the house demonstrate curb appeal, interior appeal, and quality craftsmanship?

Do the house's sustainability features and

2 strategies make a positive contribution to its marketability?

3 Does the house offer a good value to potential homebuyers?

\section{BUI LDABI LITY}

Are the drawings and construction specifications of sufficient quality and detail to enable a contractor 1 to generate an accurate, detailed construction cost estimate?

Are the drawings and construction specifications of 2 sufficient quality and detail to enable a contractor to construct the building as the design team intended it to be built?

Are all the house's materials and equipment

3 commercially available, such that the house can be immediatelv built in the private sector? 
23 Appendix K: Schematic design proposal 
FirstLight New Zealand

Deliverables 4th May 2010

U.S. Department of Energy Solar Decathlon

\section{Schematic Design Proposal}

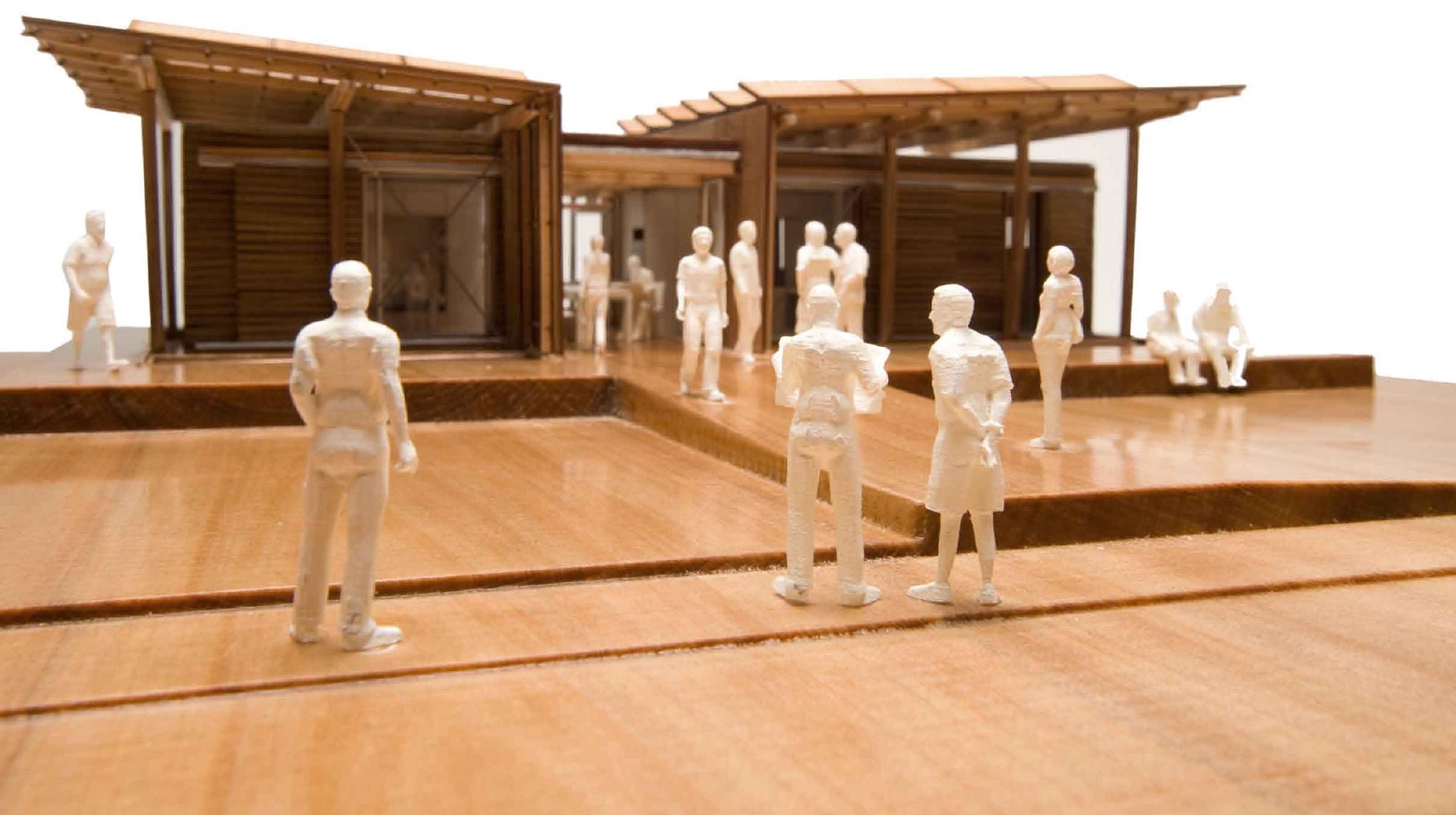




\section{Table of Contents}

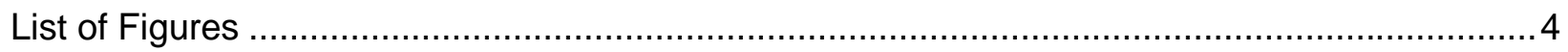

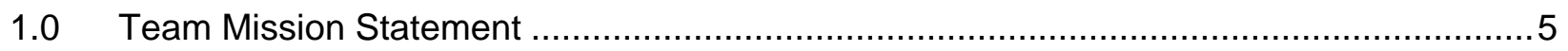

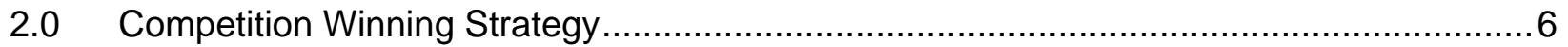

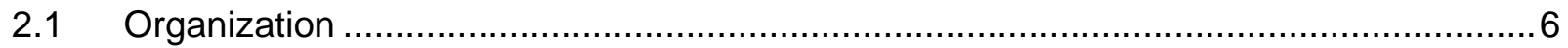

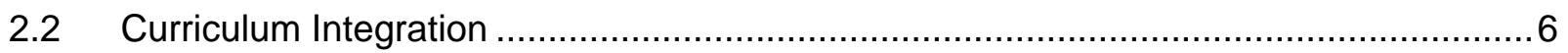

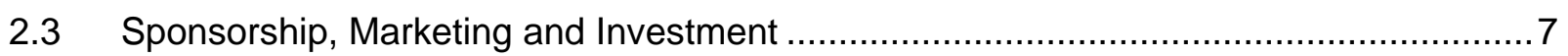

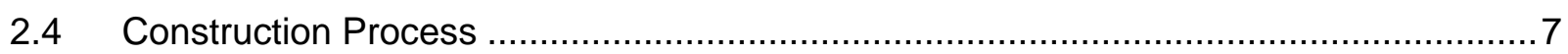

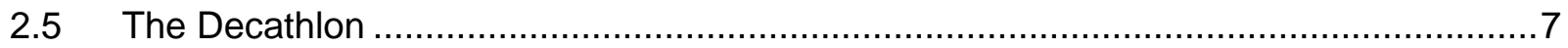

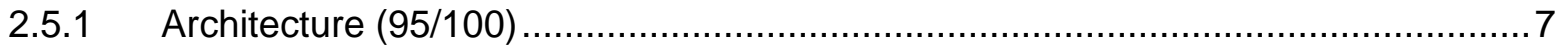

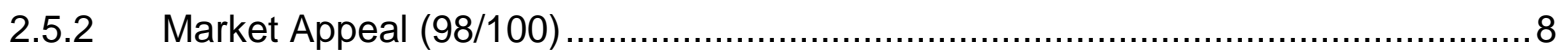

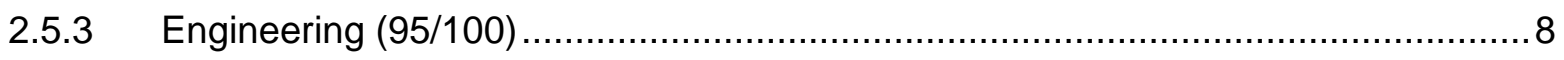

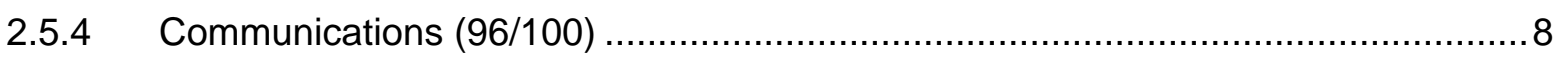

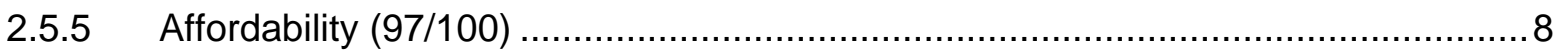

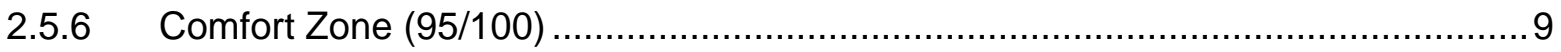

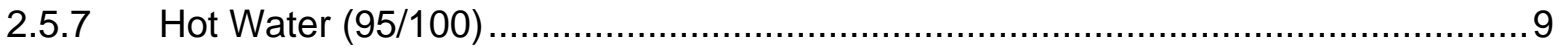

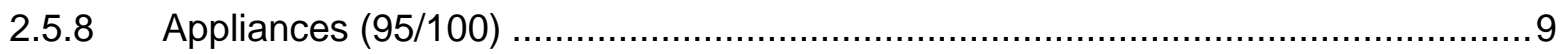

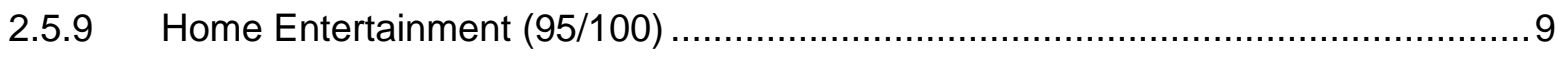

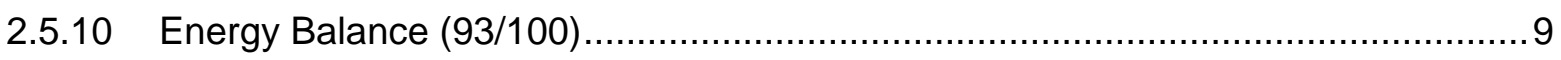

3.0 Architectural and Engineering Narrative ....................................................... 10

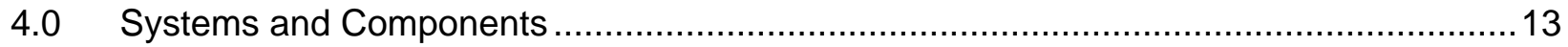

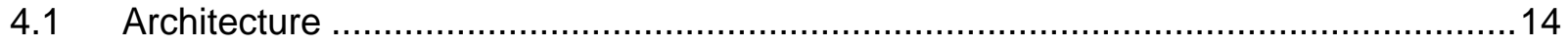

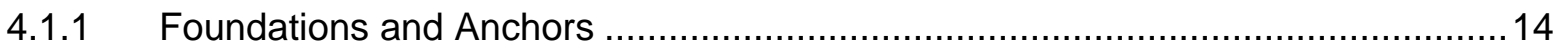

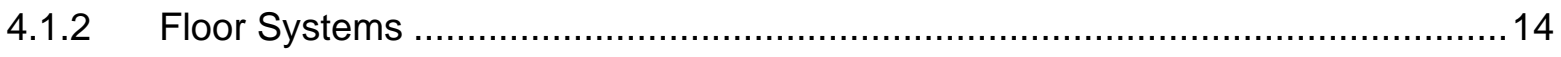

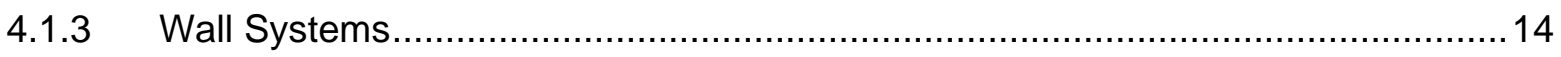

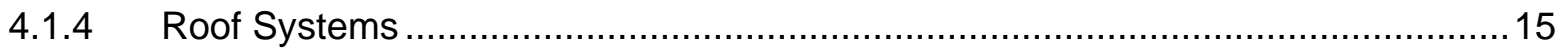

4.1.5 Glazing Systems, Sizing and Location ...................................................... 15

4.1.6 Window and Door Framing/Extrusions .................................................. 15

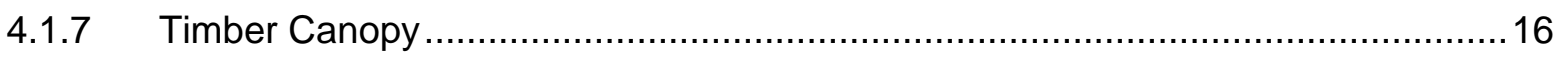

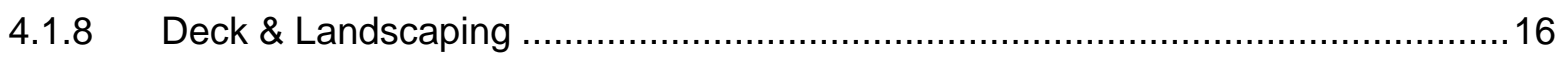

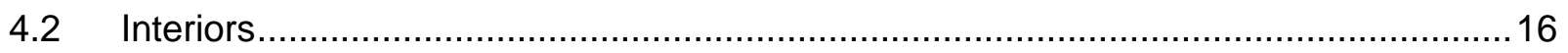

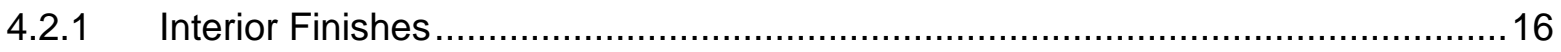

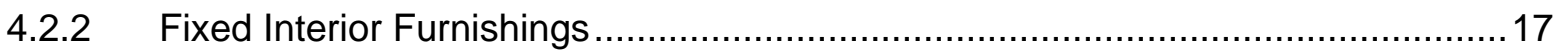

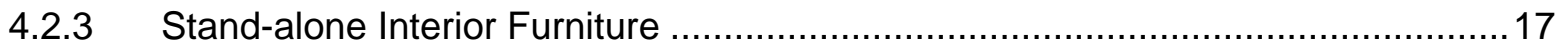

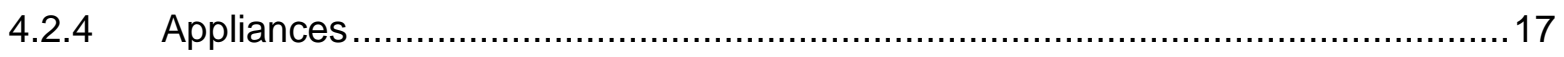

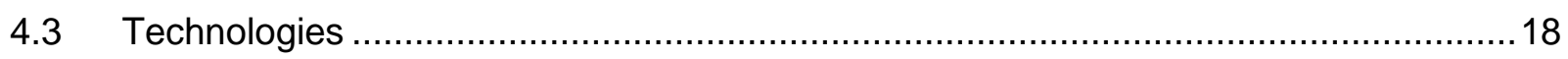




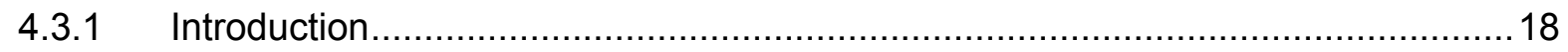

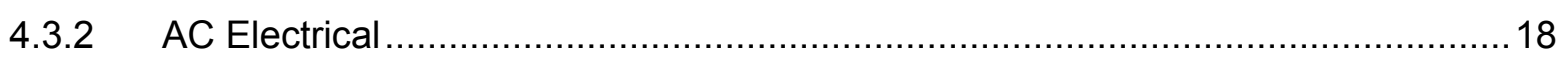

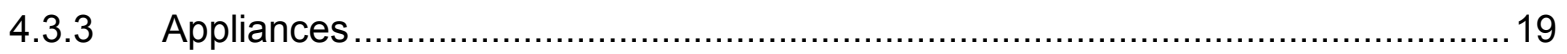

4.3.4 Accurate Modeling of Electrical Systems ................................................... 19

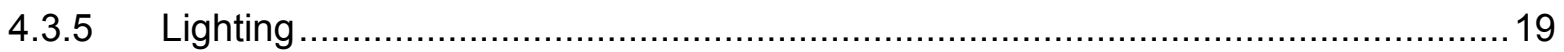

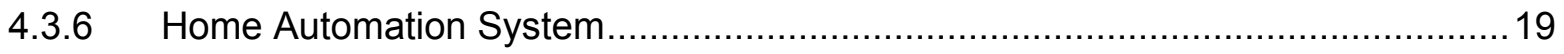

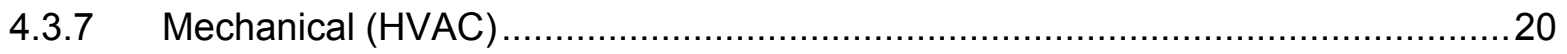

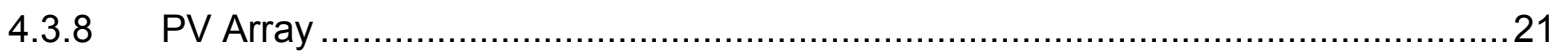

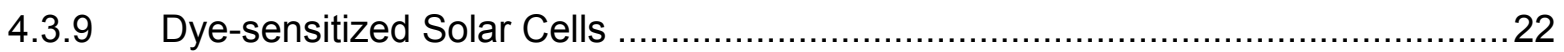

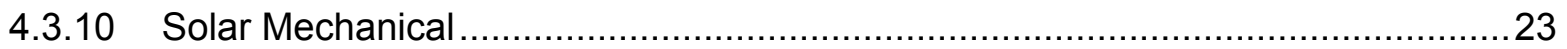

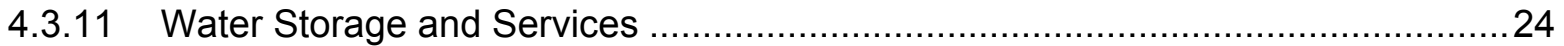

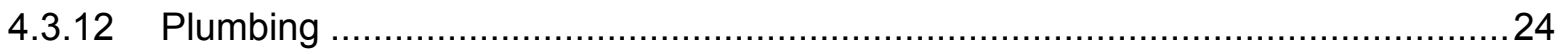

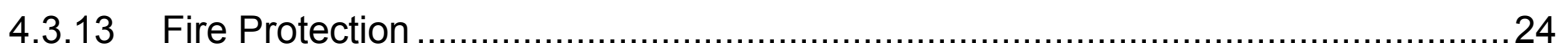

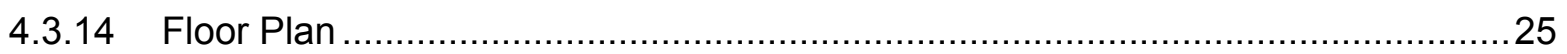

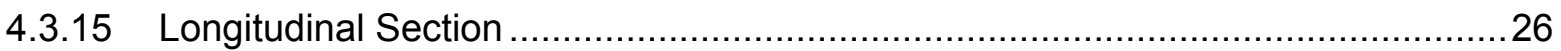

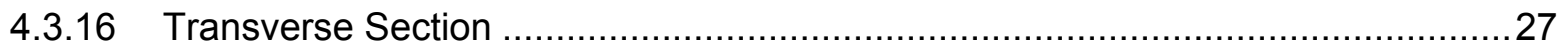

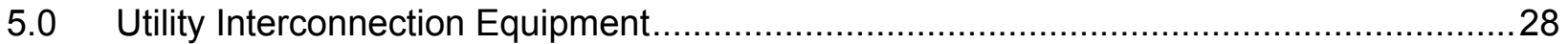

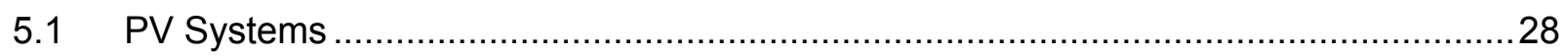

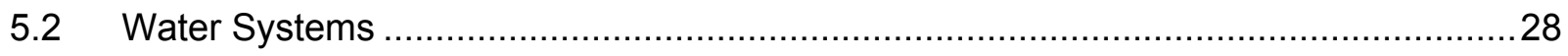

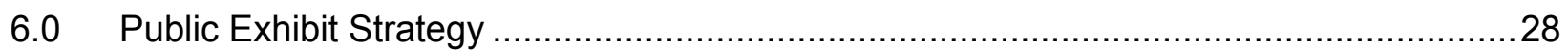

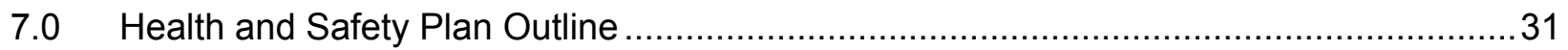

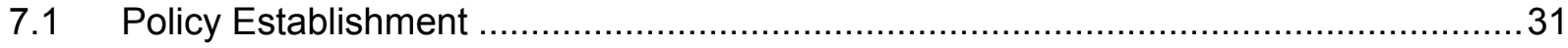

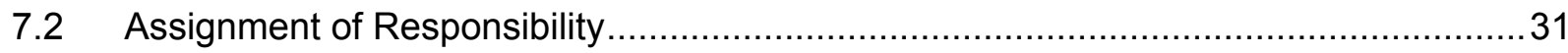

7.3 Identification and Analysis of Risks and Hazards ............................................ 31

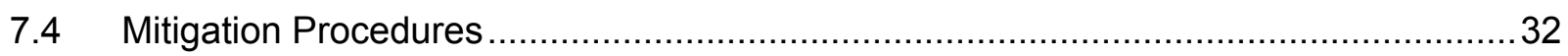

7.4.1 Team Training and Member Involvement ................................................. 32

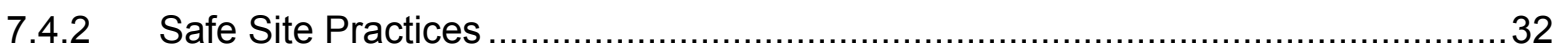

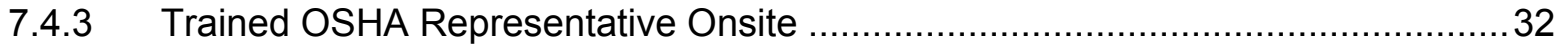

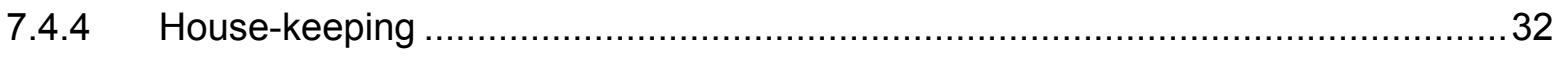

7.4.5 Enforcement of Personal Protective Equipment (PPE) ..................................32

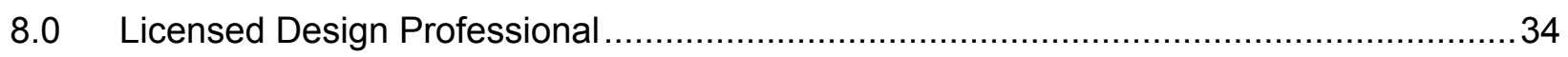

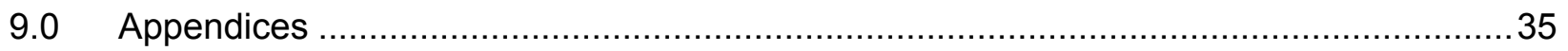

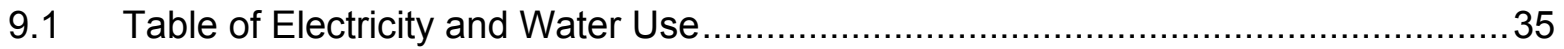

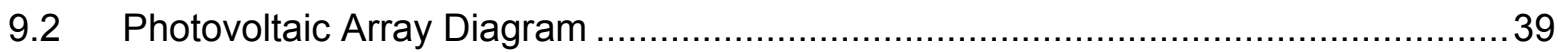

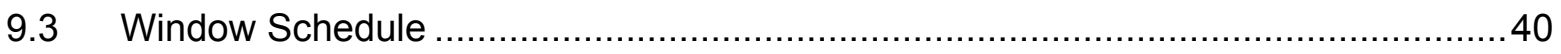




\section{List of Figures}

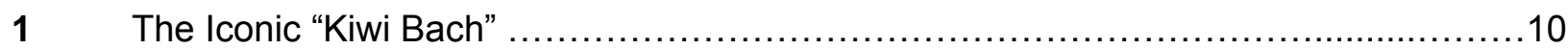

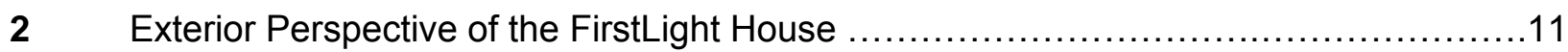

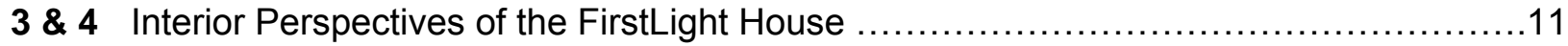

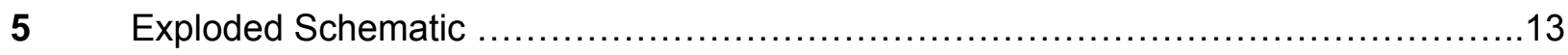

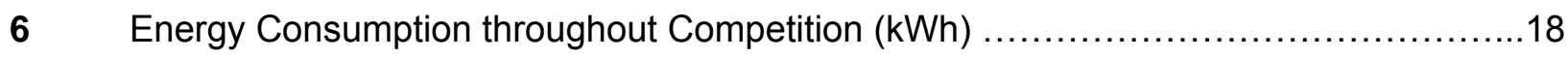

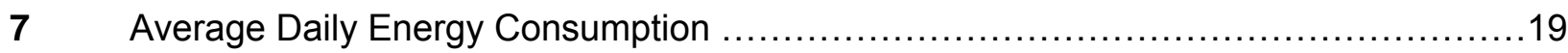

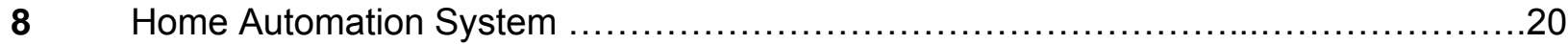

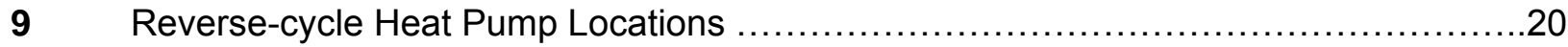

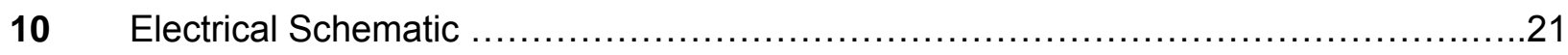

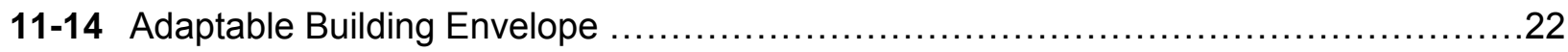

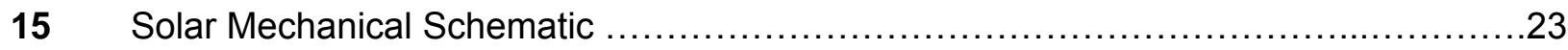

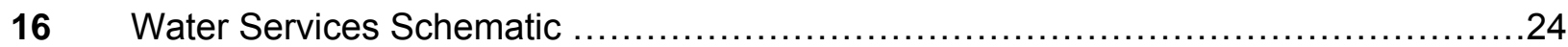

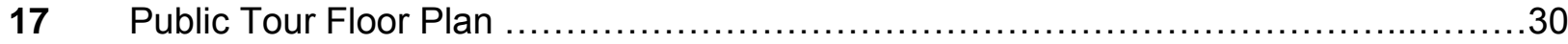




\subsection{Team Mission Statement}

Our mission is to inform the wider public and educate future design decision-makers on the innovative possibilities offered by solar architecture. We will use an interdisciplinary approach to design, incorporating energy efficiency technologies with the aim of fostering their integration into marketable applications and to facilitate the widespread adoption of zero-energy homes.

Our team has set the following objectives:

- Illustrate a poetic and performance-oriented integration of sustainable materials and technologies to enrich the architectural environment

- Demonstrate how solar energy can enhance the user experience of residential architecture

- Unite comfort and contemporary lifestyle sensibilities with energy efficiency while remaining sympathetic to the surrounding environment

- Raise awareness of the U.S. DOE Solar Decathlon through media and publicity strategies, exposing the public to the objectives and goals to which we align ourselves

- Illustrate that solar technologies are widely applicable in the marketplace of today

- Raise awareness of the ability to live a clean and green lifestyle using solar power and energy efficient technologies and appliances

- Educate the public of their own personal energy consumption and provide energy saving strategies in response to energy wastage

- Develop a home that is responsive to the surrounding environment, both aesthetically and in its systems approach

- Establish cross-faculty collaboration and enduring relationships between Victoria University and the building industry 


\subsection{Competition Winning Strategy}

Throughout every aspect of the project we have developed comprehensive strategies for the successful orchestration of the FirstLight house.

\subsection{Organization}

A student team will direct and manage the entire process, from initial concept, through developed design, to final assembly on the Mall in Washington DC. This team will span across numerous University faculties, ensuring that a wide range of expertise, creativity, and innovation is integrated within our project.

We have three primary layers of organization, including an independent advisory panel, a project management team (responsible to the University and to the US Department of Energy) and a student project delivery team. This structure will ensure the appropriate management of time, risks and resources throughout the course of the project.

A core group of post-graduate students has been formed as the Project Delivery Team. This team will coordinate the design, management, and construction process, making sure that all project outcomes are of the highest standard and in accordance with the contracted deliverables. The group is based on a model of an architectural practice, comprising a Project Architect, Construction Manager, Public Relations Manager, an Energy Analyst, Communications Manager, and an Interior and Landscape Architect.

Surrounding this team is a comprehensive support network from both within the University and across the nation. Students and advisors from the Faculties of Architecture and Design, Commerce and Administration, Engineering, Law, and the Faculty of Science provide an extensive academic resource for the project. Involvement from a range of industry manufacturers, suppliers, and professionals will also promote a level of practical and technical expertise necessary for the successful delivery of the FirstLight house to the National Mall in 2011.

\subsection{Curriculum Integration}

The curricular integration of the project within a variety of undergraduate courses and postgraduate research is generating outcomes of significant value to students, researchers and the FirstLight house itself. Through these courses and research programs a wide range of possible designs and technologies will be developed and tested before their final inclusion in the house.

Dedicated construction courses at $2^{\text {nd }}$ and $3^{\text {rd }}$ year level will assist during design development and later in the documentation phase. Senior Interior Architecture and Design students are being given the opportunity to explore their own ideas for the design of the FirstLight interior. Landscape Architecture students are contributing to the design of the surrounding landscape and Furniture Design students will be responsible for the furnishings. Courses in the Bachelor of Building Science program alongside postgraduate students will focus on the testing and analysis of systems and technologies integrated in the house. These are only a few examples of the contribution that is being made through the integration of the FirstLight project into the University curriculum. Other courses include Industrial Design, Marketing and International Business, and Advanced Materials and Nanotechnology. 


\subsection{Sponsorship, Marketing and Investment}

A thorough marketing and investment strategy is in place to attract and secure the necessary resources, both financial and in-kind, for the successful delivery of the project. This strategy is planned in three phases: Victoria University of Wellington (Internal Support), the private sector (Australasia, Asia-Pacific and the US) And New Zealand Government (national, regional and local).

This project has gathered together enormous support from the University and, in partnership with other research institutes, including New Zealand's top centre of excellence for science research and development (the MacDiarmid Institute), BRANZ - The Building Research Association of New Zealand, and an Australasian partnership with the University of Wollongong's Centre of Excellence for Electromaterials Science, has brought together an invaluable wealth of knowledge.

Significant financial support has already been confirmed by Victoria University. For the ongoing development of the project, finances will be generated through the University's investment mechanisms, such as the Victoria University of Wellington Foundation, University Alumni and external research grants and business investments.

We have established a strong network of external and private sector industry interests. We have the secured involvement of a consortium of NZ forestry and timber suppliers, along with offers of products and systems from various other private sector companies and industry and professional groupings.

As a result of University and industry commitment we have received support from the New Zealand government for the project. New Zealand Trade \& Enterprise has offered their support in order that we can showcase the environmental credentials of New Zealand export businesses. Other national government agencies with whom we are developing contacts are the Energy Efficiency and Conservation Authority, Department of Building and Housing, Ministry of Economic Development and Energy, Ministry of Research Science and Technology, and the Ministry of Tourism. We are also developing support from the Wellington City Council and Wellington Regional Council and other local authorities.

\subsection{Construction Process}

A detailed construction strategy encompassing prefabrication, packaging, shipping, and reconstruction will be critical for the successful delivery of the house onto the National Mall in September 2011. An experienced advisory team is in place for the ongoing development and refinement of construction techniques and methodologies.

\subsection{The Decathlon}

\subsubsection{Architecture (95/100)}

Throughout the design process an overriding devotion to an architecture that expresses the unique cultural identity of New Zealand has been upheld. The refinement of proportion and expression in architectural detail will continue to be developed at a technical and innovative level. The choice of materials, technologies, day and artificial lighting, and landscape design will all be integrated in response to a contemporary reinterpretation of the "Kiwi Bach" (see figures 1 - 4). We believe that this is what will give the FirstLight house its inspiration, aesthetic and functional appeal, and sense of delight. 


\subsubsection{Market Appeal (98/100)}

The FirstLight house redefines the traditional Kiwi Bach in an attempt to create a place that is receptive towards its occupants, the environment, and the climate. It unites comfort and lifestyle sensibilities with energy efficiency while remaining in tune with the surrounding environment. The homebuyers market in New Zealand places great value in these ideals giving the FirstLight house strong demographic appeal. The target homeowners are young professionals (25 - 35) and "empty-nesters" (late 40s to early 70s), representing $42 \%$ of the New Zealand population. The use of commercially available low energy-intensive materials and construction approaches will place the FirstLight house at the forefront of sustainable building development. The ability of the house to minimize the requirement for grid-supplied electricity significantly reduces the demand on potentially unsustainably-sourced power generation, providing additional incentives, both financial and environmental, to homebuyers.

\subsubsection{Engineering (95/100)}

Our approach to the building envelope has been to maximize comfort and user experience while minimizing the requirement for ancillary control systems. We have optimized the location and performance of windows to maintain a rich quality of internal space, while also providing a high degree of thermal insulation. This will be achieved through the use of energy analysis tools and CAD simulations. A reverse-cycle heat pump will maintain indoor temperatures, ventilation, and humidity. Passive methods will complement this system in the form of operable doors and windows, and adjustable thermal shutters, facilitating a reduction in energy consumption. The interior spaces of the house are thermally zoned through the use of retractable screens. This promotes a more efficient heating/cooling of the house that is responsive to the desires of its occupants. Maintenance and costs have been minimized by using established and reliable products. Through designing to a minimal footprint, thus minimizing the internal volume, we have reduced the demand loads on the HVAC systems.

\subsubsection{Communications $(96 / 100)$}

All communications materials will be aimed to effectively inform the wider public about the possibilities of applied solar architecture. A specialist team of marketing and communications students will work alongside the project delivery team. This focused group will be responsible for the delivery of the website and video walkthroughs, and will assist in the development of the public exhibit materials and presentations.

\subsubsection{Affordability (97/100)}

Innovative solutions in space planning have enabled the house to be designed to an extremely modest floor area. Many functions overlap and spaces can expand and contract dependent on occupants' needs and the season. By reducing the total floor area, material and construction costs are reduced and operation costs are minimized. This along with innovative uses of lowcost, readily available systems, materials, and technologies summarizes our strategy for delivering a building at a cost of close to $\$ 285,000$. 


\subsubsection{Comfort Zone (95/100)}

An indoor time-averaged air temperature between the range of $71.0^{\circ} \mathrm{F}$ and $76.0^{\circ} \mathrm{F}$, and a relative humidity below $60 \%$, will be maintained through the strategies identified under 2.5 .3 Engineering.

\subsubsection{Hot Water $(95 / 100)$}

A dedicated solar hot water system will be in place to ensure that we successfully meet the requirements of the hot water draws. Discussions are already in place with Industrial Designers from a partnering University, for the integration of a new system currently proving to be $40 \%$ more efficient than other commercially available products. This system is expected to be on the market in January of 2011.

\subsubsection{Appliances $(95 / 100)$}

All of the home appliances will be sourced from established manufacturers. Each appliance will be selected based on the requirements set forth by this contest criterion. Additional considerations will be made relative to the efficiency of the products and their positive contribution to the environment.

\subsubsection{Home Entertainment (95/100)}

The objectives set out for lighting, cooking, and home electronics will be achieved through the use of tested and reliable products and technologies. Together with a highly acclaimed local restaurant we will develop a menu specific for the competition. This will reflect the unique culture and cuisine of New Zealand. The ability of the social spaces to be reconfigured in response to occupation and weather, allows us to host fantastic social occasions under a number of scenarios. We are positive that our friendly nature and welcoming hospitality will be reflected in the scores awarded by the guest decathletes. The experience of the home entertainment will be equally memorable. The living room has been designed to adapt to the number of guests to form an ideal seating arrangement.

\subsubsection{Energy Balance (93/100)}

We have striven to minimize the overall energy consumption of the house (section 2.5.1-2.5.9). In conjunction with this, an energy-efficient photovoltaic array has been specified to provide all the electricity needs of the occupants. We have also integrated a system of dye-sensitized solar panels within the building envelope. Although these are of a lower efficiency when compared to other photovoltaic products, they are much more sustainably produced. We envision that dyesensitized solar cells will become the solar panels of the future and that the FirstLight house will assist in their adoption into other marketable applications. 


\subsection{Architectural and Engineering Narrative}

FirstLight demonstrates that energy efficiency and contemporary living can be brought together to create a place that is both sympathetic to the environment and tuned to our way of life.

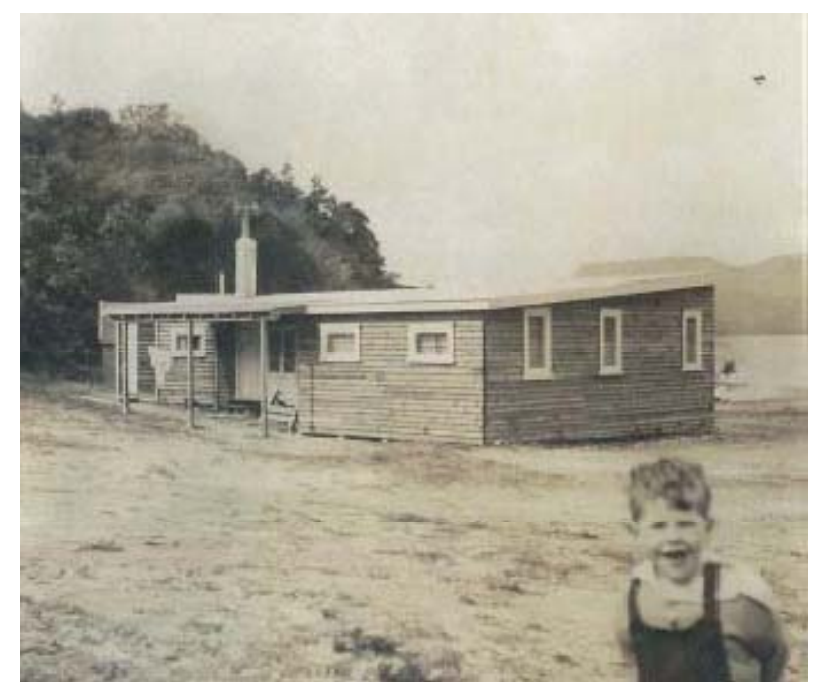

Figure 1: The Iconic "Kiwi Bach" (Home New Zealand, June/July 2008. P104)

The iconic "Kiwi bach" provided a perfect precedent for identifying the core values behind a uniquely New Zealand lifestyle. Traditionally situated in remote locations, the bach was a refuge away from city life. Here, recreation and socialization were a priority. As primarily a summer destination, life at the bach took place as much outside, on large decks and patios, as it did inside. This resulted in a seemingly modest house with open plan living, simple amenities, and shared accommodation. Our house brings these ideals of bach life into a contemporary setting, providing a permanent residence where recreation and social activities are united with environmentally sound technologies.

As a part of the adaptation to seasonal variations in climate, the distinctive outdoor living space has been internalized. This central space is light and open, with a translucent roof and large doors to the outside. It is the most important part of the house acting as a vehicle for bringing the surrounding environment indoors. Cooking, dining, and entertaining happen here, cementing its place as the social heart of the house. Daily routines oscillate through this space from the living room to the study and bedroom, as well as to the outside. It also provides the main entry and meeting point for visitors to the house.

The timber deck is continued uninterrupted through the central space creating a sense of continuity with the surrounding landscape. This space expands to include the deck allowing a multitude of outdoor living configurations, each in response to occupant desires and climatic conditions. 


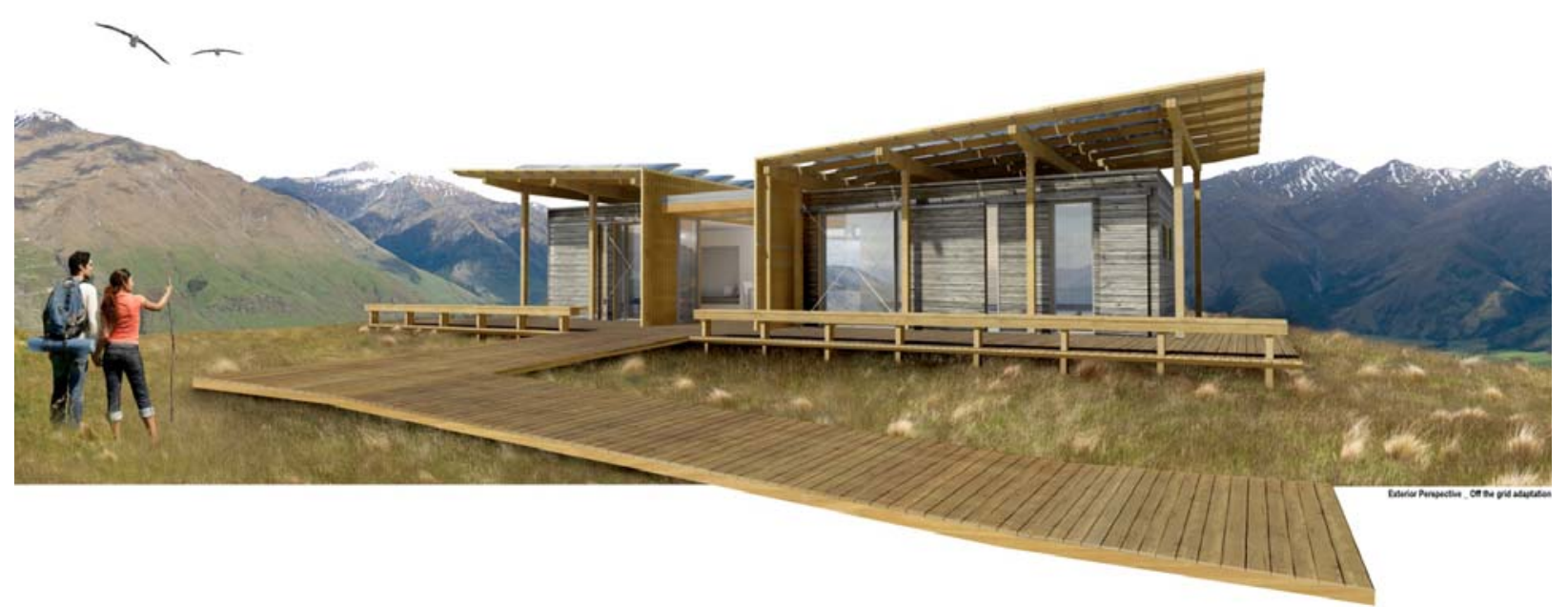

Figure 2: Exterior Perspective of the FirstLight House

The solar canopy forms a part of the landscaping and reiterates the emphasis that has been placed on the central space. Conceptually, the form directs the sun and sky into this space creating a strong focal point to the house. It is detached from the building envelope to allow for passive cooling of the solar PV panels, as well as to distinguish between what is considered landscaping and what is dwelling. The louvered timber overhang acts to shade the large southern glazing in summer and to maximize solar gains during winter.
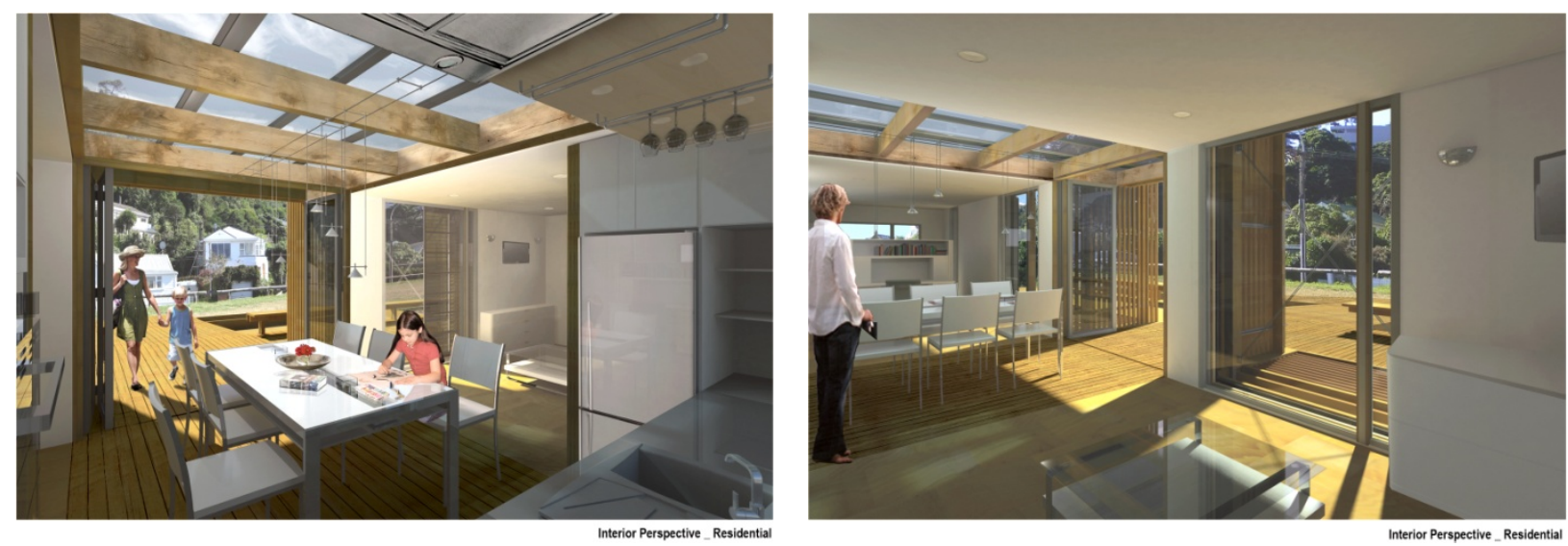

Figures 3 \& 4: Interior Perspectives of the FirstLight House

The interior design of the house is open and adaptable. A solid service core is situated along the northern wall, housing the bathroom, kitchen utilities, and mechanical plant. The rest of the interior opens out towards the sun with large full height windows and is continuous through the central space. Operable thermal shutters can slide over the windows for both insulation and privacy. Large bi-folding internal doors surrounding the central space also provide for privacy as well as thermal zoning. The living room seating transforms to become a spare bed for overnight guests and the coffee table is used to extend the dining table. These strategies have developed an efficient and adaptable use of space allowing the house to occupy a modest footprint. 
The engineering of all systems and technologies has been viewed as an integral part of the house and for the enhancement of the user experience.

The building envelope has been optimized to achieve a high level of thermal performance while maintaining a strong interior connection with the environment. This is realized through two primary strategies; firstly, an operable and intuitive building envelope with sliding thermal shutters that control heat losses/gains, and secondly, the thermal zoning of interior spaces to reduce overall HVAC loads.

An external timber canopy housing the PVs and evacuated tubes provides an elegant solution to the typically cumbersome integration of solar panels. Operable dye-sensitized solar cells work in conjunction with the thermal shutters to produce additional electricity when required. The shutters act to protect the panels during the night and at times of extreme weather. These cells will be one of the primary technical showpieces of the home, educating the public on the innovative possibilities of solar technologies.

The energy production systems have been modeled and sized to correctly reflect the energy demands of the occupants. Selected appliances meet the objectives of the contest criteria while also being in accordance with the stringent efficiency requirements as set by ourselves. LED lighting is utilized both inside the house and in the surrounding landscaping. A highly efficient reverse-cycle heat pump in conjunction with passive thermal strategies provides for all of the HVAC needs of the house.

The energy monitoring and control of the home's technologies are channeled through a single home automation system. A user interface is seamlessly integrated within the house, providing the communication link between occupants and the building technologies. This system is intuitive, learning from the occupants' day-to-day routines to better optimize the use of energy in the home. Information is continuously fed back to the users such as energy usage, peak loads vs. peak production, water usage, and climate data. The monitoring, recording, and clear representation of energy data is one of our key initiatives towards educating people on better sustainable practices.

Through the house's innovative construction techniques it will set an example for the future of prefabrication. An exceptional level of precision in the design and manufacturing of components will be essential for the successful construction, deconstruction, shipment, and final assembly on the Washington Mall in 2011.

The FirstLight house proves that the technological demands of contemporary living can be achieved with energy efficiency and with little detriment to the environment. 


\subsection{Systems and Components}

4.1.7 Timber canopy

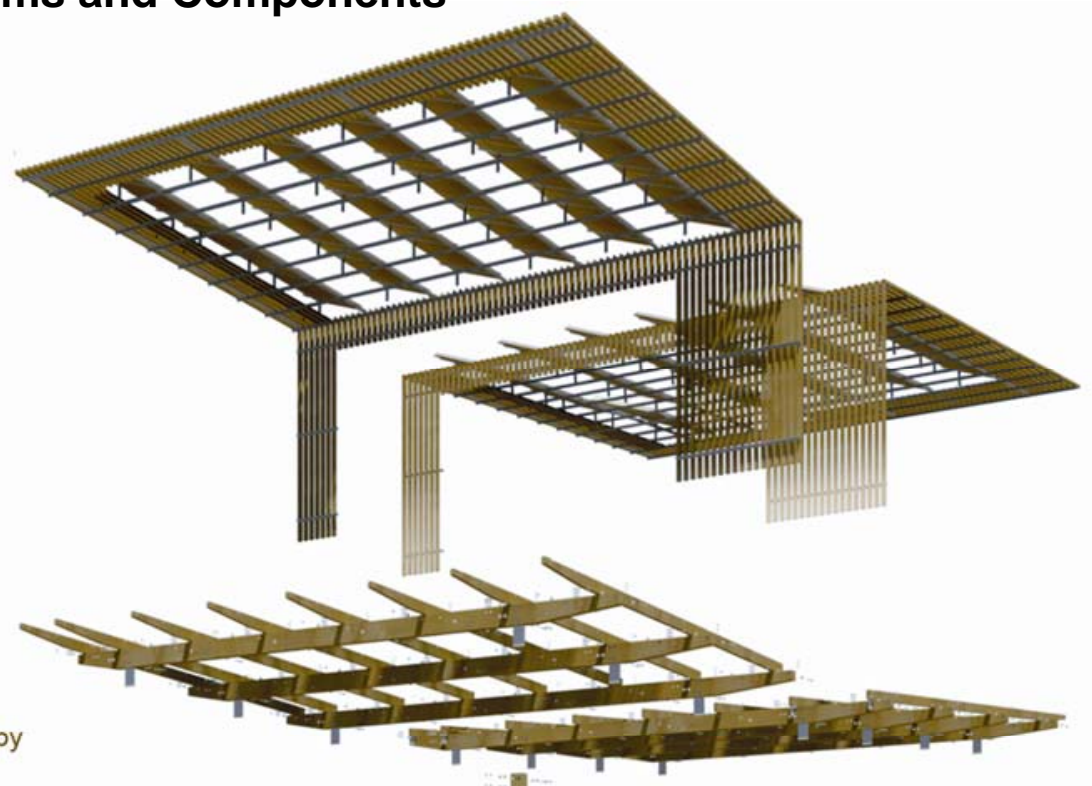

4.1.4 Roof systems

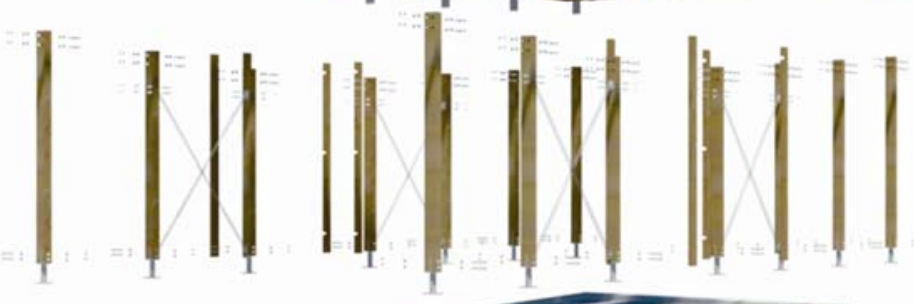

Interior finishes 4.2.1

Fixed furnishings 4.2.2

4.1.5 Glazing systems

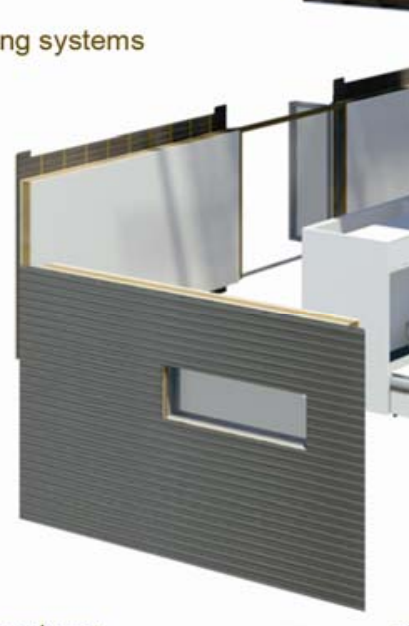

4.1.3 Wall systems

4.1.2 Floor systems

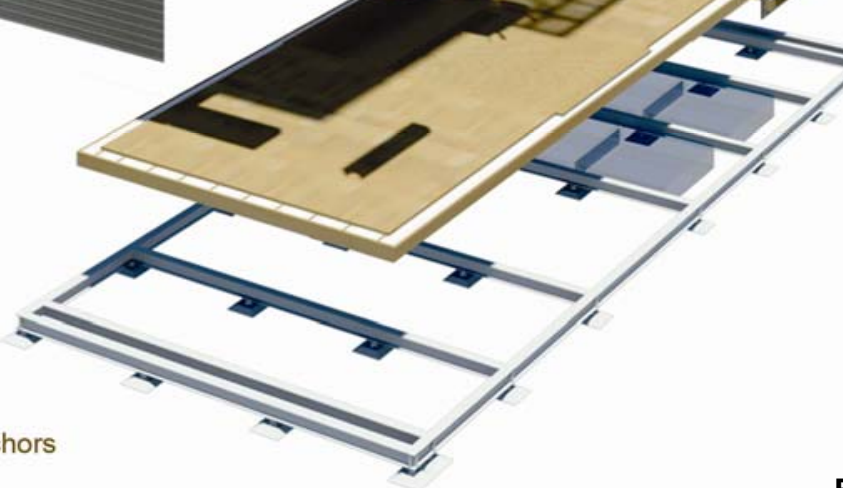

Appliances 4.2.4

Free-standing 4.2.3 furniture

Figure 5: Exploded Schematic 


\subsection{Architecture}

4.1.1 Foundations and Anchors

\begin{tabular}{|c|c|c|c|}
\hline No. & Element & Quantity & Description \\
\hline 1 & Steel Base & 21 & $\begin{array}{l}\text { The house is supported by a steel } 203 \\
\text { UB 'chassis' on } 21 \text { seismic jack }\end{array}$ \\
\hline 2 & $\begin{array}{l}\text { Adjustable Screw Jack } \\
\text { Pedestal }\end{array}$ & 21 & $\begin{array}{l}\text { pedestals which adjust according to site } \\
\text { gradient and height differentials. Steel } \\
\text { base pads are connected to the ground }\end{array}$ \\
\hline 3 & $\begin{array}{l}\text { Steel Bearer } \\
(\text { UB203×133×30) }\end{array}$ & & $\begin{array}{l}\text { with } 4 \times 450 \mathrm{~mm} \text { tie down anchor rods } \\
\text { per pad. }\end{array}$ \\
\hline & $\begin{array}{l}-5.88 \mathrm{~m}(19.3 \mathrm{ft}) \text { length } \\
-14.69 \mathrm{~m}(48.2 \mathrm{ft}) \text { length }\end{array}$ & $\begin{array}{l}7 \\
2\end{array}$ & $\begin{array}{l}\text { Joints pre-welded to the chassis allow } \\
\text { for easy bolt-on connection to the }\end{array}$ \\
\hline 4 & $\begin{array}{l}\text { 450mm (1.48”) Tie-Down } \\
\text { Anchors }\end{array}$ & 84 & \\
\hline
\end{tabular}

\subsubsection{Floor Systems}

\begin{tabular}{|c|c|c|c|}
\hline No. & Element & Quantity & Description \\
\hline 1 & $\begin{array}{l}\text { Floor Structure } \\
\text { - 15mm plywood sheathing } \\
\text { - Engineered timber joists } \\
\text { - Insulation }\end{array}$ & $\begin{array}{c}65 \mathrm{~m}^{2} \\
\left(700 \mathrm{ft}^{2}\right)\end{array}$ & $\begin{array}{l}\text { Prefabricated panels, consisting of } \\
180 \times 45 \mathrm{~mm} \text { engineered timber joists and } \\
180 \mathrm{~mm} \text { compression resistant foam } \\
\text { insulation sandwiched between plywood } \\
\text { sheathing, are bolt-fixed to the subfloor }\end{array}$ \\
\hline 2 & $\begin{array}{l}\text { Floor Finish } \\
\text { - T\&G floorboards } \\
\text { - Timber Decking }\end{array}$ & $\begin{array}{c}46 \mathrm{~m}^{2} \\
\left(495 \mathrm{ft}^{2}\right) \\
12 \mathrm{~m}^{2} \\
\left(129 \mathrm{ft}^{2}\right)\end{array}$ & $\begin{array}{l}\text { chassis. } \\
\text { Recycled timber floorboards laid NS } \\
\text { across the central space continue the } \\
\text { line of the deck through the house. }\end{array}$ \\
\hline
\end{tabular}

\subsubsection{Wall Systems}

\begin{tabular}{|c|c|c|c|}
\hline No. & Element & Quantity & Description \\
\hline 1 & $\begin{array}{l}\text { Exterior Wall Finishes (incl. } \\
\text { shutters, excl. windows and } \\
\text { openings) }\end{array}$ & $\begin{array}{c}98 \mathrm{~m}^{2} \\
\left(1054 \mathrm{ft}^{2}\right) \\
h=2.45 \mathrm{~m}\end{array}$ & $\begin{array}{l}\text { A prefabricated exterior wall system } \\
\text { comprising of timber structural members, } \\
150 \mathrm{~mm} \text { rigid foam insulation and } \\
\text { horizontal cedar weatherboard cladding }\end{array}$ \\
\hline 2 & $\begin{array}{l}\text { Exterior Wall Structure - } \\
\text { Framing, cavities, insulation }\end{array}$ & $\begin{array}{c}(8 \mathrm{ft}) \\
81 \mathrm{~m}^{2} \text { total }\end{array}$ & clips together on-site. \\
\hline & & $\left(872 \mathrm{ft}^{2}\right)$ & $\begin{array}{l}\text { Thin wall sections consisting of cedar } \\
\text { weatherboards over } 100 \mathrm{~mm} \text { insulation }\end{array}$ \\
\hline 3 & $\begin{array}{l}\text { Interior Wall Structure - East } \\
\text { Service Core (excl. openings) }\end{array}$ & $\begin{array}{l}2.3 \mathrm{~m} \times 23 \mathrm{~m} \\
\quad \approx 45 \mathrm{~m}^{2} \\
\left(484 \mathrm{ft}^{2}\right)\end{array}$ & $\begin{array}{l}\text { act as window shutters to prevent heat } \\
\text { loss overnight. }\end{array}$ \\
\hline 4 & - West Service Core & $\begin{array}{l}2.3 \mathrm{~m} \times 13 \mathrm{~m} \\
\approx 30 \mathrm{~m}^{2} \\
\left(323 \mathrm{ft}^{2}\right) \\
70 \mathrm{~m}^{2} \\
\left(754 \mathrm{ft}^{2}\right)\end{array}$ & $\begin{array}{l}\text { The internal services cores, made from a } \\
36 \mathrm{~mm} \text {, 3-layered structural particleboard } \\
\text { composite, are delivered to site fully } \\
\text { fabricated. These are craned onto the } \\
\text { foundations, around which the exterior } \\
\text { wall system is clipped. }\end{array}$ \\
\hline
\end{tabular}




\subsubsection{Roof Systems}

\begin{tabular}{|c|c|c|c|}
\hline No. & Element & Quantity & Description \\
\hline 1 & $\begin{array}{l}\text { Opaque Roof structure } \\
\text { - Bituminous sheeting } \\
\text { - structural particleboard } \\
\text { underlay } \\
\text { - Engineered timber rafters } \\
\quad-4.7 \mathrm{~m}(15.4 \mathrm{ft} \text { ) length } \\
\text { - insulation } \\
\text { - structural particleboard } \\
\text { ceiling } \\
\text { Translucent Roof Structure } \\
\text { - Timber Framing } \\
\quad-2.68 \mathrm{~m}(8.8 \mathrm{ft}) \text { length } \\
\quad-2.53 \mathrm{~m} \text { ( } 8.3 \mathrm{ft}) \text { length } \\
\text { - } 6.42 \mathrm{~m}(21.1 \mathrm{ft}) \text { length } \\
\text { - 16mm triple-glazed } \\
\text { polycarbonate panel (15mm } \\
\text { air gap) }\end{array}$ & $\begin{array}{c}2 \\
6 \\
2 \\
4 \times 4.2 \mathrm{~m}^{2} \\
\left(45 \mathrm{ft}^{2}\right)\end{array}$ & $\begin{array}{l}200 \mathrm{~mm} \text { rigid foam insulation and } \\
200 \times 75 \mathrm{~mm} \text { engineered timber hi-beam } \\
\text { rafters between } 36 \mathrm{~mm} \text { structural } \\
\text { particleboard panels brace the building } \\
\text { at roof level. } \\
\text { A triple-glazed semi-translucent roof } \\
\text { allows for diffuse natural light in the } \\
\text { central space and a visual connection } \\
\text { with the sky. Heat transfer is slowed by } \\
\text { sheets of } 40 \mathrm{~mm} \text { honeycomb } \\
\text { polycarbonate separated by a } 15 \mathrm{~mm} \text { air } \\
\text { gap. } \\
\text { It is supported on a } 225 \times 75 \mathrm{~mm} \\
\text { exposed timber frame. }\end{array}$ \\
\hline
\end{tabular}

4.1.5 Glazing Systems, Sizing and Location

\begin{tabular}{|c|c|c|c|}
\hline No. & Element & Quantity & Description \\
\hline 1 & South Windows (large) & $\begin{array}{l}2 \times 3.8 \mathrm{~m}^{2} \\
\left(41 \mathrm{ft}^{2}\right)\end{array}$ & $\begin{array}{l}\text { The southern facade contains the } \\
\text { majority of the home's glazing, to take } \\
\text { advantage of natural davlight and }\end{array}$ \\
\hline 2 & South Window (small) & $\begin{array}{l}1 \times 1.4 \mathrm{~m}^{2} \\
\left(15 \mathrm{ft}^{2}\right)\end{array}$ & $\begin{array}{l}\text { passive solar gains in winter. Horizontal } \\
\text { windows in the east and west walls let } \\
\text { in earlv morning and late afternoon sun }\end{array}$ \\
\hline 3 & $\mathrm{E}+\mathrm{W}$ Windows & $\begin{array}{l}2 \times 1.1 \mathrm{~m}^{2} \\
\left(11.8 \mathrm{ft}^{2}\right)\end{array}$ & $\begin{array}{l}\text { and visually continue the longitudinal } \\
\text { axis through the home. }\end{array}$ \\
\hline 4 & North Window (bathroom) & $\begin{array}{l}1 \times 0.24 \mathrm{~m}^{2} \\
\left(2.6 \mathrm{ft}^{2}\right)\end{array}$ & $\begin{array}{l}\text { The exterior windows comprise of low- } \\
\text { e, argon-filled triple glazing in NZ-made } \\
\text { ALti composite aluminum/ timber }\end{array}$ \\
\hline 5 & Central Bi-fold Doors & $\begin{array}{l}6 \times 1.8 \mathrm{~m}^{2} \\
\left(19.4 \mathrm{ft}^{2}\right)\end{array}$ & $\begin{array}{l}\text { joinery to minimize thermal } \\
\text { bridging. }\end{array}$ \\
\hline 6 & Interior Bi-fold Doors & $\begin{array}{l}6 \times 1.3 \mathrm{~m}^{2} \\
\left(14 \mathrm{ft}^{2}\right)\end{array}$ & $\begin{array}{l}\text { Single-glazed interior bi-fold doors } \\
\text { flanking the central space can shut off } \\
\text { each end of the house, allowing for } \\
\text { three separate thermal zones. }\end{array}$ \\
\hline
\end{tabular}

\subsubsection{Window and Door Framing/Extrusions}

(Refer to appendices 9.3 Window Schedule) 


\subsubsection{Timber Canopy}

\begin{tabular}{|c|c|c|c|}
\hline No. & Element & Quantity & Description \\
\hline 1 & $\begin{array}{l}\text { Engineered Timber Column } \\
(120 \times 150)-2.9 m(9.5 \mathrm{ft})\end{array}$ & 14 & $\begin{array}{l}\text { A composite timber/ steel post and } \\
\text { beam structure raises the solar panels } \\
\text { off the roof to allow for passive }\end{array}$ \\
\hline 2 & $\begin{array}{l}\text { Composite Timber / Steel } \\
\text { Beam }(120 \times 250)-7.9 m(26 \mathrm{ft}) \\
\text { length }\end{array}$ & 7 & $\begin{array}{l}\text { ventilation and cooling of the } \\
\text { photovoltaic array. }\end{array}$ \\
\hline 3 & $\begin{array}{l}\text { Timber Rafter }(50 \times 150) \\
-8.2 \mathrm{~m}(26.9 \mathrm{ft}) \text { length } \\
-6.0 \mathrm{~m}(19.7 \mathrm{ft}) \text { length }\end{array}$ & $\begin{array}{c}114 \text { lineal } \mathrm{m} \\
8 \\
8\end{array}$ & \\
\hline 4 & $\begin{array}{l}\text { Vertical Timber Support } \\
(50 \times 150)-3.1 \mathrm{~m}(10.2 \mathrm{ft}) \\
\text { length }\end{array}$ & 8 & \\
\hline 5 & Steel Purlin $-7.9 \mathrm{~m}(26 \mathrm{ft})$ & 25 & \\
\hline 6 & Timber Slats $(50 \times 50)$ & $\begin{array}{l}575 \mathrm{~m} \\
(1880 \mathrm{ft})\end{array}$ & $\begin{array}{l}50 \times 50 \text { timber battens shade the interior } \\
\text { from high-angle summer sun. }\end{array}$ \\
\hline 7 & $\begin{array}{l}\text { Solar Panel Structural } \\
\text { Brackets }\end{array}$ & $\begin{array}{l}\text { 39PV + } \\
\text { 2Water }\end{array}$ & \\
\hline
\end{tabular}

\subsubsection{Deck \& Landscaping}

\begin{tabular}{|c|c|c|c|}
\hline No. & Element & Quantity & Description \\
\hline 1 & $\begin{array}{l}\text { Decking \& Ramps } \\
\text { - Structure + finish } \\
\text {-decking timber }\end{array}$ & $\begin{array}{c}123 \mathrm{~m}^{2} \\
\left(1324 \mathrm{ft}^{2}\right)\end{array}$ & $\begin{array}{l}\text { Timber decking lines up with the interior } \\
\text { NS floorboards to extend the living } \\
\text { space and the transverse axis of the } \\
\text { home. }\end{array}$ \\
\hline 2 & Railings (north stair) & & Poilings on ocrecciblo porthern oxtorio \\
\hline 3 & Planting (soil) & $\begin{array}{c}84 \mathrm{~m}^{2} \\
\left(904 \mathrm{ft}^{2}\right)\end{array}$ & $\begin{array}{l}\text { Landscaping scheme will be finalized in } \\
\text { developed design phase. }\end{array}$ \\
\hline
\end{tabular}

\section{$4.2 \quad$ Interiors}

4.2.1 Interior Finishes

\begin{tabular}{|c|l|c|l|}
\hline No. & Element & Quantity & Description \\
\hline 1 & Wall finishes & $70 \mathrm{~m}^{2}$ \\
$\left(754 \mathrm{ft}^{2}\right)$ & $\begin{array}{l}\text { A white paint finish on all interior faces } \\
\text { optimizes the effect of natural daylight } \\
\text { in the interior. All paints and finishes will } \\
\text { be to Environmental Choice certification }\end{array}$ \\
& $\begin{array}{l}\text { Bathroom finishes } \\
\text { - water-resistant gypsum } \\
\text { board wall lining }\end{array}$ & $\begin{array}{c}18.5 \mathrm{~m}^{2} \\
\left(200 \mathrm{ft}^{2}\right)\end{array}$ & \begin{tabular}{l} 
NZ. \\
\hline
\end{tabular}
\end{tabular}




\begin{tabular}{|c|l|c|l|}
\hline & - waterproof floor finishes & $22.4 \mathrm{~m}^{2}$ & The size of the bathroom dictates a wet \\
3 & (walls and floors) & $\left(241 \mathrm{ft}^{2}\right)$ & finish. \\
& Kitchen joinery & $\left(34.5 \mathrm{~m}^{2}\right.$ & Finishes to be specified in the \\
& & $\left.57.3 \mathrm{fm}^{2}\right)$ & developed design phase. \\
& Cupboards & $\left(617 \mathrm{ft}^{2}\right)$ & Kitchen joinery and built-in cupboards \\
& & & \\
\hline
\end{tabular}

\subsubsection{Fixed Interior Furnishings}

\begin{tabular}{|c|l|l|l|}
\hline No. & Element & Quantity & Description \\
\hline 1 & Bed/office unit & & A Victoria University furniture design \\
2 & Kitchen bench & & paper will be run in order to custom \\
3 & Lounge Seating & design all fixed interior furniture to meet \\
4 & Fold away lounge bed & the aesthetic style and functional needs \\
& & & of the home. \\
\hline
\end{tabular}

\subsubsection{Stand-alone Interior Furniture}

\begin{tabular}{|c|l|l|l|}
\hline No. & Element & Quantity & Description \\
\hline 1 & Bedroom drawers & & To be specified in developed design \\
2 & Office chair & & phase. \\
3 & Bathroom vanity & & \\
4 & Dining table & \\
5 & Dining chairs & & \\
6 & Lounge drawers & & \\
7 & Coffee table & & \\
\hline
\end{tabular}

\subsubsection{Appliances}

\begin{tabular}{|c|l|l|l|}
\hline No. & Element & Quantity & Description \\
\hline 1 & Fridge & & Low-energy appliances with an \\
2 & Freezer & & estimated total consumption of \\
3 & Oven & & approximately 8-10 kWh will be \\
4 & Induction cooktop & \\
5 & Range hood & \\
6 & Dishwasher & \\
7 & Washing machine & \\
8 & Clothes dryer & \\
9 & Cordless telephone & \\
10 & Laptop computer & \\
11 & Flat screen LCD television & & \\
12 & Stereo system & \\
13 & DVD player & \\
14 & Digital Home Monitoring & \\
& System & \\
& & \\
\hline
\end{tabular}




\subsection{Technologies}

\subsubsection{Introduction}

With the introduction of the energy balance contest, the 2011 Solar Decathlon has shifted towards the design of a house that balances energy production with power consumption. New Zealand's FirstLight house has been designed to minimize electrical loads in order to lower the demand of the photovoltaic array and making net zero and achievable and affordable goal.

\subsubsection{AC Electrical}

The first step in the design of the electrical systems is to calculate the expected energy requirements of the home during the competition.

Based on the competition schedule and the current conceptual design proposal we expect the house will consume between 12-14kWh per day (ref appendices).

In the coming weeks we will undertake extensive energy modeling of the home to determine ways in which we can reduce this load further. Our aim is to design a home that uses an average of less than $12 \mathrm{kWh}$ per day during the contest.

Figure 6: Energy Consumption throughout Competition (kWh)

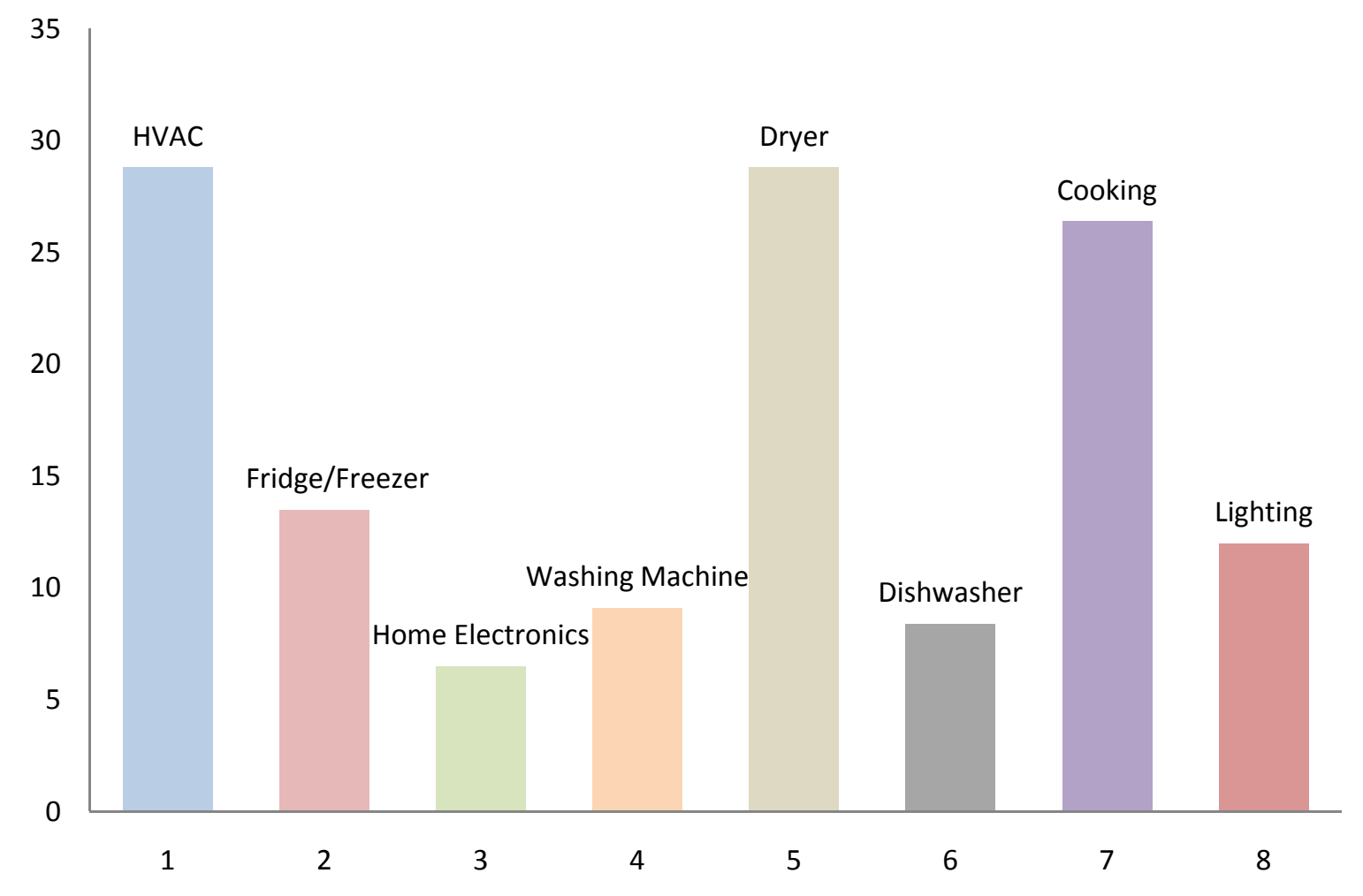




\subsubsection{Appliances}

Appliances count for close to $70 \%$ of the homes energy consumption, therefore strategic selection of our home appliances will ensure optimum efficiency, reduced costs and meet the functional requirements or the home owner. Appliances will be carefully selected using the US energy star rating system.
Figure 7: Average Daily Energy Consumption

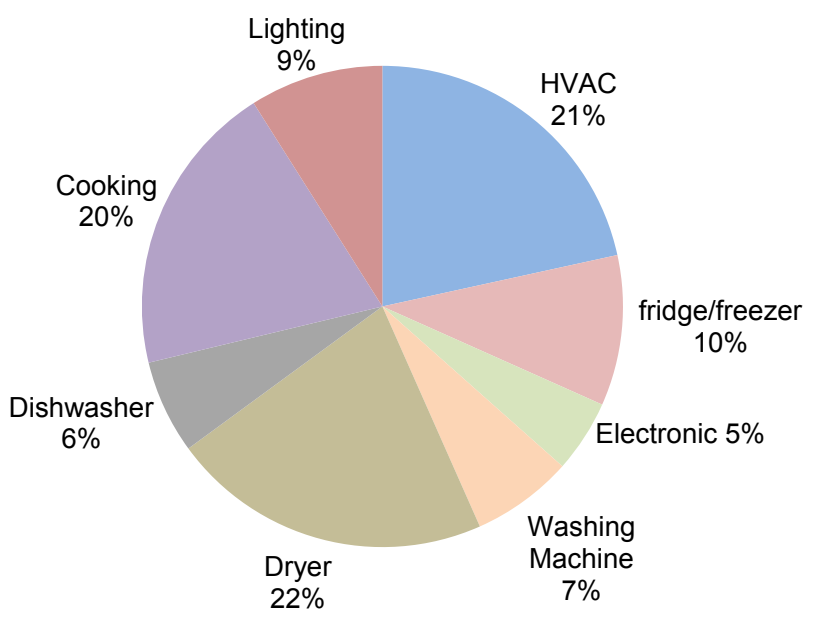

\subsubsection{Accurate Modeling of Electrical Systems}

Accurate modeling of the energy use during the competition is critical in anticipating the performance of the home. Many of the appliances used during the competition have very specific run times and so the amount of energy they consume is easy to calculate based on manufacturer's specifications. However components like the HVAC system, one of the larger electrical loads, is harder to estimate due to the variable climatic conditions affecting the performance and demand during the competition in Washington DC. We are currently in the process of analyzing the schematic design to discover areas in which we can improve the energy efficiency of the home. Accurate modeling is an essential design tool that we will use throughout the developed design phase of the project to ensure the best possible design outcome.

\subsubsection{Lighting}

The homes lighting scheme will be designed with the goal of energy minimization, reducing the overall energy demand of the home. Using low-wattage high-efficiency LED fixtures we will be able to comfortably light the house with little energy.

\subsubsection{Home Automation System}

Traditional homes lack a method of informing residents about the energy and water consumption throughout the day/month/year. Our house will not only be designed and operated as a net zero energy home, but will also inform its residents of their daily energy and water consumption. A unique, interactive programme designed specifically for the house will allow the user to control and monitor their energy use throughout the day. It allows them to become aware of how much energy they use and where they can make savings. 

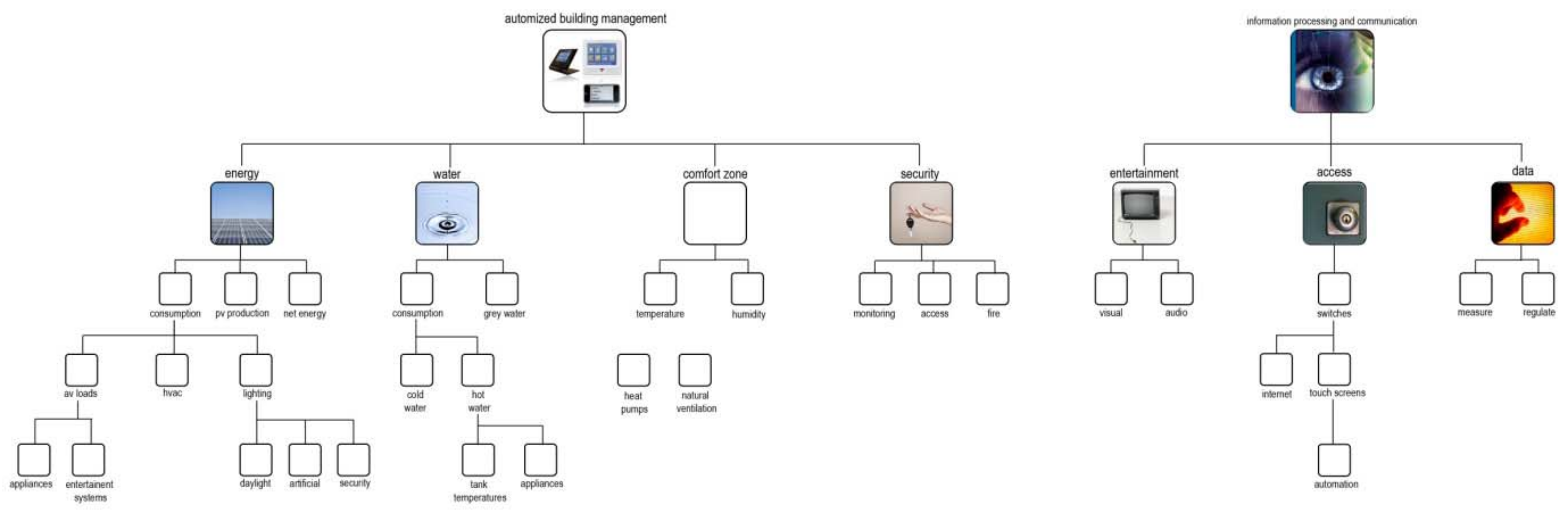

Figure 8: Home Automation System

\subsubsection{Mechanical (HVAC)}

During the times specified in the SD2011 rules, the zone temperature of the home must remain consistently within the range of $71^{\circ} \mathrm{F}-76^{\circ} \mathrm{F}\left(21.7^{\circ} \mathrm{C}-24.4^{\circ} \mathrm{C}\right)$. In order to achieve this, we have designed a simple system of heat pumps that extract energy from the air and circulate it throughout the home. The system is designed with a single heat pump on either side of the central hearth, thereby heating and cooling the two thermal zones separately. The system is designed to be as simple as possible using technology that is readily available, cost effective and extremely efficient.

Based on early thermal calculations the energy required to maintain the strict internal temperature outlined by the competition is between $2-4 \mathrm{kWh}$ per day.

Considering the huge role heating and cooling have on the energy consumption of th e house, designing a simple system that uses small amounts of power to achieve the thermal range outlined in the competition will go a long way to reducing the total energy consumption of our house.

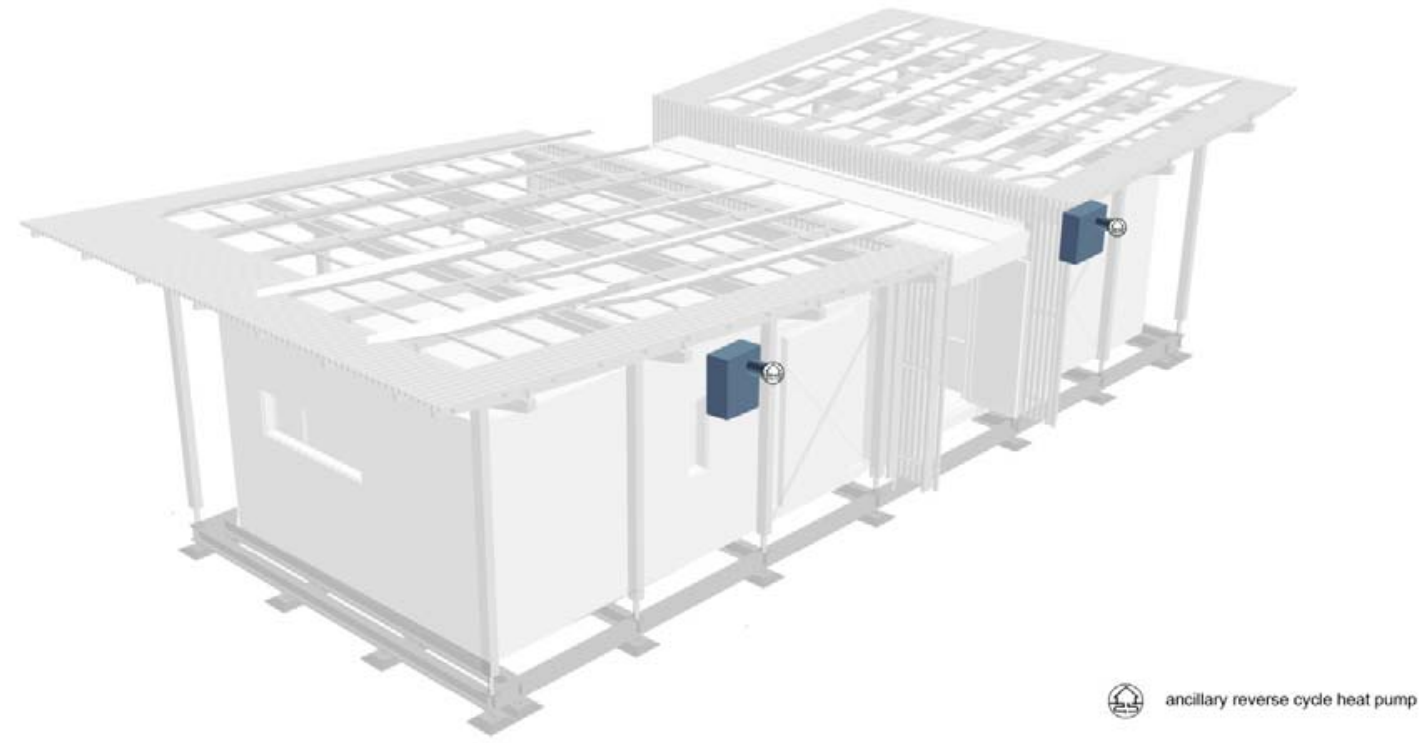

Figure 9: Reverse-cycle Heat Pump Locations 


\subsubsection{PV Array}

The selection of the photovoltaic system is an import part of our design process. With the new energy balance and affordability contests introduced into the 2011 Solar Decathlon, we see a necessary change in focus in the design of our homes. The New Zealand team aims to design an affordable, net zero energy home that is simple and efficient. In order to achieve this, the number of solar panels generating electricity on the roof must perfectly match the energy consumption of the home.

At this stage in the design process, we have completed an initial estimate of the energy consumption of the home during competition week. Based on the competition schedule we expect the house will consume between 12-14kWh per day.

We can therefore begin to calculate an initial estimate of the energy needed to be produced during competition week in order to achieve net zero energy.

In order to achieve net zero energy, we need a solar array of between 4-6kW. This is an estimate assuming that Washington DC in October will receive an average of 3.8 sunshine hours per day.

Using current Monocrystalline photovoltaic technology, we can assume that each panel will generate approximately 180 Watts at its optimal angle and peak efficiency. We would therefore need a solar array of 33 panels to achieve our $6 \mathrm{~kW}$ goal.

This is still only an initial estimate of the energy generation required, as we are still at the early stages of design, testing and modeling. We would assume that it is still on the very high side of what we will require for the competition in 2011. Through accurate energy modeling, we will review the current design and find areas where we can improve the efficiency of the home. If we can achieve our desired energy consumption, we will be able to reduce the number of solar panels on the roof by half. This will have a dramatic impact on the affordability of the home and will make it more accessible to a wider range of individuals in the New Zealand and the US markets. (Refer to appendices for diagram of the currently proposed PV array)

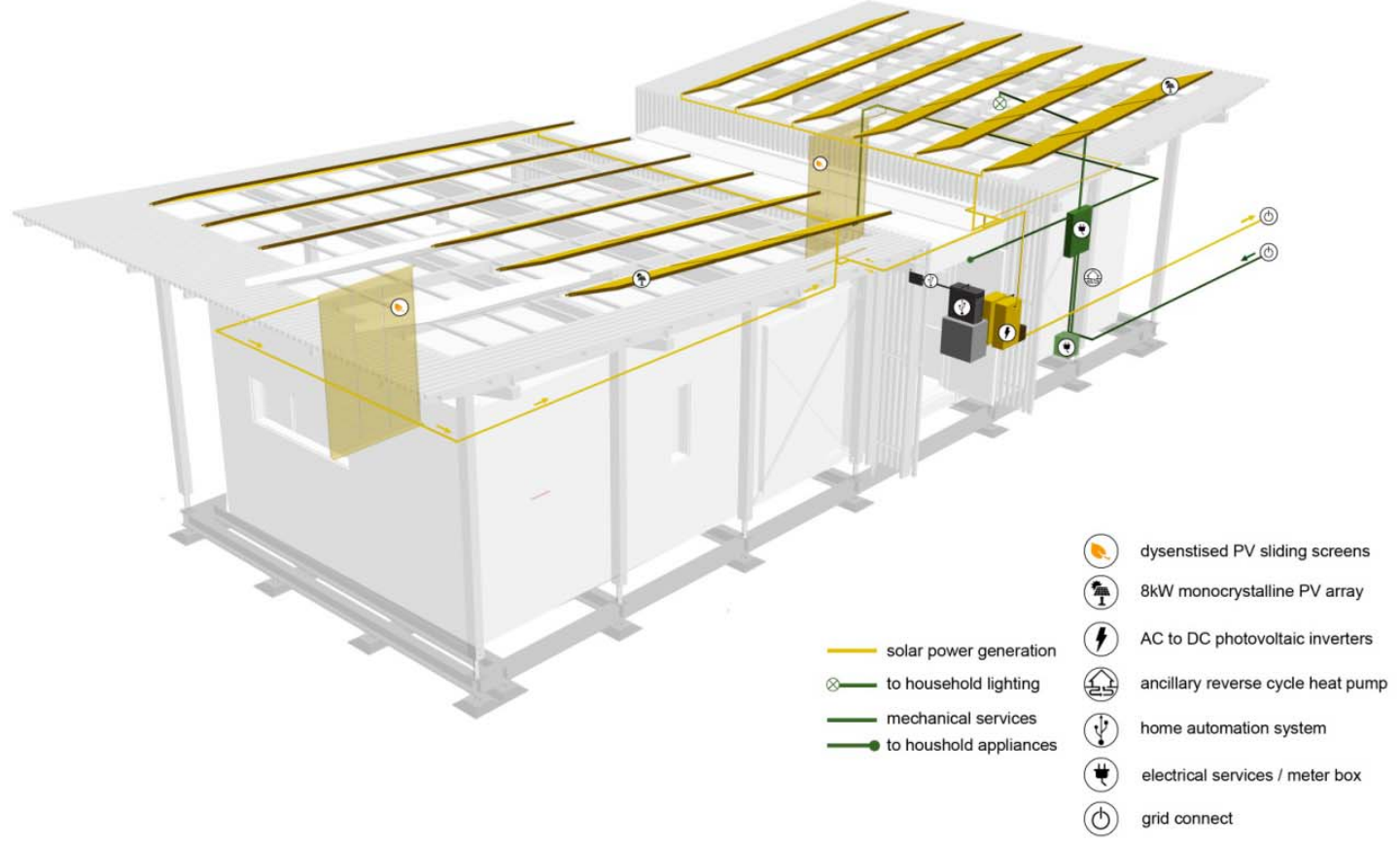

Figure 10: Electrical Schematic 


\subsubsection{Dye-sensitized Solar Cells}

Leaves of plants are tiny factories in which sunlight converts carbon dioxide gas and water into carbohydrates and oxygen. They are not very efficient however but are very effective over a wide range of sunlight conditions. In spite of the low efficiency and the fact that the leaves must be replaced, the process has worked for hundreds of millions of years, and forms the primary energy source for all life on earth.

Since the 1970s, attempts have been made to create a better solar cell based on this principle. This new generation of photovoltaic technology, desensitized solar cells, are beginning to makes their mark on the world and is the most promising advance in solar technology since the invention of the silicon cell.

Advantages of Dye-sensitized Solar Cell (DSC) technology

- Much less sensitive to angle of incidence of radiation - it is a "light sponge" soaked with dye

- Performs over widest range of light conditions

- Low sensitivity to ambient temperature changes

- Much less sensitive to shadowing - can be diode free

- Option for transparent modules - enabling wider applications

- Truly bifacial - absorbs light from both faces - can be inverted

- Production facilities for DSC utilize commonly available low cost processing equipment, vastly cheaper than that required for silicon cells

- DSC modules have lower embodied energy than all other forms of solar cells

- DSC can be packaged in tandem designs to produce integrated power packs, sensor solutions, direct chemical manufacturing

- DSC power can be amplified by tandem and optical techniques without use of concentrators

The New Zealand team has designed a set of sliding screens that incorporate this new solar technology into the design for the 2011 Solar Decathlon. These sliding screens, connected to the home automation system, can be moved into a variety of different positions depending on the requirements of the home during the day.
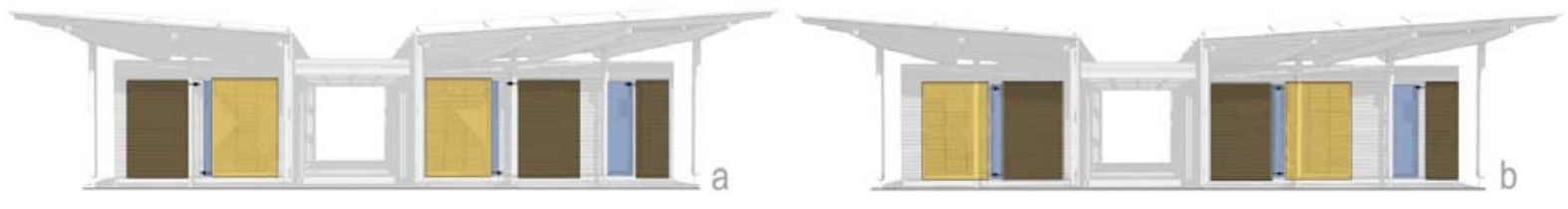

Dye-sensitized solar cells can be moved over windows during sunny or cloudy days to generate electricity while still allowing light to pass into the home. 
On cold winter days when the sliding insulated panels are needed to regulate the interior temperature the dye sensitized solar cells can be moved to continue to generate electricity.
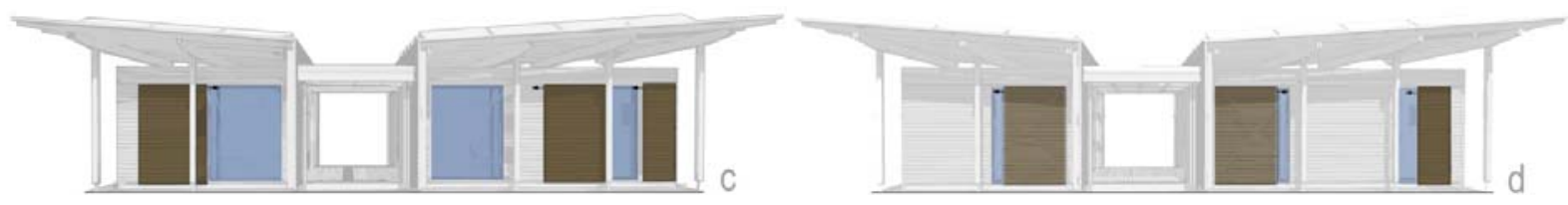

Figures 11, 12, 13 \& 14: Adaptable Building Envelope

During summer days when there is large amounts of sunlight there may be enough energy generated by the roof top solar panels. The desensitized solar cells can easily slide away behind the insulated sliding screens.

\subsubsection{Solar Mechanical}

Sixteen hot water draws will be made during contest week. Each hot water draw is 15 Gal (57 litres). In total for the week, 240 Gallons (912Litres) of hot water will be drawn and tested for its temperature. At each draw, the average temperature of the water must be at least $43.3^{\circ} \mathrm{C}(110$ $\left.{ }^{\circ} \mathrm{F}\right)$.

We are currently in the design phase for our solar hot water system. We have a number of different options that are being investigated. The one shown here is a controller based direct system of evacuated tubes. Solar radiation is absorbed by the evacuated tubes and converted into heat. Heat pipes conduct the heat from within the solar tube up to the header. Water is circulated through the header, via intermittent pump cycling. Each time the water circulates through the header the temperatures is raised by $5-10{ }^{\circ} \mathrm{C} / 9-18{ }^{\circ} \mathrm{F}$. Throughout the day, the water in the storage tank is gradually heated. A hot water heat pump extracting renewable energy in the air to heat water is used to bring the temperature of the water up to the guidelines set by the competition, when there is not enough heat in the evacuated tubes.

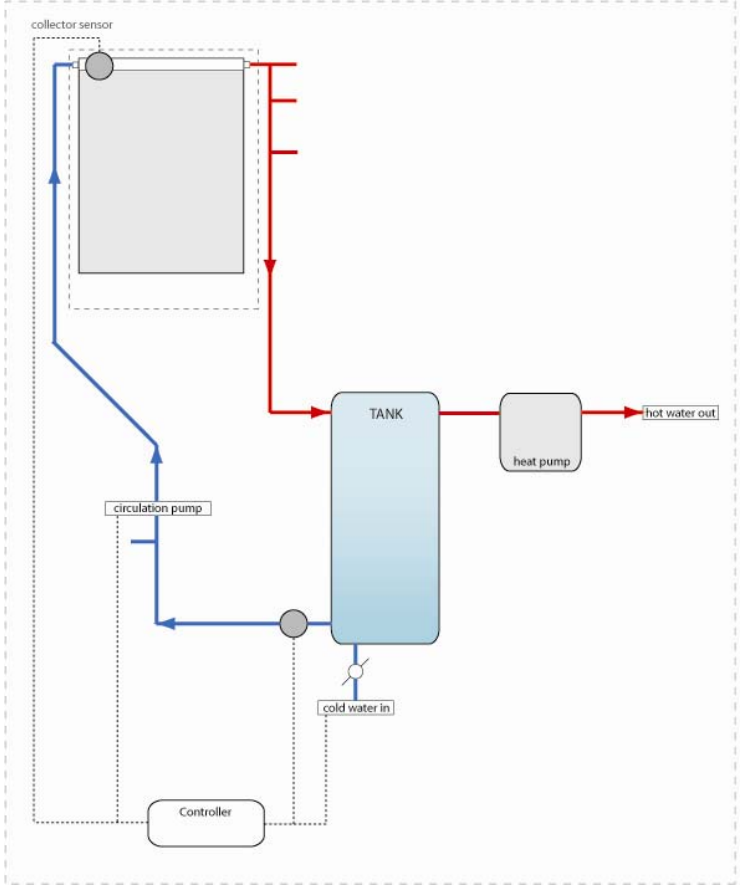

Figure 15: Solar Mechanical Schematic 


\subsubsection{Water Storage and Services}

Fresh water storage will be stored in a tank underneath the building. An initial estimate of the amount of water needed during competition week is approximately 500 gallons. Both fresh and grey water tanks are situated under the house near to the plumbing services.

Grey water will be stored throughout the completion in a tank underneath the building.

\subsubsection{Plumbing}

All of the plumbing fixtures are concentrated around one side of the home, so they can be easily incorporated as a part of the service core.

The design of our plumbing system includes a dedicated pipeline from a manifold near the hot water cylinder to each tap or fixture in the house. Hot water goes directly to where it is needed in the home. Less energy and water is wasted as hot water arrives faster at the tap. Flexible and non-metallic pipes result in a quiet and efficient plumbing system that does not suffer corrosion, scaling or microbiological build-up.
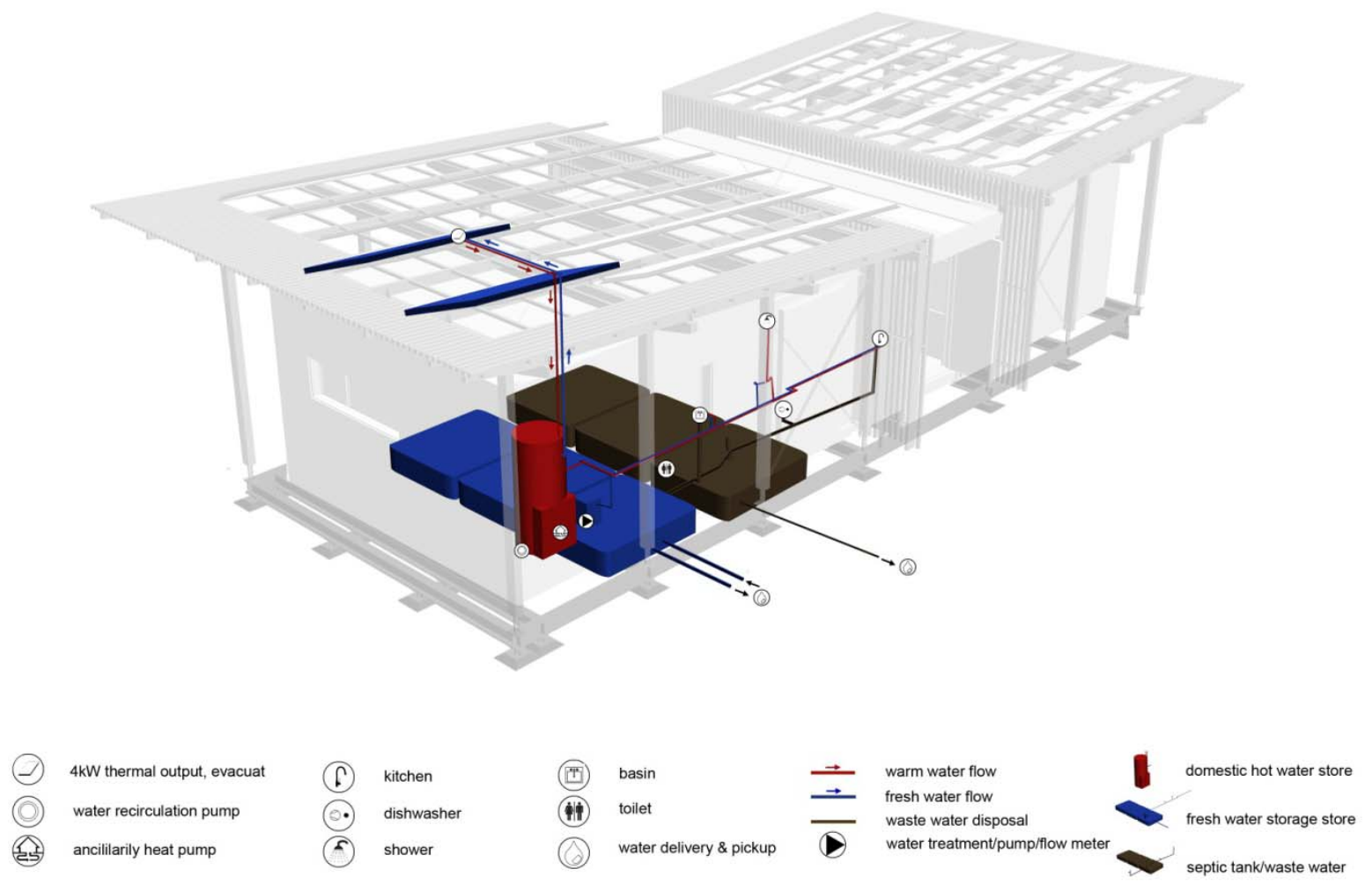

Figure 16: Water Services Schematic

\subsubsection{Fire Protection}

Our design includes an affordable built in sprinkler system designed specifically for the home environment. Linked to the domestic water supply, the system is designed to fit discreetly into the home, concealed in the ceiling. The system provides protection from fire in an affordable and efficient way. 


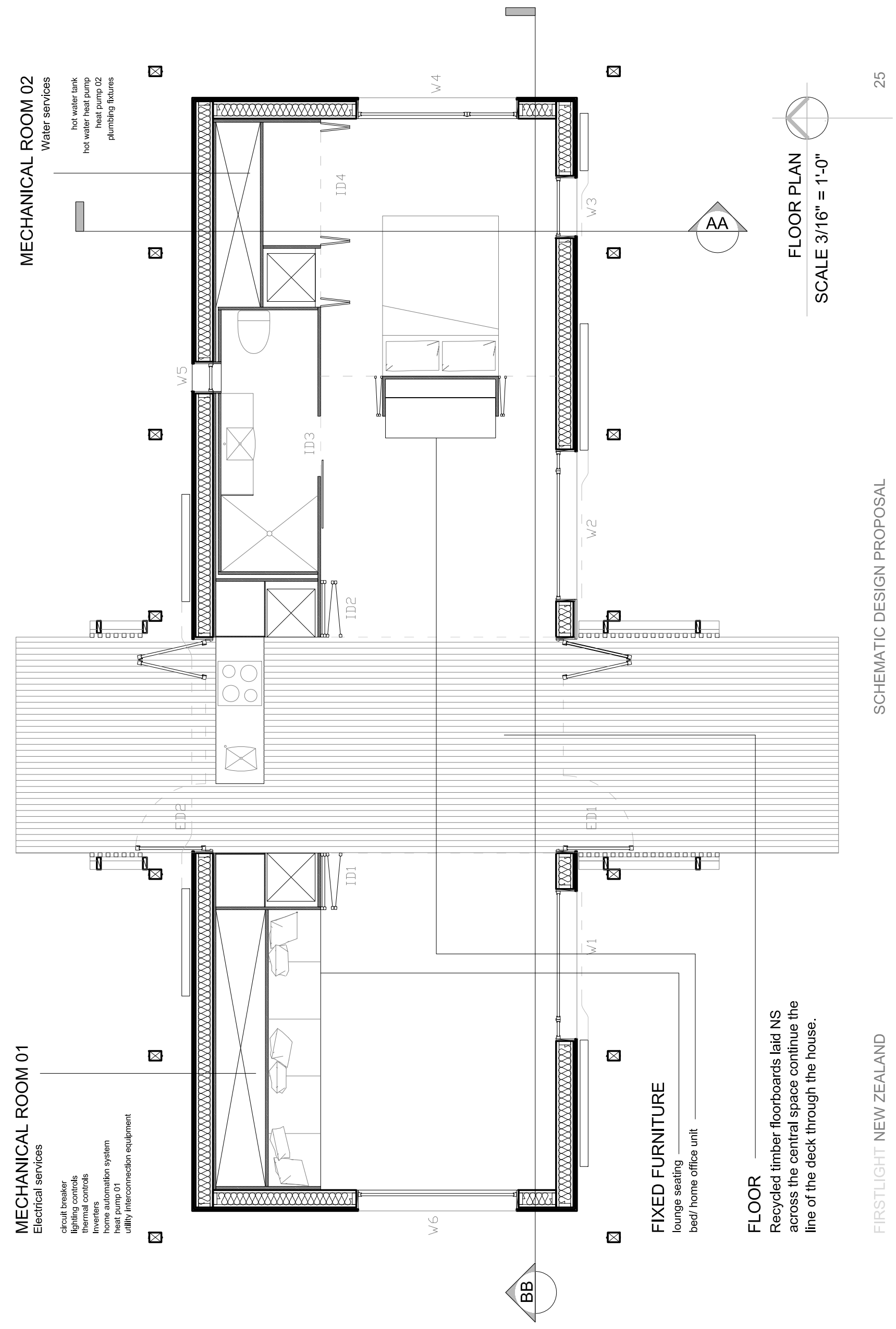




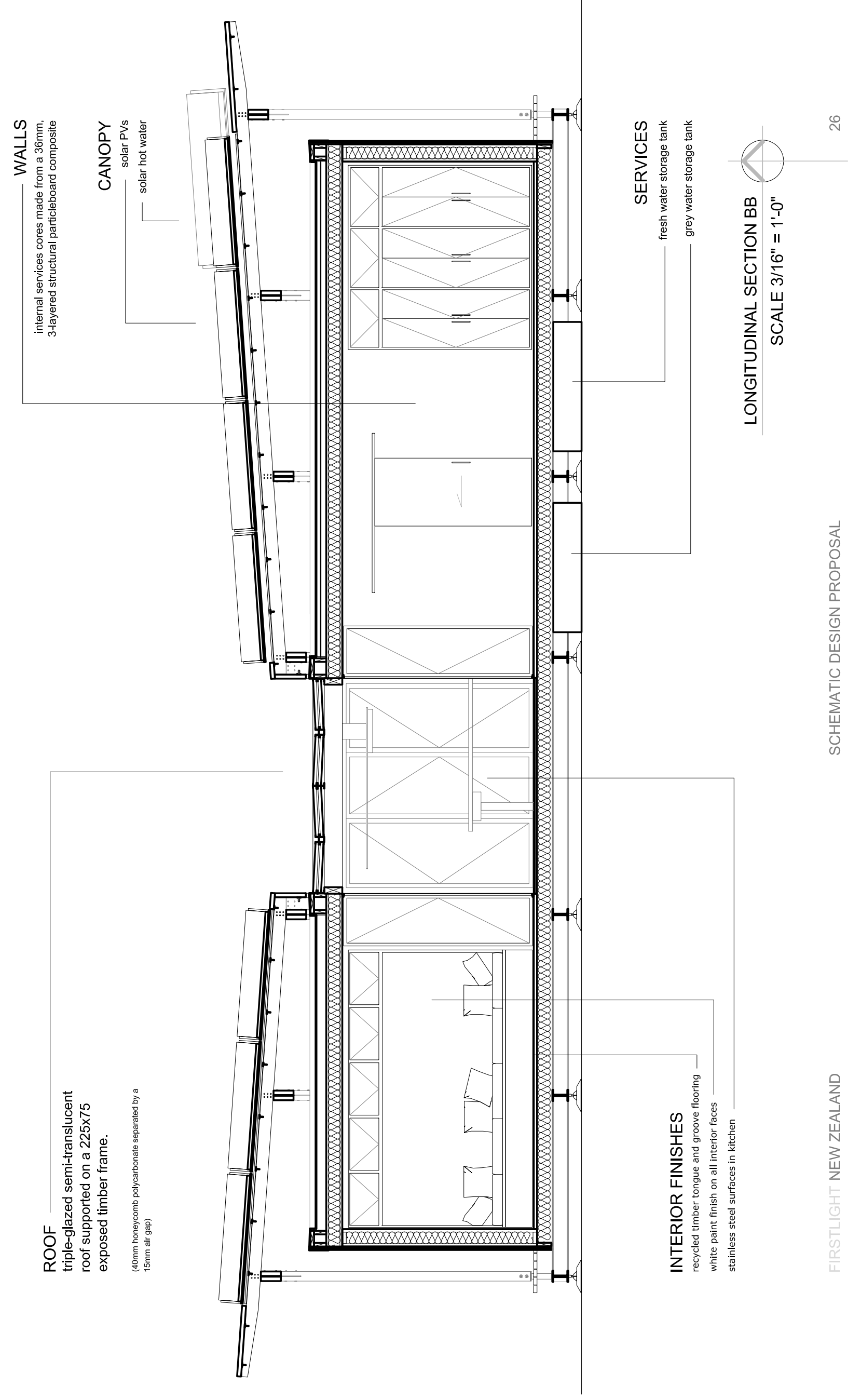



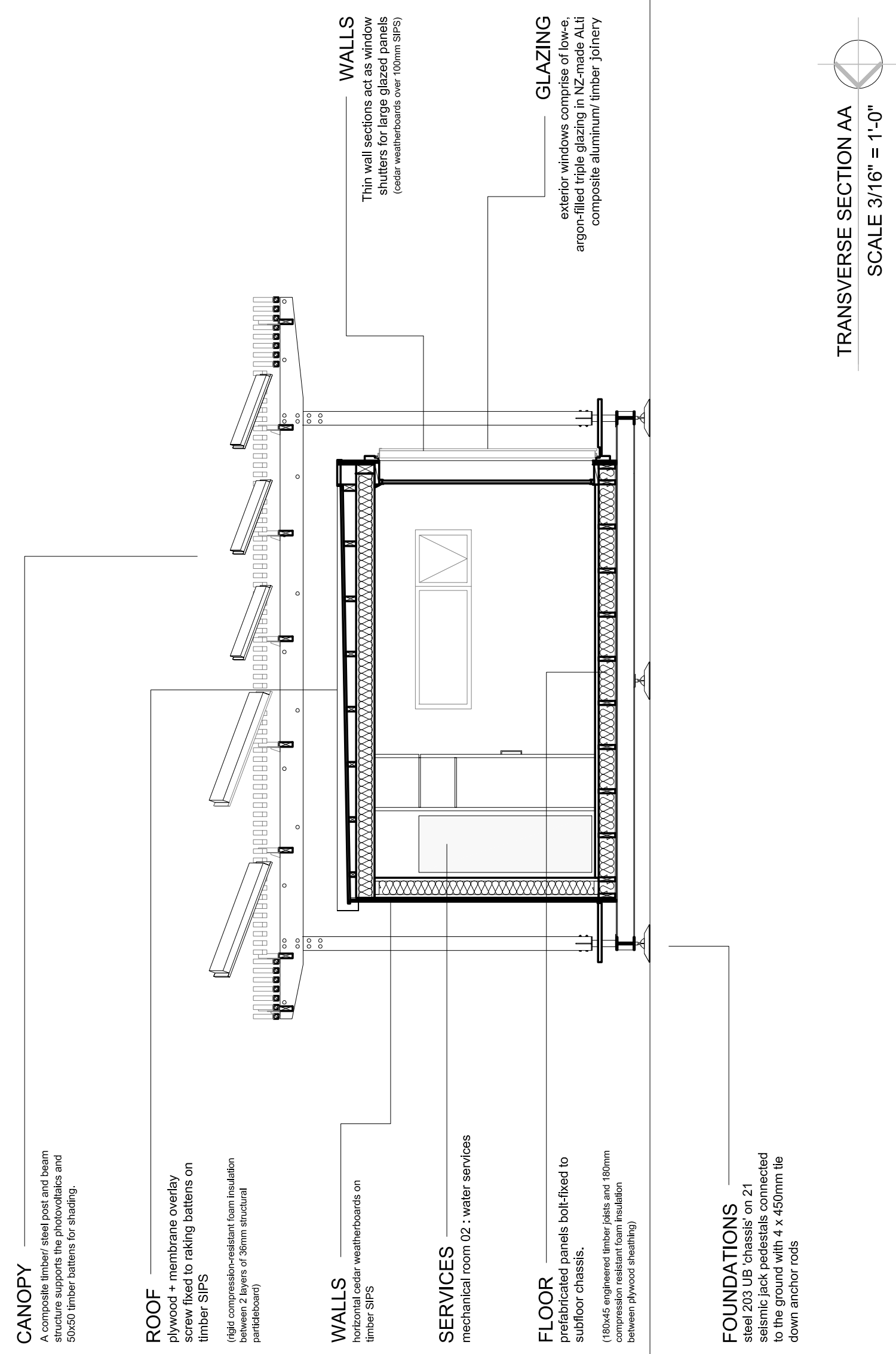


\subsection{Utility Interconnection Equipment}

\subsection{PV Systems}

Our PV array currently has 33 panels rated at 180watts each in a system with a DC rating of $6 \mathrm{~kW}$. This is only at a schematic design stage and is expected to change as the design develops.

This system consists of 10 strings. There will be 7 strings of 3 solar panels and 3 strings of 4 solar panels that will be connected in parallel and will filter into two combiner boxes. These will then go to the inverters and connect to the grid.

Utility interconnection equipment is all located on the north side of the house within Mechanical Room 01 (Ref 4.3.14 Ground Floor Plan).

\subsection{Water Systems}

Water services and electrical services have been separated into two mechanical rooms at opposite ends of the house. All of the water services can be accessed from Mechanical Room 02.

Fresh water and grey water storage are located under the house under mechanical room 02. These can be accessed from the back of the house on the North side.

\subsection{Public Exhibit Strategy}

All exhibit materials will be designed exclusively for the purpose of engaging and educating the public about the wide-ranging benefits of solar integrated design. Graphic design students from the School of Architecture and Design will work collaboratively with students from other faculties to develop appealing and informative exhibit materials. The personalized public tour of the house will follow the outline below (refer to figure 15: public tour floor plan).

\section{A Visitor Assembly Point}

Interactive LCD touch screen displays [1] provide an overview of the house, its key architectural elements, technologies, and systems. The real-time data logger [2] continuously displays energy and performance information about the home.

\section{B Tour Start Point}

Student tour guides will welcome visitors, form tour groups, and give an introduction to the team, its philosophy, and its goals.

\section{Solar Landscape}

An overview of the landscape design will be given including;

$\mathrm{PV}$ and evacuated tube integrated solar canopy [3]

Sliding dye-sensitized PV screens for low-light conditions [5]

Sliding thermal shutters to control heat transfer [6]. 


\section{House Entry Point}

This is an extension of the landscape through to the interior of the house, retaining both a visual and physical connection to the outside.

\section{E Central Living Space}

This is the social focal point of the home. A description of the space's climate mediating systems will be given; exterior and interior bi-folding doors [7 \& 8], translucent polycarbonate roof.

\section{F Living Room}

Relaxation, reading, and home entertainment space. Fold-out bed from beneath the corner sofa [17] accommodates up to two short term guests. Guide will explain the location and systems included within the electrical service core [9], and the operation of the home automation system and user interface [10]. Question and answer session.

\section{G Kitchen}

An integral part of the central heart, combining cooking, dining, socializing and entertaining. Brief description of the adaptable use of facilities; the additional fold-away bench space for food preparation [11], the full-height opening doors behind the bench [7] allowing complete transparency and providing the ability to cook outside during summer, and the detachable coffee table section [12] extending the dining table to accommodate a banquet arrangement.

\section{H Study}

Explanation of the prefabrication, assembly, and disassembly of the house (prefab service cores [13a \& 13b], bathroom [14], and flat-pack SIPS [15]).

\section{Bedroom}

Private space. Guide will explain the location and systems included within the water service core [16] (domestic hot water and laundry [W/D]).

\section{J Conclusion of Tour}

Question and answer session, brochures, summary and farewells.

For times of higher visitor volume, an "express tour" will be provided with brief descriptions given by several stationary tour guides. The long sloping deck can easily accommodate a large number of people, and the LCD displays and decathletes will help keep waiting visitors inspired. We hope to incorporate other interactive material throughout the public tour to better educate visitors about the operation of the house. 


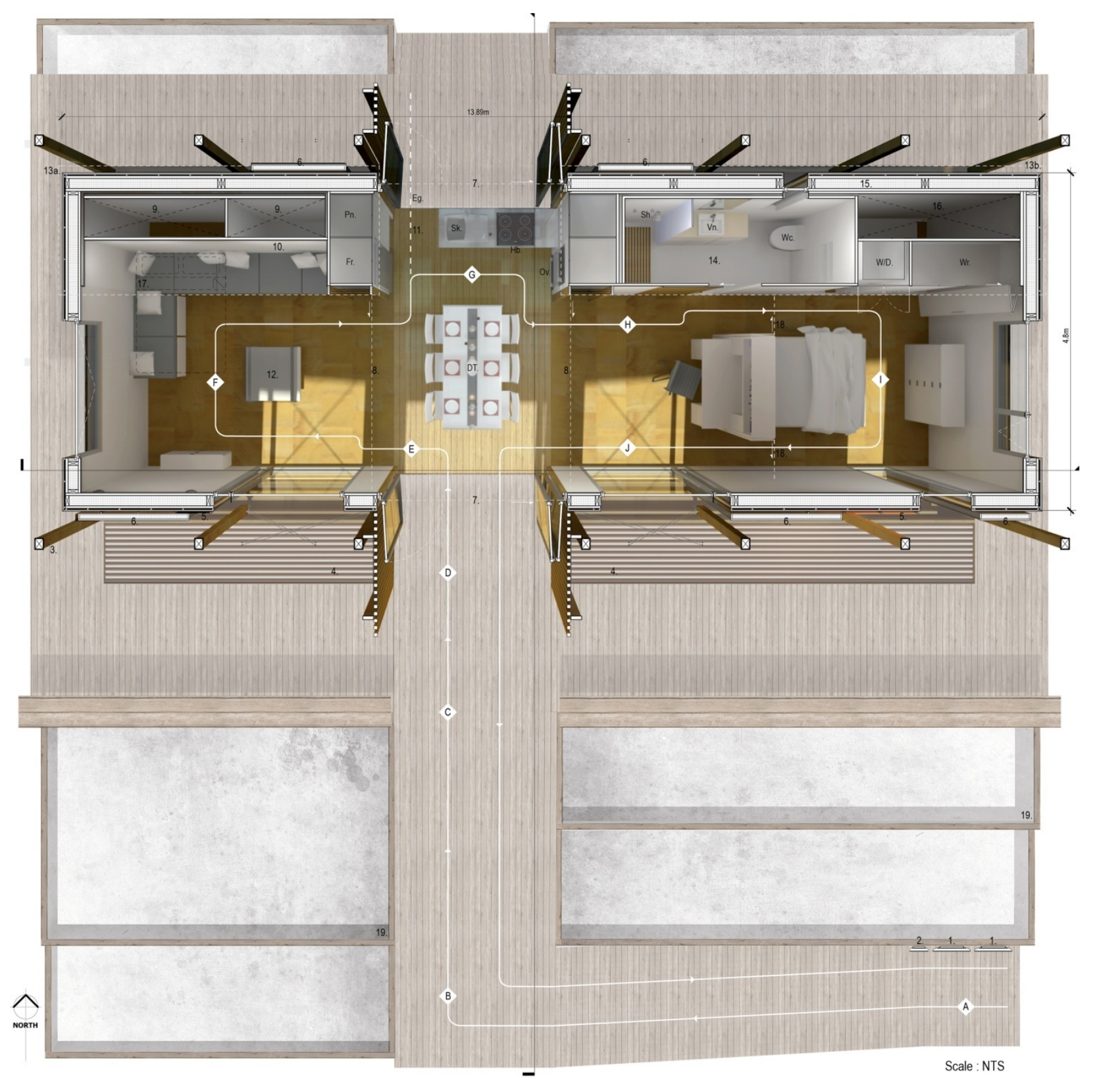

$\begin{array}{lll}\text { LCD touch screen display } & \text { DT. } & \text { Dining table } \\ \text { Real-time data logger } & \text { Pn. } & \text { Pantry } \\ \text { Solar canopy } & \text { Fr. } & \text { Fridge } \\ \text { Solar thermal heating system } & \text { Sk. } & \text { Sink } \\ \text { Sliding dye-sensitized PV screen } & \text { Hb. } & \text { Induction hob } \\ \text { Sliding thermal shutter } & \text { Ov. } & \text { Oven } \\ \text { Exterior bi-fold doors } & \text { Sh. } & \text { Shower } \\ \text { Interior bi-fold doors } & \text { Vn. } & \text { Vanity } \\ \text { Electrical / HVAC services } & \text { Wc. } & \text { Toilet } \\ \text { Home automation user interface } & \text { W/D. } & \text { Clothes washer and dryer } \\ \text { Fold-away kitchen bench } & \text { Wr. } & \text { Wardrobe } \\ \text { Coffee table } & \text { Eg. } & \text { Egress } \\ \text { Prefabricated service cores } & & \\ \text { Bathroom } & & \\ \text { SIPS } & & \\ \text { Water services } & & \\ \text { Fold-out bed } & & \\ \text { Bi-fold privacy screens } & & \\ \text { Landscape planters } & & \end{array}$

Public Exhibit Tour

A Visitor Assembly Point

B Tour Start Point

C Solar Landscape

D House Entry Point

E Central Heart

F Living Room

G Kitchen

H Study

I Bedroom

J Conclusion of Tour 


\subsection{Health and Safety Plan Outline}

\subsection{Policy Establishment}

Victoria University of Wellington is firmly committed to the provision of a safe and healthy environment for its employees, students, contractors and the public. The University recognizes that this commitment will only be achieved with positive leadership, the provision of necessary resources and continued pursuit of best practice in occupational health and safety. The University expects every member of its community to accept personal responsibility for promoting the safety and well being of themselves and those involved in, or affected by, the University's activities.

Victoria University is in the process of establishing a customized Health and Safety policy for the U.S DoE Solar Decathlon / FirstLight project. This will entail the following elements:

\subsection{Assignment of Responsibility}

The Vice Chancellor has overall responsibility for the effective management of health and safety, and requires every manager with staff responsibility to implement this policy. Defined levels of authority (in the office, on-site in New Zealand and on-site in Washington D.C) will ensure that no operations are undertaken without communication with supervising parties.

An independent OSHA specialist will be contracted to the FirstLight team in order to advise and oversee all operations leading up to, and including, construction on-site.

\subsection{Identification and Analysis of Risks and Hazards}

Victoria University will maintain an effective program to ensure that all workplace hazards are systematically identified. A directory of potential hazards will be compiled, arising from the following:

- Component manufacture

- Delivery of materials and components to site

- House assembly

- House disassembly

- Due to:

- Compressed Air Equipment

- Compressed Gas Cylinders

- Cranes and Rigging

- Electrical Systems and Equipment

- Erosion Control

- Fall Protection

- Fire Prevention

- Hand and Power Tools

- Hazardous Waste

- Hearing Conservation

- Heavy Equipment Operations

- Ladders

- Scaffolds

- Lifting 
- Motor Vehicle Operation

- Storage Tanks

- Welding, Cutting and Hot Work

\subsection{Mitigation Procedures}

Procedures for the avoidance of risks and hazards will be set up:

\subsubsection{Team Training and Member Involvement}

The OSHA 30 hour Construction Safety Training course will be completed by the FirstLight Project Student Managers, Construction Managers and Health \& Safety Officers before the November 20, 2010 deadline.

Briefings at specified times during the design documentation and construction process will ensure that a thorough knowledge of all systems and components specified, as well as their safe assembly and installation, will be gained by all construction workers.

All team members will have the opportunity to participate in the development of health and safety practices.

\subsubsection{Safe Site Practices}

The New Zealand team will ensure safe site practices are exercised at all times.

\subsubsection{Trained OSHA Representative Onsite}

At all times during construction and deconstruction, both in New Zealand prior to the U.S DoE Solar Decathlon event and on the Mall at the event itself, a contracted OSHA representative will be present on-site.

\subsubsection{House-keeping}

All relevant documentation relating to health and safety issues will be available at all times, both in the office and on-site.

\subsubsection{Enforcement of Personal Protective Equipment (PPE)}

All personal protective equipment needed to secure health and safety will be provided to team members and they will be adequately trained in its proper use, maintenance and storage. Onsite, ANSI-compliant hard hats, safety glasses, sleeved shirts, long trousers and steel-toed shoes will be worn.

\subsubsection{Other Considerations}

\section{Electrical safety}

Covered floor and wall openings

\section{Guardrails}




\section{Hazard communications}

\section{Safe operation of construction machinery}

The contractor shall ensure that employees are trained, competent and authorized to drive or operate any plant or equipment that they may use, whether regularly or on an occasional basis.

\section{Limited site access}

During construction, site access will be strictly limited to members of the FirstLight team engaged in construction processes.

\section{Identifiable construction uniform}

FirstLight construction team members will wear a clearly identifiable, ANSI-compliant uniform in order to ensure all persons on-site are approved construction workers.

\section{Emergency procedures}

Incident procedures and Accident reporting is aligned with Victoria Universities Health \& Safety procedure standards.

During the design development and construction in New Zealand: on campus dial extn: 8888 .

\section{Regulations}

NZ SD team will comply with all applicable health and safety regulations:

Health and Safety in Employment Act 1992 (NZ)

Health and Safety in Employment Regulations 1995 (NZ)

ANSI/AIHA Z10

International Building Code

OSHA Act 1970

OSHAS 18001

NPS policy 


\subsection{Licensed Design Professional}

The University is currently in negotiation with external licensed design professionals who will be responsible for the calculations and the stamping of the structural drawings. The selection process is dependent upon the expertise and predicted workloads of the selected company and will occur as early as May 2010.

FirstLights' aim is to develop the architectural design in collaboration with the selected engineering firm in order to guarantee the transportability of the house to Washington DC in September 2011. By approaching the engineers early in the design process, we also hope to incorporate a more holistic approach to economic and performance considerations.

In order to secure an uninterrupted work flow, FirstLight ensures that data exchange formats between the external sub-contractor and the student team will work harmoniously. It is part of the selection process to insure the companies' compliance with the ISO 9001 standard. An individual quality plan will be setup to assure that appropriate standards and resources will be utilized.

Feedback and indications to collaborate from companies we contacted has been very positive throughout. 


\subsection{Appendices}

9.1 Table of Electricity and Water Use

\begin{tabular}{|c|c|c|c|c|c|}
\hline & & \# Tasks & $\begin{array}{l}\text { No. } \\
\text { Hours }\end{array}$ & $\begin{array}{l}\text { Electricity } \\
\text { (kWh/day) }\end{array}$ & $\begin{array}{l}\text { Water } \\
\text { (gal) }\end{array}$ \\
\hline \multicolumn{6}{|l|}{$\begin{array}{l}\text { DAY } \\
8\end{array}$} \\
\hline & $\begin{array}{l}\text { Temperature } \\
\text { Keep Temp (22-24) }\end{array}$ & & & 3.2 & \\
\hline & $\begin{array}{l}\text { Humidity } \\
60 \% \text { Humidity }\end{array}$ & & & & \\
\hline & Refrigerator/freezer & & & 1.5 & \\
\hline & $\begin{array}{l}\text { Home Electronics } \\
\text { Operate TV \& Computer }\end{array}$ & 2 & 2 & 0.25 & \\
\hline & $\begin{array}{l}\text { Clothes Washer (1 } \\
\text { Load) }\end{array}$ & 1 & & 1.3 & 14.2 \\
\hline & Clothes Dryer (1 Load) & 1 & & 3.6 & \\
\hline & Dishwasher(1 Load) & 1 & & 1.2 & $1.95 \mathrm{gal}$ \\
\hline & Cooking & 1 & & 3.6 & 1 \\
\hline & Lighting & 3 & 3 & & \\
\hline & Hot Water (2 Draws) & 2 & & & 30 \\
\hline \multicolumn{6}{|l|}{$\begin{array}{l}\text { DAY } \\
9 \\
\end{array}$} \\
\hline & & & & & \\
\hline & $\begin{array}{l}\text { Temperature } \\
\text { Keep Temp (22-24) }\end{array}$ & & & 3.2 & \\
\hline & $\begin{array}{l}\text { Humidity } \\
60 \% \text { Humidity }\end{array}$ & & & & \\
\hline & Refrigerator/freezer & & & 1.5 & \\
\hline & $\begin{array}{l}\text { Home Electronics } \\
\text { Operate TV \& Computer }\end{array}$ & - & - & & \\
\hline & Clothes Washer & - & - & & \\
\hline & Clothes Dryer & - & - & & \\
\hline & Dishwasher & - & - & & \\
\hline & Cooking & - & - & & \\
\hline & Lighting & 3 & 3 & & \\
\hline & Hot Water & - & - & & \\
\hline \multicolumn{6}{|l|}{$\begin{array}{l}\text { DAY } \\
10\end{array}$} \\
\hline & $\begin{array}{l}\text { Temperature } \\
\text { Keep Temp (22-24) }\end{array}$ & & & 3.2 & \\
\hline & $\begin{array}{l}\text { Humidity } \\
60 \% \text { Humidity }\end{array}$ & & & & \\
\hline
\end{tabular}




\begin{tabular}{|c|c|c|c|c|c|}
\hline & Refrigerator/freezer & & & 1.5 & \\
\hline & $\begin{array}{l}\text { Home Electronics } \\
\text { Operate TV \& Computer }\end{array}$ & 3 & 3 & 0.375 & \\
\hline & Clothes Washer & 1 & & 1.3 & 14.2 \\
\hline & Clothes Dryer & 1 & & 3.6 & \\
\hline & Dishwasher & - & - & & \\
\hline & Cooking & - & - & & \\
\hline & Lighting & 3 & 3 & & \\
\hline & Hot Water & 2 & & & 30 \\
\hline \multirow{2}{*}{\multicolumn{6}{|c|}{$\begin{array}{l}\text { DAY } \\
11\end{array}$}} \\
\hline & & & & & \\
\hline & $\begin{array}{l}\text { Temperature } \\
\text { Keep Temp (22-24) }\end{array}$ & & & 3.2 & \\
\hline & $\begin{array}{l}\text { Humidity } \\
60 \% \text { Humidity }\end{array}$ & & & & \\
\hline & Refrigerator/freezer & & & 1.5 & \\
\hline & $\begin{array}{l}\text { Home Electronics } \\
\text { Operate TV \& Computer }\end{array}$ & 3 & 3 & .375 & \\
\hline & Clothes Washer & - & - & & \\
\hline & Clothes Dryer & - & - & & \\
\hline & Dishwasher & 1 & & 1.2 & 1.95 \\
\hline & Cooking & 1 & & 3.6 & 1 \\
\hline & Lighting & 3 & 3 & & \\
\hline & Hot Water & 2 & 2 & & 30 \\
\hline \multicolumn{6}{|l|}{$\begin{array}{l}\text { DAY } \\
12\end{array}$} \\
\hline 12 & $\begin{array}{l}\text { Temperature } \\
\text { Keep Temp (22-24) }\end{array}$ & & & 3.2 & \\
\hline & $\begin{array}{l}\text { Humidity } \\
60 \% \text { Humidity }\end{array}$ & & & & \\
\hline & Refrigerator/freezer & & & 1.5 & \\
\hline & $\begin{array}{l}\text { Home Electronics } \\
\text { Operate TV \& Computer }\end{array}$ & 3 & 3 & .375 & \\
\hline & Clothes Washer & 1 & & 1.3 & 14.2 \\
\hline & Clothes Dryer & 1 & & 3.6 & \\
\hline & Dishwasher & 1 & & 1.2 & 1.95 \\
\hline & Cooking & - & - & & 1 \\
\hline & Lighting & 3 & 3 & & \\
\hline & Hot Water & 2 & & & 30 \\
\hline \multirow{2}{*}{\multicolumn{6}{|c|}{$\begin{array}{l}\text { DAY } \\
13\end{array}$}} \\
\hline & & & & & \\
\hline & $\begin{array}{l}\text { Temperature } \\
\text { Keep Temp (22-24) }\end{array}$ & & & 3.2 & \\
\hline
\end{tabular}




\begin{tabular}{|c|c|c|c|c|c|}
\hline & $\begin{array}{l}\text { Humidity } \\
60 \% \text { Humidity }\end{array}$ & & & & \\
\hline & Refrigerator/freezer & & & 1.5 & \\
\hline & $\begin{array}{l}\text { Home Electronics } \\
\text { Operate TV \& Computer }\end{array}$ & 3 & 3 & .375 & \\
\hline & Clothes Washer & - & - & & \\
\hline & Clothes Dryer & - & - & & \\
\hline & Dishwasher & - & - & & \\
\hline & Cooking & - & - & & \\
\hline & Lighting & $3+1(\mathrm{DP})$ & 3 & & \\
\hline & Hot Water & 2 & & & 30 \\
\hline \multirow{2}{*}{\multicolumn{6}{|c|}{$\begin{array}{l}\text { DAY } \\
14\end{array}$}} \\
\hline & & & & & \\
\hline & $\begin{array}{l}\text { Temperature } \\
\text { Keep Temp (22-24) }\end{array}$ & & & 3.2 & \\
\hline & $\begin{array}{l}\text { Humidity } \\
60 \% \text { Humidity }\end{array}$ & & & & \\
\hline & Refrigerator/freezer & & & 1.5 & \\
\hline & $\begin{array}{l}\text { Home Electronics } \\
\text { Operate TV \& Computer }\end{array}$ & 7 & 7 & .875 & \\
\hline & Clothes Washer & 2 & & 2.6 & 28.4 \\
\hline & Clothes Dryer & 2 & & 7.2 & \\
\hline & Dishwasher & 1 & & 2.4 & 1.95 \\
\hline & Cooking & $1+1(\mathrm{DP})$ & & 3.6 & 1 \\
\hline & Lighting & 3 & & & \\
\hline & Hot Water & 2 & & & 30 \\
\hline \multirow{2}{*}{\multicolumn{6}{|c|}{$\begin{array}{l}\text { DAY } \\
15\end{array}$}} \\
\hline & & & & & \\
\hline & $\begin{array}{l}\text { Temperature } \\
\text { Keep Temp (22-24) }\end{array}$ & & & 3.2 & \\
\hline & $\begin{array}{l}\text { Humidity } \\
60 \% \text { Humidity }\end{array}$ & & & & \\
\hline & Refrigerator/freezer & & & 1.5 & \\
\hline & $\begin{array}{l}\text { Home Electronics } \\
\text { Operate TV \& Computer }\end{array}$ & 7 & 7 & .875 & \\
\hline & Clothes Washer & 1 & & 1.3 & 14.2 \\
\hline & Clothes Dryer & 1 & & 3.6 & \\
\hline & Dishwasher & 1 & & 1.2 & 1.95 \\
\hline & Cooking & $1(\mathrm{DP})$ & & 3.6 & 1 \\
\hline & Lighting & $5(\mathrm{DP}+\mathrm{MN})$ & & & \\
\hline & Hot Water & 2 & 2 & & 30 \\
\hline $\begin{array}{l}\text { DAY } \\
16\end{array}$ & & & & & \\
\hline
\end{tabular}




\begin{tabular}{|l|l|l|l|l|l|}
\hline & $\begin{array}{l}\text { Temperature } \\
\text { Keep Temp (22-24) }\end{array}$ & & 3.2 & \\
\hline $\begin{array}{l}\text { Humidity } \\
60 \% \text { Humidity }\end{array}$ & & & 1.5 & \\
\hline & Refrigerator/freezer & & & \\
\hline $\begin{array}{l}\text { Home Electronics } \\
\text { Operate TV \& Computer }\end{array}$ & 7 & 7 & .875 & \\
\hline & Clothes Washer & 2 & & 2.6 & 14.2 \\
\hline & Clothes Dryer & 2 & & 7.2 & \\
\hline & Dishwasher & 1 & & 2.4 & 1.95 \\
\hline & Cooking & 1 & & 3.6 & 1 \\
\hline & Lighting & & & & \\
\hline & Hot Water & 2 & & & 30 \\
\hline & & & & \\
\hline
\end{tabular}




\subsection{Photovoltaic Array Diagram}

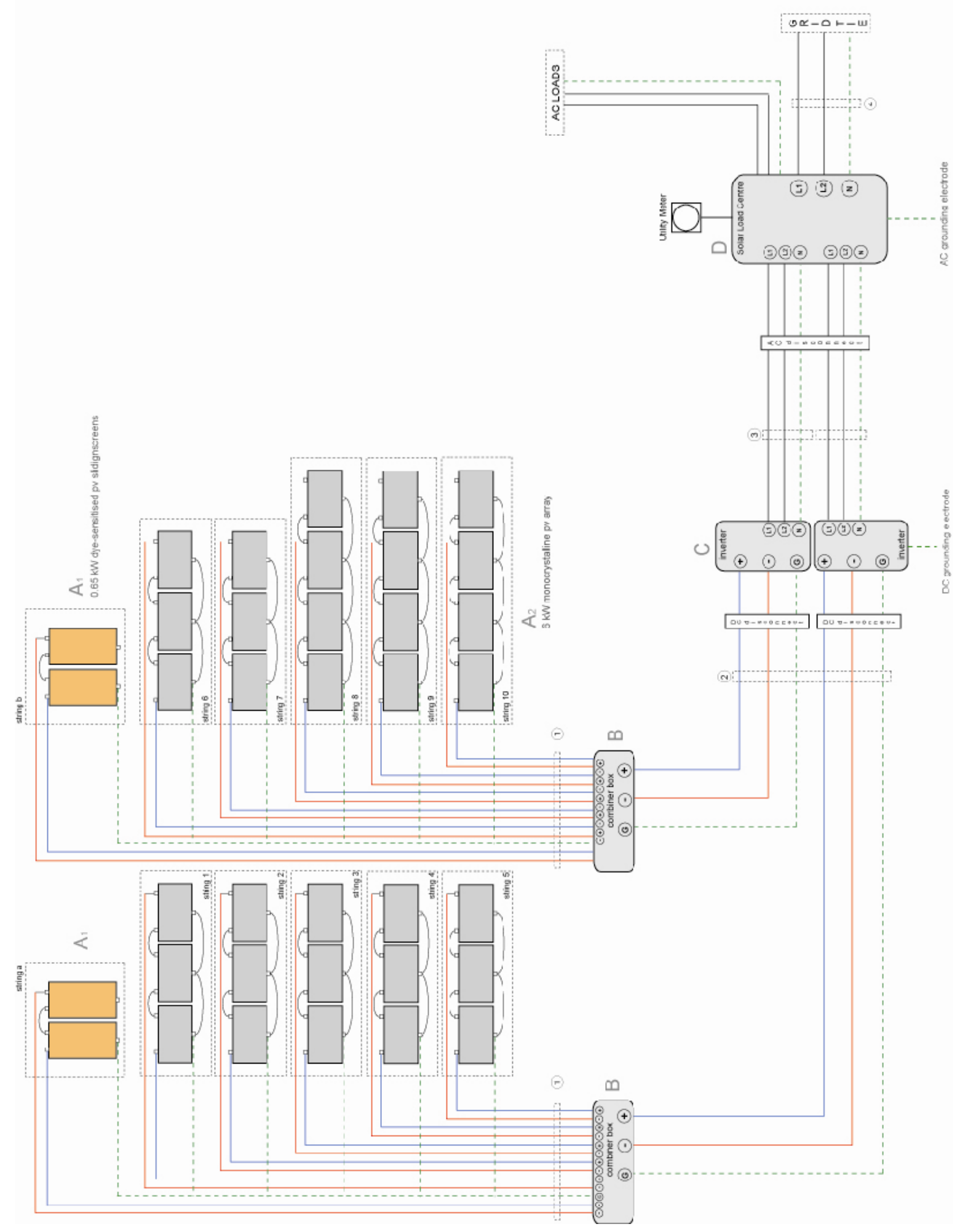




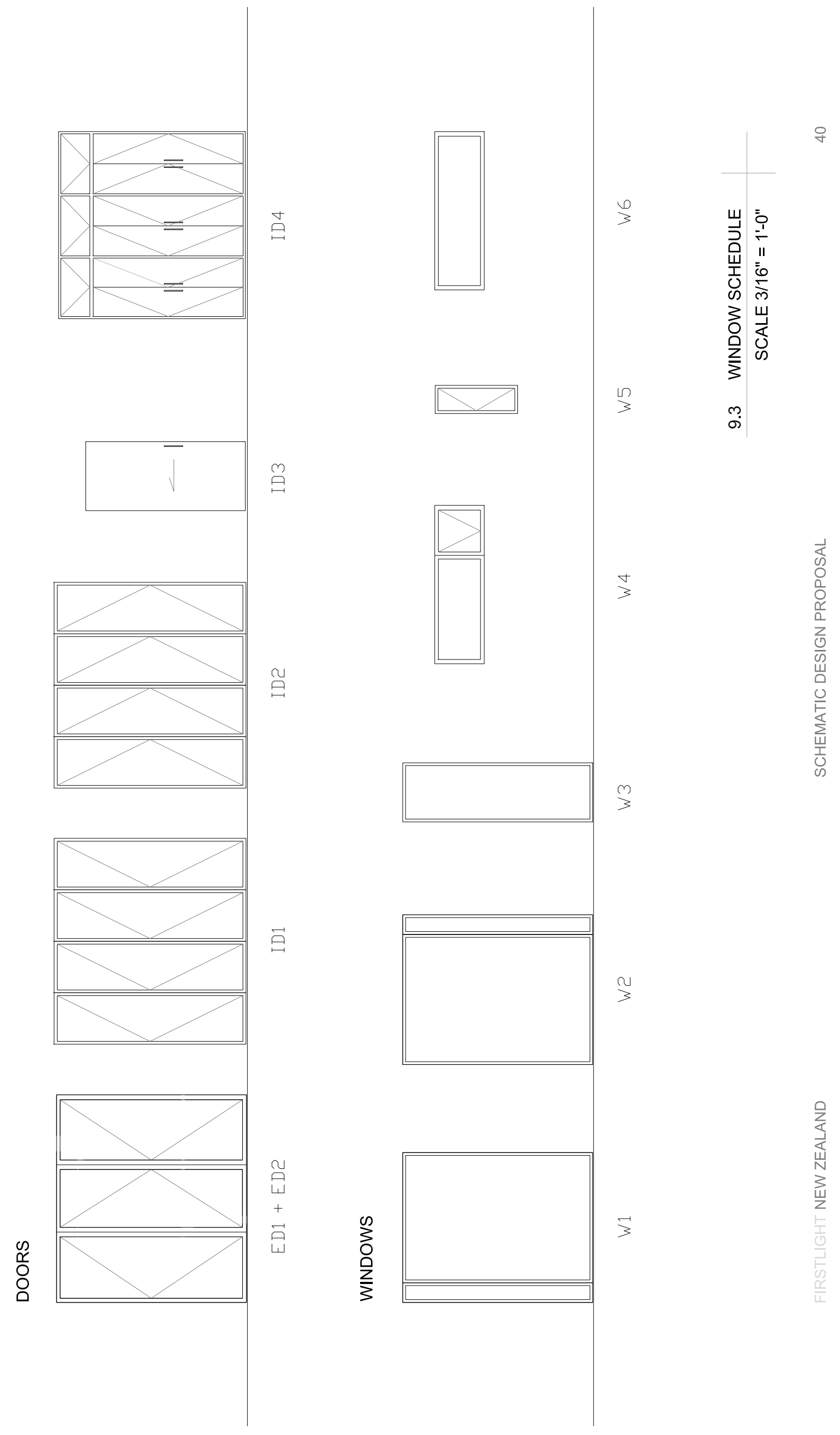

